Genetic disruption of the master pacemaker in the suprachiasmatic nucleus sheds light on the hierarchical organization of the mammalian circadian timing system

\author{
Dissertation \\ zur Erlangung des mathematisch-naturwissenschaftlichen Doktorgrades \\ "Doctor rerum naturalium" \\ der Georg-August-Universität Göttingen
}

vorgelegt von

Jana Lioba Husse

aus Schweinfurt 


\section{Thesis Committee:}

Prof. Gregor Eichele, Department Genes and Behavior,

Max-Planck-Institute for Biophysical Chemistry, Göttingen (Referee)

Prof. Erik Maronde, Institut der Anatomie III,

Johann Wolfgang Goethe Universität, Frankfurt (Co-Referee)

Prof. Nils Brose, Department of Molecular Neurobiology,

Max-Planck-Institute for Experimental Medicine, Göttingen

Date of oral examination: 14.11.2011 


\section{Declaration}

Herewith, I confirm that I have written the present PhD thesis independently and with no other sources and aids than quoted. 
DECLARATION

SUMMARY

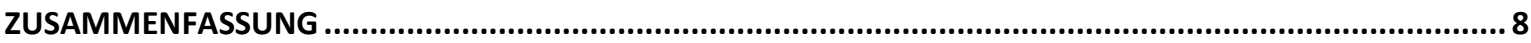

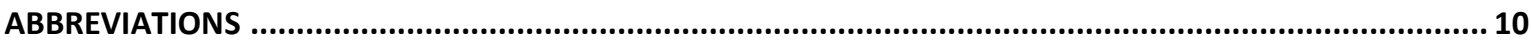

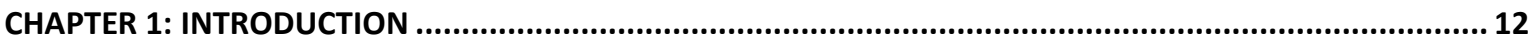

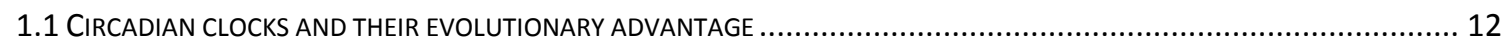

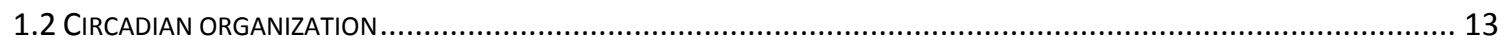

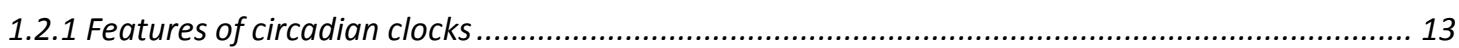

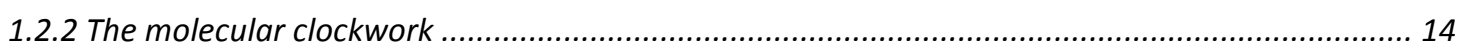

1.2.3 The master pacemaker in the suprachiasmatic nucleus (SCN) ............................................ 16

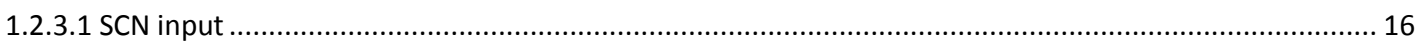

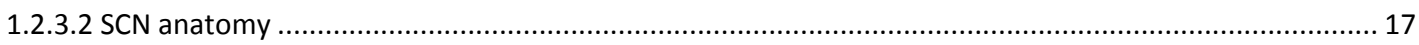

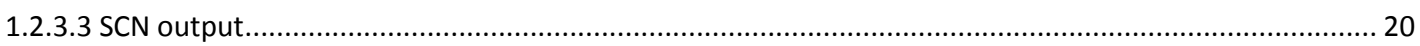

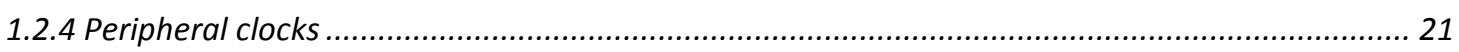

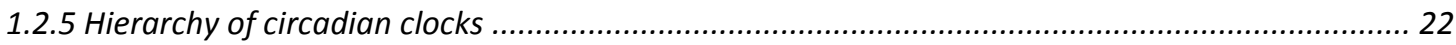

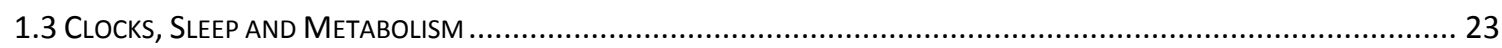

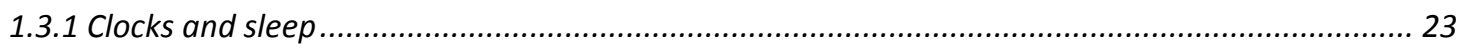

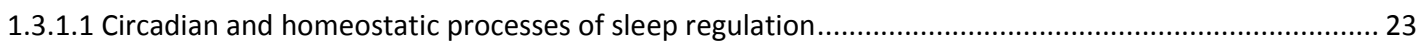

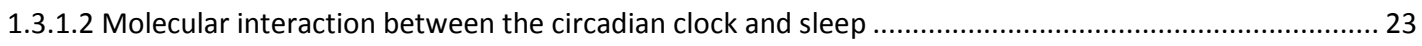

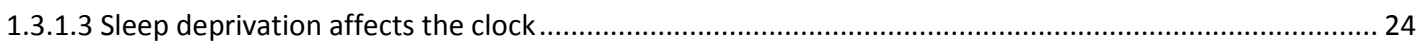

1.3.2 Publication: "A time to fast, a time to feast:the crosstalk between metabolism and the circadian

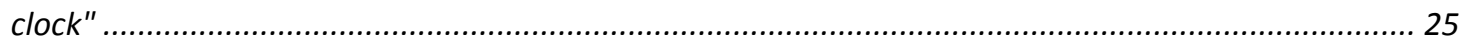

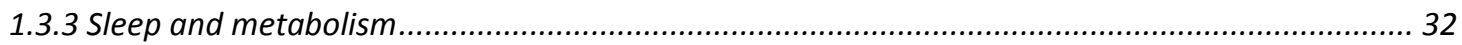

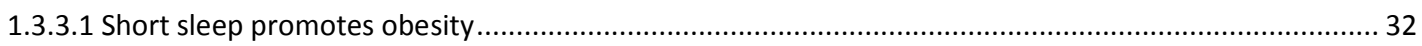

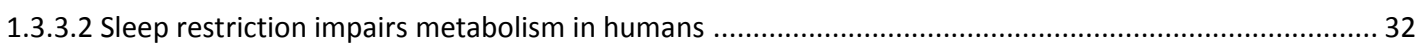

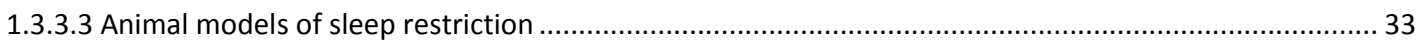

1.3.4 The circadian clock as a potential mediator between sleep and metabolism ............................ 34

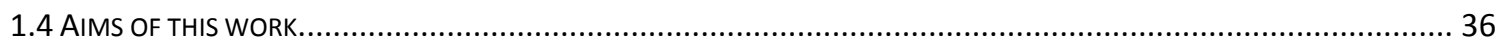

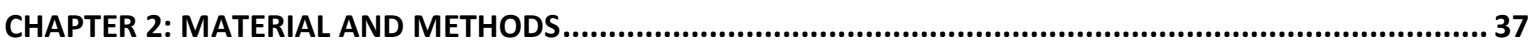

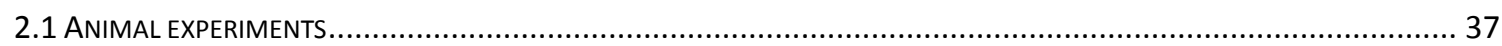

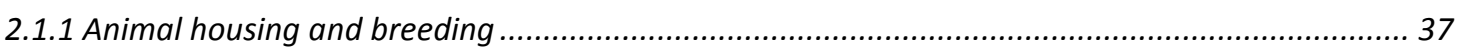

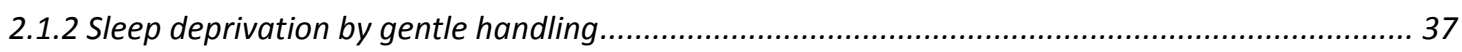

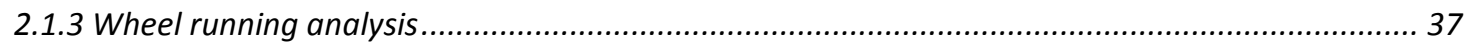

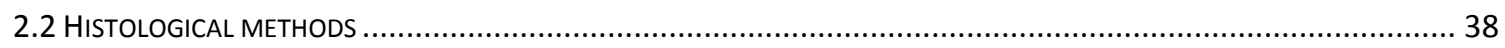

2.2.1 $\beta$-galactosidase staining of frozen brain sections............................................................. 38

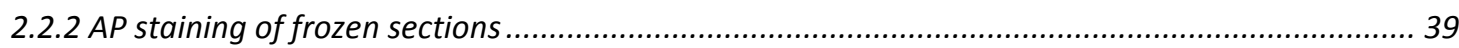

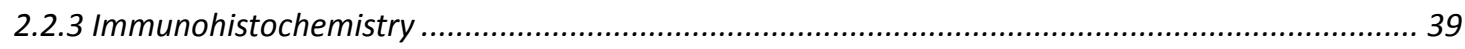

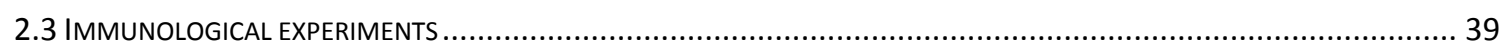

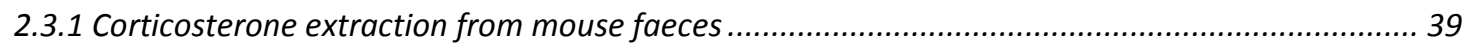

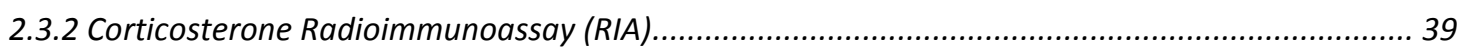

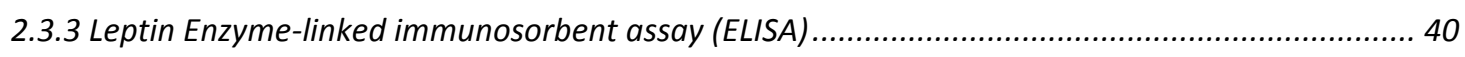

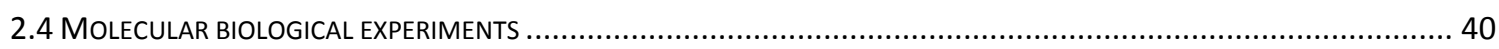

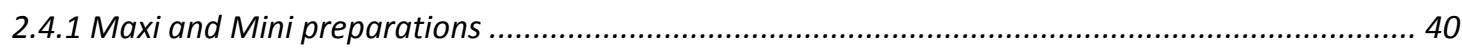

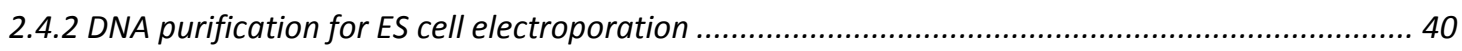

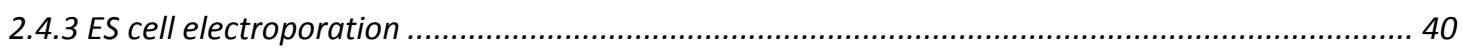

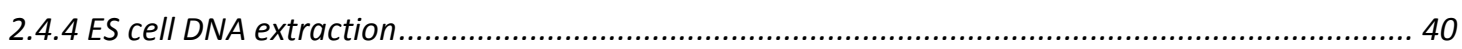

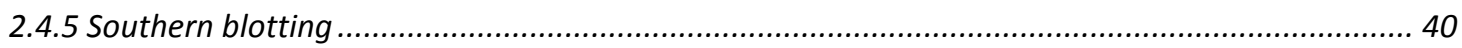

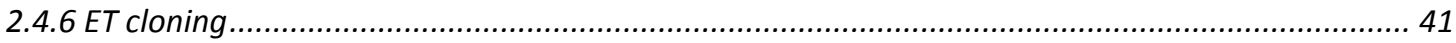


2.4.7 Flippase-induced Neomycin deletion in BAC clones ........................................................ 41

2.4.8 BAC DNA purification for pronucleus injection ..................................................................... 42

2.4.9 DNA extraction from mouse tail biopsies............................................................................. 42

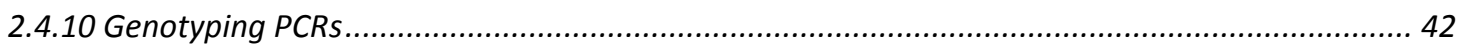

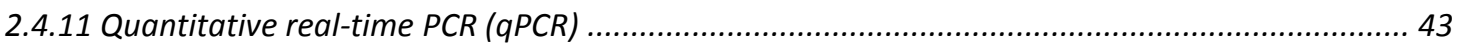

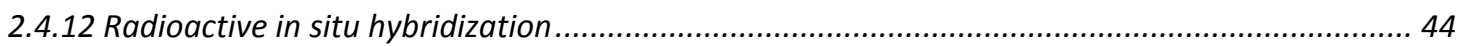

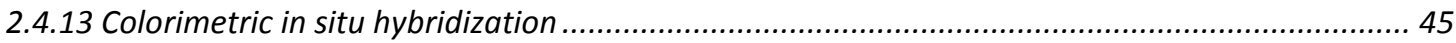

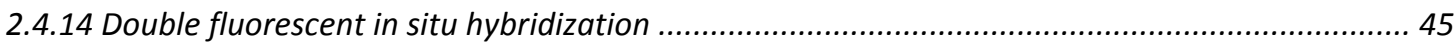

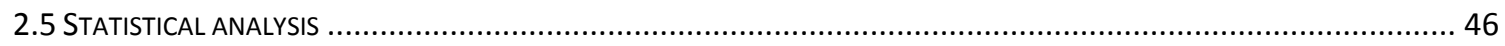

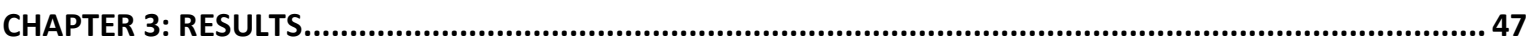

3.1 Publication: SYNAPTOtAgmin10-CRE, A DRIVER TO DISRUPT CLOCK GENES IN THE SCN................................ 47

3.2. THE SCN CLOCK IS DISPENSABLE FOR LIGHT ENTRAINMENT OF PERIPHERAL CLOCKS...........................................59

3.2.1 No evidence for clock-driven behavior in Syt10 ${ }^{\mathrm{Cre} / \mathrm{Cre}} \mathrm{Bmal1^{fl- }}$ mice .......................................... 61

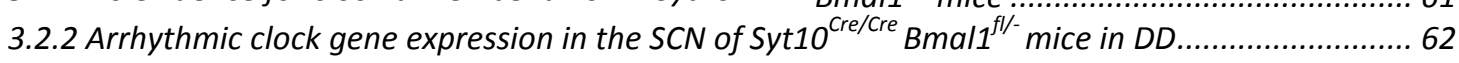

3.2.3 Corticosterone is rhythmic but dampened in Syt $10^{\mathrm{Cre} / \mathrm{Cre}} \mathrm{Bmal1}{ }^{\mathrm{fl}-}$ mice ........................................6. 63

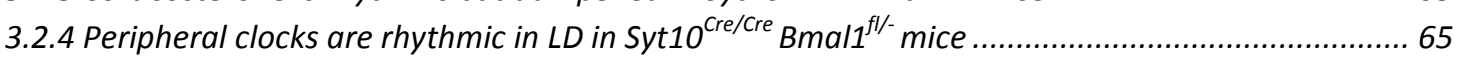

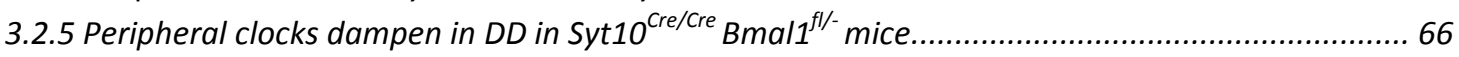

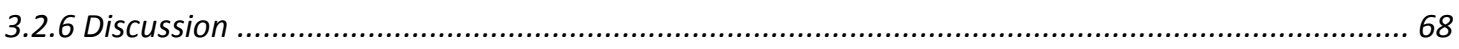

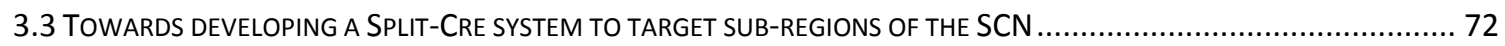

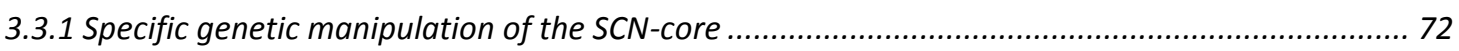

3.3.2 Genetic model and Split Cre principle ................................................................................... 72

3.3.3 Screening for suitable promoter pairs................................................................................. 75

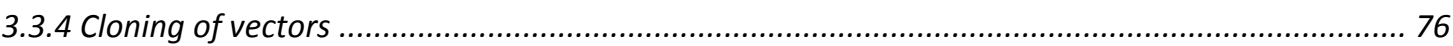

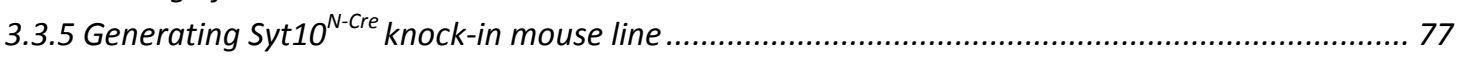

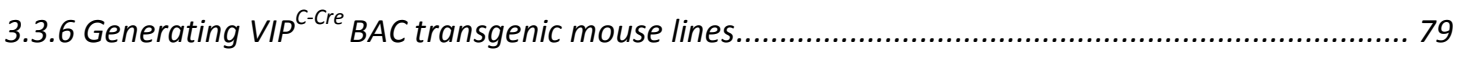

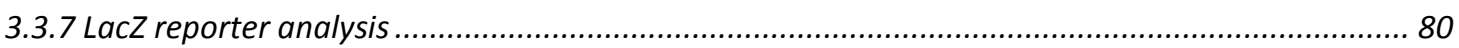

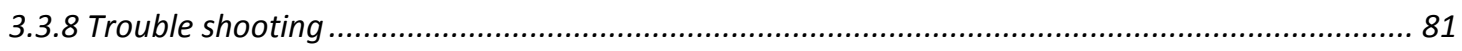

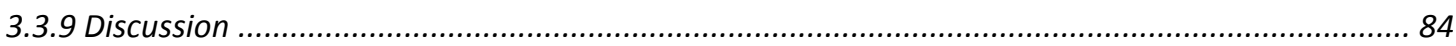

3.4 MANUSCRIPT: THe CIRCADIAN CLOCK GENES PER1 AND PER2 REgULATE THE METABOLIC RESPONSE TO SLEEP RESTRICTION

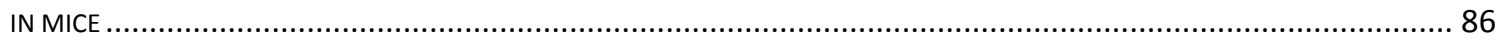

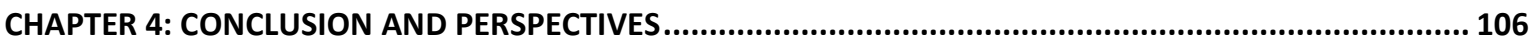

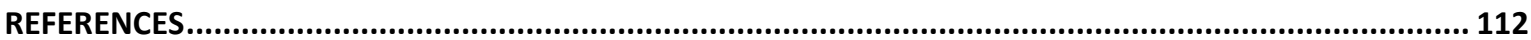

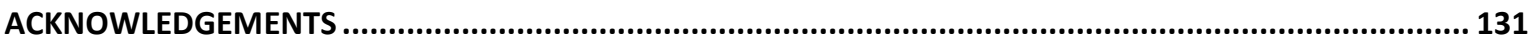

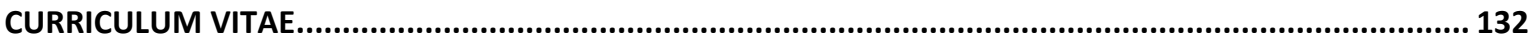




\section{Summary}

Circadian timing systems evolved in most organisms to adapt to the daily alternation of light and dark and the accompanying changes of environmental parameters such as food availability and predator occurrence. Circadian clocks allow organisms to anticipate these changes, which in turn increases their evolutionary fitness.

The first part of this thesis describes the generation and validation of a new genetic mouse model of central clock disruption. It is assumed, that the mammalian circadian timing system is hierarchically organized with a master pacemaker in the suprachiasmatic nucleus (SCN) of the hypothalamus and subordinated clocks in peripheral tissues. This view is based on SCN ablation studies showing that in the absence of the SCN all peripheral clocks become arrhythmic. An obvious flaw of SCN ablations is the concomitant scission of SCN afferents and efferents. Here we use a genetic model of SCN clock disruption. We generated a SCN Cre driver mouse line (Syt10 $0^{\text {cre }}$ ) and demonstrated strong Cre activity in the majority of SCN cells, but none in peripheral tissues with the exception of the testis. The Syt $10^{\text {cre }}$ driver line was functionally validated by deleting a conditional allele of the essential clock gene Bmal1 $\left(B m a / 1^{f / f l}\right)$. Syt $10^{\text {cre }} B m a l 1^{f l}$ mice were analyzed for their wheel running behavior in light dark (LD) and constant darkness (DD) conditions. We found a dose-dependent phenotype ranging from minor changes in period and amplitude in Syt $10^{\mathrm{Cre} / \mathrm{t}} \mathrm{Bmal}^{\mathrm{flffl} f}$ to markedly reduced rhythmicity in Syt $10^{\mathrm{Cre} /+} \mathrm{Bmal}^{\mathrm{fl}-\mathrm{-}}$ mice to a complete loss of circadian rhythmicity in Syt $10^{\text {Cre/Cre }}$ Bmal1 ${ }^{\mathrm{fl} /-}$ mice. The behavioral phenotype of Syt $10^{\mathrm{Cre} / \mathrm{Cre}} \mathrm{Bmal} \mathrm{f}^{\mathrm{fl} / \text { - }}$ mice was indistinguishable from the phenotype of $\mathrm{Bmal1}^{-/}$mice, confirming the efficiency of SCN disruption. Furthermore the behavioral phenotype of Syt $10^{\mathrm{Cre}} \mathrm{Bmal1}{ }^{\mathrm{fl}}$ mice was inversely correlated with the number of BMAL1 positive cells in the SCN. The Syt10 ${ }^{\text {cre }}$ line will be a helpful tool to investigate the complexity of the mammalian circadian network.

In the second part of this thesis Syt $10^{\mathrm{Cr} / \mathrm{Cre}} \mathrm{Bmal} 1^{\mathrm{fl} /-}$ mice are used to investigate the hierarchical structure of the mammalian circadian timing system. A major difference to the above-mentioned

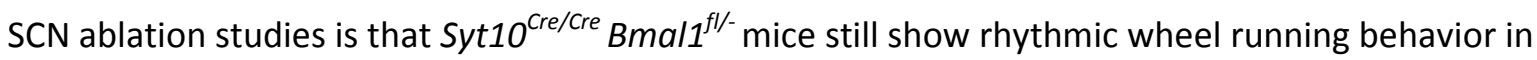
LD conditions. We showed that this behavioral synchronization to the LD cycle is directly lightand not clock-driven. The disruption of the SCN clock on the molecular level was confirmed by in situ hybridization. Despite the absence of a functional SCN clock, corticosterone is rhythmic in Syt10 ${ }^{\mathrm{Cr} / \mathrm{Cre}} \mathrm{Bmal} \mathrm{f}^{\mathrm{fl}-}$ mice in LD. However the amplitude of this rhythm is markedly reduced, indicating that although the SCN clock is dispensable for rhythmic release of corticosterone in LD, the amplitude of this rhythm is regulated by the SCN clock. Upon placing the mutant animals into DD, corticosterone rhythms dampen, indicating that in DD the SCN clock is essential for maintenance of corticosterone rhythmicity. Furthermore we analyze clock gene expression rhythms in peripheral tissues of Syt $10^{\text {cre/cre }} B m a l 1^{f l-}$ mice in LD and DD. To our surprise, peripheral clocks continue to oscillate in Syt $10^{\mathrm{Cre} / \mathrm{Cre}} \mathrm{Bmal} \mathrm{f}^{\mathrm{fl}-}$ mice in LD. This indicates that a functional clock in the SCN is not necessary for synchronized rhythmicity of peripheral clocks, but that light can directly synchronize peripheral clocks. Upon release into DD, however, clock gene rhythms in 
peripheral organs dampen. Thus in constant conditions the SCN clock is necessary to synchronize peripheral clocks.

The third part of this thesis describes the first attempts towards the development of a combinatorial Cre system, which will allow very specific targeting of brain nuclei. The idea is based on complementation of two parts of the Cre enzyme, which individually are not active. If coexpressed in one cell, however, functional Cre is reconstituted. Expression of the two Cre parts under the control of different but overlapping promoters will markedly improve the specificity of the conventional Cre/loxP system. We aimed at investigating the functional anatomy of the SCN by targeting the SCN-core region which is believed to be the input region of the SCN. This SCNcore Cre line will then be used to set very specific genetic lesions to this SCN sub-region. It will be very interesting to analyze the effects of this $\mathrm{SCN}$-core ablation on circadian output, which will help to elucidate the functional anatomy of this complex brain nucleus.

The fourth part of this thesis addresses the role of the circadian clock in integrating different physiological systems. It has been shown that the circadian clock and metabolic regulation are tightly linked. In addition, sleep curtailment (which is often experienced during shift work) is associated with negative effects on metabolic homeostasis. This prompted us to analyze whether the clock might mediate the negative effects of sleep disturbance on metabolic regulation. Our hypothesis was that in the absence of a functional clock metabolic effects of sleep disruption should be less pronounced. We were able to show that arrhythmic Per1/2 mutants which lack a functional circadian clock indeed show less metabolic alterations after sleep disturbance, indicating that the circadian clock is involved in regulating this response. This study suggests that the circadian clock integrates sleep and metabolic regulation. Thus our work may help to understand the effects of sleep curtailment on obesity, which are major problems of industrialized societies. Deepening the understanding of the underlying mechanisms could contribute to the development of new pharmaceutical approaches for these disorders. 


\section{Zusammenfassung}

Alles Leben dieser Erde ist dem täglich wiederkehrenden Wechsel von Tag und Nacht ausgesetzt. Um sich diesen Ryhtmen anzupassen, haben fast alle Lebewesen, vom Bakterium bis zum Menschen, zirkadiane Uhren entwickelt. Mittels solcher interner Zeitmesser können Lebewesen diese Rhythmen antizipieren und ihre Physiologie optimal anpassen.

Der erste Teil dieser Arbeit beschreibt die Herstellung und Validierung eines neuen transgenen Mausmodels, in dem die zentrale zirkadiane Uhr ausgeschaltet wurde. Es ist allgemein anerkannt, dass das zirkadiane System von Säugern hierarchisch organisiert ist, mit einem zentralen Schrittmacher im Nucleus Suprachiasmaticus (SCN) des Hypothalamus und untergeordneten peripheren Uhren. Dieses Modell beruht auf SCN-Läsionsstudien, die zeigen, dass in Abwesenheit des SCN alle peripheren Uhren arrhythmisch werden. Der Nachteil von Läsionen ist, dass gleichermaßen afferente und efferente Verbindungen durchtrennt werden. In dieser Arbeit wurde daher ein genetisches Modell genutzt. Eine SCN-Cre-Treiberlinie $\left(S y t 10^{\text {Cre }}\right)$ wurde hergestellt, in der gezeigt werden konnte, dass Cre im Großteil der SCN-Zellen aktiv ist, nicht aber in peripheren Geweben mit Ausnahme des Testis. Zur funktionellen Charakterisierung wurde mittels der Syt10 ${ }^{\text {Cre }}$-Linie das essentielle Uhrengen Bmal1 deletiert $\left(B m a l 1^{f l f f l}\right)$. Die Laufradaktivität von Syt10 ${ }^{\text {cre }}$ Bmal1 $1^{f l}$-Mäusen wurde unter Licht-Dunkel (LD) Bedingungen und in konstanter Dunkelheit (DD) untersucht. Es konnte ein Dosis-abhängiger Phänotyp gefunden werden: je weniger Zellen im SCN noch BMAL1-Protein exprimierten, desto weniger rhythmisch war die

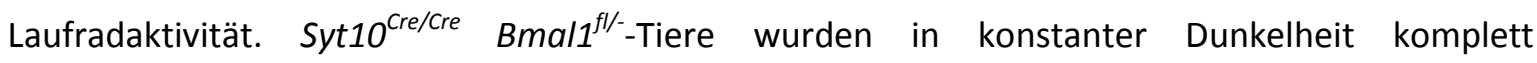
arrhythmisch, und zeigten denselben Phänotyp wie Mäuse, in denen das Bmal1 Gen in allen Zellen deletiert ist $\left(\mathrm{Bmal1}^{-1}\right)$, was die Effizienz der genetischen Manipulation bestätigt. Die Syt10 $0^{\text {cre }}$-Treiberlinie wird hilfreich sein, um die Komplexität des zirkadianen Systems von Säugern zu untersuchen.

Im zweiten Teil der Arbeit wurde die hierarchische Organisation des zirkadianen Systems an Hand

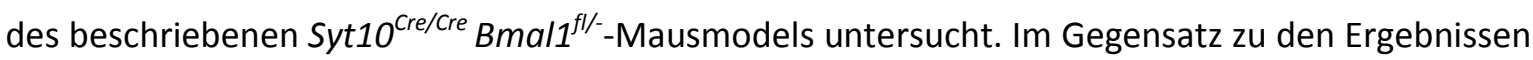
der oben beschriebenen SCN-Läsionsstudien wurde gefunden, dass Syt $10^{\mathrm{Cre} / \mathrm{Cre} B \mathrm{Bmal}} \mathrm{I}^{\mathrm{fl}-\text {-Mäuse }}$ unter LD-Bedingungen rhythmische Aktivität zeigen. Es konnte nachgewiesen werden, dass diese rhythmische Aktivität direkt Licht- und nicht Uhren-gesteuert ist. Außerdem wurde auch auf molekularer Ebene gezeigt, dass die Uhr im SCN komplett defekt ist. Trotz nicht funktioneller SCNUhr wurden unter LD-Bedingungen Glukokortikoide rhythmisch von der Nebenniere sezerniert. Dieser Glukokortikoidrhythmus war im Vergleich zu dem von Wildtyp-Tieren allerdings deutlich gedämpft. Daraus lässt sich ableiten, dass die Uhr im SCN für die rhythmische Glukokortikoidsekretion zwar nicht notwendig ist, aber an der Regulierung der Amplitude des Rhythmus beteiligt ist. Entlässt man diese Tiere in konstante Dunkelheit schwächt sich der Glukokortikoidrhythmus immer weiter ab, was darauf hinweist, dass in konstanter Dunkelheit die Uhr im SCN notwendig ist, um einen Glukokortikoidrhythmus aufrechtzuerhalten. Des Weiteren

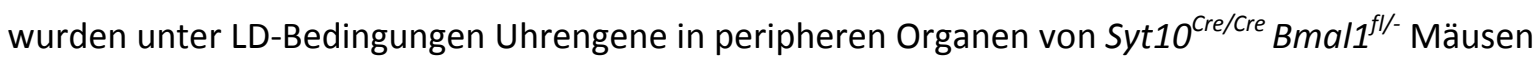


gemessen. Überraschend war, dass periphere Uhren in Syt10 ${ }^{\text {Cre/Cre }} B m a l 1^{f /-}$ Mäusen in LD rhythmisch waren, was darauf hindeutet, dass der SCN als Gewebe zwar notwendig ist um periphere Uhren zu synchronisieren, die SCN-Uhr per se aber nicht. Sobald die Tiere in konstante Dunkelheit entlassen wurden, konnte eine deutliche Dämpfung der Rhythmen in peripheren Uhren gemessen werden. Einige Uhrengene waren sogar komplett arrhythmisch exprimiert, was die hierarchische Struktur des zirkadianen Systems unter konstanten Bedingungen bestätigt.

Im dritten Teil dieser Arbeit werden die ersten Schritte zur Entwicklung eines kombinatorischen Cre-Systems beschrieben. Dieses kombinatorische Cre-System soll sehr spezifische genetische Manipulationen im Mausmodell ermöglichen. Die Idee basiert auf der Komplementierung zweier Cre-Teilproteine, die einzeln nicht aktiv sind. Sind sie aber in einer Zelle co-exprimiert, wird funktionelles Cre-Protein wiederhergestellt. Indem man beide Teile unter der Kontrolle verschiedener, aber überlappender Promotoren exprimiert, kann man ein deutlich spezifischeres Cre-Expressionsmuster erreichen, als es bisher möglich war. Ziel ist es, die funktionelle Anatomie des SCNs zu untersuchen, indem man die sogenannte "Core“-Region des SCN genetisch läsioniert. Es wird sehr interessant sein, die Effekte einer solchen genetischen SCN-Core Läsion auf das zirkadiane System zu untersuchen. Dieses Projekt wird dazu beitragen, die funktionelle Anatomie dieses komplexen Nukleus besser zu verstehen.

Der vierte Teil dieser Arbeit beschäftigt sich mit der Rolle der zirkadianen Uhr als Vermittler zwischen verschiedenen physiologischen Systemen. Es ist bekannt, dass die zirkadiane Uhr und die metabolische Regulation eng miteinander verknüpft sind. Außerdem ist eine kürzere Schlafdauer mit metabolischen Dysfunktionen assoziiert, wie zum Beispiel einer erhöhten Wahrscheinlichkeit von Fettleibigkeit. Eine Möglichkeit ist, dass die metabolischen Effekte von Schlafentzug durch die zirkadiane Uhr vermittelt werden. Daher war die Hypothese dieser Studie, dass in Abwesenheit einer funktionellen zirkadianen Uhr die metabolischen Auswirkungen von Schlafentzug reduziert sind. Um dies zu testen, wurden transgene Mäuse untersucht, die keine funktionelle Uhr besitzen (Per1/2-Doppelmutanten). Es konnte gezeigt werden, dass Schlafentzug in Per1/2-Doppelmutanten tatsächlich weniger metabolische Auswirkungen hat, was nahelegt, dass die zirkadiane Uhr an der Vermittlung dieser Effekte beteiligt ist. Diese Studie gibt erste Hinweise, dass die zirkadiane Uhr möglicherweise ein wichtiger Integrator für Schlaf und Metabolismus ist. Außerdem ist sie klinisch relevant, da Schlafentzug und Fettleibigkeit essentielle Probleme unserer industrialisierten Gesellschaft sind. Ein besseres Verständnis der zugrunde liegenden Mechanismen kann zur Entwicklung neuer pharmakologischer Ansätze beitragen. 


\section{Abbreviations}

\begin{tabular}{|c|c|}
\hline $5 \mathrm{HT}$ & serotonergic \\
\hline ACTH & Adrenocorticotropic hormone \\
\hline Agnll & Angiotensin II \\
\hline ANS & autonomic nervous system \\
\hline AP & Alkaline phosphatase \\
\hline ARC & Arcuate nucleus \\
\hline AVP & Arginine vasopressin \\
\hline BMAL1 & ARNTL \\
\hline Bmal1fl/fl & Bmal1 floxed allele \\
\hline BNST & Bed nucleus of the stria terminalis \\
\hline CalB & Calbindin \\
\hline CAM & Chloramphenicol \\
\hline CAMKII & Calcium/calmodulin kinase II \\
\hline ccgs & clock-controlled genes \\
\hline Ck1ع & Caseinkinase1epsilon \\
\hline $\mathrm{CLC}$ & Cardiotrophin-like cytokine \\
\hline Clock & Circadian Locomotor Output Cycles Kaput \\
\hline CMV & Cytomegalovirus \\
\hline CREB & cAMP response element binding protein \\
\hline CREs & cAMP response elements \\
\hline $\mathrm{CRH}$ & Corticotropin-releasing hormone \\
\hline Cry & Cryptochrome \\
\hline $\mathrm{CT}$ & circadian time \\
\hline DBP & D site albumin promoter binding protein \\
\hline DD & constant darkness \\
\hline Dlk1 & Delta-like 1 homolog \\
\hline $\mathrm{DMH}$ & Dorsomedial nucleus of the hypothalamus \\
\hline DRN & Dorsal median raphe nuclei \\
\hline DT & Diphtheria toxin \\
\hline DTR & Diphtheria toxin receptor \\
\hline E4BP4 & Nfil3 \\
\hline EEG & electroencephalogram \\
\hline ERT2 & estrogen receptor \\
\hline ES c & embryonic stem \\
\hline $\mathrm{Fbxl3}$ & F-box and leucine-rich repeat protein 3 \\
\hline GFAP & Glial fibrillary acidic protein \\
\hline Glut2 & glucose transporter 2 \\
\hline GRP & Gastrin releasing peptide \\
\hline HPA & hypothalamic-pituitary-adrenal \\
\hline IGL & Intergeniculate leaflet \\
\hline IL6 & Interleukin 6 \\
\hline ipRGCs & photic sensitive retinal ganglion cells \\
\hline Kana & kanamycin \\
\hline
\end{tabular}




\begin{tabular}{|c|c|}
\hline LacZ & ß-Galactosidase \\
\hline LD & light dark \\
\hline $\mathrm{LL}$ & constant light \\
\hline LS & the lateral septum \\
\hline MAPK & Mitogen-activated protein kinase \\
\hline MRN & Median raphe nuclei \\
\hline Neo & Neomycin \\
\hline NLS & nuclear localization signal \\
\hline Npas2 & Neuronal PAS domain protein 2 \\
\hline NPY & Neuropeptide Y \\
\hline NREM & non-REM \\
\hline $\mathrm{Nt}$ & Neurotensin \\
\hline PACAP & Pituitary adenylate cyclase-activating polypeptide \\
\hline Per & Period \\
\hline PFA & paraformaldehyde \\
\hline PGKII & cGMP-dependent protein kinase II \\
\hline PK2 & Prokineticin 2 \\
\hline POA & Preoptic area \\
\hline POMC & Pro-opiomelanocortin \\
\hline PPAR $\alpha$ & Peroxisome proliferator-activated receptor $\alpha$ \\
\hline PPARY & Peroxisome proliferator-activated receptor $\psi$ \\
\hline PRC & phase response curve \\
\hline PRKCA & Protein kinase $\mathrm{C} \alpha$ \\
\hline PVN & Paraventricular nucleus of the hypothalamus \\
\hline PVT & Paraventricular nucleus of the thalamus \\
\hline RBP4 & Retinol-binding protein 4 \\
\hline REM & rapid eye movement \\
\hline RHT & retino-hypothalamic tract \\
\hline RRES & Reverb $\alpha /$ Ror-binding promoter elements \\
\hline SCN & suprachiasmatic nucleus \\
\hline SPVZ & Subparaventricular zone of the hypothalamus \\
\hline SR & sleep restriction \\
\hline Syt10 & Synaptotagmin 10 \\
\hline Syt10Cre & Syt10Cre driver line \\
\hline TGF $\alpha$ & Transforming growth factor $\alpha$ \\
\hline TNF $\alpha$ & tumor necrosis factor \\
\hline tTA & tetracycline transactivator \\
\hline TTL & transcriptional-translational feedback loop \\
\hline TTX & tetrodotoxin \\
\hline VIP & vasoactive intestinal polypeptide \\
\hline VLPO & ventrolateral preoptic nucleus \\
\hline ZT & Zeitgeber time \\
\hline
\end{tabular}




\section{Chapter 1: Introduction}

\subsection{Circadian clocks and their evolutionary advantage}

As a result of the rotation of the earth around its axis, all life is confronted with repetitive and predictable environmental changes such as light-dark or temperature cycles, and the ensuing diurnal variations in food availability or predator occurrence. The ability to anticipate such reoccurring changes is of advantage in order to adapt properly.

Given that rather simple organisms like cyanobacteria have circadian clocks (Johnson et al., 1996), the first clocks have likely occurred very early in the history of life. The most accepted theory of why circadian clocks have evolved is Pittendrigh's "escape from light hypothesis" which states that the risk of UV induced DNA damage during the day forced replication and mitosis to be confined to the night (Pittendrigh, 1993). Interestingly, Cryptochrome genes, which represent an essential part of the mammalian circadian clockwork, have likely evolved from light-induced DNA repair enzymes (DNA photolyases) (Gehring and Rosbash, 2003; Lin and Todo, 2005).

Clocks have evolved in all three domains of life and the majority of species have a circadian clock (Bell-Pedersen et al., 2005; Rosbash, 2009). The question whether there was a common progenitor from which all clocks have evolved is not clear. The fact that clocks between the two domains bacteria and eukaryotes, but also between the kingdoms animals, fungi and plants, are rather different suggests convergent evolution (Bell-Pedersen et al., 2005). Clocks in the animal kingdom, however, have likely evolved from a common progenitor given the high degree of conservation of the genes constituting the molecular clockwork. Drosophila and mouse clocks, for example, are quite similar, however it is likely that gene duplication events in the vertebrate branch led to the fact that in mammals most clock genes exist in at least two copies, whereas in Drosophila there is a single homolog for each respective gene (Looby and Loudon, 2005).

Surprisingly, although it seems very reasonable that circadian clocks confer an evolutionary advantage, experimental proof for this is still weak (Yerushalmi and Green, 2009). So-called resonance studies, in which organisms with different endogenous periods are exposed to different external periods, have shown convincingly that resonating clocks confer a fitness advantage compared to clocks with an endogenous period length that differs from external period length (Pittendrigh and Minis, 1972; Ouyang et al., 1998; Woelfle et al., 2004; Dodd et al., 2005). This, however, does not address the question whether having a clock is better than having no clock. Some investigations in cyanobacteria, Drosophila or mice have addressed this question using either competitive growth, fertility or life span as a readout of fitness (Pittendrigh and Minis, 1972; DeCoursey et al., 2000; Beaver et al., 2002; Green et al., 2002; Dodd et al., 2005) and found that having no clock or a disrupted clock reduces fitness. However, often mutants are used in such studies raising the problem of potential pleiotropic effects (Yerushalmi and Green, 2009). What are the advantages that circadian clocks might bring? Firstly they prepare the physiology of the body for environmental changes, e.g. they prepare the digestive system for forthcoming food. In this context, one might wonder, whether organisms living in environments that are not 
subjected to overt diurnal changes (such as the deep sea or certain cave habitats) still need a circadian clock. If the main function of the clock was synchronization to environmental changes such organisms should have lost their clock. Subterranean blind mole rats, living most of their life under the earth in complete darkness retain a functional clock (Avivi et al., 2002; Oster et al., 2002). In line with this, in Drosophila, which are kept in a constant environment for more than 600 generations, rhythms persist (Sheeba et al., 1999). Thus, anticipation of a changing exogenous environment seems not be the only role of the circadian clock.

Clocks might also be important for synchronizing physiology within the body, i.e. the endogenous environment. Jet lag and shift work are conditions in which different endogenous rhythms in the body lose synchrony with each other (Boivin et al., 2007; Kiessling et al., 2010) and this internal desynchrony might be the major cause of the well-known jet lag symptoms, and maybe also for the more long-term effects of shift work like increased risk of cardiovascular disease, obesity and cancer (Zee and Goldstein, 2010). Another potential role of the clock is to temporally separate processes that are not compatible. Nitrogen fixation and photosynthesis for example need to be separated because enzymes involved in nitrogen fixation are very susceptible for destruction by oxygen. Especially in bacteria, where spatial separation is difficult due to the lack of cell organelles, temporal separation of such incompatible processes becomes crucial (Rosbash, 2009). Merrow and Roenneberg proposed an interesting theory concerning the question of why circadian clocks are self-sustained. Using a modeling approach they showed that simply increasing the coupling strength between different negative feedback loops of an oscillatory system changes it from non-self-sustained to self-sustained, suggesting that self sustainment might be a consequence rather than a prerequisite of a system that is ideally suited to synchronize to lightdark cycles (Roenneberg and Merrow, 2002). In other words, maybe the circadian system evolved in order to ideally synchronize the body to external conditions without a direct selection pressure on self-sustainment.

\subsection{Circadian organization}

\subsubsection{Features of circadian clocks}

The term circadian comes from Latin circa (approximately) and dies (day) and describes that circadian clocks run with a period of approximately 24 hours. Circadian clocks have three main features. Firstly, they are self-sustained and continue ticking in conditions devoid of any information of time of the day. This feature has first been observed in the plant mimosa when the French scientist de Mairan noticed that the typical leaf movements of this plant continue in constant darkness (Mairan, 1729). Later, Aschoff could show in his famous bunker experiments that also humans, when kept in isolation with no information about time of the day continue to show very regular sleep-wake and body temperature rhythms for weeks (Aschoff, 1965). In such free-running conditions the internal period (also called $\boldsymbol{\tau}$ ) of a certain rhythm can be calculated. Importantly, as stated above, the endogenous period is usually not exactly 24 hours and therefore has to be synchronized to the 24-hour day in order to function as a reliable timer. This 
synchronization is called entrainment and is the second important feature of circadian clocks. Entrainment cues are called Zeitgeber (German for "time giver"). Time of the day is described as Zeitgeber time (ZT) under entrained conditions and as circadian time (CT) under constant conditions with CT12 or ZT12 defined as the onset of activity. The most important Zeitgeber for mammals is light, but also non-photic cues such as temperature (Francis and Coleman, 1997; Glaser and Stanewsky, 2005; Buhr et al., 2010), exercise (Edgar and Dement, 1991; Bobrzynska and Mrosovsky, 1998) and food intake (Damiola et al., 2000) can reset clocks. The question whether social interactions can directly entrain circadian clocks is still under debate (Refinetti et al., 1992; Rajaratnam and Redman, 1999; Mistlberger and Skene, 2004). Zeitgebers vary in their efficiency in resetting clocks at different times of the day, and plotting the induced phase shift at different times results in so-called phase response curves (PRCs). Whereas photic Zeitgeber are mainly effective in resetting clock phase during the subjective night, most non-photic stimuli act during the subjective day. Entrainment has to be clearly differentiated from a mere masking effect: masking is a direct effect of a stimulus on the output of the clock, whereas entrainment resets the core clock machinery. Light, for example, can acutely suppress locomotor activity in nocturnal animals without affecting the clock machinery. A third cardinal property of most circadian clocks is temperature compensation so as to sustain a constant period over a broad range of ambient temperatures (Pittendrigh, 1954).

\subsubsection{The molecular clockwork}

The molecular mechanism of the circadian clock works cell-autonomously and is based on transcriptional-translational feedback loops (TTLs). In the 1970s Benzer and Konopka identified the first circadian fly mutant and with this pioneered the field of neurogenetics (Konopka and Benzer, 1971). A mutagenesis screen identified different alleles of the Period gene leading to either arrhythmic, short period or long period eclosion rhythms in flies. It took almost 20 years until Menaker and Ralph discovered the first mammalian circadian mutant, the Tau mutant in hamster (Ralph and Menaker, 1988). Later, Caseinkinase1epsilon (Ck1E) was identified as the Tau mutant locus (Lowrey et al., 2000). A mutagenesis screen in mice discovered the Circadian Locomotor Output Cycles Kaput (Clock) mutant mouse (Vitaterna et al., 1994) and targeted knockouts identified Period2 (Zheng et al., 1999) and Period1 (Zheng et al., 2001) as important mammalian clock genes.

We now know that the circadian clock relies on a transcriptional-translational feedback loop comprising positive and negative elements (Fig. 1). In mammals, the positive arm consists of the transcription factors CLOCK and BMAL1 (ARNTL), which via binding to so-called E-box promoter elements activate the transcription of two Cryptochrome (Cry; Cry1 and Cry2) and three Period (Per; Per1-3) genes. In the cytoplasm CRY and PER proteins form heterodimers and as such translocate back to the nucleus where they inhibit CLOCK/BMAL1 mediated transcription (Ko and Takahashi, 2006). Neuronal PAS domain protein 2 (Npas2) was found to be a paralog of Clock that can sustain clock function in the absence of the CLOCK protein (Reick et al., 2001; DeBruyne et al., 2007). Post-translational mechanisms including the ubiquitination of CRY by the SCF (F-box and leucine-rich repeat protein 3, Fbxl3) complex (Busino et al., 2007; Godinho et al., 2007; Siepka et 
al., 2007) and the phosphorylation of PER by Casein kinases (Dodd et al., 2005; Meng et al., 2008) regulate the stability of CRY and PER proteins and thereby adjust the period of the circadian clockwork (Maywood et al., 2011b). Besides the core TTL a number of additional feedback loops have been found that are thought to fine tune and stabilize the core loop. The orphan nuclear receptors Reverb $\alpha$ and Ror $\alpha$ activate and inhibit Reverb $\alpha /$ Ror-binding promoter elements (RREs) and built an accessory feedback loop by regulating the rhythmic abundance of Bmal1 transcript levels (Preitner et al., 2002; Sato et al., 2004). Similarly, D site albumin promoter binding protein (DBP) and E4BP4 (Nfil3) regulate D-box promoter elements (Ukai and Ueda, 2010). More genes involved in the clock mechanism have been discovered, and high throughput in vitro studies suggest that even more will be discovered in the future (Zhang et al., 2009).

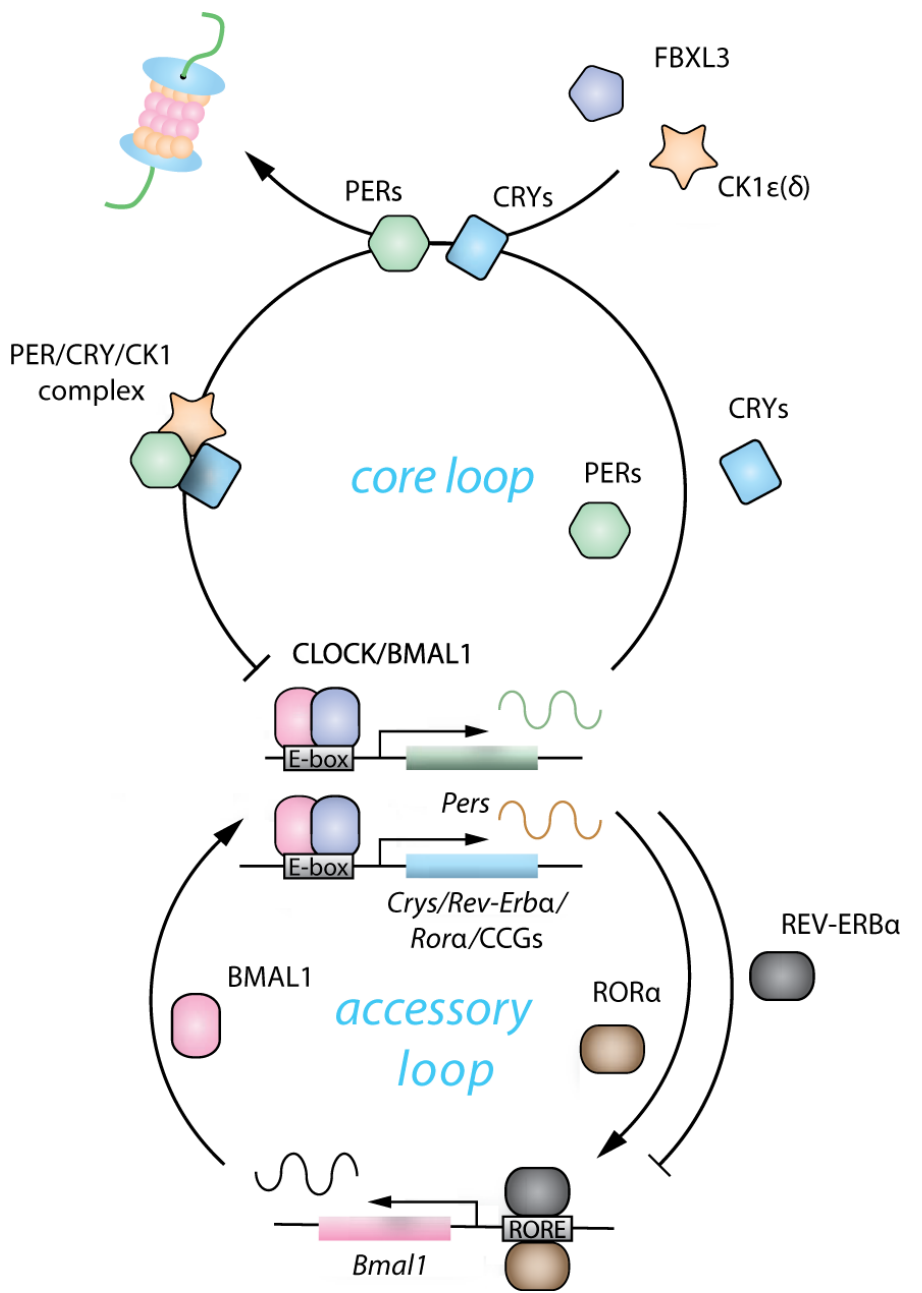

Fig. 1:

Transcriptional/translational feedback loops (TTLs) form the molecular basis of the mammalian circadian clock.

CLOCK and BMAL1 activate the transcription of Per and Cry genes via Ebox promoter elements. PER and CRY proteins form heterodimers and translocate back to the nucleus where they inhibit CLOCK/BMAL1 mediated transcriptional activation. Reverba and Ror $\alpha$ give rise to an accessory loop that regulates Bmal1 transcript levels via ROR elements. Post-translational modification of PER and CRY stability by Casein kinases and FBXL3 fine tunes period length. Modified from (Oster, 2006).

Very recent work indicates that post-translational modifications might be sufficient to drive rhythmicity in the absence of transcriptional feedback, at least in some eukaryotic cells (O'Neill and Reddy, 2011; O'Neill et al., 2011). This is reminiscent of the cyanobacterial clockwork, which at its core is built upon phosphorylation cycles of three Kai proteins (KaiA, KaiB, KaiC). Sustained 24-hour oscillations of cyanobacterial KaiC phosphorylation can be reconstituted in a test tube in the absence of transcription and translation (Nakajima et al., 2005). 
The output of the molecular clock are so-called clock-controlled genes (ccgs), many of which are characterized by E-box elements in their promoters. 5-10\% of all genes expressed in an organ are rhythmic and thus classify as clock targets (Akhtar et al., 2002; Panda et al., 2002b; Oster et al., 2006a; Storch et al., 2007). Interestingly, the ccg overlap between different organs is relatively small, thus ccgs seem to represent the specific output of the clock in a given organ regulating tissue specific circadian physiology. Clock control can be exerted in parallel at different steps of one process (e.g. the ligand is rhythmic but also the receptor) which allows fine tuning and adds stability.

\subsubsection{The master pacemaker in the suprachiasmatic nucleus (SCN)}

In mammals, the master pacemaker resides in the suprachiasmatic nucleus (SCN), which is a paired structure in the ventral hypothalamus located directly above the optic chiasm. Destruction of the SCN in rodents results in complete loss of circadian locomotor, endocrine and drinking rhythms (Stephan and Zucker, 1972). Transplantation experiments between short period mutant and wild-type hamsters demonstrated that the genotype of the $\mathrm{SCN}$ determines the period of circadian locomotor activity (Ralph et al., 1990).

\subsubsection{SCN input}

The main input to the SCN comes from the eye via the retino-hypothalamic tract (RHT) (Johnson et al., 1988b; Levine et al., 1991; de Vries et al., 1994). In the retina, a specific subset of retinal ganglion cells expresses the photo-pigment melanopsin which renders these retinal ganglion cells light sensitive (Schmutz et al., 2011). These so-called intrinsically photic sensitive retinal ganglion cells (ipRGCs) project directly to the SCN (Berson et al., 2002; Provencio et al., 2002). Importantly, however, both melanopsin expressed in the ipRGCs and also rods and cones projecting to these ipRGCs transmit photic information to the SCN. These two systems have to some extent redundant functions, as the deletion of only one of them is not sufficient to disrupt light entrainment of the circadian clock (Freedman et al., 1999; Panda et al., 2002a). Upon destruction of both systems or upon lesion of all ipRGCs, however, circadian light entrainment is lost (Hattar et al., 2003; Guler et al., 2008). IpRGCs are perfectly suited to serve as light detectors for the circadian system as they have large dendritic fields, show tonic activation by long light pulses and have a relatively high activation threshold (Berson et al., 2002; Provencio et al., 2002). These features allow integration of light signals over a long time and prevent reaction of the circadian system to noise. Melanopsin is maximally sensitive to blue light ( $480 \mathrm{~nm}$ ) (Berson et al., 2002) which perfectly fits to the spectral sensitivity of phase shifts of the circadian system in vivo (Takahashi et al., 1984).

Synapses of the RHT mainly target the ventral part of the SCN (Levine et al., 1991) and use glutamate and pituitary adenylate cyclase-activating polypeptide (PACAP) as major neurotransmitters (Hirota and Fukada, 2004). Upon binding of the glutamate and PACAP to SCN neuron receptors, an intracellular signaling cascade is activated including the calcium/calmodulin kinase II (CAMKII), mitogen-activated protein kinase (MAPK) and cGMP-dependent protein kinase II (PGKII) ultimately leading to phosphorylation of the transcription factor CAMP response element 
binding protein (CREB). Phosphorylated CREB in turn induces the expression of Period genes via binding to CAMP response elements (CREs) in their promoters (reviewed in (Hirota and Fukada, 2004)). Importantly, CREB activation and subsequent Period induction only occurs after a light pulse during the subjective night and the circadian gating of this response is at least partly mediated by rhythmic sensitivity at the level of glutamate receptors in SCN neurons (Pennartz et al., 2001). In addition protein kinase $C \alpha$ (PRKCA) mediated post-translational events play a role in the molecular resetting mechanism (Jakubcakova et al., 2007).

Light is also indirectly transmitted to the $\mathrm{SCN}$ via neuropeptide $\mathrm{Y}$ (NPY) neurons from the intergeniculate leaflet (IGL) (Jacob et al., 1999) and serotonergic input from the raphe nuclei can modulate photic input to the SCN (Muscat et al., 2005). Non-photic input is mainly transmitted via NPY neurons form the IGL and via serotonergic input from the dorsal and median raphe nuclei (DRN, MRN) (Dibner et al., 2010) (Fig. 2).

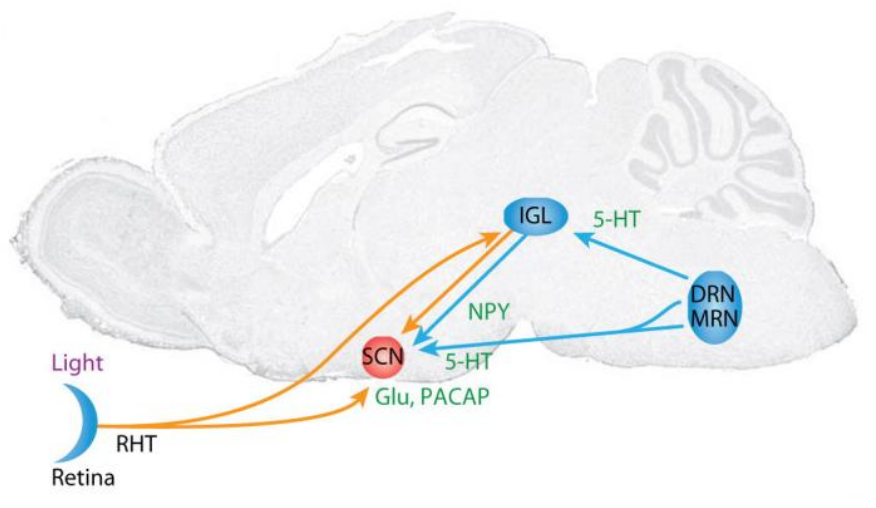

Fig. 2: Main afferents to the SCN.

Photic input to the SCN is transmitted directly via the retino-hypothalamic tract (RHT) and indirectly via the intergeniculate leaflet (IGL). The RHT stimulates SCN neurons via the release of glutamate and pituitary adenylate cyclase-activating polypeptide (PACAP). Non-photic input is mainly transmitted from the dorsal and median raphe nuclei (DRN, MRN) as well as from the IGL via serotonergic (5HT) and NPY neurotransmission. Modified from (Dibner et al., 2010).

Given that both light and serotonergic input from the raphe nuclei converge on the IGL, this nucleus allows integration of photic and non-photic Zeitgeber information. Retrograde and anterograde labeling studies in rats provided evidence for additional afferents to the SCN from thalamic, hypothalamic and limbic structures (Moga and Moore, 1997).

\subsubsection{SCN anatomy}

In the mouse, each SCN consists of 10000 cells and contains small ( $\sim 10 \mu \mathrm{m}$ in diameter) densely packed neurons (Welsh et al., 2010). Dispersed SCN neurons cell-autonomously generate rhythmic electrical activity (Welsh et al., 1995). However, synchronization between SCN oscillators is necessary to generate a precise rhythmic output (Herzog et al., 2004). Studies using circadian mouse mutants showed that intercellular coupling confers robustness to the SCN output (Liu et al., 2007). The nature of the coupling signals between SCN cells is still under investigation. It has 
been shown, however, that neurotransmission as well as paracrine signals may play important roles in SCN coupling. Action potentials seem important for coupling as treating SCN slice cultures with the voltage-gated sodium channel blocker tetrodotoxin (TTX) leads to desynchrony (Yamaguchi et al., 2003). In addition a role for electrical coupling via gap junctions has been proposed (Prosser et al., 1994; Colwell, 2000; Rash et al., 2007), however, conventional chemical synapses are probably more important (Welsh et al., 2010). A number of studies suggest vasoactive intestinal polypeptide (VIP) as a major synchronization factor in the SCN. VIP as well as VIP receptor deficient mice show strongly attenuated behavioral rhythmicity accompanied by pronounced desynchrony among SCN neurons (Colwell et al., 2003; Aton et al., 2005; Brown et al., 2007). Interestingly, reduced coupling among SCN cells also leads to a decreased number of rhythmic cells, suggesting that coupling might be necessary for some SCN neurons to sustain rhythmicity. Other neurotransmitters like gastrin releasing peptide (GRP) or neurotensin could also be implicated in SCN coupling given their capability to phase shift SCN slices (Welsh et al., 2010). Very recently, Maywood and coworkers showed a hierarchy of paracrine signals with VIP being more potent than arginine vasopressin (AVP) and AVP being more important than GRP in coupling SCN cells (Maywood et al., 2011a). Glial cells are abundant in the rodent SCN and might contribute to SCN function (Guldner, 1983; Morin et al., 1989; Moriya et al., 2000; Cambras et al., 2005). Glial fibrillary acidic protein (GFAP)-expressing astrocytes in the SCN change their morphology over the course of the day (Kalsbeek et al., 2011) and blocking glial metabolism results in disrupted wheel running rhythms in rats (Prosser et al., 1994).

The early view of the SCN as a network of relatively similar cell-autonomous oscillators has changed dramatically recently. It seems that not all SCN neurons are rhythmic and - among those that are - period and phase are surprisingly diverse. In vivo, an ordered spatio-temporal arrangement of phases between SCN cells is preserved with the dorsal SCN part phase leading the ventral SCN part during free running conditions (Hamada et al., 2004). The heterogeneous nature of the SCN is confirmed by regional expression of neuropeptides and differences in afferent and efferent connections. The most obvious divisions of the SCN are a ventrolateral core region defined by VIP expression ( $10 \%$ of SCN cells) that is surrounded by the shell expressing AVP ( $20 \%$ of SCN cells) (Welsh et al., 2010) (Fig. 3). The distribution of the main core (VIP) and shell markers (AVP) seems relatively conserved between mouse, hamster and humans (Stopa et al., 1984); for other neuropeptides, however, there is substantial diversity of expression patterns between different species. In the mouse, the SCN core contains the neurotransmitters GABA, calbindin (CalB), VIP, calretinin, GRP and neurotensin (Nt), whereas the shell contains GABA, CalB, AVP, angiotensin II and met-enkephalin positive cells (Abrahamson and Moore, 2001) (Fig. 2). 


\section{3rd ventricle}

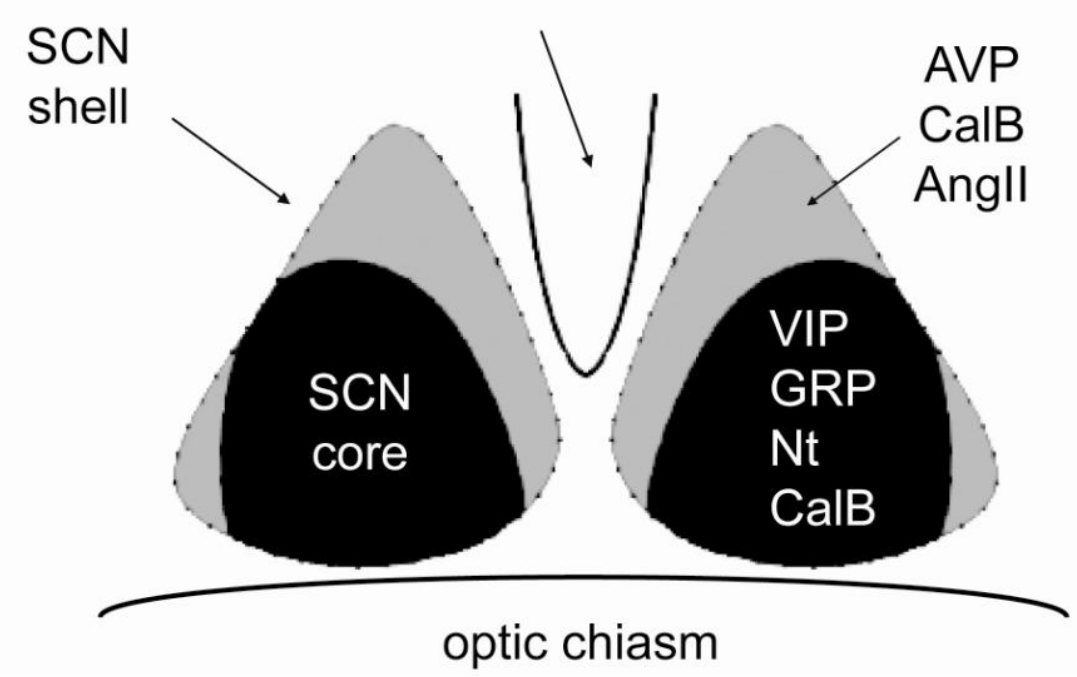

Fig. 3: The SCN is subdivided into a core and a surrounding shell region.

The murine SCN core mainly expresses vasoactive intestinal polypeptide (VIP), gastrin releasing peptide (Grp), neurotensin (Nt) and calbindin (CalB) whereas the shell is characterized by arginine vasopressin (AVP), CalB and angiotensin II (AngII) expression.

RHT fibers from the eye densely project to the $\mathrm{SCN}$ core, whereas shell neurons receive relatively sparse RHT input (Abrahamson and Moore, 2001). Input from the IGL and raphe seems to mainly target the SCN core, whereas potentially more modulating non-photic input from other brain areas like the hippocampus, the basal forebrain and other hypothalamic nuclei targets the SCN shell (Moga and Moore, 1997; Abrahamson and Moore, 2001). In addition core and shell regions might differ with respect to the distribution of efferent projections and differences in the density of the innervations of target areas has been shown (Leak et al., 1999; Abrahamson and Moore, 2001; Leak and Moore, 2001; Yan et al., 2007). Within the SCN, the core sends dense projections to the SCN shell, which only sparsely innervates core neurons (Leak et al., 1999). This pattern of connectivity suggests heterogeneous function of core and shell compartments with the core receiving photic information, which is then transmitted to the shell. This idea is supported by the fact that after a light pulse, mainly VIP-expressing cells in the SCN core exhibit increased neuronal firing rates (Kuhlman et al., 2003). In addition, a light pulse induces immediate early genes like cFos as well as the clock genes Per1 and Per 2 in the core and this signal then spreads to the shell (Yan and Silver, 2002; Hamada et al., 2004). However, it seems that Per induction in the core is not sufficient for a behavioral phase shift but requires the spreading of Per induction to the shell (Yan and Silver, 2002). Similar observations were made in a jet lag paradigm: upon a 6 hour advance of the light dark cycle, the SCN core shifts first, whereas the shell lags behind. After a 6 hour advance, re-establishment of the original phase relationship within the SCN takes up to 8 days to complete (Nagano et al., 2003; Nakamura et al., 2005; Davidson et al., 2009). Thus the SCN core seems to be the retino-recipient part of the SCN. 
The core might also be necessary for synchronized rhythmicity of the entire SCN. Targeted micro lesions of a central subregion in the hamster SCN expressing CalB results in arrhythmic locomotor activity, corticosterone release, body temperature and heart rate (LeSauter and Silver, 1999; Kriegsfeld et al., 2004). In the mouse, CalB positive cells do not form a central core region, but are interspersed along the entire SCN, thus direct comparisons between CalB positive cells in hamster and mouse are difficult. In the mouse, the VIP expressing core might be similarly important for sustaining rhythmicity within the SCN, as described above (Aton et al., 2005). In SCN slice cultures AVP is released with a period of 23.8 hours, which is very similar to the period of locomotor activity of the animal. Upon surgical separation of the ventral SCN, however, the period of AVP release shortens, indicating that the ventral SCN entrains the dorsal SCN (Noguchi et al., 2004). In addition, after separation the cells in the dorsal SCN desynchronize faster than ventral cells suggesting that the $\mathrm{SCN}$ core releases a coupling factor that is essential for sustained synchrony among shell cells (Yamaguchi et al., 2003). Of note, the classification of the SCN into a ventral core and a dorsal shell is likely an oversimplification and a more complex organization of the SCN has been considered (Morin et al., 2006). However, given the huge variation of more complex patterns of gene expression between species, the core-shell model of SCN organization, which seems relatively conserved in all mammals, is likely a good working model.

\subsubsection{SCN output}

There is still relatively little known about the output of the SCN conferring circadian rhythmicity in behavior and physiology. It seems clear, however, that the SCN uses both neuronal as well as humoral signals to transmit timing information to the rest of the body. In culture, SCN cells or transplants are capable of synchronizing non-SCN cells that are several millimeters away (Allen et al., 2001; Prolo et al., 2005). In vivo, the SCN can impose rhythms on grafted mouse embryonic fibroblasts (Pando et al., 2002). Diffusible signals from the SCN are sufficient to drive rhythmic locomotor behavior, as SCN transplants that are encapsulated in a semi-permeable membrane rescue activity rhythms in arrhythmic SCN-lesioned animals (Silver et al., 1996). However, SCN transplantation is not sufficient to restore endocrine rhythms (Meyer-Bernstein et al., 1999). On the other hand, preventing SCN neurons from firing action potentials by infusion of tetrodotoxin (TTX) abolishes rhythmic behavior, showing that both humoral and neuronal output is necessary for rhythmic behavior (Ruby et al., 1999).

AVP is rhythmically released from the SCN in vivo and was suggested as an important humoral output of the SCN (Ahren et al., 1997). Mouse and rat AVP mutants, however, show relatively normal circadian rhythmicity suggesting that AVP is at least not the only SCN output (Li et al., 2009; Loh et al., 2011). More recently transforming growth factor $\alpha$ (TGF $\alpha$ ), prokineticin 2 (PK2) and cardiotrophin-like cytokine (CLC) were identified as SCN outputs which inhibit locomotor activity upon infusion into the third ventricle (Leak et al., 1999; de la Iglesia et al., 2000; Kramer et al., 2001). The fact that SCN transplants fail to reinitiate endocrine rhythms (Meyer-Bernstein et al., 1999) highlights the importance of intact neuronal projections from the SCN. The main targets of SCN neurons reside in the medial hypothalamus, namely the paraventricular nucleus of the hypothalamus (PVN), the subparaventricular zone of the hypothalamus (SPVZ), the dorsomedial 
nucleus of the hypothalamus (DMH), the arcuate nucleus (ARC), the lateral septum (LS), the bed nucleus of the stria terminalis (BNST) and the preoptic area (POA) (Leak and Moore, 2001). In addition the SCN projects to non-hypothalamic areas, e.g. the paraventricular nucleus of the thalamus (PVT) (Buijs and Kalsbeek, 2001) (Fig. 4).

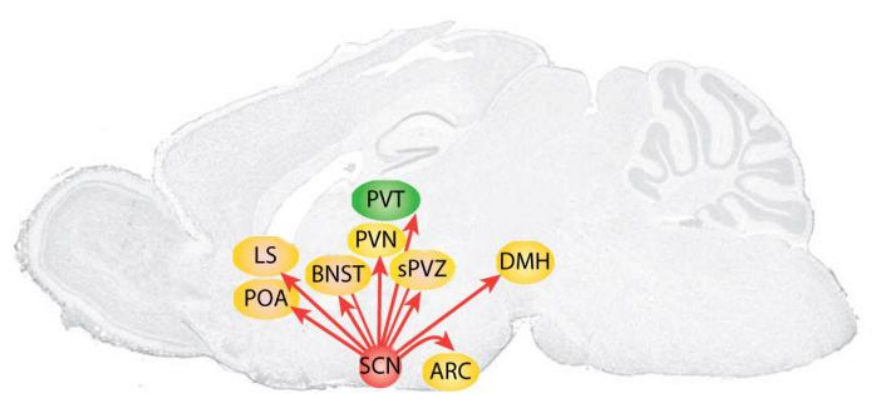

Fig. 4: The main efferents of the SCN.

The SCN mainly targets hypothalamic nuclei (yellow) like the paraventricular nucleus of the hypothalamus (PVN), the subparaventricular zone of the hypothalamus (SPVZ), the dorsomedial nucleus of the hypothalamus (DMH), the arcuate nucleus (ARC), the lateral septum (LS), the bed nucleus of the stria terminalis (BNST) and the preoptic area (POA). Also other parts of the brain are directly innervated by SCN efferents e.g. the paraventricular nucleus of the thalamus (PVT, green). Modified from (Dibner et al., 2010).

The main SCN neurotransmitters are GABA and glutamate; additionally, a number of neuropeptides are released from SCN neurons, e.g. AVP, VIP, GRP and somatostatin (Buijs and Kalsbeek, 2001). Thus the SCN transmits timing information and synchronizes physiology by both neuronal and humoral signals.

Interestingly, it seems that the rhythmicity of a physiologic parameter is often controlled at many steps in parallel. The glucocorticoid corticosterone shows a pronounced rhythm of release peaking at the beginning of the active phase (Oster et al., 2006b). The SCN projects to Corticotropin-releasing hormone $(\mathrm{CRH})$ releasing PVN neurons which in turn stimulate the release of ACTH from the pituitary (Kalsbeek and Buijs, 2002). ACTH induces the release of corticosterone from the adrenal gland while the adrenal's sensitivity to ACTH is regulated locally by adrenocortical clocks (Oster et al., 2006b). In addition to the hypothalamic-pituitary-adrenal (HPA) axis described above, autonomic signals from the splanchic nerve seem to directly stimulate the release of corticosterone from the adrenal gland and splanchic nerve denervation dampens rhythmic corticosterone release (Jasper and Engeland, 1994; Ulrich-Lai et al., 2006). In summary the circadian clock controls the rhythmicity of hormones such as corticosterone at several levels which might fine tune and also stabilize the system.

\subsubsection{Peripheral clocks}

Whereas the importance of the master clock in the SCN has been clear since the 1970s, the fact that clocks are also found in non-SCN regions has only been appreciated recently. The first 
peripheral clock was described in the retina, when it was shown that cultured hamster retinas exhibit rhythmic melatonin secretion for days in the absence of the SCN (Tosini and Menaker, 1996). Shortly afterwards fibroblasts were shown to be rhythmic in culture after synchronization with a serum shock (Balsalobre et al., 1998). With the development of luciferase reporter rats and mice that allowed the real-time reporting of circadian dynamics (Yamazaki et al., 2000; Yoo et al., 2004), endogenous clocks were described in almost all tissues including different brain areas and peripheral organs (Abe et al., 2002). The description of endogenous peripheral clocks has changed the concept of the SCN master pacemaker, such that the SCN is now rather considered to synchronize than to drive peripheral rhythms. What makes the SCN special among the tissue clocks is likely the tight synchronization of SCN cells, which is thought to be less stringent in peripheral tissues.

Importantly, Zeitgebers can differ in their effectiveness in resetting central and peripheral clocks. Food uptake, for example, has been shown to be a major Zeitgeber for peripheral tissues like the liver. Subjecting mice or rats to a restricted feeding schedule, where food is only given during their inactive phase when rodents normally do not eat, leads to a complete uncoupling of peripheral clocks from the SCN clock (Damiola et al., 2000).

The question arises why local endogenous clocks have evolved and what advantage they confer in comparison to a system that is centrally regulated. These questions are now addressed using conditional clock knock-outs or rescues of various tissue clocks (McDearmon et al., 2006; Kornmann et al., 2007; Storch et al., 2007; Bray et al., 2008; Lamia et al., 2008; Marcheva et al., 2010; Sadacca et al., 2010). It could be shown, that the retina clock is important for the retina's circadian response to light (Storch et al., 2007), whereas clocks in the liver and the pancreas are important for regulating glucose homeostasis (Lamia et al., 2008; Marcheva et al., 2010). Thus it seems that peripheral clocks are necessary for efficient physiology, however, a number of open questions remain to be solved in order to untangle the network regulation of circadian clocks in the body and their specific role in regulating animal physiology.

\subsubsection{Hierarchy of circadian clocks}

Early SCN lesion studies in rats established the $\mathrm{SCN}$ as the master pacemaker in the mammalian brain. Complete bilateral SCN lesions result in arrhythmicity of activity, drinking behavior, corticosterone release and body temperature in rodents (Moore and Eichler, 1972; Stephan and Zucker, 1972; Lehman et al., 1987; Ralph et al., 1990; Refinetti et al., 1994; Silver et al., 1996; Sujino et al., 2003). In addition, SCN lesions lead to blunted gene expression rhythms in peripheral organs in constant darkness (DD) (Akhtar et al., 2002; Guo et al., 2005; Guo et al., 2006) as well as under light-dark conditions (LD) (Sakamoto et al., 1998) which led to the hypothesis that the SCN as the master pacemaker drives rhythmicity in all other peripheral tissues. Similar effects are seen after SCN isolation by knife cuts, indicating that the destruction of neuronal efferents from the SCN is sufficient to induce arrhythmicity (Stephan and Nunez, 1977).

Importantly, SCN lesions induce arrhythmic activity, drinking behavior and corticosterone release also under LD conditions (Moore and Eichler, 1972; Stephan and Zucker, 1972; Lehman et al., 1987; Sujino et al., 2003), suggesting that light information, which is necessary for light induced 
masking effects, is transmitted via the SCN. As described above, locomotor activity rhythms can be rescued in SCN lesioned animals by transplantation of fetal SCN tissue and the period of the rhythm is determined by the period of the transplant (Lehman et al., 1987; Ralph et al., 1990). Interestingly, although SCN transplants rescue free running periods, they do not rescue photic entrainment and transplanted animals free run in LD conditions (Lehman et al., 1987; Sujino et al., 2003). The lack of light entrainment is probably due to absent or non-functional RHT innervation of SCN transplants.

Importantly, while SCN grafts do rescue behavioral rhythmicity, endocrine rhythms are not restored as has been shown for corticosterone and melatonin rhythms (Meyer-Bernstein et al., 1999). Clock gene rhythms in peripheral organs are rescued in liver, kidney and muscle tissue, but not in heart, spleen and adrenal under DD conditions (Guo et al., 2005; Guo et al., 2006), suggesting that the SCN regulates peripheral organs via diverse pathways. A study using the Period2::Luc reporter system in mice has shown that tissues are still rhythmic after SCN lesions in explant cultures (Yoo et al., 2004). However, the authors point out that rhythmicity in Period2::Luc explant cultures not necessarily represents the in vivo state of these oscillators (as the culturing procedure might synchronize peripheral cells) and therefore the question whether peripheral rhythms persist after SCN lesions in vivo remains open.

\subsection{Clocks, Sleep and Metabolism}

\subsubsection{Clocks and sleep}

\subsubsection{Circadian and homeostatic processes of sleep regulation}

The most obvious circadian rhythm in mammals is the sleep-wake rhythm. Sleep can be divided into rapid eye movement (REM) and non-REM (NREM) phases. According to the "2-processmodel" sleep is regulated by a circadian process " $C$ " that defines the timing of sleep and a homeostatic process " $\mathrm{S}$ " describing the increase in sleep pressure with extended waking (Borbely, 1982; Daan et al., 1984). Neuroanatomically, the circadian process is based on the SCN, whereas the homeostatic process involves a dispersed but connected network of arousal- and sleeppromoting circuits in the hypothalamus, thalamus, forebrain, midbrain, pons and medulla (Saper et al., 2010). Thus, circadian and homeostatic processes seem to be separated at least neuroanatomically (critically reviewed in (Mistlberger, 2005)). The SCN exerts control of the timing of sleep and wake by both direct and indirect (second or third order) connections to various sleep-wake areas including the DMH, the ventrolateral preoptic nucleus (VLPO) and the medial POA (Mistlberger, 2005).

\subsubsection{Molecular interaction between the circadian clock and sleep}

On the molecular level the separation of circadian and homeostatic processes of sleep is far less clear. A number of mouse clock gene mutants show (apart from disruption or abolishment of sleep rhythms) changes in sleep homeostatic parameters. Hypersomnolence is observed in Cry1/2 double knock-out as well as in Bmal1 deficient mice (Wisor et al., 2002; Laposky et al., 2005), 
hyposomnolence has been shown for Clock mutant and Npas2 deficient mice (Naylor et al., 2000; Franken et al., 2006), whereas total sleep time is unchanged in Period single and double mutants (Kopp et al., 2002; Shiromani et al., 2004). Sleep deprivation challenges the sleep homeostat and the amount of sleep rebound or the increase in delta band $(0.5-4 \mathrm{~Hz})$ activity in the NREM electroencephalogram (EEG) after sleep deprivation are used as measures of sleep drive. Bmal1 knock-outs show increased rebound (Laposky et al., 2005), whereas most other clock mutants have reduced sleep or delta rebound after sleep deprivation (Franken et al., 2000; Wisor et al., 2002; Laposky et al., 2005; Franken et al., 2006). Although not commented on by the authors, Period1/2 double mutants also show an enhanced delta rebound, suggesting that Period genes might be involved in sleep homeostatic processes (Shiromani et al., 2004).

After having verified a sleep-like state in Drosophila (Hendricks et al., 2000), fly clock mutant studies provided similar results as those described for mice (Hendricks et al., 2000; Shaw et al., 2002; Hendricks, 2003). Similarly, human clock gene polymorphisms have been linked to disturbances in sleep timing: mutations in $h P e r 2$ or $h C K I \delta$ lead to familial advanced sleep phase syndrome (Toh et al., 2001; Xu et al., 2005) and delayed sleep phase syndrome has been associated with polymorphisms in the hPER3 gene (Ebisawa et al., 2001). In addition, polymorphisms in the clock gene hPER3 have been correlated to increased sleep drive and reduced cognitive performance after sleep deprivation (Viola et al., 2007). Taken together, mouse, fly and human studies provide evidence for an interaction of process $C$ and $S$ at the molecular level, and clock genes seem to be involved not only in circadian but also in homeostatic regulation.

\subsubsection{Sleep deprivation affects the clock}

Sleep deprivation affects the circadian clock on the molecular, behavioral and electrophysiological level. Clock genes seem to be directly regulated by sleep deprivation. Per1 and Per2 expression in the forebrain and in other brain regions is up-regulated by sleep deprivation (Wisor et al., 2002; Franken et al., 2007; Wisor et al., 2008). Whole-genome transcriptome analysis disentangles genes that are mainly regulated by sleep and those that are regulated by time of the day. Surprisingly, $80 \%$ of the genes that were rhythmic in the brain in control conditions were not rhythmic any more after sleep deprivation (Maret et al., 2007). Genes that are mostly sleep dependent include those involved in the stress response, synaptic plasticity, transcription factors, heat shock genes and immediate early genes (Maret et al., 2007; Yan et al., 2008; Thompson et al., 2010). Interestingly, the liver transcriptome is even more affected than that of the brain (Maret et al., 2007).

On the behavioral level sleep deprivation is able to phase shift activity rhythms of hamsters in constant darkness, thus sleep deprivation can serve as a Zeitgeber in mammals at least in the absence of other clock synchronizers (Antle and Mistlberger, 2000; Mistlberger et al., 2002). In addition, sleep states directly and acutely affect SCN electrical activity and superimpose an ultradian rhythm on circadian neuronal firing. During REM sleep SCN activity is acutely upregulated (Deboer et al., 2003) and sleep deprivation severely dampens the rhythm of SCN electrical activity (Deboer et al., 2007). 
1.3.2 Publication: A time to fast, a time to feast: the crosstalk between metabolism and the circadian clock

Judit Kovac ${ }^{*}$, Jana Husse ${ }^{*} \&$ Henrik Oster ${ }^{\#}$

* These authors contributed equally to this work

\# To whom correspondence should be addressed: henrik.oster@mpibpc.mpg.de

Molecules and Cells, 2009, Volume 28, pages 75-80. 


\section{A Time to Fast, a Time to Feast: The Crosstalk between Metabolism and the Circadian Clock}

\begin{abstract}
Judit Kovac $^{1,3}$, Jana Husse ${ }^{2,3}$, and Henrik Oster ${ }^{1, *}$
The cyclic environmental conditions brought about by the $24 \mathrm{~h}$ rotation of the earth have allowed the evolution of endogenous circadian clocks that control the temporal alignment of behaviour and physiology, including the uptake and processing of nutrients. Both metabolic and circadian regulatory systems are built upon a complex feedback network connecting centres of the central nervous system and different peripheral tissues. Emerging evidence suggests that circadian clock function is closely linked to metabolic homeostasis and that rhythm disruption can contribute to the development of metabolic disease. At the same time, metabolic processes feed back into the circadian clock, affecting clock gene expression and timing of behaviour. In this review, we summarize the experimental evidence for this bimodal interaction, with a focus on the molecular mechanisms mediating this exchange, and outline the implications for clock-based and metabolic diseases.
\end{abstract}

\section{INTRODUCTION}

The adaptation to environmental changes brought about by the succession of day and night offers strong advantages for the efficient usage of natural resources and, hence, is a major evolutionary selection criterion (Pittendrigh, 1993). Not surprisingly, all but the simplest species living on Earth have evolved timekeeping mechanisms that enable them to predict and adapt to upcoming time-dependent events (Harmer et al., 2001). These internal clocks, termed circadian from Latin "circa diem" meaning "about a day", are a remarkable example of parallel evolution that emphasizes the importance of temporal resolution for living organisms. Circadian clocks anticipate daily events and adapt behaviour and physiology in an attempt to minimise energy expenditure and maximise the chance of survival.

Circadian regulation does not only serve the alignment of internal and external rhythms, but also provides a powerful means to achieve temporal compartmentalisation at both interand intracellular levels (Takahashi et al., 2008). According to the current model, mammalian circadian clocks are based on cellular oscillators built from a set of clock genes organised in interlocked transcriptional feedback loops. The transcription factors CLOCK (or, in some tissues, NPAS2) and BMAL1 (ARNTL) drive expression of two Cry and three Per genes, as well as hundreds of so called clock controlled genes (CCGs) via E-box mediated regulation. PER and CRY proteins negatively feed-back on CLOCK/BMAL1 activity, thereby generating a stable $24 \mathrm{hr}$ rhythm of transcriptional activity. Several accessory feedback loops - one of them involving the nuclear hormone receptors Rev-erb $\alpha$ (Nr1d1) and Ror $\alpha$ (Rora) - stabilise this rhythm and provide further means for in- and output to and from the molecular clock (Ko and Takahashi, 2006). The nature of CCGs varies between different tissues, providing a way to translate time information into physiologically meaningful signals (Duffield, 2003).

In mammals, a master circadian pacemaker is located in the hypothalamic suprachiasmatic nuclei (SCN). From the SCN peripheral clocks throughout the rest of the body are synchronised with each other and with external time. The synchronisation mechanisms of the circadian timing system have not yet been fully understood, but likely involve humoral, neuronal as well as indirect pathways such as the activity-mediated regulation of food intake and body temperature (Stratmann and Schibler, 2006). The major synchroniser (or Zeitgeber) of circadian rhythms is light. Light information reaches the SCN from visual and non-visual photoreceptors in the retina via the retinohypothalamic tract and results in the release of glutamate at SCN synapses (Foster and Hankins, 2007). Other Zeitgeber exist, but their signalling mechanisms are poorly studied. Some of them involve other brain nuclei and, most likely, other (peripheral) clocks. A striking example for this is the entrainment of peripheral oscillators by metabolic signals. Independently of the SCN, the temporal restriction of food access can rapidly reset clock gene rhythms in many tissues such as the liver or the kidney (Damiola et al., 2000). Similarly, light has been shown to directly affect clocks in the adrenal cortex and the secretion of endocrine factors such as glucocorticoids from this gland (Ishida et al., 2005; Oster et al., 2006). It is likely that other time cues will affect different oscillators and provide additional input for the entrainment of the circadian timing system.

While food restriction uncouples SCN and peripheral clocks, there is also feedback from the periphery to the master pacemaker. This includes arousal-associated circuits and hormonesensitive brain areas such as the raphe or the arcuate nuclei

${ }^{1}$ Circadian Rhythms Group, Max Planck Institute of Biophysical Chemistry, 37077 Göttingen, Germany, ${ }^{2}$ Genes and Behaviour Department, Max Planck Institute of Biophysical Chemistry, 37077 Göttingen, Germany, ${ }^{3}$ These authors contributed equally to this work.

*Correspondence: henrik.oster@mpibpc.mpg.de 
that themselves project to the SCN (Buijs et al., 2006). A direct neuronal feedback, e.g. from the autonomic nervous system, is likely, but experimental evidence for this is still missing. The optimisation of energy expenditure is one of the main functions of circadian timekeeping (see above). Thus, efficient interactivity of the circadian and metabolic regulatory centres is crucial for optimal environmental adaptation. The molecular aspects of this cross-talk and its (patho-) physiological implications are summarised below.

\section{Circadian control of metabolism}

A major function of the circadian system is the regulation of the metabolic machinery in preparation for temporal variations in the abundance of nutrients. Not surprisingly, various humoral factors associated with metabolic control show diurnal rhythms of concentration such as glucose, fatty acids and triglycerides, but also glucocorticoids, insulin and catecholamines. By these means clock-regulated anticipation of external events optimizes physiological energy expenditure and, hence, increases general fitness (Bray and Young, 2007).

In humans, clock-related metabolic regulation is tightly linked to the regulation of sleep. The circadian clock regulates the sleep/ wake cycle by synchronising phases of sleepiness and arousal throughout the day. In addition, a homeostatic component of unknown anatomical origin regulates the "need for sleep" in response to prolonged wakefulness. Recent work suggests that both processes are not entirely separated and clock genes may affect both circadian and homeostatic circuits (Mistlberger, 2005). Changes in human lifestyle - most prominently observed during the last decades - have led to a striking decrease in average sleep duration in most industrial countries, correlated with a dramatic increase in the prevalence of metabolic disorders (Laposky et al., 2008). Acute sleep restriction in healthy subjects promotes increased appetite, reduced leptin secretion, elevated ghrelin levels, and increased glucose resistance (Spiegel et al., 1999; 2004). Likewise, shift workers show higher metabolic risk factors for the development of obesity, diabetes type II, metabolic syndrome and cardio-vascular disease (Bray and Young, 2007) All these attributes are under circadian control, indicating that metabolic phenotypes might be the consequence of a misalignment between circadian clocks and physiology (Shea et al., 2005). Genetic variations in human circadian clock genes have been associated with metabolic phenotypes. Haplotype analyses revealed that CLOCK gene polymorphisms are correlated with the development of metabolic syndrome, while certain BMAL1 alleles are linked to type II diabetes and hypertension (Scott et al., 2007; Woon et al., 2007). These data propose that the transcription factors of the positive limb of the circadian clock may serve a protective role in the incidence of metabolic diseases.

Indications for a causal relationship between the circadian clock and metabolic regulation have been documented in circadian clock mutant mice (see Table 1). The dominant negative Clock mutant shows irregular locomotor activity and food intake behaviour. Clock animals develop obesity combined with increased levels of cholesterol, triglycerides, glucose and leptin, and a decrease in insulin secretion (Turek et al., 2005). Additionally, these mice absorb more lipids and carbohydrates than peptides via the intestine, most likely due to a lack of cyclic nutrient transport proteins (Pan and Hussain, 2009). Both, Clock mutant and Bmal1 deficient mice show impaired gluconeogenesis, glucose tolerance and insulin sensitivity (Rudic et al., 2004). In liver-specific Bmal1 deficient animals, defects in glucose balance are reflected by a loss of rhythmicity in the expression of genes important for glucose mobilisation such as glucose-6-phosphate translocase (SIc37a4), phosphoenolpyruvate carboxykinase 2 (Pck2), adenylate kinase 4 (Ak3/1) and glucose transporter 2 (Slc2a2) (Lamia et al., 2008). Similar to Clock mutant mice, Per2 deficient animals consume more food during their normal rest phase and develop obesity when fed on a high fat diet. Interestingly, this phenotype can be restored after intraperitoneal application of the melanocyte stimulating hormone $\alpha-\mathrm{MSH}$, involved in the regulation of appetite (Yang et al., 2009). Increased serum levels of very low density lipoproteins (VLDLs) and apolipoprotein C-III were found in mice lacking Rev-erba (Raspe et al., 2002).

Peripheral clocks regulate cell and tissue physiology via the rhythmic activation of hundreds of CCGs in a tissue-specific manner (Fig. 1). Transcriptome studies in metabolically relevant peripheral tissues such as liver, adipocytes, pancreas and the heart highlight the importance of CCGs in the regulation of numerous metabolic processes (Laposky et al., 2008). It seems that many key regulatory elements of energy conversion pathways, such as glucose and lipid metabolism, mediate metabolic alignment with external time. In cultured adipocytes, BMAL1 controls adipogenesis via the induction of $P P A R \gamma$, AP2 (FABP4), sterol regulatory element binding protein 1 (SREBP-1) and CCAAT/enhancer binding proteins (C/EBPS) (Shimba et al., 2005). Defects in adipocyte differentiation were also seen in the absence of REV-ERB $\alpha$, an upstream regulator of $B m a l 1$ transcription (Wang and Lazar, 2008). Additionally, REV-ERB $\alpha$ represses lipid metabolism by binding to an AGGTAC motif in the promoter region of ApoC-III (Raspe et al., 2002). In skeletal muscle, $\mathrm{ROR} \alpha$ regulates lipid homeostasis via direct activation of carnitine palmitoyltransferase 1 (CPT1), involved in fatty acid oxidation, and caveolin-3 (Lau et al., 2004). Rhythmic transcriptional activation by CLOCK/BMAL1 is a key regulator of lipid metabolic enzymes such as acyl-CoA oxidase $(A O X)$, 3hydroxy-3-methylglutaryl coenzyme A (HMG-CoA) synthase (Hmgcs 1) and cellular retinol binding protein II (CRBP II) (Inoue et al., 2005).

Circadian regulation of metabolism is not limited to peripheral clocks, but at the same time involves functional modulation of metabolic control centres in the brain. Rhythmic clock gene expression has not only been shown in the SCN, but in many other brain regions. These include the forebrain nuclei proximal to the third ventricle that express orexigenic (NPY, AgRP) and anorexigenic (POMC, CART) neuropeptides, as well as the dorsomedial nucleus and orexin-expressing neurons of the lateral hypothalamus (Green et al., 2008). Both regions serve as relay sites to arousal- and feeding-regulatory centres in the brainstem and the basal hypothalamus, respectively. Clock gene function itself is essential for normal regulation of ghrelin, CART and orexin levels in the hypothalamus (Turek et al., 2005). Thus, the appropriate integration of central and peripheral metabolic circadian regulation seems essential for the finetuning of overall metabolic homeostasis.

A possible risk factor for cardiovascular disease is a circadian dysfunction of the heart, where CLOCK regulates myocardial oleate oxidation and oxygen consumption by activation of fatty acid transport protein 1 (SIC27a1) as well as of the a3 and b3 subunits of NADH hydrogenase (Ndufa3/b3) (Bray et al., 2008). Furthermore, metabolic processes unrelated to energy balance have been reported to be regulated by the circadian clock. BMAL1 target genes are involved in xenobiotic detoxification and the conversion of reactive oxygen species (ROS) which are prime candidates for causing age-related degenerative processes (Kondratov et al., 2006). PER2, on the other hand, has a protective role in the susceptibility to alcohol and the 
Table 1. Mediators of circadian clock metabolism interaction

\begin{tabular}{|c|c|c|c|c|}
\hline Factor & Tissue & Function & Targets & References \\
\hline \multicolumn{5}{|l|}{ Clock genes } \\
\hline Bmal1 & $\begin{array}{l}\text { Liver } \\
\text { Adipocytes }\end{array}$ & $\begin{array}{l}\text { Glucose mobilisation } \\
\text { Adipogenesis }\end{array}$ & $\begin{array}{l}\text { Slc37a4, Pck2, Ak3l1, Slc2a2 } \\
\text { Pparg2, Ap2, Srebp-1, C/EBPs }\end{array}$ & $\begin{array}{l}\text { Lamia et al. (2008) } \\
\text { Shimba et al. (2005) }\end{array}$ \\
\hline Clock & $\begin{array}{l}\text { Hypothalamus } \\
\text { Heart }\end{array}$ & $\begin{array}{l}\text { Appetite regulation } \\
\text { Oleate oxidation } \\
\text { Oxygen consumption }\end{array}$ & $\begin{array}{l}\text { Orexin, Ghrelin, Cart } \\
\text { Slc27a1 } \\
\text { Ndufa3/b3 }\end{array}$ & $\begin{array}{l}\text { Turek et al. (2005) } \\
\text { Bray et al. (2008) }\end{array}$ \\
\hline Per2 & Hypothalamus & Appetite regulation & $\alpha-\mathrm{MSH}$ & Yang et al. (2009) \\
\hline Rev-erb $\alpha$ & $\begin{array}{l}\text { Adipose tissue } \\
\text { Liver, serum, kidney }\end{array}$ & $\begin{array}{l}\text { Adipocyte differentiation } \\
\text { Triglyceride catabolism }\end{array}$ & $\begin{array}{l}\text { Pparg2 } \\
\text { APOC-III, VLDL triglycerides }\end{array}$ & $\begin{array}{l}\text { Wang and Lazar (2008) } \\
\text { Raspe et al. (2002) }\end{array}$ \\
\hline Ror $\alpha$ & Skeletal muscle & Fatty acid oxidation & Cpt1, Caveolin-3 & Lau et al. (2004) \\
\hline \multicolumn{5}{|c|}{ Metabolic sensors } \\
\hline Ppara & Liver & Lipid and energy metabolism & $\begin{array}{l}\text { Bmal1, } \\
\text { REV-ERB } \alpha\end{array}$ & $\begin{array}{l}\text { Canaple et al. (2006); } \\
\text { Gervois et al. (1999) }\end{array}$ \\
\hline Pparg & Adipose tissue & Adipocyte differentiation & REV-ERB $\alpha$ & Fontaine et al. (2003) \\
\hline$P g c-1 \alpha$ & Liver, skeletal muscle & $\begin{array}{l}\text { Gluconeogenesis and energy } \\
\text { metabolism }\end{array}$ & $B m a / 1$, REV-ERB $\alpha$ & Liu et al. (2007) \\
\hline $\begin{array}{l}\text { Sirt1, Nampt, } \\
\text { redox state }\end{array}$ & $\begin{array}{l}\text { Liver, mouse embryonic } \\
\text { fibroblasts }\end{array}$ & Cellular metabolism & $\begin{array}{l}\text { CLOCK (NPAS2) /BMAL1-mediated } \\
\text { transcription }\end{array}$ & $\begin{array}{l}\text { Nakahata et al. (2009); } \\
\text { Ramsey et al. (2009); } \\
\text { Rutter et al. (2001) }\end{array}$ \\
\hline CO, heme & Liver, HeLa cells & Oxidative metabolism & REV-ERB $\alpha$, NPAS2 & $\begin{array}{l}\text { Dioum et al. (2002); } \\
\text { Kaasik and Lee (2004); } \\
\text { Yin et al. (2007) }\end{array}$ \\
\hline
\end{tabular}

pathology of addiction (Spanagel et al., 2005).

\section{Metabolic control of circadian rhythms}

From the evidence summarised above it seems clear that major aspects of metabolism are under circadian control. However, communication between metabolism and the clock is not linear. Instead, there seems to be a bidirectional relationship where metabolic cues feedback on the regulation of circadian timing. Evidence from both human and animal studies as well as possible molecular mechanisms underlying such metabolic clock control are discussed in the following paragraphs.

The prevalence of obesity has been steadily increasing in the last decades, as has sleep curtailment (see above). Obese people tend to show changes in sleep architecture indicative of circadian clock disturbances (Resnick et al., 2003). For sleep disorders it is sometimes difficult to differentiate between altered sleep homeostasis and changes in the circadian control of sleep, but altered daily rhythms of humoral parameters in obese people strongly suggest an involvement of the circadian timing system. Obese people show severely blunted to absent rhythms in glucose tolerance over the course of the day (Van Cauter et al., 1997). Additionally, the diurnal secretion rhythms of ghrelin are severely altered in obese people compared with lean subjects (Yildiz et al., 2004). However, how the circadian deregulation of such parameters influences the development of the disease remains to be shown.

In rodents obesity can be either induced by high fat feeding (HFF) or by genetic manipulation resulting in an obese phenotype. Both approaches indicate that obesity impairs the regulation of circadian clocks. Feeding mice with a high fat chow lengthens the period of circadian locomotor activity and changes circadian

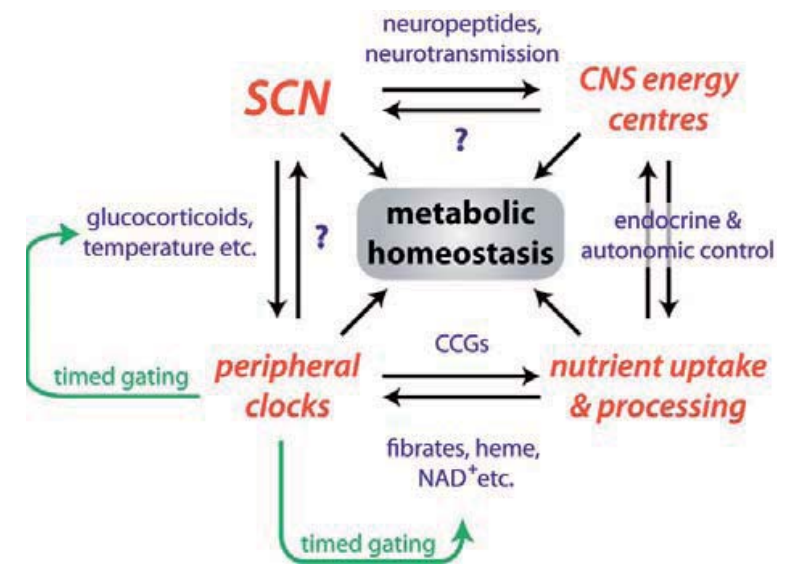

Fig. 1. Interaction of circadian and metabolic regulatory centres in the control of metabolic homeostasis. Central and peripheral circadian and metabolic centres (red) interact via humoral and neuronal factors (blue). Clock-controlled gating of the sensitivity of the target tissue for external stimuli (green) minimises the effect of noise and sporadic signalling events, promoting robust coupling between different oscillatory functions. For more details see text.

feeding patterns. Moreover, HFF affects clock gene rhythms in the liver as well as the circadian pattern of leptin, insulin and glucocorticoid levels in the blood (Kohsaka et al., 2007). Interestingly, not only feeding but also the complete withdrawal of food during fasting changes clock gene expression in peripheral tissues (Kawamoto et al., 2006). Obesity-inducing genetic mutations also lead to severe impairments of circadian rhythmicity. Mice defi- 
cient of the adipocyte satiety signal leptin (ob/ob) show a clear obese phenotype correlated with dampened locomotor activity rhythms and disrupted sleep architecture (Laposky et al., 2006). In another mouse model of diabetic obesity ( $K K-A^{y}$ mice) it was shown that the circadian clock is impaired at the molecular level. Clock gene rhythms in liver and white adipose tissue of $K K-A^{y}$ mice are severely attenuated (Ando et al., 2005). One study compared the effects of HFF and genetically induced obesity on clock gene expression and showed that clock gene rhythms in the CNS are equally disturbed in all obesity models (Kaneko et al., 2009). Taken together, human and mouse studies clearly suggest that obesity alters circadian clock regulation at the behavioural, physiological and molecular level.

The fact that feeding time can act as a Zeitgeber and change the phase of clock genes in peripheral organs, and most prominently in the liver, has long been known. Mice or rats that are subjected to a restricted feeding (RF) schedule, wherein food is only given for some hours during their normal sleeping time, show a complete uncoupling of peripheral clocks from the master pacemaker in the SCN: while clock gene expression in peripheral organs is entrained by the feeding schedule, the SCN retains its synchrony with the external light/dark cycle (Damiola et al., 2000). It remains unclear how the food-induced entrainment of peripheral clocks functions at the molecular level. Injection of the synthetic glucocorticoid dexamethasone can phase shift clock genes in the liver in a time-dependent manner (Balsalobre et al., 2000). Deletion of the glucocorticoid receptor in the liver, however, does not prevent entrainment of the liver clock after RF (Le Minh et al., 2001). Of course, nutrient components (carbohydrates, lipids and amino acids) themselves could affect the clock, and recent data suggest that metabolic cues might act on clock function through nuclear hormone receptors (NRs), some of which directly participate in the regulation of the circadian machinery. As sensors of dietary lipids, vitamins and lipophilic hormones, NRs are prime candidates for linking metabolism to the circadian clock. Indeed, about $50 \%$ of NRs show diurnal variations in expression and, hence, are themselves regulated by the circadian clock (Yang et al., 2006). Importantly, the two orphan nuclear receptors REV-ERB $\alpha$ (NR1D1) and ROR $\alpha$ (RORA) together represent one of the transcriptional feedback loops that underlie circadian regulation at the cellular level (Preitner et al., 2002; Sato et al., 2004). As Rev-erb $\alpha$ is required for adipogenesis and Ror $\alpha$ is important for lipid homeostasis, these two NRs might directly link metabolism to circadian clock function (Lau et al., 2004; Wang and Lazar, 2008). Peroxisome proliferator-activated receptor $\alpha$ (PPARA) is another important NR, a sensor for fatty acids and is involved in the regulation of energy metabolism (Lefebvre et al., 2006). Fibrates are known PPARA agonists that are used to treat symptoms of obesity and metabolic syndrome. Rev-erb $\alpha$ is a target of PPARA and fibrate treatment induces Rev-erb $\alpha$ expression via binding of PPARA to PPARA response elements in the Rev-erb $\alpha$ promoter (Gervois et al., 1999). Interestingly, PPARA is necessary for normal circadian clock gene expression in peripheral tissues such as the liver (Canaple et al., 2006). PPARA regulates Bmal1 expression via a PPAR response element in the Bmal1 promoter and is reciprocally regulated by CLOCK/BMAL1 (see Table 1). Ppara expression is phase shifted in response to a RF schedule and Ppara knockout mice show altered phase shifts in brown adipose tissue and heart after RF, implying that this NR might be one of the molecular mediators of food entrainment (Goh et al., 2007). Similar functions as for PPARA have also been proposed for its close relative PPARG (Fontaine et al., 2003). A known PPARinteracting factor is PGC-1 $\alpha$ (PPARGC1A), a transcriptional co- activator that plays a critical role in the maintenance of energy metabolism in a number of tissues. PGC-1 $\alpha$ is involved in thermogenesis in brown adipose tissue and in the regulation of gluconeogenesis in the liver (Lin et al., 2005). Besides metabolic abnormalities $\mathrm{Pgc}-1 \alpha$ deficient mice display changes in important circadian parameters with a lengthened period of locomotor activity and perturbed clock gene expression in different tissues. PGC-1 $\alpha$ induces the clock gene Bmal1 via coactivation of RORs. Interestingly, and similar to Ppara deficient mice, food entrainment of the periphery is disrupted after a RF schedule in Pgc-1 $\alpha$ deficient mice (Liu et al., 2007), implicating that PGC-1 $\alpha$ might be involved in RF induced clock resetting.

Besides the involvement of NRs and NR-interacting factors in transmitting food signals to the molecular clock, clock genes themselves can be sensors for the metabolic state of the cell. Carbon monoxide (CO) inhibits the DNA binding of NPAS2 by favouring inactive BMAL1 homodimerization instead of active NPAS2/BMAL1 heterodimerization (Dioum et al., 2002). Along this line, NPAS2 and REV-ERB $\alpha$ have both been shown to act as heme sensors, where heme binding controls the DNA binding activity of these two core clock components (Kaasik and Lee, 2004; Yin et al., 2007). However, heme not only controls clock function, but the regulation of the rate limiting enzyme of heme biosynthesis, ALAS1, by the clock, reciprocally impacts on heme production itself (Kaasik and Lee, 2004). Additional evidence for clock genes being sensors of the cellular metabolic state comes from studies showing that the DNA binding activity of CLOCK/BMAL1 heterodimers is dependent on the redox state of the cell (Rutter et al., 2001). The molecular cascade underlying this phenomenon involves the rate limiting enzyme in the NAD synthesis, NAMPT, and the histone deacetylase SIRT1, a suppressor of CLOCK/BMAL1-mediated transcription (Nakahata et al., 2009; Ramsey et al., 2009). Interestingly - and similar to what was shown for heme - Nampt transcription itself is clock controlled, providing a mechanism for a gating of the sensitivity of the clock that allows a time-dependent response of peripheral circadian clocks to redox state signalling (Fig. 1).

\section{CONCLUSION}

In summary, it has become increasingly clear that circadian and metabolic regulation is tightly interlocked at both physiological and molecular levels (Fig. 1). The expression or enzymatic activity for key regulators of metabolic homeostasis show circadian rhythms, while metabolic sensors such as NRs and redox equivalents can directly feed-back on the transcriptional processes underlying the generation of circadian rhythmicity. These findings all point at a critical role for the circadian clock in the optimisation of energy expenditure and, thus, the increase of fitness under highly selective natural conditions. Such strict selective pressure does not exist under normal laboratory conditions. This might underlie the surprising fact that the evolutionary advantage of having a functional circadian timekeeping system has so far, at least in mammals, not been experimentally proven. Informative studies have been conducted in simpler species such as plants (Michael et al., 2003) and cyanobacteria. Mixing cultures of different strains of Synechococcus elongates shows that only those bacteria with an internal circadian period which closely matches the external light/dark cycle survive (Woelfle et al., 2004). Short life spans have been reported for Bmal1-deficient mice, but not for other clock mutants, indicating that this phenotype might represent a pleiotropic function of Bmal1 besides its regulation of circadian timing (Kondratov et al., 2006).

Our modern lifestyle imposes new ways of pressure on the 
functionality of metabolism and clocks. Strictly timed (or even shift) work schedules and transcontinental travel together with the omnipresence of artificial lighting represent strong challenges for a primarily light-driven system such as the circadian clock. The consequence is what has been coined as social jetlag, a chronic misalignment of internal and external rhythms (Wittmann et al., 2006). Social jetlag - just like its air travel-associated brother might have strong implications for the functionality of metabolism, but also for immunity and cognitive performance.

The bilateral relationship of metabolic homeostasis and circadian clock function outlined above makes both systems vulnerable to factors impinging on the other. At the same time, it also offers new roads for the treatment of diseases associated with either of both processes. Time-scheduled and nutrientcontrolled food uptake can influence clock phase and stability and, thus, might help to alleviate disease symptoms associated with circadian misalignment such as sleep disruption, jetlag and various neuropsychiatric disorders (Oster and Foster, 2008). Likewise, resetting clock phase or strengthening internal synchronization, e.g. by timed light exposure or scheduled sleep/ wake times, might affect metabolic pathologies such as obesity, diabetes and night eating syndrome (Levi and Schibler, 2007). Given the increasing prevalence and fatality rates of obesityassociated disorders, tackling the circadian clock has the potential to become an important instrument in fighting obesity as a major plague of the industrialised world.

\section{ACKNOWLEDGMENTS}

We would like to thank Drs. Lars Geffers and Murat Yaylaoglu for critical comments on the manuscript. Work in the lab is supported by an Emmy Noether fellowship (H.O.) and a project grant (SFB654 Project B5) of the German Research Council (DFG).

\section{REFERENCES}

Ando, $\mathrm{H}$, Yanagihara, $\mathrm{H}$, Hayashi, $\mathrm{Y}$, Obi, $\mathrm{Y}$, Tsuruoka, $\mathrm{S}$, Takamura, T., Kaneko, S., and Fujimura, A. (2005). Rhythmic messenger ribonucleic acid expression of clock genes and adipocytokines in mouse visceral adipose tissue. Endocrinology 146, 5631-5636.

Balsalobre, A., Brown, S.A., Marcacci, L., Tronche, F., Kellendonk C., Reichardt, H.M., Schütz, G., and Schibler, U. (2000). Resetting of circadian time in peripheral tissues by glucocorticoid signaling. Science 289, 2344-2347.

Bray, M.S., and Young, M.E. (2007). Circadian rhythms in the development of obesity: potential role for the circadian clock within the adipocyte. Obes. Rev. 8, 169-181.

Bray, M.S., Shaw, C.A., Moore, M.W.S., Garcia, R.A.P., Zanquetta M.M., Durgan, D.J., Jeong, W.J., Tsai, J.-Y., Bugger, H., Zhang, D., et al. (2008). Disruption of the circadian clock within the cardiomyocyte influences myocardial contractile function, metabolism, and gene expression. Am. J. Physiol. Heart Circ. Physiol. 294, H1036-1047.

Buijs, R.M., Scheer, F.A., Kreier, F., Yi, C., Bos, N., Goncharuk, V.D., and Kalsbeek, A. (2006). Organization of circadian functions: interaction with the body. Prog. Brain Res. 153, 341-360.

Canaple, L., Rambaud, J., Dkhissi-Benyahya, O., Rayet, B., Tan, N.S., Michalik, L., Delaunay, F., Wahli, W., and Laudet, V. (2006). Reciprocal regulation of brain and muscle Arnt-like protein 1 and peroxisome proliferator-activated receptor alpha defines a novel positive feedback loop in the rodent liver circadian clock. Mol. Endocrinol. 20, 1715-1727.

Damiola, F., Le Minh, N., Preitner, N., Kornmann, B., Fleury-Olela F., and Schibler, U. (2000). Restricted feeding uncouples circadian oscillators in peripheral tissues from the central pacemaker in the suprachiasmatic nucleus. Genes Dev. 14, 29502961.

Dioum, E.M., Rutter, J., Tuckerman, J.R., Gonzalez, G., GillesGonzalez, M.A., and McKnight, S.L. (2002). NPAS2: a gas- responsive transcription factor. Science 298, 2385-2387.

Duffield, G.E. (2003). DNA microarray analyses of circadian timing: the genomic basis of biological time. J. Neuroendocrinol. 15, 991-1002.

Fontaine, C., Dubois, G., Duguay, Y., Helledie, T., Vu-Dac, N., Gervois, P., Soncin, F., Mandrup, S., Fruchart, J.C., FruchartNajib, J, et al (2003). The orphan nuclear receptor RevErbalpha is a peroxisome proliferator-activated receptor (PPAR) gamma target gene and promotes PPARgamma-induced adipocyte differentiation. J. Biol. Chem. 278, 37672-37680.

Foster, R.G., and Hankins, M.W. (2007). Circadian vision. Curr. Biol. 17, R746-751.

Gervois, P., Chopin-Delannoy, S., Fadel, A., Dubois, G., Kosykh, V., Fruchart, J.C., Najib, J., Laudet, V., and Staels, B. (1999). Fibrates increase human REV-ERBalpha expression in liver via a novel peroxisome proliferator-activated receptor response element. Mol. Endocrinol. 13, 400-409.

Goh, B.C., Wu, X., Evans, A.E., Johnson, M.L., Hill, M.R., and Gimble, J.M. (2007). Food entrainment of circadian gene expression altered in PPARalpha-/- brown fat and heart. Biochem. Biophys. Res. Commun. 360, 828-833.

Green, C.B., Takahashi, J.S., and Bass, J. (2008). The meter of metabolism. Cell 134, 728-742.

Harmer, S.L., Panda, S., and Kay, S.A. (2001). Molecular bases of circadian rhythms. Annu. Rev. Cell Dev. Biol. 17, 215-253.

Inoue, I., Shinoda, Y., Ikeda, M., Hayashi, K., Kanazawa, K., Nomura, M., Matsunaga, T., Xu, H., Kawai, S., Awata, T., et al. (2005). CLOCK/BMAL1 is involved in lipid metabolism via transactivation of the peroxisome proliferator-activated receptor (PPAR) response element. J. Atheroscler. Thromb. 12, 169-174.

Ishida, A., Mutoh, T., Ueyama, T., Bando, H., Masubuchi, S., Nakahara, D., Tsujimoto, G., and Okamura, H. (2005). Light activates the adrenal gland: timing of gene expression and glucocorticoid release. Cell Metab. 2, 297-307.

Kaasik, K., and Lee, C.C. (2004). Reciprocal regulation of haem biosynthesis and the circadian clock in mammals. Nature 430 , 467-471.

Kaneko, K., Yamada, T., Tsukita, S., Takahashi, K., Ishigaki, Y., Oka, Y., and Katagiri, H. (2009). Obesity alters circadian expressions of molecular clock genes in the brainstem. Brain Res. 1263, 58-68.

Kawamoto, T., Noshiro, M., Furukawa, M., Honda, K.K., Nakashima, A., Ueshima, T., Usui, E., Katsura, Y., Fujimoto, K., Honma, S., et al. (2006). Effects of fasting and re-feeding on the expression of Dec1, Per1, and other clock-related genes. J. Biochem. 140, 401-408.

Ko, C.H., and Takahashi, J.S. (2006). Molecular components of the mammalian circadian clock. Hum. Mol Genet. 15, R271-277.

Kohsaka, A., Laposky, A.D., Ramsey, K.M., Estrada, C., Joshu, C., Kobayashi, Y., Turek, F.W., and Bass, J. (2007). High-fat diet disrupts behavioral and molecular circadian rhythms in mice. Cell Metab. 6, 414-421.

Kondratov, R.V., Kondratova, A.A., Gorbacheva, V.Y., Vykhovanets, O.V., and Antoch, M.P. (2006). Early aging and age-related pathologies in mice deficient in BMAL1, the core componentof the circadian clock. Genes Dev. 20, 1868-1873.

Lamia, K.A., Storch, K.-F., and Weitz, C.J. (2008). Physiological significance of a peripheral tissue circadian clock. Proc. Natl. Acad. Sci. USA 105, 15172-15177.

Laposky, A.D., Shelton, J., Bass, J., Dugovic, C., Perrino, N., and Turek, F.W. (2006). Altered sleep regulation in leptin-deficient mice. Am. J. Physiol. Regul. Integr. Comp. Physiol. 290, R894903.

Laposky, A.D., Bass, J., Kohsaka, A., and Turek, F.W. (2008). Sleep and circadian rhythms: key components in the regulation of energy metabolism. FEBS Lett. 582, 142-151.

Lau, P., Nixon, S.J., Parton, R.G., and Muscat, G.E. (2004). RORalpha regulates the expression of genes involved in lipid homeostasis in skeletal muscle cells: caveolin-3 and CPT-1 are direct targets of ROR. J. Biol. Chem. 279, 36828-36840.

Le Minh, N., Damiola, F., Tronche, F., Schutz, G., and Schibler, U. (2001). Glucocorticoid hormones inhibit food-induced phaseshifting of peripheral circadian oscillators. EMBO J. 20, 71287136.

Lefebvre, P., Chinetti, G., Fruchart, J.C., and Staels, B. (2006). Sorting out the roles of PPAR alpha in energy metabolism and vascular homeostasis. J. Clin. Invest. 116, 571-580. 
Levi, F., and Schibler, U. (2007). Circadian rhythms: mechanisms and therapeutic implications. Annu. Rev. Pharmacol. Toxicol. 47, 593-628.

Lin, J., Handschin, C., and Spiegelman, B.M. (2005). Metabolic control through the PGC-1 family of transcription coactivators. Cell Metab. 1, 361-370.

Liu, C., Li, S., Liu, T., Borjigin, J., and Lin, J.D. (2007). Transcriptional coactivator PGC-1alpha integrates the mammalian clock and energy metabolism. Nature 447, 477-481.

Michael, T.P., Salome, P.A., Yu, H.J., Spencer, T.R., Sharp, E.L., McPeek, M.A., Alonso, J.M., Ecker, J.R., and McClung, C.R (2003). Enhanced fitness conferred by naturally occurring variation in the circadian clock. Science 302, 1049-1053.

Mistlberger, R.E. (2005). Circadian regulation of sleep in mammals: Role of the suprachiasmatic nucleus. Brain Res. Rev. 49, 429454.

Nakahata, Y., Sahar, S., Astarita, G., Kaluzova, M., and SassoneCorsi, P. (2009). Circadian control of the NAD+ salvage pathway by CLOCK-SIRT1. Science 324, 654-657.

Oster, H., and Foster, R.G. (2008). The interaction of light and the circadian clock network - a new therapeutic approach for the treatment of neuropsychiatric disorders? In Progress in Circadian Rhythms Research, A.-L. Léglise, ed. (Hauppauge, NY: Nova Science Publishers), pp. 35-65.

Oster, H., Damerow, S., Kiessling, S., Jakubcakova, V., Abraham, D., Tian, J., Hoffmann, M.W., and Eichele, G. (2006). The circadian rhythm of glucocorticoids is regulated by a gating mechanism residing in the adrenal cortical clock. Cell Metab. 4 163-173.

Pan, X., and Hussain, M.M. (2009). Clock is important for food and circadian regulation of macronutrient absorption in mice. J. Lipid Res. [Epub ahead of print]

Pittendrigh, C.S. (1993). Temporal organization: reflections of a Darwinian clock-watcher. Annu. Rev. Physiol. 55, 16-54.

Preitner, N., Damiola, F., Lopez-Molina, L., Zakany, J., Duboule, D. Albrecht, U., and Schibler, U. (2002). The orphan nuclear receptor REV-ERBalpha controls circadian transcription within the positive limb of the mammalian circadian oscillator. Cell 110 , 251-260.

Ramsey, K.M., Yoshino, J., Brace, C.S., Abrassart, D., Kobayashi, Y., Marcheva, B., Hong, H.K., Chong, J.L., Buhr, E.D., Lee, C., et al. (2009). Circadian clock feedback cycle through NAMPTmediated NAD+ biosynthesis. Science 324, 651-654.

Raspe, E., Duez, H., Mansen, A., Fontaine, C., Fievet, C., Fruchart, J.-C., Vennstrom, B., and Staels, B. (2002). Identification of Reverb\{alpha\} as a physiological repressor of apoC-III gene transcription. J. Lipid Res. 43, 2172-2179.

Resnick, H.E. Redline, S., Shahar, E. Gilpin, A, Newman, A Walter, R., Ewy, G.A., Howard, B.V., and Punjabi, N.M. (2003) Diabetes and sleep disturbances: findings from the Sleep Heart Health Study. Diabetes Care 26, 702-709.

Rudic, R.D., McNamara, P., Curtis, A.M., Boston, R.C., Panda, S. Hogenesch, J.B., and Fitzgerald, G.A. (2004). BMAL1 and CLOCK, two essential components of the circadian clock, are involved in glucose homeostasis. PLoS Biol. 2, e377.

Rutter, J., Reick, M., Wu, L.C., and McKnight, S.L. (2001). Regulation of clock and NPAS2 DNA binding by the redox state of NAD cofactors. Science 293, 510-514.

Sato, T.K., Panda, S., Miraglia, L.J., Reyes, T.M., Rudic, R.D., McNamara, P., Naik, K.A., FitzGerald, G.A., Kay, S.A., and Hogenesch, J.B. (2004). A functional genomics strategy reveals Rora as a component of the mammalian circadian clock. Neuron 43, 527-537.

Scott, E.M. Carter, A.M., and Grant, P.J. (2007). Association between polymorphisms in the Clock gene, obesity and the metabolic syndrome in man. Int. J. Obes. 32, 658-662.
Shea, S.A., Hilton, M.F., Orlova, C., Ayers, R.T., and Mantzoros, C.S. (2005). Independent circadian and sleep/wake regulation of adipokines and glucose in humans. J. Clin. Endocrinol. Metab. 90, 2537-2544.

Shimba, S., Ishii, N., Ohta, Y., Ohno, T., Watabe, Y., Hayashi, M., Wada, T., Aoyagi, T., and Tezuka, M. (2005). Brain and muscle Arnt-like protein-1 (BMAL1), a component of the molecular clock, regulates adipogenesis. Proc. Natl. Acad. Sci. USA 102, 1207112076

Spanagel, R., Pendyala, G., Abarca, C., Zghoul, T., SanchisSegura, C., Magnone, M.C., Lascorz, J., Depner, M., Holzberg, D., Soyka, M., et al. (2005). The clock gene Per2 influences the glutamatergic system and modulates alcohol consumption. Nat. Med. 11, 35-42.

Spiegel, K, Leproult, R and Van Cauter, E. (1999). Impact of sleep debt on metabolic and endocrine function. Lancet 354 , 1435-1439.

Spiegel, K., Tasali, E., Penev, P., and Cauter, E.V. (2004). Brief communication: sleep curtailment in healthy young men is associated with decreased leptin levels, elevated ghrelin levels, and increased hunger and appetite. Ann. Intern. Med. 141, 846850.

Stratmann, M., and Schibler, U. (2006). Properties, entrainment, and physiological functions of Mammalian peripheral oscillators. J. Biol. Rhythms 21, 494-506.

Takahashi, J.S., Hong, H.K., Ko, C.H., and McDearmon, E.L. (2008). The genetics of mammalian circadian order and disorder: implications for physiology and disease. Nat. Rev. Genet. 9, 764775.

Turek, F.W., Joshu, C., Kohsaka, A., Lin, E., Ivanova, G., McDearmon, E., Laposky, A., Losee-Olson, S., Easton, A., Jensen, D.R., et al. (2005). Obesity and metabolic syndrome in circadian Clock mutant mice. Science 308, 1043-1045

Van Cauter, E., Polonsky, K.S., and Scheen, A.J. (1997). Roles of circadian rhythmicity and sleep in human glucose regulation. Endocr. Rev. 18, 716-738.

Wang, J., and Lazar, M.A. (2008). Bifunctional role of Rev-erbalpha in adipocyte differentiation. Mol. Cell. Biol. 28, 2213-2220.

Wittmann, M., Dinich, J., Merrow, M., and Roenneberg, T. (2006). Social jetlag: misalignment of biological and social time. Chronobiol. Int. 23, 497-509.

Woelfle, M.A., Ouyang, Y., Phanvijhitsiri, K., and Johnson, C.H. (2004). The adaptive value of circadian clocks: an experimental assessment in cyanobacteria. Curr. Biol. 14, 1481-1486.

Woon, P.Y., Kaisaki, P.J., Braganca, J., Bihoreau, M.-T., Levy, J.C., Farrall, M., and Gauguier, D. (2007). Aryl hydrocarbon receptor nuclear translocator-like (BMAL1) is associated with susceptibility to hypertension and type 2 diabetes. Proc. Natl. Acad. Sci. USA $104,14412-14417$

Yang, X., Downes, M., Yu, R.T., Bookout, A.L., He, W., Straume, M., Mangelsdorf, D.J., and Evans, R.M. (2006). Nuclear receptor expression links the circadian clock to metabolism. Cell 126, 801-810.

Yang, S., Liu, A., Weidenhammer, A., Cooksey, R.C., McClain, D., Kim, M.K., Aguilera, G., Abel, E.D., and Chung, J.H. (2009). The role of mPer2 Clock gene in glucocorticoid and feeding rhythms. Endocrinology 150, 2153-2160.

Yildiz, B.O., Suchard, M.A., Wong, M.L., McCann, S.M., and Licinio, J. (2004). Alterations in the dynamics of circulating ghrelin, adiponectin, and leptin in human obesity. Proc. Natl. Acad. Sci. USA 101, 10434-10439.

Yin, L., Wu, N., Curtin, J.C., Qatanani, M., Szwergold, N.R., Reid, R.A., Waitt, G.M., Parks, D.J., Pearce, K.H., Wisely, G.B., et al. (2007). Rev-erbalpha, a heme sensor that coordinates metabolic and circadian pathways. Science 318, 1786-1789. 


\subsubsection{Sleep and metabolism}

\subsubsection{Short sleep promotes obesity}

The prevalence of obesity and type 2 diabetes has increased drastically in almost all countries of the world in the last decades which cannot be fully explained by changes in lifestyle such as the availability of high-caloric food and reduced physical activity (Van Cauter and Knutson, 2008). At the same time, average sleep times have decreased from eight to nine hours in 1960 to seven hours in 1995. Today more than $30 \%$ of adults report sleeping less than six hours per night (Knutson, 2007; Knutson et al., 2007; Knutson and Van Cauter, 2008). Thus the question arises whether sleep curtailment contributes to obesity directly. Cross-sectional and longitudinal epidemiologic studies have shown an association between short sleep and obesity (Van Cauter and Knutson, 2008). Some studies show a linear negative correlation between sleep time and body mass index (Hasler et al., 2004; Gangwisch et al., 2005; Hitze et al., 2009), whereas others report a U-shaped correlation with ideal sleep durations between 7 and 8 hours per night (Taheri et al., 2004; Chaput et al., 2007). Longitudinal studies found that short sleep is associated with increased risk of obesity later in life (Hasler et al., 2004; Taheri et al., 2004; Gangwisch et al., 2005). Hasler and colleagues estimated that every extra hour of sleep is associated with a $50 \%$ reduction in the risk of becoming obese (Hasler et al., 2004). This association seems not limited to adults, as short sleep also correlates with higher body mass index in children (Hitze et al., 2009). Short sleep times have similarly been associated with increased risk of type 2 diabetes in a number of studies (Gottlieb et al., 2005; Knutson and Van Cauter, 2008).

\subsubsection{Sleep restriction impairs metabolism in humans}

Human laboratory studies confirm epidemiologic evidence for sleep loss associated metabolic effects. Six consecutive days of sleep restriction lead to severely impaired glucose homeostasis (Spiegel et al., 1999): Glucose clearance after a glucose injection as well as after breakfast is $40 \%$ slower and the insulin response to glucose is $30 \%$ reduced. Thus both, glucose effectiveness (describing non-insulin-dependent glucose disposal) as well as acute insulin response to glucose is reduced by a lack of sleep, which leads to a $40 \%$ lower disposition index - a marker for diabetes risk. The authors also report a dose-dependent decrease in insulin sensitivity, which predicts a progressive development of insulin resistance with chronic sleep restriction (Spiegel et al., 1999). A more recent study investigating glucose regulation after moderate sleep loss showed slower glucose clearance after morning breakfast despite increased insulin response, thus indicating insulin resistance (Schmid et al., 2011). Additional studies confirmed impaired glucose regulation after sleep restriction in humans (Spiegel et al., 2004a; Knutson et al., 2007).

Other metabolic changes that have been reported in sleep restriction laboratory studies include an increase in afternoon/evening cortisol, elevated sympatho-vagal balance, increased hunger and appetite ratings and increased ghrelin and decreased leptin levels (Knutson et al., 2007; Knutson and Van Cauter, 2008). In a study with free access to food, increased hunger feelings were accompanied by $22 \%$ increased food intake, with a significant increase in fat intake (Brondel et al., 2010). Whereas ghrelin has been shown to be reduced by sleep loss in most studies, effects 
on leptin are less clear (Knutson, 2007) . A number of studies show decreased leptin levels during sleep deprivation (Spiegel et al., 2004b; Spiegel et al., 2004a; Mullington et al., 2009), whereas others show either no effects or increased leptin levels after sleep restriction (Simon et al., 1998; Shea et al., 2005). In addition, interleukin 6 (IL6) and tumor necrosis factor (TNF $\alpha$ ), inflammatory adipokines secreted by macrophages in adipose tissues, are increased by sleep restriction (Vgontzas et al., 1999; Vgontzas et al., 2004; Haack et al., 2007). Inflammation of adipose tissue and increased macrophage infiltration of adipose tissue resembles obese phenotypes, as it has been reported that adipokines released by macrophages are increased with obesity (Rasouli and Kern, 2008).

In summary it is likely that a number of factors contribute to the sleep loss induced risk of developing obesity and type 2 diabetes: food intake increases (either by a decrease in the anorexigenic hormone leptin and an increase in the orexigenic hormone ghrelin or by increased expression of the orexigenic neuropeptide $Y$ (NPY) and decreased expression of the anorexigenic pro-opiomelanocortin (POMC) in the hypothalamus (Koban et al., 2006)) and at the same time energy expenditure might decrease (Benedict et al., 2011). In addition glucose regulation seems severely impaired and insulin resistance is likely to develop.

\subsubsection{Animal models of sleep restriction}

A number of different sleep restriction protocols have been developed for animals. These differ in the amount of forced locomotion and stress induction and vary from total sleep deprivation to specific REM or NREM sleep deprivation. Sleep restriction usually leads to more slow wave activity (Delta activity, 0.5-4 Hz) during recovery NREM sleep which has been interpreted as intensified sleep (Tobler and Jaggi, 1987; Franken et al., 1993). Pioneering work form the 1980s demonstrated that in rats total sleep deprivation leads to death within 2-3 weeks (Rechtschaffen et al., 1983). Sleep deprivation was achieved by the so-called disc-over-water method where animals are kept on a platform surrounded by water and EEG is used as readout to determine sleep. Upon sleep onset the platform is rotated such that the animal has to move in order to prevent falling into the water. Rodents can also be sleep deprived using a rotating wheel or a modified version of the disc-over-water method, the so-called flowerpot method. Mice or rats are kept on a small platform surrounded by water. As soon as the animal enters REM sleep, muscle ataxia causes the animals to make facial contact with or even fall into the water. In this way, REM sleep is prevented, although partially fragmented NREM sleep accompanies this method (Koban and Swinson, 2005; Koban et al., 2008). The least stressful method to sleep restrict rodents is the so-called gentle handling method, in which the animals are continuously monitored by an experimenter and as soon as they adopt a sleep-like posture, sleep is prevented by introducing novel objects into the cage (Tobler and Jaggi, 1987; Franken et al., 1993). Many, but not all, of the described sleep restriction protocols induce activation of the HPA axis and thus increase the levels of the stress hormone corticosterone (Rechtschaffen and Bergmann, 1995; Meerlo et al., 2002; Bodosi et al., 2004; Mongrain et al., 2010).

Most studies showed that during sleep restriction rodents progressively loose body weight, while at the same time they increase their food intake (Rechtschaffen et al., 1983; Rechtschaffen and 
Bergmann, 1995; Everson and Crowley, 2004; Koban and Swinson, 2005; Koban et al., 2008). Increased food intake is likely a compensatory mechanism to prevent body weight loss resulting from increased metabolic rate (Bergmann et al., 1989). Brown adipose tissue-mediated compensatory thermogenesis might be the cause for increased energy expenditure (Koban and Swinson, 2005). Along this line, excessive heat loss has been shown during sleep restriction, and sleep deprived rats chose progressively higher ambient temperatures in a thermocline (Landis et al., 1992). The increase in food intake is accompanied by increased NPY and decreased POMC expression in the hypothalamus (Koban et al., 2006; Koban et al., 2008). In addition the levels of leptin and grehlin are changed in many rodent sleep restriction paradigms. Whereas most studies show that ghrelin is up-regulated by sleep loss, the effects of sleep restriction on leptin levels are less clear. Some studies show a decrease in leptin, which could explain the food intake increase (Everson and Crowley, 2004; Koban and Swinson, 2005), whereas others show no effects or even slightly increased leptin levels during the night (Bodosi et al., 2004). Interestingly, similar to what has been reported in human studies, sleep deprivation in rodents also affects the expression of adipokines (Rosa Neto et al., 2010). In summary, sleep restriction in animals leads to bodyweight loss, increased food intake, increased metabolic rate accompanied by increased brown adipose thermogenesis, changes in leptin and ghrelin levels, increased NPY and reduced POMC expression in the hypothalamus, changes in adipokine release and (in some studies) in corticosterone levels.

\subsubsection{The circadian clock as a potential mediator between sleep and metabolism}

As described above, both clock and sleep disruption lead to metabolic impairments. Until now, the interaction of clocks, sleep and metabolism was mainly investigated by looking at only two of these systems at the same time. However, it seems very interesting to investigate all three in one study. Sleep restriction affects core clock genes and potentially also clock outputs (as has been shown for the SCN electrical activity). In addition, clocks regulate many rate-limiting steps in metabolic pathways, thus a change in the core clock mechanism would be translated into altered physiology. It is therefore tempting to speculate that the circadian clock might mediate sleep loss induced metabolic effects (Fig. 5). 


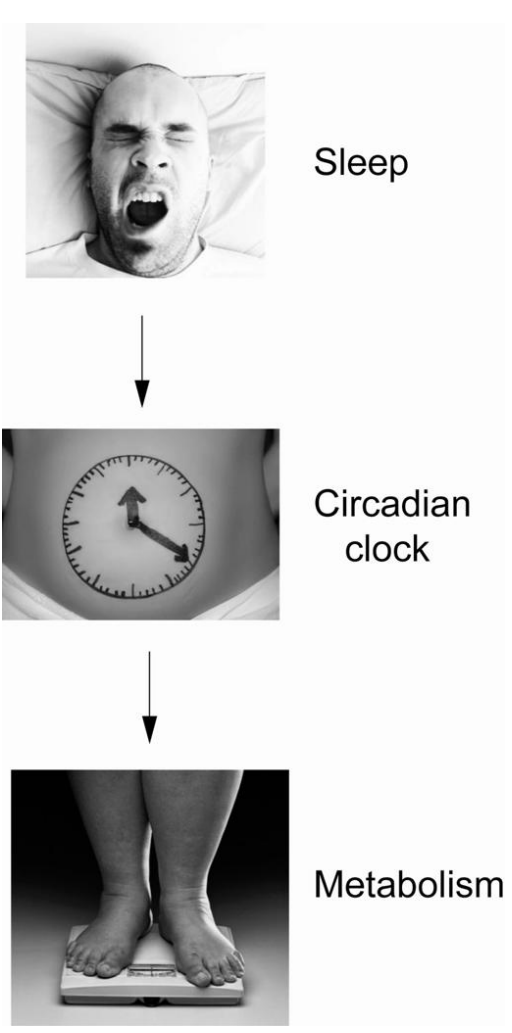

\begin{abstract}
Fig. 5: The circadian clock might mediate sleep loss induced metabolic effects.

Sleep deprivation affects the circadian system at behavioral, electrophysiological and molecular levels. Per genes, for example, are activated in the brain after sleep deprivation. The circadian clock controls many metabolically relevant pathways by regulating the expression of clock controlled genes. In addition, a vast body of literature suggests that clock disruption leads to metabolic impairment in mice and humans. Thus we hypothesize that the circadian clock might mediate sleep loss induced metabolic effects.
\end{abstract}

There is clear evidence that clock disruption promotes metabolic dysfunction. Conditionally disrupting the liver clock in mice leads to impaired glucose regulation, which might be caused by dampened expression rhythms of metabolically relevant genes (Lamia et al., 2008). Similar observations were made in pancreas specific clock mutant mice, which develop diabetes-like symptoms (Marcheva et al., 2010). Thus, if sleep restriction leads to a change in the expression of core clock genes this would alter the expression rhythms of metabolic clock output genes which in turn might trigger the metabolic abnormalities described after sleep restriction. In this case, the circadian clock would be a new target for pharmacological treatments to improve metabolic homeostasis under conditions of sleep deprivation, e.g. during shift work. 


\subsection{Aims of this work}

One major aim of this work is to functionally characterize the hierarchical structure of the circadian system by genetically disrupting the master clock in the SCN. Electrical ablation experiments established the SCN as the central circadian pacemaker in mammals driving behavioral and endocrine rhythms. In addition, clock gene expression rhythms are lost in peripheral organs of SCN-lesioned animals. On the other hand, it has been shown that the SCN synchronizes peripheral organs in part via neuronal signals. Thus, the SCN ablation model is complicated by the fact that neuronal projections from and to the SCN are destroyed and therefore neuronal signaling form the SCN to the periphery is completely lost. In particular, under LD conditions light information, which is transmitted from the eye to peripheral organs via the $\mathrm{SCN}$, cannot reach the periphery in SCN-lesioned animals.

To overcome this problem, we use a genetic approach to conditionally disrupt the circadian clock (via deletion of the essential clock gene Bmal1) in the SCN using the Cre/loxP system. After verification of the efficiency of our SCN knock-out model, peripheral clock gene rhythms will be investigated under entrained and constant conditions. These experiments will elucidate whether, and under which conditions, peripheral clocks are capable of sustaining rhythmicity in the absence of an SCN clock in vivo.

To further refine this approach we aimed at generating a SCN Cre driver that would specifically target the light-receptive core sub-region of the SCN. We decided to use a binary Split-Cre system which allows highly specific targeting based on overlapping promoter pairs. Such a SCN sub-region Cre driver will be very useful to functionally dissect the anatomy of the SCN.

In a third project we aimed at investigating the interaction between clocks, sleep and metabolism. It has been shown that sleep disruption leads to metabolic impairments, e.g. altered glucose homeostasis. Clock disruption also results in metabolic syndrome, obesity and glucose homeostatic impairments. Thus we postulated that the effects of sleep disruption on metabolism might be mediated by the circadian clock. To test this hypothesis we decided to analyze the metabolic effects of sleep disruption in clock-less Per1/Per2 double mutant mice and wild-type controls. If the circadian clock indeed has a role in mediating metabolic effects of sleep disruption, then metabolism in arrhythmic Per $1 / 2$ double mutants should be less affected by sleep loss than in wild-type animals. 


\section{Chapter 2: Material and Methods}

\subsection{Animal experiments}

\subsubsection{Animal housing and breeding}

All animal experiments were carried out in compliance with the German Law on Animal Welfare and were approved by the Office for Consumer Protection and Food Safety of the State of Lower Saxony. Mice were housed in transparent, individually ventilated cages (IVCs) with filter tops in specific pathogen free (SPF) conditions. Room temperature and humidity were held constant at $21{ }^{\circ} \mathrm{C}$ and $55 \%$, respectively, and animals were kept in a 12 hour light 12 hour dark cycle. Standard chow and water was provided ad libitum. Breeding was established either in pairs or triples (2 females and one male) and not before the age of 7 weeks. Pups were weaned and ear marked at the age of 3 weeks and $0.5 \mathrm{~cm}$ tail biopsies were taken for genotyping.

\subsubsection{Sleep deprivation by gentle handling}

Mice were sleep deprived for six hours at the beginning of their usual inactive phase (ZTO-6). Light intensity was set to 50 lux. Mice were group-caged in groups of 4-5 mice per cage. Cages were arranged such that all cages could be watched at all times and bedding material was removed in order to be able to watch every mouse. As soon as one of the mice did not move for more than 5 seconds and started to adopt a sleeping posture or closed its eyes, the cage lid was opened and objects were introduced to spark the mice's curiosity (paper towel strips, paper cubes, racks, straw, water bottles, tunnels, running wheels, etc). If these objects were not successful in arousing the mouses curiosity for a longer time, cage lids were kept open, cages were tilted or mice were gently touched.

\subsubsection{Wheel running analysis}

Wheel running experiments were performed as described (Jud et al., 2005). Mice between 2 and 6 months of age were used for the experiments, where possible littermates were used as controls. During recording of wheel running activity, mice were kept individually in transparent plastic cages equipped with a running wheel. Wheel revolutions were detected via a magnetic switch connected to a computer system. 12 cages were kept in one isolation chamber, in which lights were controlled via a computer system. Temperature $\left(20 \pm 0.5^{\circ} \mathrm{C}\right)$ and humidity $(50-60 \%)$ were kept constant. Genotypes, which were compared were always distributed equally between different isolation cabinets. Cages were changed every 2-3 weeks, preferentially during the active phase of the animals to minimize effects of the cage change on phase or period of the activity rhythm as has been reported before (Bobrzynska and Mrosovsky, 1998). Cages were not changed in phases that were used for period or phase calculations. Mice were provided standard chow food (Ssniff V1126) and water ad libitum. 
For 12 hour light 12 hour dark (LD) experiments mice were kept in 350 lux light intensity with lights on defined as ZTO, lights off as ZT12. The percentage of activity in the light phase was calculated over a period of one week relative to the total activity at the same days. For phase shifting experiments (jet lag) animals were entrained to LD for 2 weeks, then the light cycle was shifted 6 hours in advance by turning the light on 6 hours earlier (short night protocol). Onsets were determined during the days following the light shift and transient days were defined as days at which the onset of activity was different from the expected onset after a 6 hour shifted LD cycle. For constant darkness (DD) experiments, mice were entrained for in LD 2 weeks and then released into DD. Period, amplitude and onset error were calculated from a 10 day-period in DD, the first 3 days in DD were not used for the calculation. Period and amplitude were calculated using $\chi 2$-periodogram analysis, onset error was calculated as mean deviation of real onset from a least-squares-fit regression line. For constant light experiments (LL) mice were entrained for in LD 2 weeks and then released into LL (light intensity is described separately for each experiment). As described for DD, period and amplitude were calculated from a 10-day period. For light pulse experiments, mice were entrained for 2 weeks in LD, followed by 2 weeks DD. The activity onset (circadian time (CT) 12) was determined for each animal individually and a 15 min light pulse (350 lux) was given manually at CT14. Mice were kept undisturbed in DD for the following 2 weeks. For the calculation of the phase shift a regression line was fitted through the onsets before the light pulse and a second regression line was fitted through the onsets after the light pulse. The difference (in hours) between these two regression lines at the day of the light pulse was taken as the phase shift. During the collection of faeces, mice were kept in similar cages as described above, but the bottom of the cage was replaced by a metal grid. Faeces were collected on paper towel, which was placed below the cage. Activity analysis was performed using the ClockLab plugin (Actimetrics) for MatLab.

\subsection{Histological methods}

\subsection{1 ß-galactosidase staining of frozen brain sections}

OCT (Tissue-Tek) embedded, fresh frozen 10-25 $\mu \mathrm{m}$ brain sections were used. Sections were fixed in $0.2 \%$ glutaraldehyde in $1 \times$ PBS ( $137 \mathrm{mM} \mathrm{NaCl}, 2.7 \mathrm{mM} \mathrm{KCl}, 10 \mathrm{mM} \mathrm{Na} \mathrm{HPO}_{4}, 1.8 \mathrm{mM} \mathrm{KH}_{2} \mathrm{PO}_{4}$ ) for $5 \mathrm{~min}$, washed in $1 \times$ PBS for $5 \mathrm{~min}$ and incubated vertically over night with staining solution (5 $\mathrm{mM}$ potassium ferricyanide, $5 \mathrm{mM}$ potassium ferrocyanide, $2 \mathrm{mM} \mathrm{MgCl}, 1 \mathrm{mg} / \mathrm{ml} \mathrm{X}-\mathrm{Gal}, 1 \mathrm{mM}$ Phosphate, $150 \mathrm{mM} \mathrm{NaCl}$ ) at $30-37^{\circ} \mathrm{C}$. The next day, sections were washed in $1 x$ PBS for $5 \mathrm{~min}$, counterstained with Nuclear fast Red solution (Sigma-Aldrich) for $5 \mathrm{~min}$ and dehydrated in progressively increasing ethanol concentrations (30\%, 70\%, 90\%, 100\% ethanol, each step $2 \mathrm{~min}$ ) followed by $2 \mathrm{x}$ incubation with Xylene for $2 \mathrm{~min}$. Cover slips were mounted with DPX mounting medium (Sigma). 


\subsubsection{AP staining of frozen sections}

OCT (Tissue-Tek) embedded, fresh frozen 10-25 $\mu \mathrm{m}$ brain sections were used. Sections were fixed in $0.2 \%$ glutaraldehyde (in PBS) for 5 min, washed $3 x$ in $1 x$ PBS for 5 min, heated to $70^{\circ} \mathrm{C}$ for 15 min in pre-warmed PBS in a water bath, cooled down for 2 min, washed 2x with 1x PBS for 5 min, equilibrated in AP buffer ( $1 \mathrm{M}$ Tris/ $\mathrm{HCl} \mathrm{pH} \mathrm{9.5,} 5 \mathrm{M} \mathrm{NaCl}, 1 \mathrm{M} \mathrm{MgCl}_{2}$ ) for 10 min and incubated vertically with AP staining solution (AP buffer with $1 \%$ sodium deoxycholate, $2 \%$ NP-40, $0.35 \%$ NBT, $0.35 \% \mathrm{BCIP}$ ) at $4^{\circ} \mathrm{C}$. The next day, sections were washed in $1 \mathrm{x}$ PBS for $5 \mathrm{~min}$, counterstained with Nuclear fast Red solution (Sigma-Aldrich) for $5 \mathrm{~min}$ and dehydrated in progressively increasing ethanol concentrations (30\%, 70\%, 90\%, 100\% ethanol, each step $2 \mathrm{~min}$ ) followed by $2 \mathrm{x}$ incubation with Xylene for 2 min. Cover slips were mounted with DPX mounting medium (Sigma).

\subsubsection{Immunohistochemistry}

OCT (Tissue-Tek) embedded, fresh frozen $10 \mu \mathrm{m}$ brain sections were used. Sections were fixed in ice-cold $4 \%$ paraformaldehyde (PFA) for $15 \mathrm{~min}$ on ice, washed $3 \mathrm{x}$ for $5 \mathrm{~min}$ with $1 \times$ TNT (0.1M Tris/ $\mathrm{HCl} \mathrm{pH} \mathrm{7.5,} 150 \mathrm{mM} \mathrm{NaCl}, 0.05 \%$ Tween20), blocked in $10 \%$ normal goat serum(NGS, in $1 \mathrm{x}$ TNT) for $1 \mathrm{~h}$ and incubated with anti-MOP3 (BMAL1) antibody (Novus Biologicals) diluted 1:1000 in $10 \%$ NGS at $4^{\circ} \mathrm{C}$ over night. The next day sections were washed $3 \times$ for 5 min with $1 \times$ TNT, incubated with the secondary antibody (anti-rabbit AF488/AF594, Invitrogen) diluted 1:400 in $10 \%$ NGS at room temperature for 2 hours, washed $3 x$ for 5 min in $1 \times$ TNT, washed in $\mathrm{ddH}_{2} \mathrm{O}$ and mounted with Vectashield mounting medium containing DAPI (Vector Laboratories).

\subsection{Immunological experiments}

\subsubsection{Corticosterone extraction from mouse faeces}

Faecal samples were collected in 4 hour intervals and stored at $-80^{\circ} \mathrm{C}$ until used. Samples were dried in a speed VAC over night and homogenized using $2.8 \mathrm{~mm}$ ceramic beads (Peqlab) in a Precellys Homogenizer running $5 x$ the following program: $3 x 30 \mathrm{sec}$ at $6800 \mathrm{rpm}$. Homogenized samples were dissolved in $10 \mathrm{ml}$ ethanol, boiled for $20 \mathrm{~min}$ in a water bath and centrifuged at 900 rcf for $15 \mathrm{~min}$. Supernatant was poured into petri-dishes and pellets were re-extracted by adding $5 \mathrm{ml}$ ethanol and vortexing for $1 \mathrm{~min}$. After centrifugation at $900 \mathrm{rcf}$ for $15 \mathrm{~min}$ the second supernatant was added to the first supernatant in the petri-dish and samples were dried in an oven at $55^{\circ} \mathrm{C}$ for $45-90 \mathrm{~min}$. Dried extracts were dissolved in $1 \mathrm{ml}$ methanol and stored at $-80^{\circ} \mathrm{C}$ until use.

\subsubsection{Corticosterone Radioimmunoassay (RIA)}

Corticosterone was measured from plasma or faeces samples using the ImmuChem Double Antibody 125I-Radioimmunoassay Kit (MP Biomedicals) with the following modifications: for each reagent only $1 / 4$ of the volume was used, plasma samples were used at 1:200 dilutions, faeces samples were used at 1:5 dilutions. All samples were measured in duplicate and corticosterone 
concentrations were calculated from standard values by fitting a one-site competition function using Graph Pad software.

\subsubsection{Leptin Enzyme-linked immunosorbent assay (ELISA)}

Leptin ELISA on plasma samples was performed using the Mouse Leptin ELISA Kit (Crystal Chem) according to the manufacturers' protocol.

\subsection{Molecular biological experiments}

\subsubsection{Maxi and Mini preparations}

Maxi and Mini preparations were performed using the NucleoBond AX500 (Machery Nagel) and the QIAprep Spin (Qiagen) Kits, respectively.

\subsubsection{DNA purification for ES cell electroporation}

The sequence-verified Syt10 $0^{N-C r e}$ targeting vector was linearized with the restriction enzyme Ascl. The efficiency of the digestion was verified on a test-gel and the DNA fragment was phenolchloroform extracted followed by DNA precipitation with 2 volumes ethanol and 1/10 $3 \mathrm{M} \mathrm{NaAc}$. After washing twice with ice-cold $70 \%$ ethanol, the DNA pellet was dissolved in sterile $1 x$ TE (10 $\mathrm{mM}$ Tris-Cl, $1 \mathrm{mM}$ EDTA, $\mathrm{pH}$ 7.6) and kept at $4^{\circ} \mathrm{C}$ until use.

\subsubsection{ES cell electroporation}

ES cell electroporation was performed by Sharif Mahsur at the MPI-BPC transgenic core facility. Linearized vector was electroporated into 129/SvPas embryonic stem (ES) cells. Clones were screened for integration of the transgene by G418 (Geneticin, neomycin analog) selection and resistant clones were grown in 24 well plates.

\subsubsection{ES cell DNA extraction}

$500 \mu$ lysis buffer $(10 \mathrm{mM}$ Tris- $\mathrm{HCl}$ pH 7.5, $10 \mathrm{mM}$ EDTA, $10 \mathrm{mM} \mathrm{NaCl}, 1 \mathrm{mg} / \mathrm{ml}$ proteinase $\mathrm{K}, 0.5 \%$ SDS) was added to each well and incubated over night at $55^{\circ} \mathrm{C}$. The next day, the content of each well was transferred into a $1.5 \mathrm{ml}$ tube and $200 \mu$ freshly prepared ice-cold $\mathrm{NaCl} /$ ethanol mix (15 $\mu \mathrm{l} 5 \mathrm{M} \mathrm{NaCl}$ per $1 \mathrm{ml}$ cold $100 \%$ ethanol) was added. After inverting several times, the samples were centrifuged for $15 \mathrm{~min}$ at $13000 \mathrm{rpm}$ at $4^{\circ} \mathrm{C}$ and supernatant was discarded. After washing twice with $700 \mu \mathrm{l} 70 \%$ ethanol, the pellet was briefly air-dried and dissolved in $40 \mu \mathrm{lTE}$.

\subsubsection{Southern blotting}

A $50 \mu \mathrm{l}$ restriction digest was performed over night with Sphl restriction enzyme and fragments were separated on a $0.8 \%$ gel containing ethidium bromide. Denaturing was performed for $40 \mathrm{~min}$ in denaturing solution $(0.5 \mathrm{M} \mathrm{NaOH}, 1.5 \mathrm{M} \mathrm{NaCl})$, followed by neutralizing $2 x$ in neutralizing solution (1 M Tris, $1.5 \mathrm{M} \mathrm{NaCl}, \mathrm{pH}$ 7.2) for 20 min each. DNA was blotted onto HybondN membrane (Amersham) using the Dry blot technique in neutralizing solution over night. DNA was 
UV cross-linked and incubated in pre-hybridization mix $(3 \mathrm{ml} 20 x \mathrm{SSC}, 3 \mathrm{ml}$ MP mix (5\% Milk

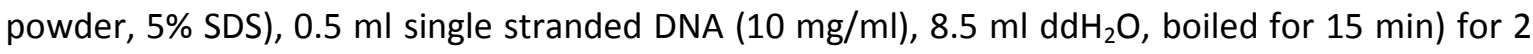
hours at $65^{\circ} \mathrm{C}$. Meanwhile radioactive probes were generated from $35 \mathrm{ng}$ PCR templates (internal probe: forward primer: 5'-CTATCTGATTCACGGGCTGGTGTG-3', reverse primer: 5'TAATCAGAAGACAGGTCATGCGAG-3' and external probe: forward primer: 5'AGAGTTGCACACACTTCGGTGCAC-3', reverse primer: 5'-CAAGATGGCTTCTTTAATGACCCCAG-3') using the Rediprime ${ }^{\mathrm{TM}}$ II DNA Labeling System (GE Healthcare) and ${ }^{32} \mathrm{P}$ labeled dCTPs (Easy Tides Deoxyciytidine 5-triphophate, Perkin Elmer) according the manufacturers' protocol. The probe was purified using the Illustra ${ }^{\mathrm{TM}}$ probequant G-50 micro columns (GE Healthcare), heated to $95^{\circ} \mathrm{C}$ for 5 mins and cooled on ice for $5 \mathrm{~min}$. Hybridization was performed at $65^{\circ} \mathrm{C}$ over night in hybridization mix ( $3 \mathrm{ml}$ 20x SSC, $3 \mathrm{ml} \mathrm{MP} \mathrm{mix,} 4 \mathrm{ml} 50 \%$ Dextransulfate, $0.75 \mathrm{ml} 10 \mathrm{mg} / \mathrm{ml}$ single

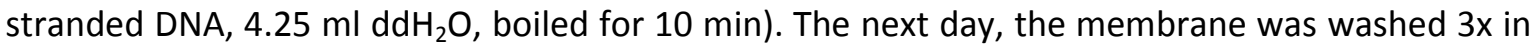
washing buffer 2 ( 0.1 SSC with $0.1 \%$ SDS) and a Biomax MS film (Kodak) was exposed for several days.

\subsubsection{ET cloning}

ET cloning method is based on DNA engineering by homologous recombination (Muyrers et al., 2001). Single VIP BAC clones (RP 23-25A8) were picked from a LB plate (10 g trypton, $5 \mathrm{~g}$ yeast extract, $10 \mathrm{~g} \mathrm{NaCl}, 15 \mathrm{~g}$ agar to 1 liter $\mathrm{H}_{2} \mathrm{O}$ ) containing $15 \mu \mathrm{g} / \mu \mathrm{l}$ chloramphenicol (CAM) and incubated in $1.4 \mathrm{ml} \mathrm{LB}$ with CAM at $37^{\circ} \mathrm{C}$ with shaking at $600 \mathrm{rpm}$ over night. $1.4 \mathrm{ml}$ LB with CAM were inoculated with $40 \mu \mathrm{l}$ of the over night culture and incubated for $3 \mathrm{~h}$ at $37^{\circ} \mathrm{C}$ at $600 \mathrm{rpm}$. The bacteria were made electro-competent by centrifugation at $13000 \mathrm{rpm}$ for $1 \mathrm{~min}$ at $4^{\circ} \mathrm{C}$ and washing $3 \mathrm{x}$ with ice-cold water. Bacteria were dissolved in $30 \mu \mathrm{l}$ ice-cold $\mathrm{ddH}_{2} \mathrm{O}$ and $1 \mu \mathrm{l}$ ET plasmid (Gene Bridges) was electroporated with $1.8 \mathrm{kV} .1 \mathrm{ml}$ LB was added, the culture was incubated for $70 \mathrm{~min}$ at $30^{\circ} \mathrm{C}$ at $300 \mathrm{rpm}$ and $50 \mu \mathrm{l}$ were plated on LB plates containing CAM and $50 \mu \mathrm{g} / \mu \mathrm{l}$ Spectinomycin (Spect) and incubated over night at $30^{\circ} \mathrm{C}$. The next day, $1.4 \mathrm{ml}$ LB with CAM and Spect were inoculated with a single clone and incubated over night at $30^{\circ} \mathrm{C}$ at $600 \mathrm{rpm}$. $30 \mu \mathrm{l}$ of the over night culture were incubated with $1.4 \mathrm{ml} \mathrm{LB}$ with CAM and Spect for 2 hours at $30^{\circ} \mathrm{C}$ at $600 \mathrm{rpm} .1 .43 \mu \mathrm{l}$ of $0.4 \mathrm{M} \mathrm{IPTG}$ was added and incubated for 1 hour at $37^{\circ} \mathrm{C}$ at $600 \mathrm{rpm}$. Cells were made electro-competent as described above and $100 \mathrm{ng}$ of the linearized vector was electroporated. $100 \mu \mathrm{l}$ bacteria were plated and incubated at $37^{\circ} \mathrm{C}$ over night. From this plate, 10 clones were picked and analyzed via miniprep, PCR and restriction digest.

\subsubsection{Flippase-induced Neomycin deletion in BAC clones}

A single BAC clone was incubated with $1.4 \mathrm{ml} \mathrm{LB}$ with CAM $(15 \mu \mathrm{g} / \mathrm{ml})$ and $30 \mu \mathrm{g} / \mathrm{ml}$ kanamycin (Kana) and incubated at $37^{\circ} \mathrm{C}$ at $650 \mathrm{rpm}$. The next day, a $1.4 \mathrm{ml} \mathrm{LB}$ culture with CAM and Kana was inoculated with $30 \mu \mathrm{l}$ of the over night culture and incubated for $3 \mathrm{~h}$ at $650 \mathrm{rpm}$ at $37^{\circ} \mathrm{C}$. Bacteria were made electro-competent by washing $3 \times$ with $1 \mathrm{ml}$ ice-cold $\mathrm{H}_{2} \mathrm{O}$ and $1 \mu$ Flippase plasmid containing a thermosensitive promoter (706-Flp, Gene Bridges) was electroporated. $1 \mathrm{ml}$ LB was added and the culture was shaken for $1.5 \mathrm{~h}$ at $30^{\circ} \mathrm{C}$ and $25 \mu$ l were plated on a LB plate containing $5 \mu \mathrm{g} / \mathrm{ml}$ tetracycline (Tet), CAM and Kana and incubated for 24 hours at $30^{\circ} \mathrm{C}$. The 
next day, a single colony was picked and grown in $1 \mathrm{ml} \mathrm{LB}$ with CAM for $2-3$ hours at $30^{\circ} \mathrm{C}$. The temperature was switched to $37^{\circ} \mathrm{C}$ and the culture was grown over night and plated on a LB plate containing CAM the next day. Single colonies were picked and in parallel one LB culture containing CAM and Kana and one LB culture containing only CAM were inoculated and grown at $37^{\circ} \mathrm{C}$ over night. Those clones which only grew on CAM but not on CAM and Kana were selected and verified via mini prep and restriction digest and PCR.

\subsubsection{BAC DNA purification for pronucleus injection}

BAC Maxi was performed using the NucleoBond BAC 100 Kit (Machery Nagel) according the manufacturers' protocol. BAC DNA was dissolved in $100 \mu \mathrm{l}$ TE and linearized by restriction digest with Not1 enzyme over night at $37^{\circ} \mathrm{C}$. The linearized vector was run on a $0.6 \%$ agarose gel and gel purified as follows: the respective band was cut and transferred into a dialysis bag filled with TE and current was applied. Successful migration of the DNA to the TE buffer was verified by UV light. The TE buffer containing the DNA fragment was then phenol-chloroform purified and precipitated with ethanol and $3 \mathrm{M} \mathrm{NaAc}$. After washing with ice-cold $80 \%$ ethanol, the pellet was dissolved in sterile $0.1 \times$ TE buffer.

\subsubsection{DNA extraction from mouse tail biopsies}

$0.5 \mathrm{~cm}$ mouse tail biopsies were digested in tail extraction buffer $(200 \mathrm{mM}$ Tris $/ \mathrm{HCl} \mathrm{pH} \mathrm{8.0,50} \mathrm{mM}$ EDTA pH 8.0, $100 \mathrm{mM} \mathrm{NaCl}, 1 \% \mathrm{SDS}, 0.25 \mu \mathrm{g} / \mu \mathrm{l}$ Proteinase $\mathrm{K}$, Roche) for $3-12$ hours at $55^{\circ} \mathrm{C}$. Samples were centrifuged at $14000 \mathrm{rpm}$ for $10 \mathrm{~min}$ and supernatant was transferred into a new tube. DNA was precipitated by adding 1 volume isopropanol, inverting and centrifugation at $14000 \mathrm{rpm}$ for $10 \mathrm{~min}$. Pellets were washed in 70\% ethanol and dissolved in 1x TE.

Alternatively, tails were digested in PBND buffer (50mM KCl, $10 \mathrm{mM}$ Tris $(\mathrm{pH} 8.3), 2.5 \mathrm{mM} \mathrm{MgCl}_{2}$, $0.1 \mathrm{mg} / \mathrm{ml}$ gelatin, 0.45\% v/v NP40, $0.45 \mathrm{v} / \mathrm{v}$ Tween 20, $0.015 \mu \mathrm{g} / \mu \mathrm{l}$ Proteinase $\mathrm{K}$, Roche) for 2 hours at $55^{\circ} \mathrm{C}$ followed by Proteinase $\mathrm{K}$ inactivation for 1 hour at $85^{\circ} \mathrm{C}$. After centrifugation at $14000 \mathrm{rpm}$ for $10 \mathrm{~min}, 1 \mu \mathrm{l}$ of this tail extract was directly used for the PCR reaction (Crude tail PCR, modified from (PerkinElmerCetus, 1989)).

\subsubsection{Genotyping PCRs}

Genotyping for Per1 and Per2 was performed using tail extracted DNA as described above, all other genotyping PCRs were performed directly on tail extracts without DNA precipitation (see crude tail PCR). Per1 and Per1 genotyping was performed as described previously (Zheng et al., 1999; Zheng et al., 2001). For all other genes GoTaq Flexi DNA Polymerase (Promega) was used according to the manufacturers' protocol, primers were used at a concentration of $10 \mu \mathrm{M}$. Primer sequences and PCR product sizes are given in table 1 . PCRs were run with an annealing temperature of $65^{\circ} \mathrm{C}\left(59^{\circ} \mathrm{C}\right.$ for Bmal1 PCR) for 37 cycles and PCR products were separated on a 1.5 $\%$ agarose gel. Knock-in mouse lines were usually tested with 3 primer pairs to differentiate between homozygous and heterozygous animals, whereas transgenic lines were genotyped with two primers detecting the transgene and were thus either positive or negative. 
Table 1: Genotyping primer sequences and PCR products.

\begin{tabular}{|c|c|c|c|}
\hline PCR & Primer & Sequence: 5'-3' & PCR products \\
\hline \multirow[t]{3}{*}{ Per1 } & Per1 $R$ & AGAACTGAGGACCCAAGCTG & Wild-type: 550 bp \\
\hline & Per1 F & TTGCCTACAGCCTCCTGAGT & Mutant: $350 \mathrm{bp}$ \\
\hline & Per1 $m t F$ & GGGGAACTTCCTGACTAGGG & \\
\hline \multirow[t]{3}{*}{ Per2 } & Per2R & GAACACATCCTCATTCAAAGG & Wild-type: $381 \mathrm{bp}$ \\
\hline & Per2 Neo & CGCATGCTCCAGACTGCCTTG & Mutant: $120 \mathrm{bp}$ \\
\hline & Per2 F & GCTGGTCCAGCTTCATCAACC & \\
\hline \multirow[t]{3}{*}{ Syt10 } & Syt10 F & AGACCTGGCAGCAGCGTCCGTTGG & Wild-type: 420 bp \\
\hline & Syt10R & AAGATAAGCTCCAGCCAGGAAGTC & Knock-in: 550 bp \\
\hline & Syt10KIR & GGCGAGGCAGGCCAGATCTCCTGTG & \\
\hline \multirow[t]{2}{*}{ VIP } & VIP C-CRE F & CGAATGCAGGATGCATGGGCTCTACAG & $1200 \mathrm{bp}$ \\
\hline & VIP C-CRER & CCATCCTCGAGCAGCCTCACCATGG & \\
\hline \multirow[t]{3}{*}{ Per2 Luc } & Per2 LucF & GGCTGTGTTTACTGCGAGAGTGAGG & Wild-type: 212 bp \\
\hline & Per2 Luc WT R & CCACAAGATCTTCCCCCTCTTCCG & Knock-in: 718 bp \\
\hline & Per2 Luc $R$ & GTCCCTATCGAAGGACTCTGGCAC & \\
\hline \multirow[t]{3}{*}{ Bmal1 } & Bmal KOF & СTCCTAACTTGGTITITGTCTGT & Wild-type: 327 bp \\
\hline & Bmal R & CTGACCAACTTGCTAACAATTA & Floxed allele: $431 \mathrm{bp}$ \\
\hline & Bmal flox $F$ & ACTGGAAGTAACTTTATCAAACTG & Mutant allele: $570 \mathrm{bp}$ \\
\hline \multirow[t]{3}{*}{ LacZ } & LacZ KI & GCGAAGAGTTTGTCCTCAACC & Wild-type: 650 bp \\
\hline & LacZF & AAAGTCGCTCTGAGTTGTTAT & Knock-in: 340 bp \\
\hline & LacZR: & GGAGCGGGAGAAATGGATATG & \\
\hline \multirow[t]{2}{*}{ Flp } & FLPF: & GCATCATGTGCTGCTGAACTAACC & $400 \mathrm{bp}$ \\
\hline & FLPR: & AGTGATCTCCCAGATGCTTTCACC & \\
\hline \multirow[t]{2}{*}{ Neo deletion } & AmCyan F: & GAGCACCGCATCGCCAGAACCG & $700 \mathrm{bp}$ if $\mathrm{Neo}$ is deleted \\
\hline & Syt10 R: & AAGATAAGCTCCAGCCAGGAAGTC & $2600 \mathrm{bp}$ if $\mathrm{NeO}$ is not deleted \\
\hline
\end{tabular}

\subsubsection{Quantitative real-time PCR (qPCR)}

RNA Isolation was performed using Trizol reagent (Invitrogen) according the manufacturer's protocol. DNAse treatment was performed using TURBO DNA-free ${ }^{\mathrm{TM}}$ Kit (Ambion). RNA from samples for the sleep restriction study was extracted from RNAlater (Ambion, Darmstadt, Germany) protected liver and epididymal adipose tissue samples using RNeasy Mini Kit and RNeasy Lipid Tissue Mini Kit (Qiagen, Hilden, Germany), respectively. On-column DNAse treatment was performed to avoid residual genomic DNA contamination. cDNA synthesis was performed using Superscript II (Invitrogen) with Oligo-dT primer (only for Split Cre chapter) or random hexamer primer. qPCR was performed using iQ SYBR Green Supermix on an iCycler thermocycler (Bio-Rad) according to the manufacturer's protocol. Each well of a 96 well plate was loaded with $10 \mu \mathrm{l}$ Supermix, $5 \mu \mathrm{l}$ CDNA (diluted 1:40, for SCN: 1:10) and $5 \mu \mathrm{l}$ primer mix (1.4 $\mu \mathrm{M}$ each). Cycling parameters were as follows: $95^{\circ} \mathrm{C}$ for $7 \mathrm{~min}, 95^{\circ} \mathrm{C}$ for $10 \mathrm{sec}, 60^{\circ} \mathrm{C}$ for $25 \mathrm{sec}, 72^{\circ} \mathrm{C}$ for $20 \mathrm{sec}$, steps 2-4 were repeated for 40 cycles. To determine specificity of each primer set a melt curve was determined by heating the PCR product to $95^{\circ} \mathrm{C}$ with increments of $0.5^{\circ} \mathrm{C} / 10 \mathrm{sec}$. For each new primer pair a standard curve was run to estimate efficiency; only primer pairs with an efficiency of $100 \%+/-5 \%$ were used. Primer sequences are given in table 2. CT (threshold cycling) values were exported from the iCycler software (Biorad) and relative expression values were obtained by nomalizing against the house keeping gene Eefa1 (Pfaffl, 2001). All values were normalized against the average of each circadian profile for each gene. 
Table 2: Primer sequences for qPCR.

\begin{tabular}{|c|c|}
\hline Primer name & Sequence $\left(5^{\prime} \rightarrow 3^{\prime}\right)$ \\
\hline \multicolumn{2}{|l|}{ Clock genes } \\
\hline EefaF & AATTCACCAACACCAGCAGCAA \\
\hline Eefa $R$ & TGCCCCAGGACACAGAGACTTCA \\
\hline Per1F & AGTTCCTGACCAAGCCTCGTTAG \\
\hline Per1R & CTTGCCCTCTGCTTGTCATC \\
\hline Per2F & GCCAAGTTTGTGGAGTTCCTG \\
\hline Per2R & CTTGCACCTTGACCAGGTAGG \\
\hline$B m a l 1 F$ & CCTAATTCTCAGGGCAGCAGAT \\
\hline Bmal1 R & TCCAGTCTTGGCATCAATGAGT \\
\hline$D b p F$ & AATGACCTTTGAACCTGATCCCGCT \\
\hline$D b p R$ & GCTCCAGTACTTCTCATCCTTCTGT \\
\hline Reverba F & AGCTCAACTCCCTGGCACTTAC \\
\hline Reverba $R$ & CTTCTCGGAATGCATGTTGTTC \\
\hline \multicolumn{2}{|c|}{ Bmal1 KO quantification } \\
\hline Six6 F & AGA GTG GTA CCT TCA GGA CCC ATA \\
\hline Six6 R & AGAACCTGCTGCTGG AGTCTGTTT \\
\hline Bmal1 KOF & TGACCCTCATGGAAGGTTAGAA \\
\hline Bmal1 KOR & CAGCCATCCTTAGCACGGT \\
\hline \multicolumn{2}{|c|}{ Metabolic genes } \\
\hline Glut2 F & GCTGGTGTGACTGTAAGTGGG \\
\hline Glut2 $R$ & GCTGGTGTGACTGTAAGTGGG \\
\hline$R b p 4 F$ & TITCTGTGGACGAGAAGGGT \\
\hline$R b p 4 R$ & TGGTCATCGTTTCCTCGCTG \\
\hline Pparg $F$ & TCGCTGATGCACTGCCTATG \\
\hline Pparg $R$ & GAGAGGTCCACAGAGCTGATT \\
\hline
\end{tabular}

\subsubsection{Radioactive in situ hybridization}

Radioactive in situ hybridization was performed as described previously (Albrecht et al., 1997; Oster et al., 2003b). The Per2 probe corresponds to nucleotides 229-768 (AF036893), the Dbp probe corresponds to nucleotides 2-951 (NM016974). Templates had been cloned into PCR II Topo or PCR script cloning vectors as described (Oster et al., 2003a) and were amplified by Maxi preparation as described above. Plasmids were linearized using the restriction enzymes Ecorl (Per2) and Notl (Dbp) and purified via phenol-chloroform extraction and ethanol precipitation. 1 $\mu \mathrm{g}$ linearized plasmid was used to generate ${ }^{35} \mathrm{~S}$-UTP (Perkin Elmer) labeled RNA probes, using MAXIscript ${ }^{\circledR}$ In Vitro Transcription Kit (Ambion) and T3 (Per2) or SP6 (Dbp) polymerases. Pellets were dissolved in in situ hybridization buffer (Ambion) and 1\% dithiothreitol (DTT) was added. Incorporation of radioactive nucleotides was determined by liquid scintillation and only probes with counts above $0.25 \mathrm{M} \mathrm{cpm} / \mu \mathrm{l}$ were used. Probes were stored at $-20^{\circ} \mathrm{C}$ over night. 
In situ hybridization was performed on fresh frozen $14 \mu \mathrm{m}$ brain sections. Sections were washed for 5 min in 1x PBS, fixed for 20 min in 4\% PFA (in PBS, pH 7.4), washed for 5 min in 1x PBS, treated with Proteinase $\mathrm{K}$ (Roche, $40 \mu \mathrm{g} / \mathrm{ml}$ in $50 \mathrm{mM}$ Tris/HCl, $5 \mathrm{mM}$ EDTA pH 8.5) for $5 \mathrm{~min}$, incubated in $0.2 \mathrm{~N} \mathrm{HCl}$ for $5 \mathrm{~min}$, washed in $1 \times$ PBS for $5 \mathrm{~min}$, re-fixed for $20 \mathrm{~min}$ in 4\% PFA (in PBS, $\mathrm{pH} 7.4)$, acetylated in $0.1 \mathrm{M}$ Triethanolamine/ $\mathrm{HCl}$ pH8 $(750 \mu$ lacetic anhydride were added to 250 $\mathrm{ml}$ for $3 \mathrm{~min}$, then another $750 \mu \mathrm{l}$ acetic anhydride were added for $7 \mathrm{~min}$ ), washed in $1 \times$ PBS for 5 $\mathrm{min}$, incubated in $0.9 \% \mathrm{NaCl}$ for $5 \mathrm{~min}$ and dehydrated in progressively decreasing concentrations of ethanol $(30 \%, 50 \%, 70 \%, 90 \%, 2 \times 100 \%)$ for $30 \mathrm{sec}$ each. Sections were air-dried in a RNASefree chamber. Slides were covered with $100 \mu \mathrm{l}$ probe diluted to 2-6 M cpm per slide in Hyb Mix (In Situ Hybridization Buffer, Ambion, 0.02\% DTT) and mounted with cover slips. Hybridization was performed in humidified chambers ( 5 XSC, 50\% formamide) in an incubation oven over night at $55^{\circ} \mathrm{C}$. The next day, slides were washed in removal wash buffer (5x SSC/ $20 \mathrm{mM}$ mercaptoethanol $(\mathrm{ME}))$ for $30 \mathrm{~min}$ at $64^{\circ} \mathrm{C}$ in a shaking water bath; after $10 \mathrm{~min}$ cover slips were carefully removed. Formamide washing was performed for $30 \mathrm{~min}$ at $64^{\circ} \mathrm{C}$ (2x SSC/50\% formamide/ $40 \mathrm{mM} \mathrm{ME}$ ). Sections were incubated $2 x$ in $1 x$ NTE $(50 \mathrm{mM}$ sodium chloride, $10 \mathrm{mM}$ Tris/ HCl, $5 \mathrm{mM}$ EDTA, pH 8) for $15 \mathrm{~min}$ at $37^{\circ} \mathrm{C}$, RNAse treated for $30 \mathrm{~min}$ at $37^{\circ} \mathrm{C}$ (RNAse $\mathrm{A}(20 \mu \mathrm{g} / \mathrm{ml}$ in NTE), washed in $1 \mathrm{x}$ NTE for $15 \mathrm{~min}$ at $37^{\circ} \mathrm{C}$, incubated in formamide buffer (2x SSC/50\% formamide/ $40 \mathrm{mM} \mathrm{ME}$ ) for $30 \mathrm{~min}$ at $64^{\circ} \mathrm{C}$, washed in $0.1 \mathrm{x}$ SSC for $15 \mathrm{~min}$ at room temperature and de-hydrated in progressively increasing ethanol concentrations (30\%, 60\%, 80\% ethanol/ $0.3 \mathrm{M}$ ammonium acetate, $95 \%, 2 \times 100 \%$ ethanol). Slides were air-dried before being exposed to a film (Kodak BioMax MS).

Developed films were scanned with a densitometer (Hewlett Packard) and quantification of relative expression levels was performed by densitometric analysis using Scion Image 1.62 software. Three sections per brain were analyzed and background subtracted from adjacent hypothalamic areas on the same section. Following film exposure, slides were coated with liquid film (KODAK NTB Autoradiography Emulsion), exposed 4x as long as they were exposed to the Biomax MS film and developed using Kodak D-19 developer and fixer solutions and counterstained with DAPI.

\subsubsection{Colorimetric in situ hybridization}

Automated in situ hybridization on $25 \mu \mathrm{m}$ fresh frozen sections was performed as described (Visel et al. 2007; Yaylaoglu et al. 2005). A 1019 bp Syt10 template was used for riboprobe generation (NM_018803, nts 279 to 1298 ) at a concentration of $200 \mathrm{ng} / \mu \mathrm{l}$.

\subsubsection{Double fluorescent in situ hybridization}

Automated double fluorescent in situ hybridization was performed according to the protocol for colorimetric in situ hybridization with modifications as described below. $25 \mu \mathrm{m}$ frozen sections were used. Prehybridization and hybridization was performed as described (Visel et al. 2007; Yaylaoglu et al. 2005). One probe was labeled with the hapten digoxigenin (DIG), the second probe was labeled with the hapten dinitrophenyl (DNP), and probes were added sequentially to 
the slides ( 1 hour apart). The next day, formamide and SSC washes as well as sheep serum blocking steps were performed as previously described for the colorimetric in situ hybridization (Visel et al. 2007; Yaylaoglu et al. 2005). Sections were incubated in TNB (0.5\% Blocking Reagent (PerkinElmer) in 1× TN (10 mM Tris-Cl, pH 7.6, $10 \mathrm{mM} \mathrm{NaCl})$ ) for $10 \mathrm{~min}$. The DNP-labeled probe was detected and signal amplified using the TSA plus DNP (HRP) system (Perkin Elmer): The antiDNP HRP antibody (1:250 in TNB, provided with TSA Kit) was added for 1 hour, followed by TNT (1x TN, 0.05\% Tween20, Sigma) washing and incubation with DNP tyramide amplification reagent for 25 min. After washing in TNT and 30 min incubation in TNB, anti-DNP HRP antibody was added for one hour, followed by TNT washing and Cy5 (red) incubation for $25 \mathrm{~min}$. Slides were washed with 1x NTE and the remaining HRP signal was blocked by incubation with $25 \mathrm{mM}$ Benzhydrazide (BZH) for $5 \mathrm{~min}$. Then, the DIG hapten was detected with anti-DIG-HRP antibody, tyramide amplification and AF488 (green) labeling as described for the DNP hapten. Controls, in which the second hapten detection was omitted, were always run in parallel to ensure efficient blocking of the first HRP signal by BZH.

\subsection{Statistical analysis}

Data are expressed as mean +/- SEM. Statistical comparisons were made using Graph Pad Prism software and p-values below 0.05 were considered significant. Student's t-tests were used for comparison of two groups and ANOVAs when more than two groups were compared. Where time and group interactions were compared two-way ANOVAs with Bonferroni post-tests were used. Where normality tests revealed deviations from a Gaussian distribution, non-parametric analyses were used (Mann-Whitney $U$ test or Kruskal-Wallis test with Dunn's Multiple Comparison posttest, respectively). To compare data to a hypothetical median Wilcoxon signed rank tests were applied. 


\section{Chapter 3: Results}

3.1 Publication: Synaptotagmin10-Cre, a driver to disrupt clock genes in the SCN

Jana Husse, Xunlei Zhou, Anton Shostak, Henrik Oster and Gregor Eichele

Journal of Biological Rhythms, Volume 26, pages 379-389 


\title{
Synaptotagmin10-Cre, a Driver to Disrupt Clock Genes in the SCN
}

\author{
Jana Husse, Xunlei Zhou, ${ }^{1}$ Anton Shostak, Henrik Oster, and Gregor Eichele ${ }^{2}$ \\ Genes and Behavior Department, Max Planck Institute for Biophysical Chemistry, \\ Goettingen, Germany
}

\begin{abstract}
Surgical lesion of the suprachiasmatic nuclei (SCN) profoundly affects the circadian timing system. A complication of SCN ablations is the concomitant scission of SCN afferents and efferents. Genetic disruption of the molecular clockwork in the SCN provides a complementary, less invasive experimental approach. The authors report the generation and functional analysis of a new Cre recombinase driver mouse that evokes homologous recombination with high efficiency in the SCN. They inserted the Cre recombinase cDNA into the Synaptotagmin10 (Syt10) locus, a gene strongly expressed in the SCN. Heterozygous Synaptotagmin10-Cre (Syt10 $\left.{ }^{\text {Cre }}\right)$ mice have no obvious circadian locomotor phenotype, and homozygous animals show slightly reduced light-induced phase delays. Crosses of Syt10 Cre mice with $\beta$-galactosidase reporter animals revealed strong Cre activity in the vast majority of SCN cells. Cre activity is not detected in nonneuronal tissues with the exception of the testis. The authors demonstrate that conditionally deleting the clock gene Bmal1 using the Syt10 ${ }^{\text {Cre }}$ driver renders animals arrhythmic.
\end{abstract}

Key words suprachiasmatic nucleus, SCN, circadian, clock, Bmal1, Cre driver, Synaptotagmin 10

In the mouse, gene targeting in embryonic stem (ES) cells as well as N-ethyl-N-nitrosourea (ENU)mediated mutagenesis plays a key role in elucidating the molecular basis of the mammalian circadian clock (Bunger et al., 2000; van der Horst et al., 1999; Vitaterna et al., 1994; Zheng et al., 2001; Zheng et al., 1999). The mammalian circadian clockwork rests on a limited number of core clock proteins that form interlocked transcriptional-translational feedback loops creating a 24-h rhythm. This machinery drives rhythmic expression of hundreds of clock-controlled genes that regulate a wide range of rhythmic physiological functions (Ko and Takahashi, 2006). Clocks have been found in almost all cells and tissues of the body. They are equipped with the complete molecular clockwork and exhibit a self-sustained circadian rhythm even when kept in explant culture (Balsalobre et al., 1998; Tosini and Menaker, 1996; Yamazaki et al., 2000; Yoo et al., 2004). The mammalian circadian system is organized in a hierarchical manner with the central pacemaker in the suprachiasmatic nucleus (SCN) controlling numerous peripheral clocks (Dibner et al., 2010). Pioneering lesion studies carried out in the early 1970s established the SCN as the central

1. Present address: University of Heidelberg, Institute of Anatomy and Cell Biology, Heidelberg, Germany.

2. To whom all correspondence should be addressed: Gregor Eichele, Genes and Behavior Department, Max Planck Institute for Biophysical Chemistry, Am Fassberg 11, 37077 Goettingen, Germany; e-mail: Gregor.Eichele@mpibpc.mpg.de.

JOURNAL OF BIOLOGICAL RHYTHMS, Vol. 26 No. 5, October 2011 379-389

DOI: $10.1177 / 0748730411415363$

(C) 2011 The Author(s) 
pacemaker (Moore and Eichler 1972; Stephan and Zucker 1972).

Over the past decade, mice deficient for each of the core clock genes have been generated. Typically, such animals are characterized by smaller or greater defects in locomotor circadian rhythmicity and, additionally, may also show a number of phenotypes, including metabolic defects, changes in the reward system, or memory impairments (Abarca et al., 2002; Garcia et al., 2000; Turek et al., 2005). It is as yet unclear whether these defects are clock mediated and, if they are, which tissue clocks exert control. In the adrenal, for example, transplantation experiments have been used to address the function of a tissue clock (Kiessling et al., 2010; Oster et al., 2006). An alternative to transplantation and surgical ablation is the tissue-specific deletion of core clock genes using the Cre-loxP system (Storch et al., 2007; Lamia et al., 2008; Marcheva et al., 2010).

In view of the overarching role of the $\mathrm{SCN}$ in circadian timekeeping, we attempted to knock-out clock genes such as Bmal1 specifically in this nucleus. To achieve this goal, we generated a SCN Cre driver that can delete conditional alleles of genes of interest in this nucleus. The Allen Brain Atlas (Lein et al., 2007) has uncovered numerous genes that are expressed in the SCN. However, genes solely expressed therein were not found. In situ hybridization on brain sections identified Synaptotagmin10 (Syt10) as a gene that is strongly expressed in the SCN with relatively few other expression sites in the CNS, even during development (www.genepaint.org, Genepaint ID MH808). Synaptotagmins are involved in regulated exocytosis of synaptic vesicles and are thought to function as calcium sensors (Gustavsson and Han, 2009). Most Synaptotagmins are widely expressed throughout the nervous system, and Syt1, 2, 4, 5, 9, 11, 13, 14, and 16 are also found in the SCN, albeit much less enriched therein than Syt10. The presence of multiple Synaptotagmins in the SCN is beneficial for the design of a Cre driver mouse, as it makes it less likely that inserting the Cre recombinase gene into the Syt10 locus would result in a major impairment of neuronal function as paralogs of Syt10 should compensate for a loss of this particular Synaptotagmin.

Here we report the generation and characterization of a Syt $10^{\text {Cre }}$ driver line that enables SCN targeting without targeting of peripheral, nonneuronal clocks. We verified the usefulness of the Syt10 ${ }^{\text {Cre }}$ driver line by knocking out a conditional Bmal1 allele. Depending on the dosage of $\mathrm{Cre}$ recombinase, we obtained mice with phenotypes ranging from minimal circadian perturbation to complete arrhythmicity.

\section{MATERIALS AND METHODS}

\section{Cloning of Syt10 ${ }^{\text {Cre }}$ Targeting Vector}

We replaced the ATG in exon 1 of the Syt10 gene by a Cre cassette. Nts 92-229 (NM_018803.2) were replaced with the $\mathrm{Cre}$ cassette composed of the $i \mathrm{Cre}$ (Shimshek et al., 2002), an internal ribosomal entry site (IRES), followed by an enhanced green fluorescent protein (EGFP) reporter cDNA and a Flippase recognition target (FRT)-flanked PGKneomycin selection marker. An 8.7-kb genomic region ( $5.3 \mathrm{~kb}$ upstream of exon 1 and $3.4 \mathrm{~kb}$ downstream of exon 1) was cloned by recombineering (Liu et al., 2003) from a BAC clone (BMQ295d20). Exon 1 was then replaced by the Cre knock-in cassette.

\section{Generation and Genotyping of Syt10 ${ }^{\text {Cre }}$ Knock-in Mice}

Gene targeting of Syt10 ${ }^{\text {Cre }}$ knock-in mice was performed by GenOway using 129Sv/Pas embryonic stem cells. DNA from G418-resistant clones was digested with SphI and analyzed by Southern blotting. Targeted cells were identified using a 474-bp probe generated by PCR (P1; forward primer: 5'-CAAGATGGCT TCTTTAATGACCCCAG-3', reverse primer: 5'-AGAGT TGCACACACTTCGGTGCAC-3') that hybridizes with the 3' homology arm. SphI digestion of the targeted allele resulted in an $8.9-\mathrm{kb}$ band in addition to the 14.7-kb wild-type band (Fig. 1A). For positive clones, the $5^{\prime}$ homology arm was independently tested using a suitable PCR probe. Targeted clones were injected into blastocysts. Chimeric offspring were backcrossed to C57BL/6. The resulting F1 generation was screened for germline transmission by Southern blotting as described for ES cells and PCR genotyping using the following primers: $S y t 10$ F: 5'-AGACCTGGCAGCAGCGTCCGTTGG-3', Syt10 $R: 5^{\prime}$-AAGATAAGCTCCAGCCAGGAAGTC-3', and Syt10 KI R: 5'-GGCGAGGCAGG CCAGATCTCCTGTG-3'. PCR was performed for 38 cycles with an annealing temperature of $65^{\circ} \mathrm{C}$. A wild-type band of $426 \mathrm{bp}$ and a mutant band of $538 \mathrm{bp}$ were separated on a $1.5 \%$ agarose gel (Fig. 1C). In order to delete the FRT-flanked neomycin cassette, mutant mice were crossed to an ubiquitously expressing Flippase line on C57BL/6 background (Farley et al., 2000). Offspring were tested for neomycin deletion by PCR. The Flippase allele was out-crossed in the next generation by back-crossing to C57BL/6. 
B

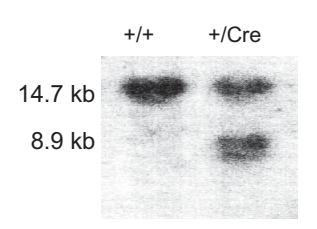

\section{C}

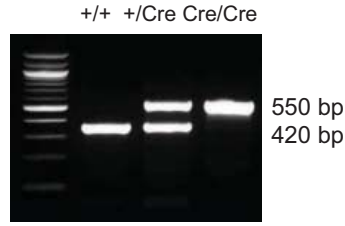

D
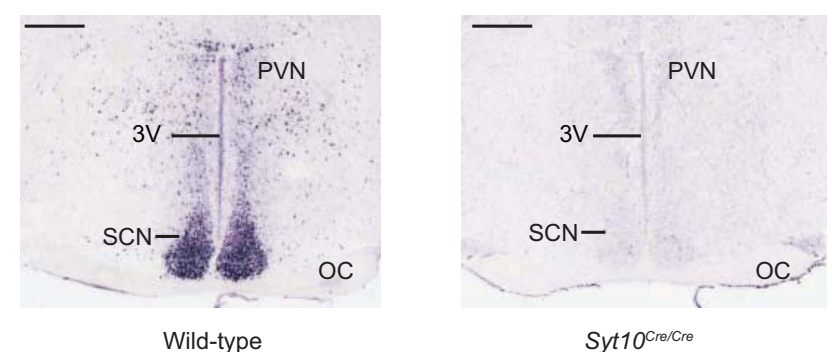

Syt10 Cre/Cre

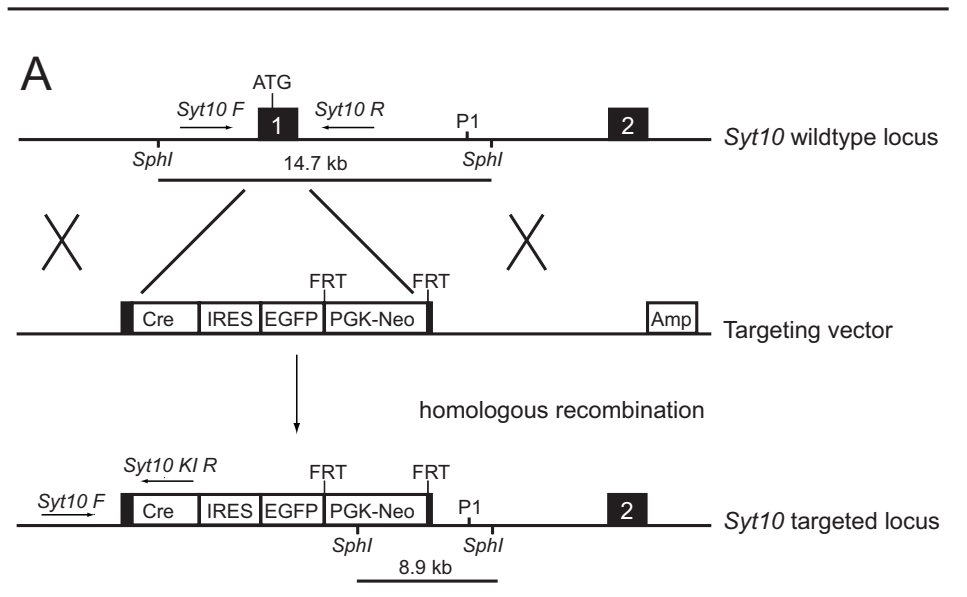

2005) and counterstained with Nuclear Fast Red or DAPI. Quantification of recombination efficiency was performed as follows: $10-\mu \mathrm{m}$ cryosections were first stained with DAPI followed by colorimetric detection of $\beta$-galactosidase activity. The SCN was outlined and the number of DAPI-stained nuclei (a measure of cell number) and of $\beta$-galactosidase dots were counted, and the ratio of $\beta$-galactosidase dots/nuclei was computed. Two sections per SCN region (rostral, central, caudal) from 4 different animals were included. An identical analysis was carried out on SCNs of animals in which $\beta$-galactosidase activity is seen throughout the SCN (see Suppl. Table S1 for further information). Finally, the ratio of these two counts was calculated to obtain the percentage of SCN cells expressing Cre recombinase in Syt10 ${ }^{\text {rel/+ }}$ R26R $\mathrm{LacZ} /+^{\mathrm{L}}$ mice.

\section{In Situ Hybridization}

Automated in situ hybridization on $25-\mu \mathrm{m}$ frozen sections was performed as described (Visel et al., 2007; Yaylaoglu et al., 2005). A 1019-bp Syt10 template was used for riboprobe generation (NM_018803, nts 279 to 1298). Riboprobe concentration was $200 \mathrm{ng} / \mu \mathrm{L}$.

Figure 1. Generation of $S y t 10^{\mathrm{Cre}}$ knock-in mice. (A) Schematic of the Syt10 wild-type locus, the targeting vector, and the resulting targeted locus. Exons are indicated in black. Position of genotyping primers (Syt10 F, Syt10 R, and Syt10 KI R) are depicted by arrows. Southern fragments are shown as lines. The probe used for Southern genotyping is marked as P1. (B) Southern genotyping of F1 littermates obtained from chimera-C57BL/6 crosses. A 474-bp probe (P1) detected a 14.7-kb wild-type and an 8.9-kb mutant SphI fragment. (C) PCR genotyping of F1 littermates obtained from Syt10 ${ }^{\mathrm{Crel}+\mathrm{H}}$ intercrosses using the genotyping primers Syt10 F, Syt10 R, and Syt10 KI R. A $420-b p$ wild-type and a 550-bp mutant band are separated on a $1.5 \%$ agarose gel. (D) Syt10 expression in the SCN as determined by in situ hybridization in wild-type and Syt10 ${ }^{\text {CrelCre }}$ mice. Scale bar: $0.5 \mathrm{~mm}$. Abbreviations: $3 \mathrm{~V}$, third ventricle; Amp, ampicillin resistance gene; Cre, Cre recombinase; FRT, Flippase recognition target; EGFP, enhanced green fluorescent protein; IRES, internal ribosomal entry site; Neo, neomycin resistance; OC, optic chiasm; PGK, phosphoglycerine kinase A promoter; PVN, paraventricular nucleus of the hypothalamus; SCN, suprachiasmatic nucleus.

\section{$\beta$-Galactosidase Staining}

Syt $10^{\text {Cre/+ }} R 26 R^{\text {LacZ/+ }}$ mice were sacrificed by cervical dislocation; brains were quickly removed and frozen in O.C.T (Tissue-Tek). Then, $25-\mu$ m cryosections were stained for $\beta$-galactosidase as described (Sakurai et al.,

\section{Gene Expression Analysis by Reverse Transcription PCR}

Syt10 ${ }^{\mathrm{Cr} / \mathrm{t}}$ males were sacrificed and tissues were harvested in RNA Later solution (Ambion). RNA was Trizolextracted (Invitrogen) and DNAse treated (TURBODNA-free Kit, Ambion). CDNA synthesis was performed (Superscript II, Invitrogen) with the Oligo-dT primer. A 490-bp PCR fragment encompassing the Cre sequence was amplified using the following primers: Cre RT forward: 5'-GTGGATGCTGGGGAGAGAGCCAAGC-3' and Cre RT reverse: 5'-CAGACCAGGCCAGGTATCTCTGCCC-3'. From the same samples, Eef1a1 was amplified as an internal standard. 


\section{Gene Expression Analysis by Quantitative Real-Time PCR}

Animals were sacrificed at zeitgeber time (ZT) 18, brains were harvested, and brain punches of the anterior ventral hypothalamus comprising the SCN were taken from 1-mm-thick brain sections. RNA and cDNA were prepared as described above. QPCR was performed using iQ SYBR Green Supermix on an iCycler thermocycler (Bio-Rad) according to the manufacturer's protocol. Eef1a1 was used as a standard, and quantification was performed as described (Kiessling et al., 2010). Primer sequences were as follows: Bmal1 forward: 5'-TGACCCTCATGGAAGGTTAGAA-3', Bmal1 reverse: 5'-CAGCCATCCTTAGCACGGT-3', Eef1a1 forward: 5'-AATTCACCAACACCAGCAGCAA-3', and Eef1a1 reverse: 5'-TGCCCCAGGACACAGAGACTTCA-3'. Sample sizes were 9 animals for wild-type and 3 animals for each of the other genotypes.

\section{Immunohistochemistry}

First, $10-\mu \mathrm{m}$ frozen sections were fixed in ice-cold $4 \%$ PFA for $15 \mathrm{~min}$, washed 3 times in TNT buffer ( 10 $\mathrm{mM}$ Tris- $\mathrm{HCl}, 150 \mathrm{mM} \mathrm{NaCl}$, and $0.05 \%$ Tween), blocked in $10 \%$ normal goat serum for $1 \mathrm{~h}$, and incubated with anti-BMAL1 antibody (1:1000 rabbit anti-MOP3; Novus Biologicals) overnight at $4{ }^{\circ} \mathrm{C}$. The next day, sections were washed 3 times with TNT buffer, incubated with the secondary antibody (1:400 anti-rabbit AF488; Invitrogen) for $2 \mathrm{~h}$ at room temperature, washed again, and mounted with DAPI containing mounting medium. BMAL1-positive cells in a $240 \times 187 \mu \mathrm{m}$ rectangle in 3 medial SCN sections were counted. For each genotype, 3 animals were analyzed.

\section{Behavioral Experiments}

All animal experiments were carried out in compliance with the German Law on Animal Welfare. Breeding strategies can be found in Supplementary Table S1. Mouse housing and behavioral monitoring were performed as described (Jud et al., 2005). Males on a mixed 129Sv/C57BL/ 6 background of 2 to 5 months of age were used. Controls: where feasible, littermates were used. Mice were kept on a 12:12 light dark (LD, 350-lux) cycle before transfer to constant darkness (DD) or constant light (LL, 100 lux). A 15-min 350-lux light pulse was given manually at circadian time (CT) 14. Behavioral data were analyzed using
ClockLab acquisition and analysis software package (Actimetrics). Period and amplitude were calculated using $\chi^{2}$ periodogram analysis. Phase shifts in an Aschoff type I protocol were calculated as described (Jud et al., 2005). Onset error was calculated as mean deviation of real onset from a least squares-fit regression line over a period of 10 consecutive days in DD. Ultradian (period of 5-10 h) amplitudes were calculated using $\chi^{2}$ periodogram analysis of 5 consecutive days of the second week in DD.

\section{Data Analysis}

Statistical comparisons were made in GraphPad Prism, and $p$ values below 0.05 were considered significant. Normality tests revealed that not all behavioral data followed a Gaussian distribution, and hence nonparametric analyses were performed throughout: Mann-Whitney $U$ test for comparison of two groups and Kruskal-Wallis test for comparison of morethantwogroups.QPCRandimmunohistochemistry data were analyzed using $t$ tests.

\section{RESULTS}

\section{Generation of Syt10 ${ }^{\text {Cre }}$ Mice}

The construct used for targeting the Syt10 locus replaced the endogenous Syt10 ATG located in exon 1 by the Cre cDNA sequence (Fig. 1A). This targeting should result in a knock-out of endogenous Syt10. We generated Syt10 ${ }^{\mathrm{Cre}}$ mice by $129 \mathrm{~Sv}$ ES cell targeting and subsequent blastocyst injections. We verified the genotype of F1 animals by Southern blotting and PCR (Fig. 1B,C). Subsequently, the FRT-flanked neomycin resistance cassette was deleted. The deletion of Syt10 was confirmed by in situ hybridization to coronal SCN sections. Syt10 transcripts were not detectable in homozygous Syt10 ${ }^{\text {Cre/Cre }}$ mutants, neither in the SCN (Fig. 1D) nor in any of the other Syt10 expression sites in the brain (not shown).

Syt $10^{\text {Cre }}$ heterozygous and homozygous mice are viable and fertile with no obvious morphological abnormalities. Breeding experiments revealed that Cre is active in the male germline. Hence, offspring of a father who is $S y t 10^{\mathrm{Cr} r}$ positive and also carries a conditional allele of the gene to be deleted will be completely deficient in the paternally derived allele of the gene of interest. In the case of the reporter $R 26 R L a c Z$, the resulting embryos will stain for $\beta$-galactosidase ubiquitously (for further information, see Suppl. Table S1). 


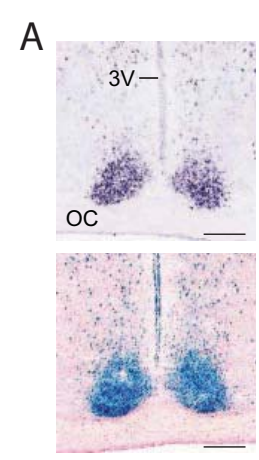

rostral SCN

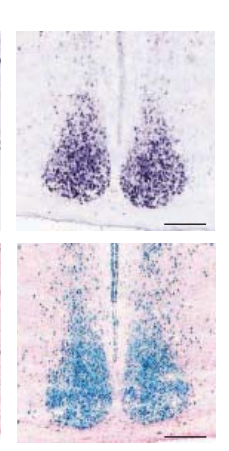

central SCN

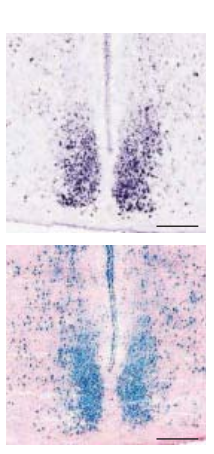

caudal SCN
B

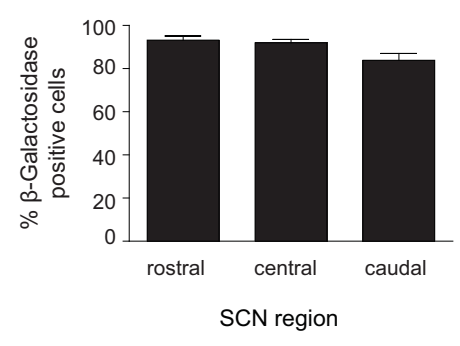

Figure 2. Strong Cre activity in the SCN of Syt10 ${ }^{\text {Crel+ }} R 26 R^{\text {LacZl+ }}$ mice. (A) Syt10 expression and Cre activity at different levels along the rostrocaudal axis of the $\mathrm{SCN}$ as determined by in situ hybridization (upper panels) or $\beta$-galactosidase staining (lower panels). Sections shown for the two techniques are $25 \mu \mathrm{m}$ apart. Scale bar: $0.2 \mathrm{~mm}$. (B) Percentage of $\beta$-galactosidase positive cells in the SCN. No significant differences were detected between the $3 \mathrm{SCN}$ axial levels $(n=4)$. Abbreviations: $3 \mathrm{~V}$, third ventricle; $\mathrm{OC}$, optic chiasm.

\section{Activity of Cre Is Brain Specific and SCN Enriched}

We crossed Syt $10^{\text {Cre }}$ mice to the R26RLacZ reporter line that expresses $\beta$-galactosidase after Cre-mediated excision of a stop cassette (Soriano, 1999). Consistent with the in situ hybridization data, $\beta$-galactosidase staining was very strong throughout the SCN (Fig. 2A). To estimate the percentage of $\mathrm{SCN}$ cells expressing Cre recombinase, the number of $\beta$-galactosidase dots in the SCN of $S y t 10^{\text {Cre/+ }} R 26 R^{\text {LacZ/+ }}$ mice was determined relative to the SCN of mice that ubiquitously express $\beta$-galactosidase (see Materials and Method). We found that $\sim 90 \%$ of the SCN cells in Syt10 ${ }^{\text {Cre/+ }} R 26 R^{\text {LacZ/+ }}$ mice were $\beta$-galactosidase positive (Fig. 2B). The variation between rostral, central, and caudal levels (93\%, 92\%, and $84 \%$ respectively) is not significant. The $\beta$-galactosidase negative cells could be glia cells that do not express Syt10 (Zhang et al., 2004).

Cre activity was detected in a variety of other brain structures. Coronal sections at the level of the SCN showing Syt10 expression detected by in situ hybridization (Suppl. Fig. S1A) and Cre activity detected by $\beta$-galactosidase reporter analysis (Suppl. Fig. S1B) give a good indication of the extent to which Cre is active in non-SCN areas. Supplementary Figure S2 shows $\beta$-galactosidase staining in a variety of brain tissues. We observed that Cre-expressing cells are embedded in numerous non-Cre-expressing cells. By contrast, in the SCN, the majority of cells are $\beta$-galactosidase positive (Fig. 2A). The $\beta$-galactosidase reporter expression pattern was also seen using the human alkaline phosphatase reporter line (Lobe et al., 1999). Phosphatase staining pattern in these mice was very similar to that of $\beta$-galactosidase (data not shown).

To examine whether Cre-induced recombination occurred outside the CNS, we performed $\beta$-galactosidase staining on sections of various tissues isolated from Syt10 ${ }^{\text {rel+t }}$ R26RLacZ ${ }^{\text {LacZ/+ }}$ mice (Fig. 3A). We did not detect any Cre activity in peripheral tissues except for the seminiferous tubules of the testis, an expression site presaged by the breeding experiments (Suppl. Table S1). To further confirm the lack of Cre expression in peripheral tissues, we performed Cre-specific reverse transcription PCR reactions on RNA isolated from 19 tissues of Syt10 ${ }^{\mathrm{Cr} / \mathrm{+}}$ mice. A Cre PCR product was detected only in neuronal tissues, including the eye and the spinal cord, and in testis (Fig. 3B). In summary, the Syt $10^{\text {Cre }}$ driver is highly active in the SCN and, to a somewhat lesser extent, in other brain regions. Importantly, we did not detect any Cre activity in nonneuronal tissues with the exception of testis.

\section{A Minor Light-Resetting Phenotype in $\mathrm{Sy} 110^{\mathrm{Cre} / \mathrm{Cre}}$ Homozygous Mice}

We analyzed the circadian behavior of heterozygous and homozygous Syt $10^{\text {Cre }}$ mice. Male wild-type, Syt $10^{\mathrm{Cre} / \mathrm{t}}$ andSyt10 ${ }^{\mathrm{Cre} / \mathrm{Cre}}$ littermates were tested for wheel-running behavior in a standard experimental setup. In a 12:12 LD cycle, Syt10 ${ }^{\mathrm{Cre} / \mathrm{+}}$ as well as Syt10 $\mathrm{Cre/Cre}$ mice entrained normally (Fig. 4A). Total activity levels as well as onset variability were not different between genotypes. When released into DD, all genotypes showed a similar endogenous period (Fig. 4B; 23.5 h, 23.4 h, and 23.7 h in wild-type, Syt10 Cre/t, and $\mathrm{Sy} t 10^{\mathrm{Cr} / \mathrm{Cre}}$, respectively). Locomotor activity onset error as a measure of rhythm instability was also not different between genotypes (Fig. 4C). 


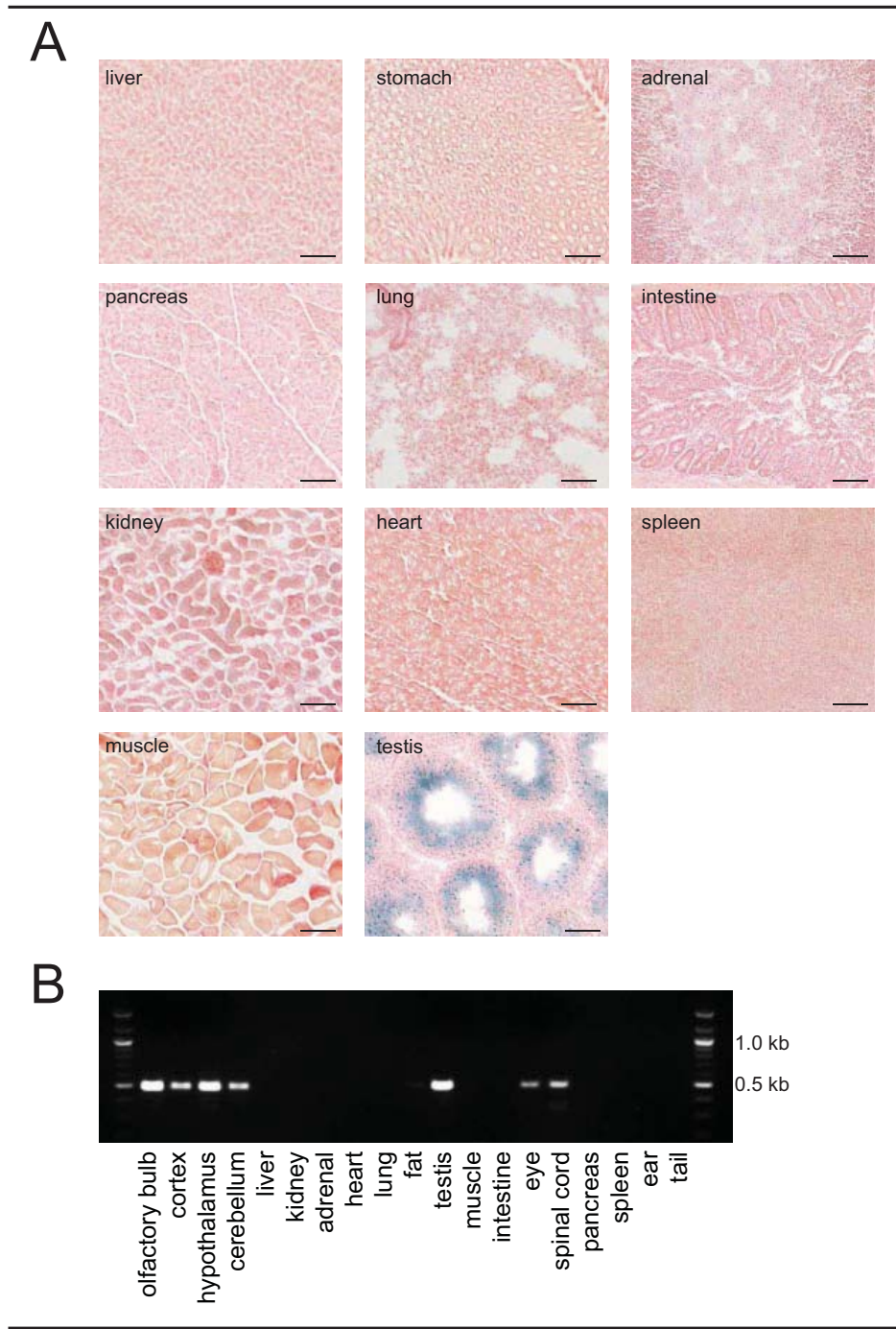

Figure 3. Cre activity is detected only in neuronal tissues and in testis. (A) $\beta$-galactosidase staining of various organs isolated from $\mathrm{Sy} t 10^{\mathrm{Crel+}} \mathrm{R} 26 \mathrm{RLacZ} \mathrm{Z}^{+-}$mice. No Cre-mediated recombination resulting in $\beta$-galactosidase expression is detectable in peripheral organs with the exception of the seminiferous tubules of the testis. Scale bar: $0.1 \mathrm{~mm}$. (B) Cre-specific reverse transcription PCRs on RNA isolated from various tissues of $\mathrm{Sy} \mathrm{t10}^{\mathrm{Crel+}}$ mice.

Next, we investigated the light response of the circadian system in all 3 genotypes by giving a 15-min light pulse at CT14. Wild-type as well as heterozygous mice showed the expected phase delay of approximately $140 \mathrm{~min}$ (Benloucif and Dubocovich, 1996). Syt10 $\mathrm{Cr} / \mathrm{Cre}$ mice, however, displayed a reduced phase delay of 90 min (Fig. 4D; wild-type vs. Syt10 Cre/Cre; $p=0.006$ ). Given this slightly reduced light response of the circadian system in homozygous mice, we determined their freerunning period in LL. This parameter is influenced by both the endogenous circadian period and the light responsiveness of the circadian system (Daan and Pittendrigh, 1976). We did not find differences in the period between wild-type and heterozygous littermates. Homozygous mutants, however, showed a slightly shortened period in LL (Fig. 4E; $25.1 \mathrm{~h}$ and $24.6 \mathrm{~h}$ in wild-type and Syt10 ${ }^{\mathrm{Cre} / \mathrm{Cre}}$, respectively; $p=$ $0.03)$.

Therefore, the Syt $10^{\text {Cre }}$ driver line even in the homozygous state seems suitable for circadian experiments as it shows only a minor light-resetting phenotype. Both the circadian period and the stability of locomotor activity rhythms under LD and DD conditions are normal. Heterozygous mutants do not show any impairment in the tested circadian behavioral paradigms.

\section{Cre Dosage-Dependent Circadian Phenotype in Conditional Bmal1-Deficient Mice}

The only single-gene knock-out identified so far that produces a complete arrhythmic locomotor phenotype is Bmal1 (Bunger et al., 2000). Hence, we crossed the Syt10 ${ }^{\mathrm{Cre}}$ line with a mouse line carrying a conditional allele of Bmal1 that allows Cre-mediated deletion of the exon encoding the BMAL1 basic helix loophelix (bHLH) domain (Bmal1 ${ }^{\text {fff }}$ ) (Storch et al., 2007). We analyzed wheel-running behavior in 12:12 LD and DD conditions.

Syt10 Cre/+ Bmal1 $^{\text {flfl }}$ mice showed a shortened period in DD (Fig. 5A,B; $23.5 \mathrm{~h}$ and $22.9 \mathrm{~h}$ in wild-type and $S y t 10^{\mathrm{Cr} / \mathrm{t}}$ Bmal1 $^{f l f l}$, respectively; $p=0.002$ ). These mice were still rhythmic under both LD and DD conditions (Fig. 5A and Suppl. Fig. S3). However, rhythmicity in DD was less stable, and quantification of the onset error revealed increased onset variability in Syt10 $\mathrm{Cre} / \mathrm{H}^{\mathrm{Bmal}} \mathrm{f}^{\mathrm{flfl} \mathrm{l}}$ mice compared to wild-type controls (Fig. 5C; $0.38 \mathrm{~h}$ and $0.78 \mathrm{~h}$ in wildtype and Syt10 ${ }^{\mathrm{Cr} / \mathrm{+}}$ Bmal1 $1^{\mathrm{flfl} f}$, respectively; $\left.p=0.038\right)$. It appears that in Syt10 ${ }^{\mathrm{Cre} / \mathrm{H}}$ Bmal1 ${ }^{\mathrm{flfl}}$ mice, the amount of Cre activity was insufficient to fully delete Bmal1 in all SCN cells.

Next we used a Bmal1 $1^{f l-}$ background that, based on previous work, should in itself not produce a circadian 


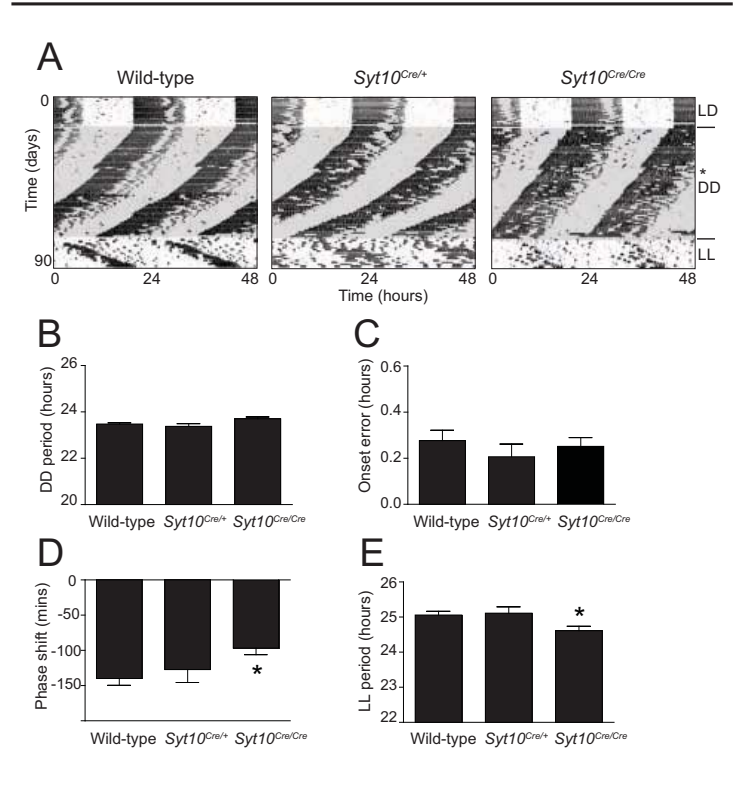

Figure 4. No major circadian locomotor impairments in Syt10 ${ }^{\mathrm{Cre}}$ mice. (A) Representative double-plotted actograms of wild-type, Syt10 ${ }^{\text {Crelt }}$, and Syt10 ${ }^{\text {Cre/Cre }}$ mice kept in a 12-h light/12-h dark cycle (LD) and sequentially released in constant darkness (DD) followed by constant light (LL). The day of a 15-min light pulse is indicated with a star. (B) Magnitude of period in constant darkness by $\chi^{2}$ periodogram analysis. (C) Onset error in constant darkness. (D) Magnitude of phase shift after a 15-min light pulse at CT14. (E) Magnitude of period in constant light by $\chi^{2}$ periodogram analysis. All data are shown as mean and SEM and analyzed using a MannWhitney test, ${ }^{*}$ indicates $p<0.05$ tested against wild-type, $n=8$ per genotype.

phenotype (Bunger et al., 2000; Storch et al., 2007) but would clearly require less Cre activity since one Bmal1 allele is already mutated. Such $\mathrm{Syt}_{10} \mathrm{Crel+}^{\mathrm{B}} \mathrm{Ball}^{\mathrm{fl} /-}$ animals have a shorter period in DD compared to wild-type (Fig. 5A,B, Suppl. Fig. S3; $23.5 \mathrm{~h}$ and $22.6 \mathrm{~h}$ in wild-type and Syt10 ${ }^{\mathrm{Cre} / \mathrm{+}} \mathrm{Bmal1}^{\mathrm{fl} / \mathrm{-}}$, respectively; $\left.p=0.0004\right)$. Onset variability analysis revealed that $\mathrm{Syt}_{\mathrm{t}} \mathrm{C}^{\mathrm{Cre/t}} \mathrm{Bmal1}^{\mathrm{fl} /}$ animals have higher onset errors than wild-type controls (Fig. 5C; $0.38 \mathrm{~h}$ and $1.31 \mathrm{~h}$ in wild-type and Syt $10^{\mathrm{Crel+}}$ Bmal1 ${ }^{\mathrm{fl} / \text {, }}$, respectively; $p=0.0024)$. Overall, $S y t 10^{\mathrm{Crel}^{-}} \mathrm{Bmal1}^{\mathrm{fl} / \text { - }}$ animals display impaired activity rhythms but are not completely arrhythmic. This led us to conclude that a single Cre allele is insufficient to produce enough Bmal1-deficient cells in the SCN to result in total circadian arrhythmicity.

We next examined Syt10 ${ }^{\mathrm{Cre} / \mathrm{Cre}} \mathrm{Bmal1}^{\mathrm{fl} / \text { - mice }}$ and did get a fully arrhythmic phenotype (Fig. 5A and Suppl. Fig. S3). Ten of 11 animals were totally arrhythmic in DD; a $\chi^{2}$ periodogram analysis did not reveal any significant circadian rhythmicity. In LD conditions, these mice were still rhythmic; however, in the light phase, they were more active than wild-type controls
(5.3\% and $18.2 \%$ light activity in wild-type and Syt 10 Cre//re Bmal1 $^{f l /}$, respectively; $p=0.046$ ). One best appreciates the extent of the arrhythmic phenotype of $S y t 10^{\mathrm{Cr} / / \mathrm{Cre}}$ Bmal1 $^{f l-}$ mice by a comparison with pan-Bmal1 knockout animals (Syt10 ${ }^{\mathrm{Cre} / \mathrm{Cre}} \mathrm{Bmal1}^{--}$). The phenotype of Syt $10^{\mathrm{Cr} / \mathrm{Cre}} \mathrm{Bmal}^{\mathrm{fl} /}$ is indistinguishable from the Syt $10^{\mathrm{Cr} / / \mathrm{Cre}}$ Bmall $^{-/}$phenotype in LD and in DD (Fig. 5 and Suppl. Fig. S3). Periodograms of both genotypes show no clear circadian peak (Fig. 5A). Thus, the Syt10 ${ }^{\text {Cre/Cre }}$ Bmal1 ${ }^{\text {fl/- }}$ model is a very efficient SCN knock-out and completely mimics the circadian behavioral phenotype of panBmal1 knock-out mice. Overall, the onset variability, a measure for rhythm instability, was progressively increasing with increasing likelihood that both Bmal1 alleles were deleted (Fig. 5C). It has been shown before that in arrhythmic clock mutants, ultradian rhythms can become more prominent (Abraham et al., 2006). We therefore analyzed the periodogram amplitude in the ultradian range (5-10 h) in the different genotypes. Decreasing circadian amplitudes (Fig. 5A) clearly correlated with increasing ultradian amplitudes (Fig. 5D). In summary, the Syt10 Cre evokes a variety of circadian phenotypes ranging from normal rhythmicity to totally arrhythmic phenotypes in a Cre dosage-dependent manner. Increasing the probability of a recombined Bmal1 allele by either using 2 Cre alleles or by working with a $f l-$ background increases the severity of the phenotype, eventually leading to a complete loss of circadian locomotor rhythmicity in Syt $10^{\mathrm{Cre} / \mathrm{Cre}}$ Bmal1 ${ }^{f l /}$ mice.

To examine whether the Cre dose-dependent circadian defects correlate with the amount of Bmal1 expression in the SCN, we quantified Bmal1 mRNA and BMAL1 protein levels in wild-type, Syt10 ${ }^{\mathrm{Cre} / \mathrm{H}} \mathrm{Bmall}^{\mathrm{fl} / \text {, }}$ and Syt10 ${ }^{\mathrm{Cr} / \mathrm{Cre}} \mathrm{Bmal1}^{\mathrm{fl} / \mathrm{-}}$ mice at ZT18, which is the time point of maximal Bmal1 expression in the SCN (Oishi et al., 2000). QPCR analysis of SCN punches revealed a significant reduction of Bmal1 mRNA levels to less than $50 \%$ of wild-type levels in both conditional genotypes (Fig. 6A; $47 \%$ and $40 \%$ in Syt $10^{\mathrm{Crel+}} \mathrm{Bmall}^{\mathrm{fl} / \mathrm{C}}$ and $\mathrm{Syt} 10^{\mathrm{Cre} /}$ ${ }^{C r e} B_{\text {Bmal1 }}^{f l-} ; t$ test; $p=0.0081$ and $p=0.004$, respectively). Differences between Syt10 Cre/+ Bmal1 ${ }^{\mathrm{fl} / \text { - }}$ and Syt10 Cre//re $B_{m a l 1}^{f l /}$ genotypes were not significant. This analysis may underestimate the degree of knock-out in the SCN since SCN punches contain non-SCN tissue in which Bmal1 expression is normal. We thus performed immunohistochemistry with an anti-BMAL1 antiserum (for validation of the anti-BMAL1 immunoreactivity, see Suppl. Fig. S4). A progressive reduction of BMAL1 immunoreactivity with increasing Cre dosage was seen (Fig. 6B). Relative to wild-type, the SCN of Syt10 Cre/t+ Bmal1 $^{f l-}$ mice had a reduction of BMAL1-positive cells 


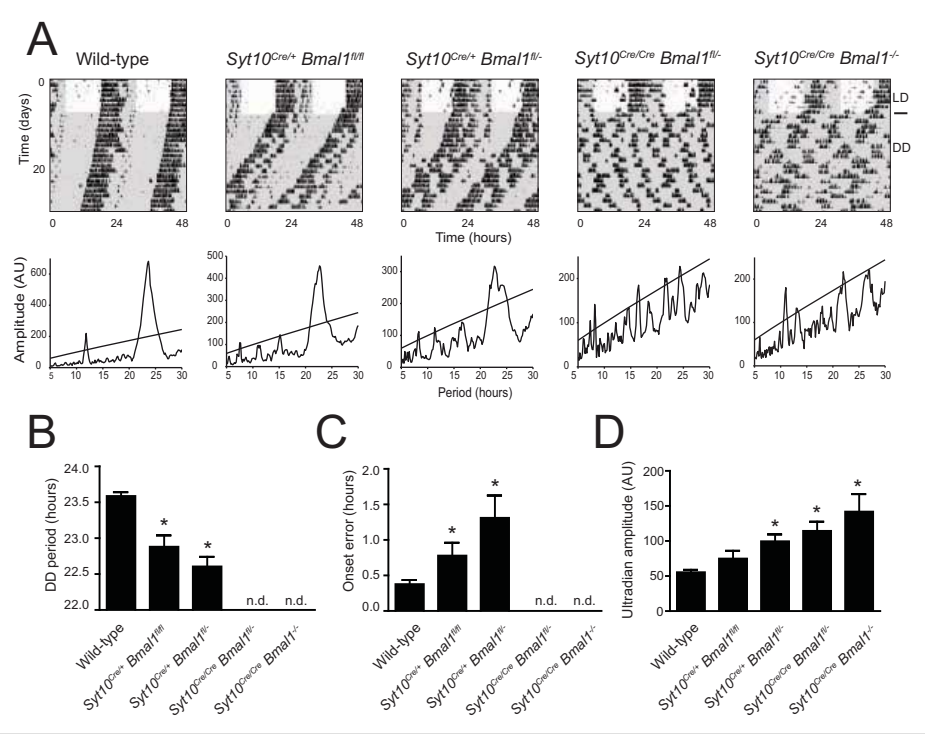

Figure 5. Circadian phenotypes in Syt10 ${ }^{\text {Cre }}$-driven Bmal1 knock-outs. (A) Representative double-plotted actograms and periodograms of wild-type, Syt10 ${ }^{\mathrm{Crel}-\mathrm{H}}$

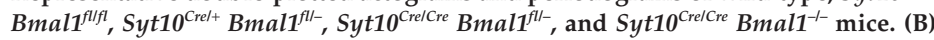
Magnitude of period in DD determined by $\chi^{2}$ periodogram analysis. In Syt10 ${ }^{\mathrm{Cre} / \mathrm{Cre}}$ Bmal1 $^{f l-}$ and Syt10 ${ }^{\mathrm{Cr} / \mathrm{Cre}} \mathrm{Bmal1}^{-1-}$ mice, no circadian rhythmicity was detected (n.d.). (C) Onset error was determined for consecutive 10 days in DD. (D) Amplitudes in the ultradian range $(5-10 \mathrm{~h})$ were calculated from 5 days in DD. All data are shown as mean and SEM and analyzed using a Mann-Whitney test; * indicates $p<0.05$ tested against wild-type.

to $35 \%$, and in the SCN of Syt10 ${ }^{\mathrm{Cr} / / \mathrm{Cre}} \mathrm{Bmal1}^{\mathrm{fl} / \mathrm{-}}$ animals, merely $17 \%$ of the cells expressed BMAL1 (Fig. 6C; $t$ test; $p=0.0012$ and $p=0.0005$, respectively, tested against wild-type). The number of BMAL1-positive cells in Syt10 ${ }^{\mathrm{Cr} / \mathrm{Cre}} \mathrm{Bmall}^{\mathrm{fl} / \mathrm{a}}$ animals was significantly reduced compared to Syt10 $\mathrm{Crel}^{\mathrm{B}+\mathrm{Bmal}} \mathrm{Bm}^{\mathrm{fl}-\mathrm{a}}$ animals (Fig. 6C; $t$ test; $p=0.0077)$. The expression of BMAL1 thus correlated with the behavioral phenotypes of these conditional mutants (see Fig. 5).

\section{DISCUSSION}

The Syt10 ${ }^{\text {Cre }}$ driver mouse line will be useful to delete conditional alleles of clock or other genes that are expressed in the SCN. Cre activity is found only in neuronal tissues and seminiferous tubules of the testis. Cre activity is strong in the vast majority of SCN cells. We demonstrate that knocking out a conditional allele of the essential clock gene Bmal1 using the Syt $10^{\mathrm{Cre}}$ driver renders animals arrhythmic as expected from an efficient SCN clock knock-out. Additionally, we show that the number of BMAL1-positive cells in the SCN correlates with the severity of the behavioral phenotype.
A significant benefit of a knock-in strategy is that it avoids typical problems seen with transgenics such as positional or copy number effects that might complicate an analysis of Cre-mediated effects. By expression of Cre from the Syt10 locus, we achieve Cre activity patterns that are highly similar to the endogenous Syt10 expression pattern. The driver is capable of targeting the majority of SCN cells. The cells that show no Cre-mediated $\beta$-galactosidase signal could be glial cells that are present in the SCN (Van den Pol, 1980) and do not to express Syt10 (Zhang et al., 2004).

Knocking out Syt10 has no major effect on circadian behavior, as the period in constant darkness and the entrainment to light-dark cycles remain unchanged. There is, however, a one-third reduction in the magnitude of light-induced phase delays and a slight decrease in the period in constant light. The fact that circadian impairments in Syt10 ${ }^{\mathrm{Cre}}$ mice are minor may be due to the expression of several other Synaptotagmins in the SCN. The lack of a pronounced circadian phenotype in Syt10 ${ }^{\mathrm{Cre}}$ mice is a prerequisite for making the Syt $10^{\mathrm{Cre}}$ driver line suitable for circadian research.

We observed drastic effects on circadian rhythmicity when the Syt10 Cre driver line is used to delete Bmal1. This result is in line with transplantation experiments and inducible expression of dominant negative CLOCK protein, both of which show that the genotype of the SCN determines locomotor period (Hong et al., 2007; Ko et al., 2010; Ralph et al., 1990; Sujino et al., 2003). Germline deletion of Bmal1 and restoring Bmal1 expression under the Secretogranin 2 promoter in the brain causes not only circadian defects but also a reduction in life span, body weight, and overall activity levels (Bunger et al., 2005; Bunger et al., 2000; McDearmon et al., 2006). Such deficiencies are not seen in Syt10 $\mathrm{Cre} / \mathrm{Cre}$ Bmal1 $1^{\mathrm{fl}-}$ animals, an advantage that will facilitate further analysis of the circadian phenotype of these mice. Lesion and transplantation experiments led to one of the major advances in chronobiological research, the discovery of the $\mathrm{SCN}$ as the master pacemaker of the mammalian brain (Moore and Eichler, 1972; Ralph et al., 1990; Stephan and Zucker, 1972). The chief difference between deleting Bmal1 in the SCN and SCN lesion experiments is that in the former case, the SCN afferent and efferent neuronal connections are not impaired. The fact that SCN 


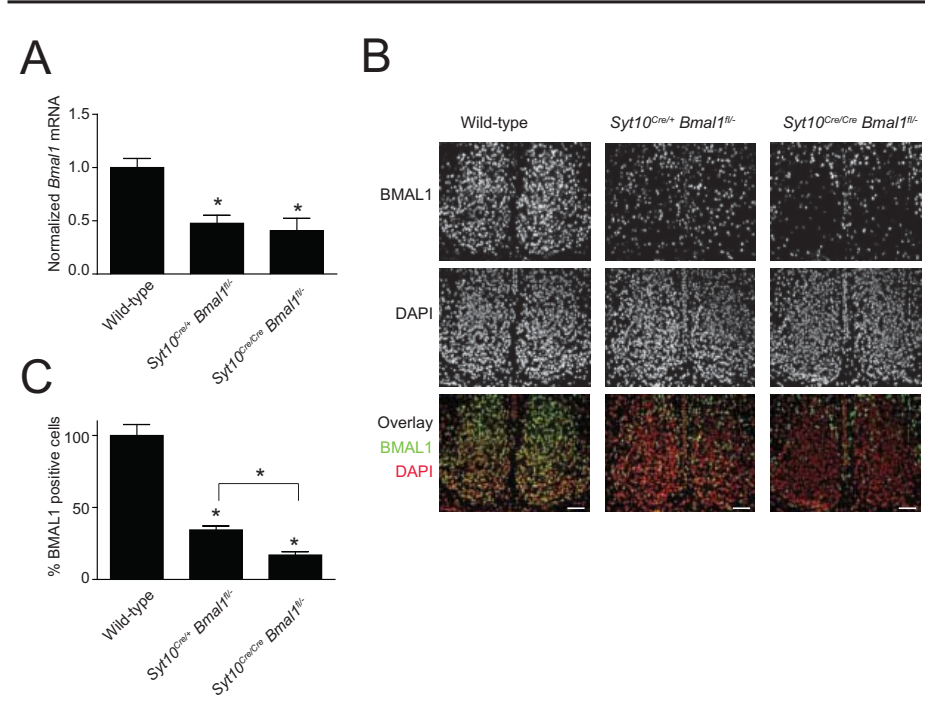

Figure 6. Quantification of Bmal1/BMAL1 levels in the SCN. (A) Relative expression levels of Bmal1 in SCN punches. (B) Representative images of SCN sections immunostained with anti-BMAL1 antibody (top row) and counterstained with DAPI (center). The lower row shows the overlay of BMAL1 immunoreactivity (green) and DAPI (red). Scale bar: $75 \mu \mathrm{m}$. (C) Percentage of BMAL1-positive cells in mutant SCN relative to wild-type. All data are shown as mean and SEM and analyzed using a $t$ test; ${ }^{*}$ indicates $p<0.05$.

afferents and efferents are destroyed in such lesion experiments may complicate experiments investigating the role of neuronal connections between the SCN and the periphery.

We found gene dosage effects in that the number of BMAL1-positive cells in the SCN correlated with behavioral rhythmicity. This is reminiscent of what has been shown for the CLOCK mutation. It was found that the ratio of CLOCK mutant and wild-type cells in the SCN correlated with behavioral rhythmicity (LowZeddies and Takahashi, 2001). The ability to evoke gene deletion in a graded manner should be informative when examining how clock gene dosage in the SCN affects circadian rhythmicity or the expression of other (clock) genes. The benefit of such titrating experiments has also been demonstrated in a recent elegant in vitro study (Baggs et al., 2009). These authors downregulated clock genes in a dose-dependent manner by adding different amounts of small interfering RNAs to human osteosarcoma cells. This led them to uncover novel network features of the circadian timing system. In the context of a recent study showing stochastic rhythmicity in complete Bmal1 knock-out mice (Ko et al., 2010), it will be interesting to investigate whether and how a stepwise reduction of Bmal1 in the SCN affects oscillations of SCN neuronal networks.

The currently known canonical clock genes are not required for viability. However, it would not come as a surprise if yet unknown clock genes existed that are also required for a range of noncircadian functions, including viability. Potential examples are Creb or Glycogen synthase kinase-3ß (Iitaka et al., 2005; Obrietan et al., 1999). In such cases, the Syt10 ${ }^{\text {Cre }}$ driver mouse can be useful to overcome lethality and produce mice suitable for circadian analysis.

When using the Syt $10^{\text {Cre }}$ driver line, one should consider the following points: First, the efficiency of Cre-mediated homologous recombination might vary depending on the targeted allele used. It has been shown that the exact location and distance between two loxP sites can affect recombination efficacy (Zheng et al., 2000). Thus, deletion of other conditional gene alleles might require less $\mathrm{Cre}$ to elicit a full penetrance of phenotype than in the case of Bmal1 ${ }^{f l / f l}$. Hence, Syt10 Cre/t and Syt10 Cre//re should be compared with respect to their recombination efficiency. Second, only females (and not males) that are carriers for Syt $10^{\mathrm{Cre}}$ and the conditional allele of interest must be used for breeding. Otherwise, germline deletion of the conditional allele will occur, and all cells in the body will be deficient for the gene of interest. A guide for breeding strategies using the Syt $10^{\text {Cre }}$ is found in Supplementary Table S1. A caveat with using Syt10 ${ }^{\mathrm{Cre}}$ in combination with a mouse in which one of the targeted alleles has already been removed (e.g., Bmal1 ${ }^{f /-}$ ) is that the heterozygous targeted animal may already have a phenotype. In summary, we believe that our Syt10 Cre line will be a helpful tool to investigate the complexity of the mammalian circadian network.

\section{ACKNOWLEDGMENTS}

We thank Axel Visel and Christina Thaller for their early work on expression patterns of Synaptotagmins. We thank Johanna Barclay for helpful comments on the manuscript. H.O. is an Emmy Noether Fellow of the German Research Foundation (DFG). 


\section{CONFLICT OF INTEREST STATEMENT}

The author(s) have no potential conflicts of interest with respect to the research, authorship, and/or publication of this article.

\section{NOTE}

Supplementary online material for this article is available on the Journal of Biological Rhythms website at http://jbr.sagepub.com/supplemental.

\section{REFERENCES}

Abarca C, Albrecht U, and Spanagel R (2002) Cocaine sensitization and reward are under the influence of circadian genes and rhythm. Proc Natl Acad Sci U S A 99:9026-9030.

Abraham D, Dallmann R, Steinlechner S, Albrecht U, Eichele G, and Oster H (2006) Restoration of circadian rhythmicity in circadian clock-deficient mice in constant light. J Biol Rhythms 21:169-176.

Baggs JE, Price TS, DiTacchio L, Panda S, Fitzgerald GA and Hogenesch JB (2009) Network features of the mammalian circadian clock. PLoS Biol 7:e52.

Balsalobre A, Damiola F, and Schibler U (1998) A serum shock induces circadian gene expression in mammalian tissue culture cells. Cell 93:929-937.

Benloucif S and Dubocovich ML (1996) Melatonin and light induce phase shifts of circadian activity rhythms in the C3H/HeN mouse. J Biol Rhythms 11:113-125.

Bunger MK, Walisser JA, Sullivan R, Manley PA, Moran SM, Kalscheur VL, Colman RJ, and Bradfield CA (2005) Progressive arthropathy in mice with a targeted disruption of the Mop3/Bmal-1 locus. Genesis 41:122-132.

Bunger MK, Wilsbacher LD, Moran SM, Clendenin C, Radcliffe LA, Hogenesch JB, Simon MC, Takahashi JS, and Bradfield CA (2000) Mop3 is an essential component of the master circadian pacemaker in mammals. Cell 103:1009-1017.

Daan S and Pittendrigh CS (1976) A functional analysis of circadian pacemakers in nocturnal rodents. J Comp Physiol A Neuroethol Sens Neural Behav Physiol 106:253-266.

Dibner C, Schibler U, and Albrecht U (2010) The mammalian circadian timing system: Organization and coordination of central and peripheral clocks. Annu Rev Physiol 72:517-549.

Farley FW, Soriano P, Steffen LS, and Dymecki SM (2000) Widespread recombinase expression using FLPeR (flipper) mice. Genesis 28:106-110.

Garcia JA, Zhang D, Estill SJ, Michnoff C, Rutter J, Reick M, Scott K, Diaz-Arrastia R, and McKnight SL (2000) Impaired cued and contextual memory in NPAS2deficient mice. Science 288:2226-2230.

Gustavsson N and Han W (2009) Calcium-sensing beyond neurotransmitters: Functions of synaptotagmins in neuroendocrine and endocrine secretion. Biosci Rep 29:245-259.

Hong HK, Chong JL, Song W, Song EJ, Jyawook AA, Schook AC, Ko CH, and Takahashi JS (2007) Inducible and reversible Clock gene expression in brain using the tTA system for the study of circadian behavior. PLoS Genet 3:e33.

Iitaka C, Miyazaki K, Akaike T, and Ishida N (2005) A role for glycogen synthase kinase-3beta in the mammalian circadian clock. J Biol Chem 280:29397-29402.

Jud C, Schmutz I, Hampp G, Oster H, and Albrecht U (2005) A guideline for analyzing circadian wheel-running behavior in rodents under different lighting conditions. Biol Proced Online 7:101-116.

Kiessling S, Eichele G, and Oster H (2010) Adrenal glucocorticoids have a key role in circadian resynchronization in a mouse model of jet lag. J Clin Invest 120: 2600-2609.

Ko CH and Takahashi JS (2006) Molecular components of the mammalian circadian clock. Hum Mol Genet 15(Suppl 2):R271-R277.

Ko CH, Yamada YR, Welsh DK, Buhr ED, Liu AC, Zhang EE, Ralph MR, Kay SA, Forger DB, and Takahashi JS (2010) Emergence of noise-induced oscillations in the central circadian pacemaker. PLoS Biol 8:e1000513.

Lamia KA, Storch KF, and Weitz CJ (2008) Physiological significance of a peripheral tissue circadian clock. Proc Natl Acad Sci U S A 105:15172-15177.

Lein ES, Hawrylycz MJ, Ao N, Ayres M, Bensinger A, Bernard A, Boe AF, Boguski MS, Brockway KS, Byrnes EJ, et al. (2007) Genome-wide atlas of gene expression in the adult mouse brain. Nature 445:168-176.

Liu P, Jenkins NA, and Copeland NG (2003) A highly efficient recombineering-based method for generating conditional knockout mutations. Genome Res 13:476-484.

Lobe CG, Koop KE, Kreppner W, Lomeli H, Gertsenstein M, and Nagy A (1999) Z/AP, a double reporter for cremediated recombination. Dev Biol 208:281-292.

Low-Zeddies SS and Takahashi JS (2001) Chimera analysis of the Clock mutation in mice shows that complex cellular integration determines circadian behavior. Cell 105:25-42.

Marcheva B, Ramsey KM, Buhr ED, Kobayashi Y, Su H, Ko CH, Ivanova G, Omura C, Mo S, Vitaterna MH, et al. (2010) Disruption of the clock components CLOCK and BMAL1 leads to hypoinsulinaemia and diabetes. Nature 466:627-631.

McDearmon EL, Patel KN, Ko CH, Walisser JA, Schook AC, Chong JL, Wilsbacher LD, Song EJ, Hong HK, Bradfield CA, et al. (2006) Dissecting the functions of the mammalian clock protein BMAL1 by tissue-specific rescue in mice. Science 314:1304-1308.

Moore RY and Eichler VB (1972) Loss of a circadian adrenal corticosterone rhythm following suprachiasmatic lesions in the rat. Brain Res 42:201-206.

Obrietan K, Impey S, Smith D, Athos J, and Storm DR (1999) Circadian regulation of cAMP response elementmediated gene expression in the suprachiasmatic nuclei. J Biol Chem 274:17748-17756.

Oishi K, Fukui H, and Ishida N (2000) Rhythmic expression of BMAL1 mRNA is altered in Clock mutant mice: 
Differential regulation in the suprachiasmatic nucleus and peripheral tissues. Biochem Biophys Res Commun 268:164-171.

Oster H, Damerow S, Kiessling S, Jakubcakova V, Abraham D, Tian J, Hoffmann MW, and Eichele G (2006) The circadian rhythm of glucocorticoids is regulated by a gating mechanism residing in the adrenal cortical clock. Cell Metab 4:163-173.

Ralph MR, Foster RG, Davis FC, and Menaker M (1990) Transplanted suprachiasmatic nucleus determines circadian period. Science 247:975-978.

Sakurai Y, Ohgimoto K, Kataoka Y, Yoshida N, and Shibuya M (2005) Essential role of Flk-1 (VEGF receptor 2) tyrosine residue 1173 in vasculogenesis in mice. Proc Natl Acad Sci US A 102:1076-1081.

Shimshek DR, Kim J, Hubner MR, Spergel DJ, Buchholz F, Casanova E, Stewart AF, Seeburg PH, and Sprengel $\mathrm{R}$ (2002) Codon-improved Cre recombinase (iCre) expression in the mouse. Genesis 32:19-26.

Soriano P (1999) Generalized lacZ expression with the ROSA26 Cre reporter strain. Nat Genet 21:70-71.

Stephan FK and Zucker I (1972) Circadian rhythms in drinking behavior and locomotor activity of rats are eliminated by hypothalamic lesions. Proc Natl Acad Sci U S A 69:1583-1586.

Storch KF, Paz C, Signorovitch J, Raviola E, Pawlyk B, Li T, and Weitz CJ (2007) Intrinsic circadian clock of the mammalian retina: Importance for retinal processing of visual information. Cell 130:730-741.

Sujino M, Masumoto KH, Yamaguchi S, van der Horst GT, Okamura H, and Inouye ST (2003) Suprachiasmatic nucleus grafts restore circadian behavioral rhythms of genetically arrhythmic mice. Curr Biol 13:664-668.

Tosini G and Menaker M (1996) Circadian rhythms in cultured mammalian retina. Science 272:419-421.

Turek FW, Joshu C, Kohsaka A, Lin E, Ivanova G, McDearmon E, Laposky A, Losee-Olson S, Easton A, Jensen DR, et al. (2005) Obesity and metabolic syndrome in circadian Clock mutant mice. Science 308:1043-1045.

Van den Pol AN (1980) The hypothalamic suprachiasmatic nucleus of rat: intrinsic anatomy. J Comp Neurol 191:661-702.

van der Horst GT, Muijtjens M, Kobayashi K, Takano R, Kanno S, Takao M, de Wit J, Verkerk A, Eker AP, van Leenen D, et al. (1999) Mammalian Cry1 and Cry2 are essential for maintenance of circadian rhythms. Nature 398:627-630.

Visel A, Carson J, Oldekamp J, Warnecke M, Jakubcakova V, Zhou X, Shaw CA, Alvarez-Bolado G, and Eichele G (2007) Regulatory pathway analysis by high-throughput in situ hybridization. PLoS Genet 3:1867-1883.

Vitaterna MH, King DP, Chang AM, Kornhauser JM, Lowrey PL, McDonald JD, Dove WF, Pinto LH, Turek FW, and Takahashi JS (1994) Mutagenesis and mapping of a mouse gene, Clock, essential for circadian behavior. Science 264:719-725.

Yamazaki S, Numano R, Abe M, Hida A, Takahashi R, Ueda M, Block GD, Sakaki Y, Menaker M, and Tei H (2000) Resetting central and peripheral circadian oscillators in transgenic rats. Science 288:682-685.

Yaylaoglu MB, Titmus A, Visel A, Alvarez-Bolado G, Thaller C, and Eichele G (2005) Comprehensive expression atlas of fibroblast growth factors and their receptors generated by a novel robotic in situ hybridization platform. Dev Dyn 234:371-386.

Yoo SH, Yamazaki S, Lowrey PL, Shimomura K, Ko CH, Buhr ED, Siepka SM, Hong HK, Oh WJ, Yoo OJ, et al. (2004) PERIOD2::LUCIFERASE real-time reporting of circadian dynamics reveals persistent circadian oscillations in mouse peripheral tissues. Proc Natl Acad Sci U S A 101:5339-5346.

Zhang Q, Fukuda M, Van Bockstaele E, Pascual O, and Haydon PG (2004) Synaptotagmin IV regulates glial glutamate release. Proc Natl Acad Sci U S A 101: 9441-9446.

Zheng B, Albrecht U, Kaasik K, Sage M, Lu W, Vaishnav S, Li Q, Sun ZS, Eichele G, Bradley A, et al. (2001) Nonredundant roles of the mPer1 and mPer2 genes in the mammalian circadian clock. Cell 105: 683-694.

Zheng B, Larkin DW, Albrecht U, Sun ZS, Sage M, Eichele G, Lee CC, and Bradley A (1999) The mPer2 gene encodes a functional component of the mammalian circadian clock. Nature 400:169-173.

Zheng B, Sage M, Sheppeard EA, Jurecic V, and Bradley A (2000) Engineering mouse chromosomes with Cre-loxP: Range, efficiency, and somatic applications. Mol Cell Biol 20:648-655. 


\subsection{The SCN clock is dispensable for light entrainment of peripheral clocks}

\subsubsection{The hierarchical structure of the mammalian circadian timing system}

It is a widely held view that the mammalian circadian timing system is organized in a hierarchical manner with a master clock in the SCN and subordinated clocks in other brain areas and peripheral tissues. Evidence for this comes mostly from SCN lesion studies, which showed that in the absence of the SCN rhythms at all levels are lost, spanning locomotor activity (Stephan and Zucker, 1972; Lehman et al., 1987; Ralph et al., 1990; Sujino et al., 2003), drinking behavior (Stephan and Zucker, 1972), body temperature (Refinetti et al., 1994; Scheer et al., 2005), heart rate (Scheer et al., 2005), release of hormones such as corticosterone and melatonin (Moore and Eichler, 1972; Meyer-Bernstein et al., 1999; Sage et al., 2001) as well as gene expression rhythms in peripheral tissues (Akhtar et al., 2002; Guo et al., 2005; Guo et al., 2006).

Importantly the SCN seems not only necessary for sustained peripheral rhythmicity in constant darkness (DD) but also during light dark (LD) conditions. Most studies show that locomotor activity is not synchronized to the LD cycle after SCN lesions, indicating that masking (e.g. the acute suppressing effect of light on locomotor activity) is lost in the absence of the SCN (Stephan and Zucker, 1972; Ibuka et al., 1977; Aguilar-Roblero et al., 1986; Lehman et al., 1987; Sujino et al., 2003). For simplification we will use the term masking for rhythms that are directly lightcontrolled and not controlled by an endogenous clock in the remainder of the text. In addition, corticosterone release is arrhythmic in LD conditions (Moore and Eichler, 1972; Sage et al., 2001) and no rhythmic clock gene expression is detectable in SCN lesioned animals in LD (Sakamoto et al., 1998; Hara et al., 2001; Terazono et al., 2003). Interestingly, SCN transplants, which re-initiate hormonal but not neuronal output from the $\mathrm{SCN}$, rescue some peripheral rhythms but not others in DD: corticosterone rhythms are not rescued and thus seem to depend on functional neuronal connections from the SCN (Meyer-Bernstein et al., 1999). Gene expression rhythms in peripheral tissues are restored in liver and kidney, but not in heart and spleen (Guo et al., 2005; Guo et al., 2006). Thus it seems that neuronal connections are necessary to synchronize at least some peripheral rhythms and autonomic connections between the SCN and many peripheral organs have been demonstrated (Moore and Eichler, 1972; Larsen et al., 1998; Gerendai and Halasz, 2000; Buijs et al., 2003; Engeland and Arnhold, 2005; Bando et al., 2007; Vujovic et al., 2008). For the adrenal trans-neuronal tracings demonstrated that signals from the SCN are transmitted to the PVN, which transmits information to the intermedio-lateral column (IML) of the spinal cord, from which then the adrenal cortex is innervated (Buijs et al., 1999). Thus the SCN is connected to the adrenal cortex via 3 synapses. A similar polysynaptic pathway has been shown for the connection between SCN and liver (la Fleur et al., 2000). Stimulation of the SCN electrical activity can modulate the activity of sympathetic nerves (Nishino et al., 1976).

Light can directly activate Period gene expression in the adrenal via sympathetic innervation by the splanchnic nerve (Ishida et al., 2005). This rapid Period induction is followed by increased corticosterone release. Interestingly, these direct effects of light on the adrenal are time of day 
dependent and this gating mechanism is lost after SCN lesion, suggesting that neuronal signals from the SCN are involved in synchronizing peripheral clocks to the light dark cycle (Ishida et al., 2005). In line with this, adrenal denervation leads to arrhythmic corticosterone release in LD conditions (Ottenweller et al., 1978; Ottenweller and Meier, 1982; Jasper and Engeland, 1994). Similar results have been described for autonomous innervation of the liver (Terazono et al., 2003; Cailotto et al., 2009). Destruction of autonomous innervation of the liver leads to arrhythmic hepatic clock gene expression suggesting that neuronal signals are necessary for the liver clock to synchronize to the LD cycle (Terazono et al., 2003). In summary, these experiments suggest that neuronal signals from the $\mathrm{SCN}$ are involved in the synchronization of peripheral clocks to the light dark cycle. Thus, to investigate the question of the role of the SCN clock in gating light signals to the periphery a model is necessary in which the SCN clock is disrupted but neuronal connections are left intact. We have previously described a mouse model which meets these criteria. We used a Synaptotagmin 10 (Syt10) driven Cre driver mouse to knock-out Bmal1 in the SCN (Syt10 $\left.{ }^{\text {Cre/cre }} B m a l 1^{f /-}\right)$ and verified the efficiency of the knock-out (Husse et al., 2011). We decided to use these Syt $10^{\text {Cre/Cre }} B m a l 1^{f l-}$ mice to investigate the effect of the SCN clock on clock gene expression rhythms in peripheral tissues. Of note, the Syt10 $0^{\text {cre }}$ driver is not active in peripheral tissues except for testis, and thus peripheral clocks are equipped with the complete molecular machinery to generate rhythms. 


\subsubsection{No evidence for clock-driven behavior in Syt10 ${ }^{\mathrm{Cre} / \mathrm{Cre}} \mathrm{Bmal1}{ }^{\mathrm{fl}-}$ mice}

We had shown previously that Syt $10^{\text {cre/Cre }} \mathrm{Bmal1}^{\mathrm{fl} /-}$ mice are arrhythmic in DD and behaviorally undistinguishable from Bmal1 ${ }^{--}$mice (Husse et al., 2011). In LD conditions, however, the former mice are still rhythmic which is probably due to masking effects and not to residual rhythmic SCN output. To obtain further evidence that LD locomotor behavior in Syt $10^{\mathrm{Cre} / \mathrm{Cre}} \mathrm{Bmal}^{\mathrm{fl} / \mathrm{-}}$ mice is indeed light-driven and not clock-driven, we performed additional wheel running analyses. It has been reported previously that some clock mutants, which show arrhythmic locomotor activity in DD, can sustain rhythmicity in LL (Steinlechner et al., 2002; Abraham et al., 2006). Thus we tested locomotor activity of Syt10 ${ }^{\text {Cre/Cre }} \mathrm{Bmal}^{\mathrm{fl}-\text { - }}$ mice in constant light (LL, $100 \mathrm{lux}$ ).

A
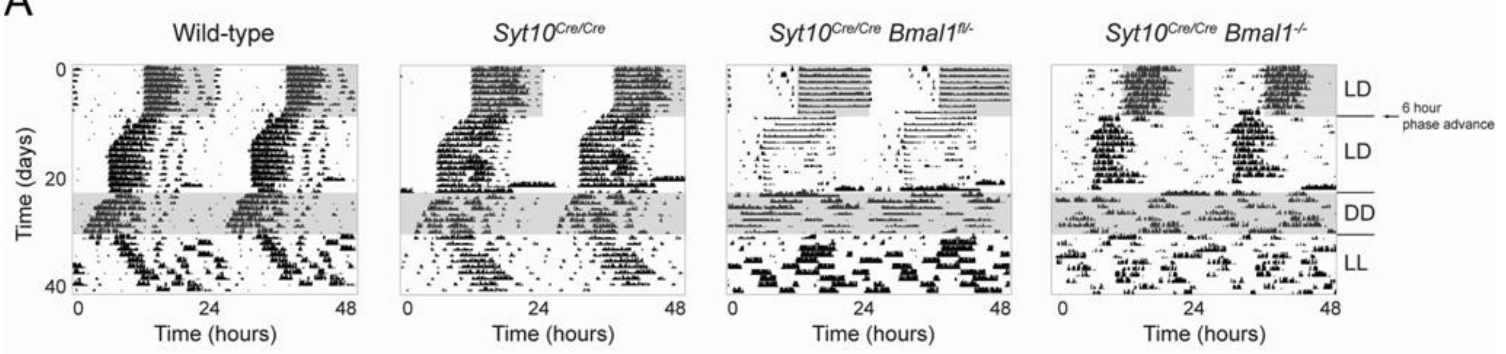

B
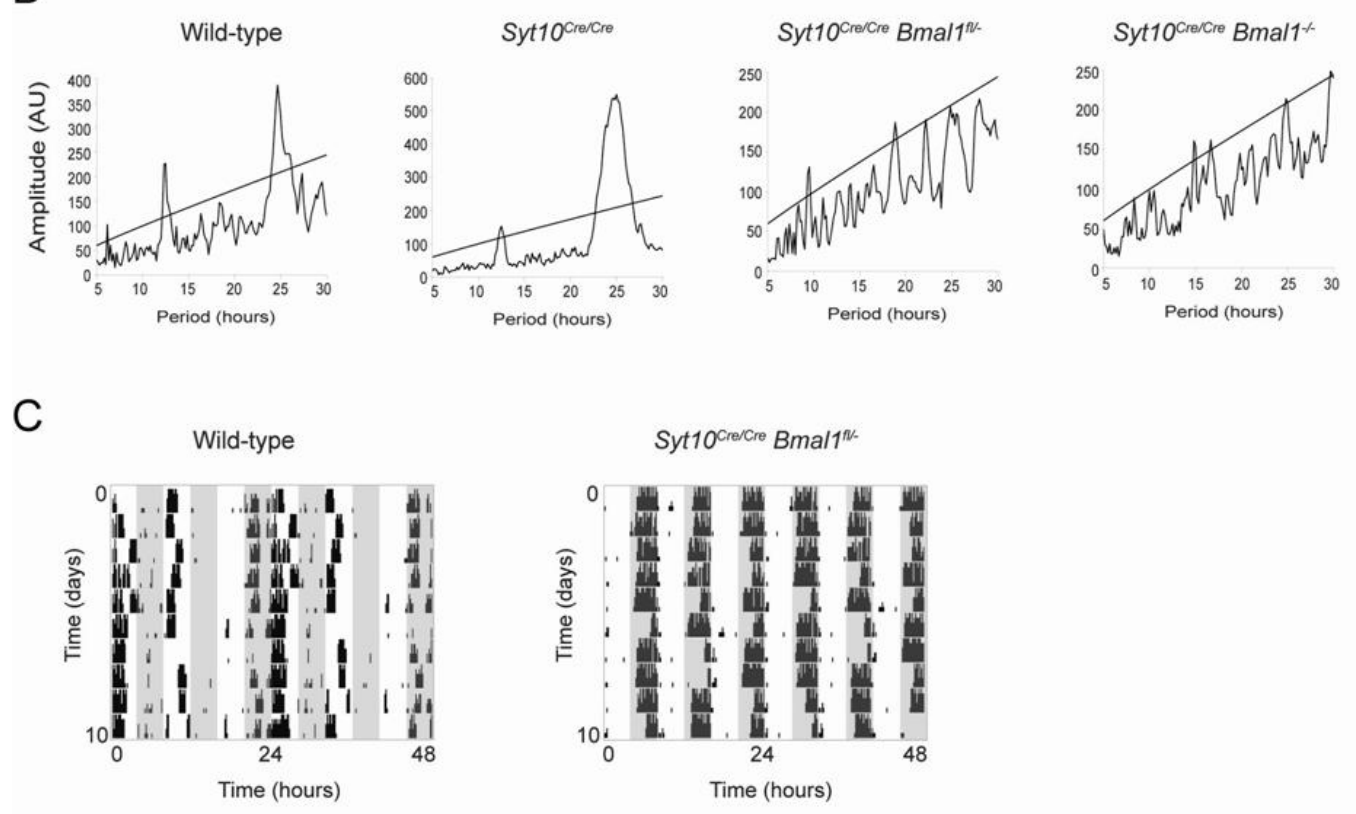

Figure 6: Behaviorally, Syt10 ${ }^{\mathrm{Cre} / \mathrm{Cre}} \mathrm{Bmali}^{\mathrm{fl} / \text { - }}$ mice are not clock- but light-driven.

Syt $10^{\text {Cre/Cre }} \mathrm{Bmal}^{\mathrm{fl} / \mathrm{-}}$ and control mice were analyzed in light dark (LD) conditions, in a 6 hour phase advance paradigm (jet lag), under constant darkness (DD) and constant light (LL) conditions. Representative double plotted actograms are shown in A. Analysis of LD and DD behavior has been described earlier (Husse et al., 2011). Rhythmicity in LL was analyzed using $\chi 2$ periodogram analysis (B). The phenotype of Syt10 cre/cre

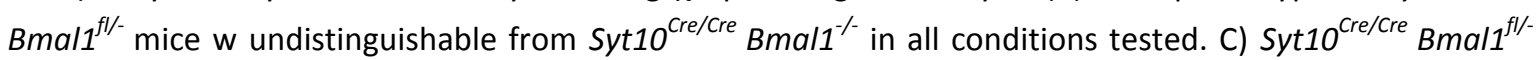
and wild-type control mice were subjected to a 4 hour light 4 hour dark T cycle (T-cycle actograms were kindly provided by Anton Shostak). 


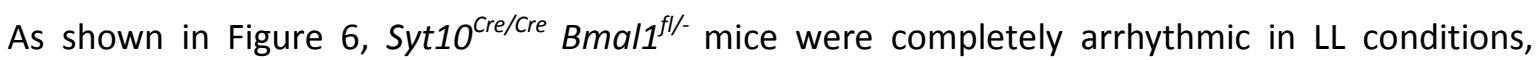
whereas control wild-type and Syt10 $0^{\text {Cre/Cre }}$ mice shoed robust rhythmicity (Fig. 6A,B). Periodogram analysis revealed that Syt $10^{\mathrm{Cre} / \mathrm{Cre}} \mathrm{Bmal} \mathbf{1}^{\mathrm{fl} /-}$ mice showed no clear circadian peak and were thus considered arrhythmic in the circadian range. Importantly, the phenotype of Syt $10^{\mathrm{Cre} / \mathrm{Cre}} \mathrm{BmalI^{ \textrm {fl } - }}$

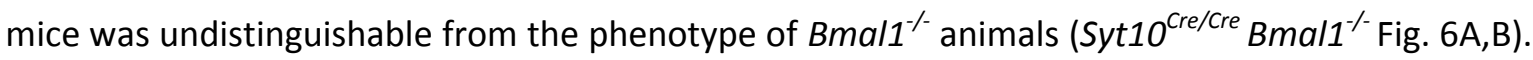
Syt10 ${ }^{\text {Cre/Cre }} \mathrm{Bmal} 1^{\mathrm{fl} / \text { - }}$ mice were further subjected to a 6-hour phase advance of the light-dark cycle (experimental jet lag). A transient adaptation of activity rhythms to such rapidly changed external phase would indicate that an internal clock mechanism prevents rapid synchronization to the new LD cycle. The control mice took 6-8 days to adapt their behavioral activity to the new LD cycle which is in line with previous results (Kiessling et al., 2010). In contrast, Syt10 ${ }^{\mathrm{Cr} / \mathrm{Cre}} \mathrm{Bmal} 1^{\mathrm{fl} / \text { - }}$ mice as well as Bmal1 ${ }^{-1}$ animals adapted their activity to the new light dark cycle immediately on the first day after the shift, suggesting that behavioral rhythmicity in LD is directly under the control of light (masked) and not of an endogenous clock (Fig. 6A). In all conditions tested, the phenotype of Syt $10^{\mathrm{Cre} / \mathrm{Cre}}$ mice was not different from wild-type mice, indicating that the deletion of Syt10 had no effect on wheel-running behavior. This result is slightly different from what we had reported previously (Husse et al., 2011): homozygous Syt $10^{\text {cre/cre }}$ mice had a slightly but significantly shorter period in LL accompanied by a reduced phase shift response to a light pulse. We believe that these minor differences are due to genetic background effects, since the mice tested in this study had been backcrossed to $\mathrm{C57BL} / 6$, whereas the mice tested in the first published study were on a mixed C57BL/6; Sv129 background. Finally we subjected Syt10 $0^{\mathrm{Cre} / \mathrm{Cre}} \mathrm{Bmal}{ }^{\mathrm{fl} /-}$ mice to short T cycles of 4 hour light and 4 hour darkness, resulting in 3 dark and 3 light phases per day. Short T cycles can be used to differentiate between masking and entrainment effects: entrainment would result in activity confined to 2 of the 3 dark periods and thus a diurnal activity rhythm overlaid with masking bouts of inactivity during the light phases, whereas the absence of a clock would result in equally distributed activity bouts between all 3 dark phases, based exclusively on masking effects. Syt $10^{\text {Cre/cre }} \mathrm{Bmal} \mathrm{f}^{\mathrm{fl}-}$ mice were equally active in all 3 dark phases which strongly speaks for masking and not for entrainment (Fig. 6C). Thus, masking is preserved in the absence of an SCN clock, but no evidence for clock-driven behavior is found in Syt $10^{\mathrm{Cre} / \mathrm{Cre}} \mathrm{Bmal1}^{\mathrm{fl}-\text { mice. }}$

\subsubsection{Arrhythmic clock gene expression in the SCN of Syt10 ${ }^{\mathrm{Cre} / \mathrm{Cre}} \mathrm{Bmal1}^{\mathrm{fl}-}$ mice in DD}

We have shown previously that in $\mathrm{Syt} 10^{\mathrm{Cr} / / \mathrm{Cre}} \mathrm{Bmal1^{ \textrm {fl } / - }}$ mice the majority of SCN cells are depleted of BMAL1 protein (Husse et al., 2011) which we expect to result in a breakdown of the molecular clockwork in the SCN. To confirm the disruption of the SCN clock on the molecular level, we analyzed clock gene expression rhythms in the SCN of Syt $10^{\mathrm{Cre} / \mathrm{Cre}} \mathrm{Bmal1}{ }^{\mathrm{fl} /-}$ and Syt $10^{\mathrm{Cre} / \mathrm{Cre}} \mathrm{Bmal}{ }^{+/-}$ (control) animals on the second day in DD by radioactive in situ hybridization. Rhythms in Dbp and

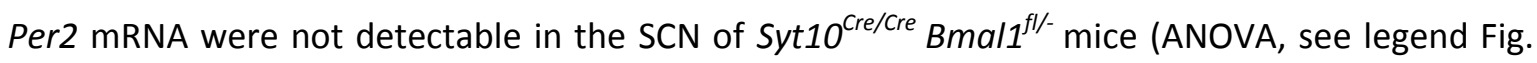
7). Expression of both genes was down-regulated in the knock-out mice at all time points and also higher resolution imaging after emulsion dipping did not reveal any single cells that still show increased levels of Dbp or Per2 expression (Fig. 7B-C, E-F). We conclude that also on the molecular level there is no evidence for residual rhythmicity in the $\mathrm{SCN}$ of Syt $10^{\mathrm{Cre} / \mathrm{Cre}} \mathrm{Bmal}^{\mathrm{fl} / \text { - }}$ mice. 
A

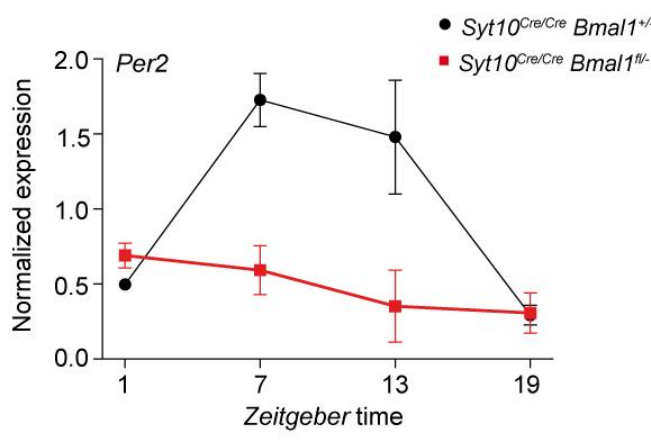

B

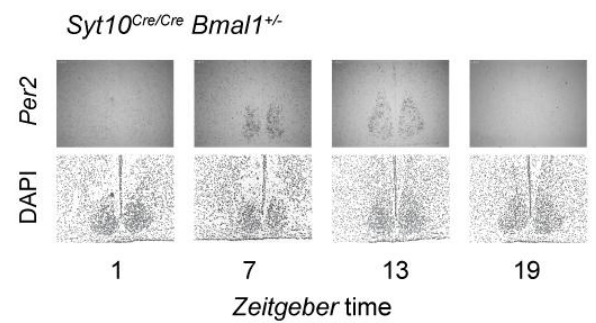

C

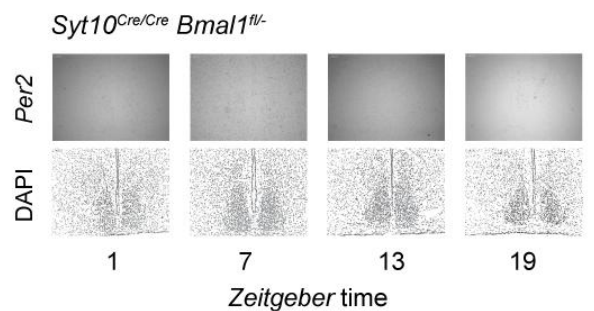

D

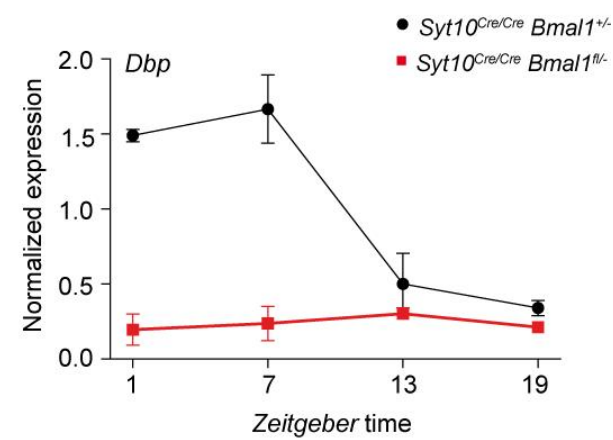

E

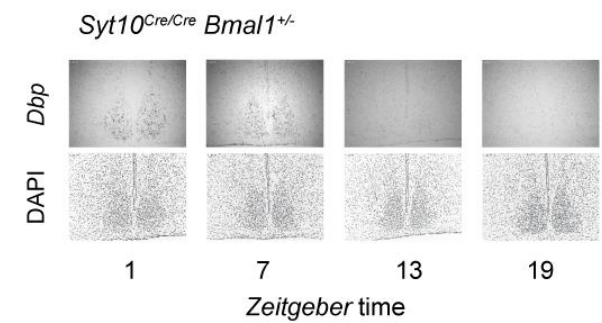

$\mathrm{F}$

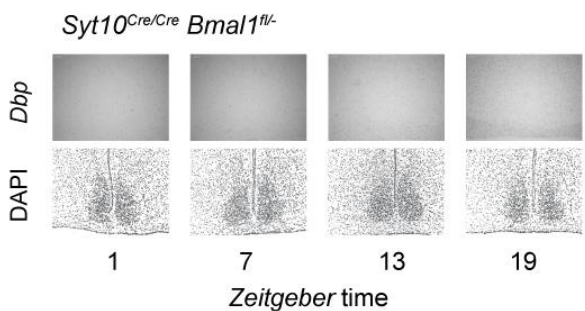

Figure 7: Clock gene rhythms are lost in Syt10 ${ }^{\mathrm{Cre} / \mathrm{Cre}} \mathrm{Bmal1}^{\mathrm{fl} / \mathrm{SCN}}$ SC in DD.

Clock gene expression in the SCN was measured by radioactive in situ hybridization on the second day in DD. Quantification (A) and representative in situ and DAPI pictures (B, C) for Per2 and Dbp (D-F). 3 mice were analyzed per genotype at each time point. Data are shown as mean $+/$ - SEM. ANOVA analysis revealed significant changes over time for controls (Syt10 ${ }^{\text {Cre/Cre }} \mathrm{Bmal1}^{+-} ; \mathrm{p}=0.0031$ for Per2 and $\mathrm{p}=0.0006$ for Dbp),

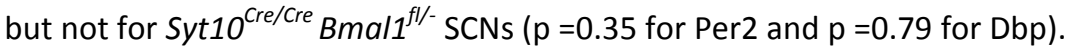

\subsubsection{Corticosterone is rhythmic but dampened in $\mathrm{Syt} 10^{\mathrm{Cre} / \mathrm{Cre}} \mathrm{Bmal1}^{\mathrm{fl} /-}$ mice}

After having obtained evidence for SCN arrhythmicity on the behavioral (wheel running) and molecular level (in situ hybridization), we aimed at analyzing peripheral rhythms. Corticosterone is rhythmically released from the adrenal and this rhythm seems to be both systemically controlled by the SCN as well as locally by the adrenal clock (Oster et al., 2006b). SCN lesion studies, however, showed that the rhythm of corticosterone is abolished in the absence of the SCN (Moore and Eichler, 1972; Sage et al., 2001). To investigate whether this effect is due to the absence of the SCN neurons (and therefore disruption of the light entrainment pathway to the periphery) or whether the deletion of the molecular clock in the SCN would be sufficient, we measured corticosterone rhythms in Syt $10^{\mathrm{Cre} / \mathrm{Cre}} \mathrm{Bmal1}^{\mathrm{fl} / \text { - }}$ and Syt10 $0^{\mathrm{Cre} / \mathrm{Cre}} \mathrm{Bmal1}^{+/-}$(control) animals. We extracted corticosterone from faeces samples collected at 4-hour intervals. The advantage of 
this non-invasive method is that individual animals can be measured over a long time in animals whose clock is monitored by running wheel activity. We measured corticosterone rhythms first in LD and followed its rhythm upon release of the animal into DD.

A

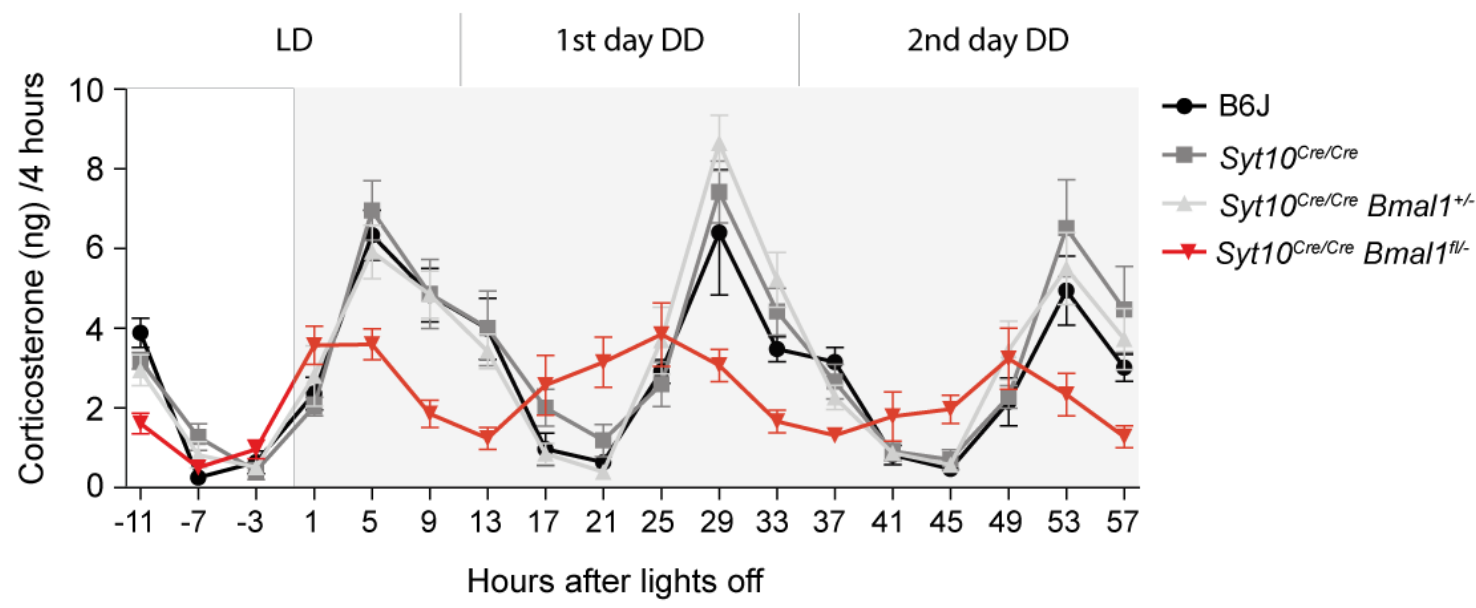

B Syt10 cre/cre Bmal1 $1^{\text {thl }}$

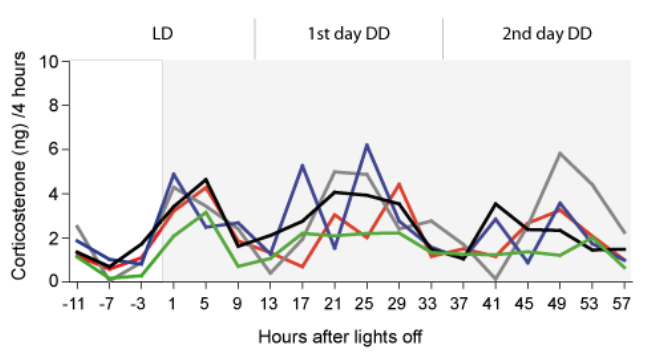

C Syt10 cre/cre Bmal1 ${ }^{\text {+1- }}$

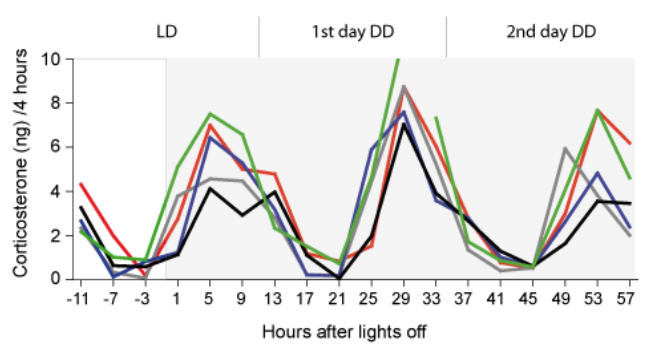

Figure 8: Corticosterone rhythms are dampened in Syt10 ${ }^{\mathrm{Cre} / \mathrm{Cre}} \mathrm{Bmal1}^{\mathrm{fl}-\mathrm{m}}$ mice.

Corticosterone from faecal extracts collected at 4-hour intervals was analyzed for one day in LD and the first two days in DD. A) Syt $10^{\mathrm{Cre} / \mathrm{Cre}} \mathrm{Bmal1}{ }^{\mathrm{fl} /-}$ mice were compared to B6J, Syt $10^{\mathrm{Cre} / \mathrm{Cre}}$ and Syt $10^{\mathrm{Cre} / \mathrm{Cre}} \mathrm{Bmal1^{+/- }}$ mice. 5 mice per genotype were analyzed (for B6J only 3 mice were analyzed). Data are shown as mean +/- SEM. ANOVA analysis on single days (LD, DD day $1, D D$ day 2 ) revealed changes of corticosterone levels over time for all days and genotypes with the exception of day 2 in DD for Syt $10^{\mathrm{Cre} / \mathrm{Cre}} \mathrm{Bmal} 1^{\mathrm{fl} / \text { - }}$ mice $(p=0.09)$. Plotting data for individual animals for Syt $10^{\mathrm{Cre} / \mathrm{Cre}} \mathrm{Bmal1}^{\mathrm{fl} /-}$ (B) and $S y t 10^{\mathrm{Cre} / \mathrm{Cre}} \mathrm{Bmal1}^{+/-}$(C) showed substantial desynchrony not only between animals but also within individuals Syt10 ${ }^{\mathrm{Cre} / \mathrm{Cre}} \mathrm{Bmal} 1^{\mathrm{fl} / \text { - }}$ mice.

Wild-type as well as Syt10 $10^{\text {Cre/Cre }}$ mice showed high amplitude rhythms of corticosterone release in LD and DD (Fig. 8A). Also Syt10 ${ }^{\mathrm{Cre} / \mathrm{Cre}} \mathrm{Bmal1}^{+/}$mice showed corticosterone rhythms in LD and DD, which were not different from those in wild-type and Syt $10^{\mathrm{Cre} / \mathrm{Cre}}$ mice. Syt $10^{\mathrm{Cre} / \mathrm{Cre}} \mathrm{Bmal} 1^{\mathrm{fl} /-}$ mice also excreted corticosterone rhythmically in LD, though with a dampened amplitude. Upon release into $D D$, corticosterone excretion showed sustained rhythmicity for at least one day (Fig. $8 \mathrm{~A}$, ANOVA, $p<0.001$ and $p=0.03$ in LD and first day in $D D$, respectively), although the amplitude 
of this rhythm was reduced compared to LD. On the second day in DD corticosterone release did not significantly vary over the course of the day (ANOVA, $p=0.08$ ). Profiles of individual animals showed that the reduced amplitude was not merely due to desynchrony among animals, but that in individual Syt10 ${ }^{\text {Cre/Cre }} \mathrm{Bmal} \mathrm{f}^{\mathrm{fl}-}$ mice corticosterone excretion rhythms diminish over time (Fig. 8B). In contrast, controls kept rhythmicity also at the individual level (Fig. 8C). In summary, after Syt10 ${ }^{\text {Cre }}$ driven Bmal1 deletion, although being arrhythmic at the level of the SCN, animals showed clear corticosterone rhythms in LD, which dampened over time in DD. To determine whether rhythmic corticosterone release in LD is directly light-controlled or instead controlled by the local adrenal clock, we tested whether peripheral clocks remain rhythmic in $5 y t 10^{\mathrm{Cre} / \mathrm{Cre}} \mathrm{Bmal} \mathrm{fl}^{\mathrm{fl}-}$ mice.

\subsubsection{Peripheral clocks are rhythmic in LD in Syt10 ${ }^{\mathrm{Cre} / \mathrm{Cre}} \mathrm{Bmal1}^{\mathrm{fl}-\text { - }}$ mice}

We investigated rhythmicity of peripheral clocks by measuring clock gene expression in peripheral organs. SCN lesion studies suggest that peripheral clocks cannot sustain rhythmicity in the absence of the SCN even in LD conditions (Sakamoto et al., 1998; Hara et al., 2001; Terazono et al., 2003). In Syt10 ${ }^{\mathrm{Cr} / \mathrm{Cre}} \mathrm{Bmal} 1^{\mathrm{fl} /-}$ mice, however, peripheral clocks sustained rhythmicity in LD (Fig. 9).
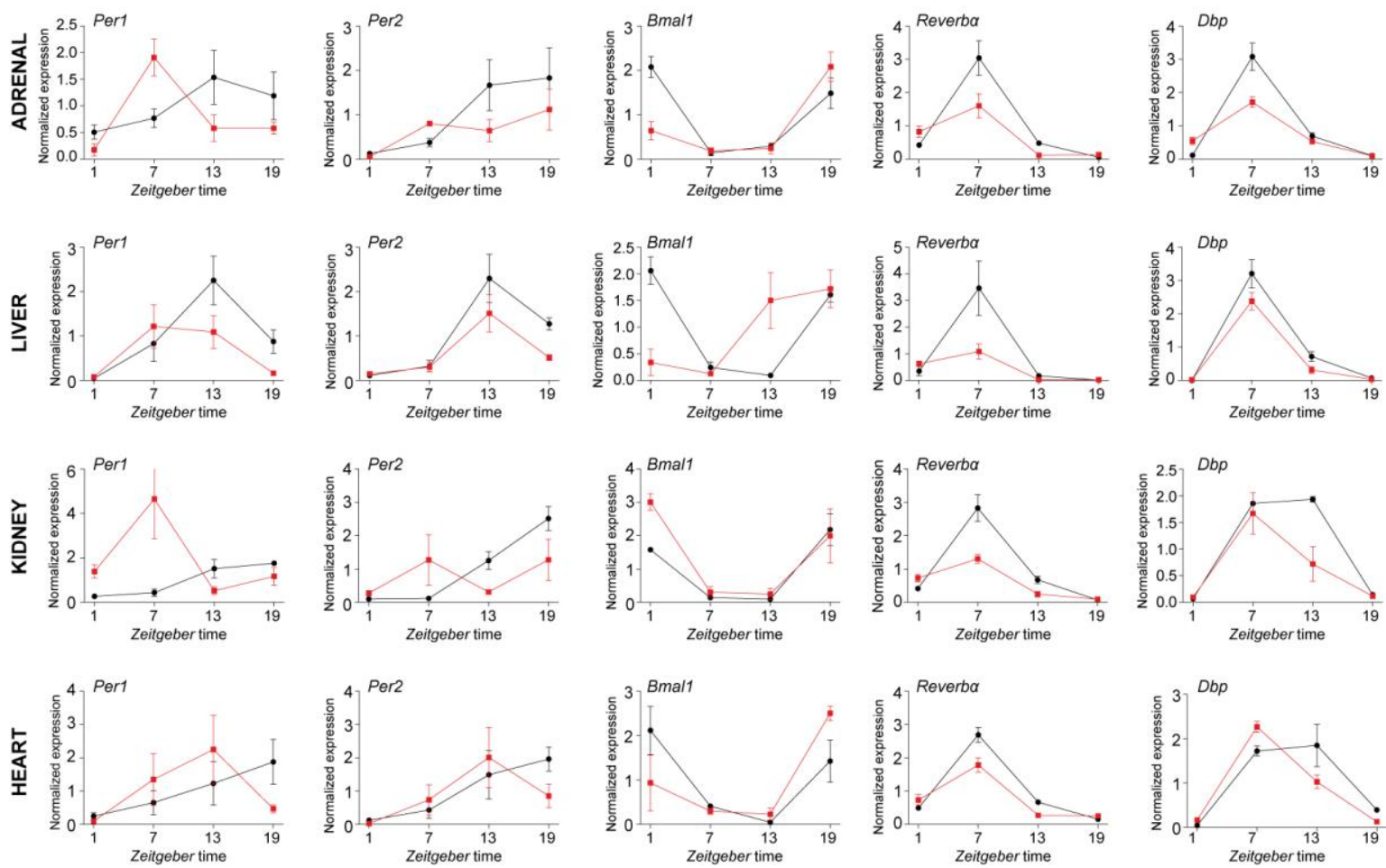

Figure 9: Clock gene expression in peripheral organs is rhythmic in Syt10 ${ }^{\mathrm{Cre} / \mathrm{Cre}} \mathrm{Bmal1}{ }^{\mathrm{fl} /-}$ mice in LD.

Clock gene expression in peripheral organs was measured by qPCR. Syt10 ${ }^{\mathrm{Cre} / \mathrm{Cre}} \mathrm{Bmal1}{ }^{\mathrm{fl} /-}$ data are shown in red, Syt10 ${ }^{\mathrm{Cre} / \mathrm{Cre}} \mathrm{Bmal1}^{+/-}$(controls) data are shown in black. 3 animals were analyzed per genotype at each time point. Data are shown as mean +/- SEM. 


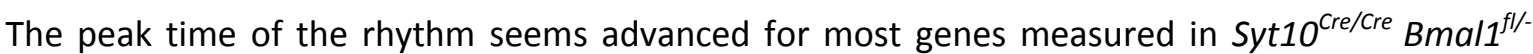
mice, which may reflect the advanced activity onsets observed in most Syt $10^{\mathrm{Cre} / \mathrm{Cre}} \mathrm{Bmal}{ }^{\mathrm{fl} / \text { - }}$ mice (Husse et al., 2011). However to statistically quantify phase shifts, a better temporal resolution will be necessary. In conclusion a functioning SCN clock seems not to be necessary for synchronized rhythmicity within peripheral clocks.

\subsubsection{Peripheral clocks dampen in DD in Syt10 ${ }^{\mathrm{Cre} / \mathrm{Cre}} \mathrm{Bmal1}^{\mathrm{fl} /-}$ mice}

To test whether peripheral clocks maintain high amplitude synchronized rhythms under Zeitgeber-less conditions, we measured clock gene rhythms at the second day in DD. As one would expect, clock gene rhythms were clearly dampened and even lost for some genes (Fig. 10).
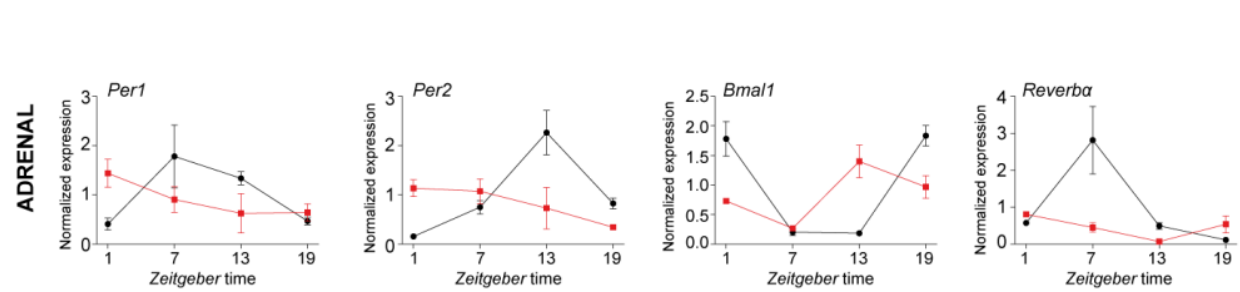

- Syt10crecio Bmal1 - Syt10crecre Bmal1
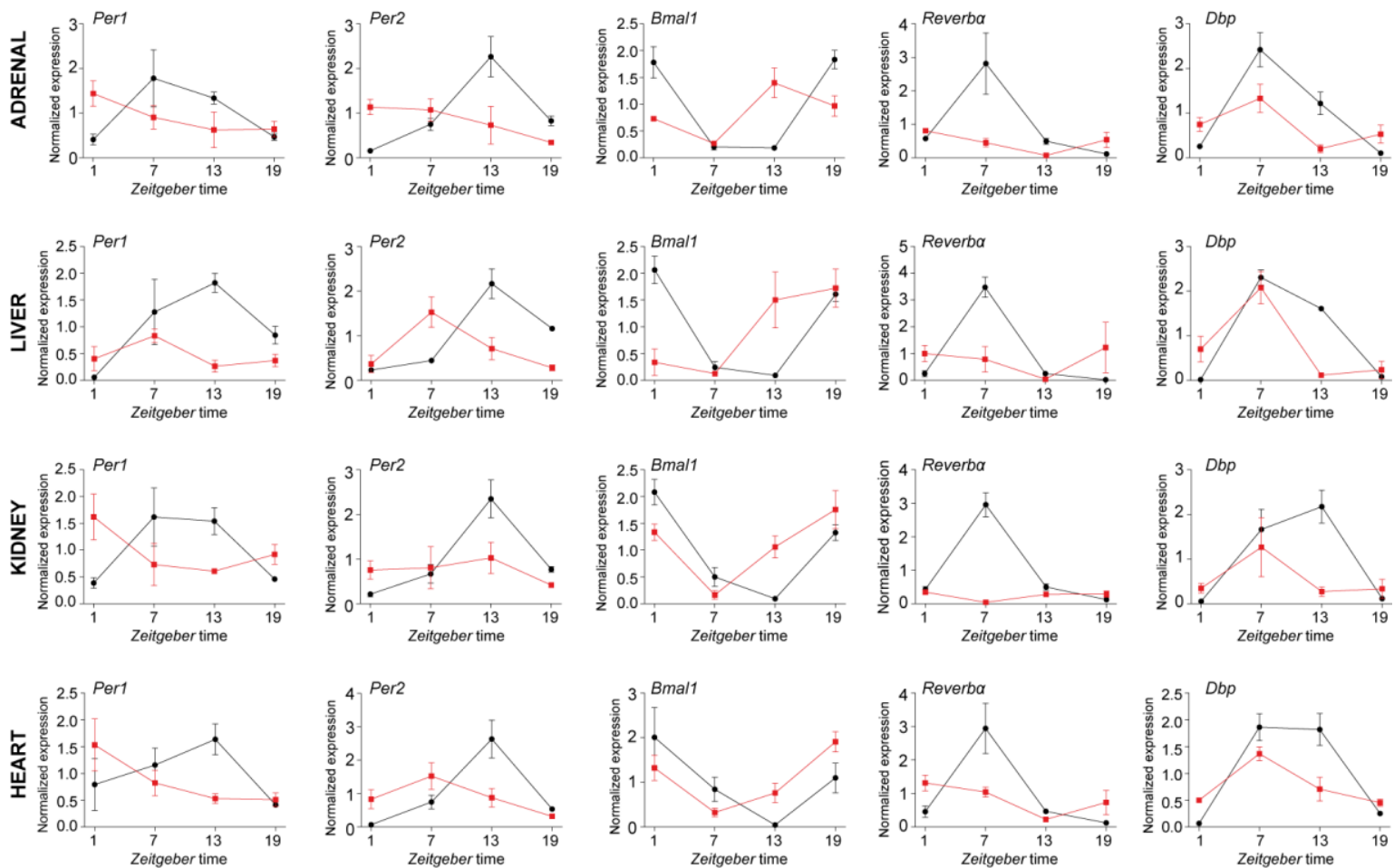

Figure 10: Clock gene rhythms in peripheral organs are lost or dampened in Syt $10^{\mathrm{Cre} / \mathrm{Cre}} \mathrm{Bmal1}^{\mathrm{fl} /-}$ mice on the second day in DD.

Clock gene expression was analyzed on the second day in DD. Syt10 ${ }^{\mathrm{Cre} / \mathrm{Cre}} \mathrm{Bmal}^{\mathrm{fl} / \text { - }}$ data are shown in red, Syt10 ${ }^{\mathrm{Cre} / \mathrm{Cre}} \mathrm{Bmal1}^{+/-}$(controls) data are shown in black. 3 animals were analyzed per genotype at each time point. Data are shown as mean +/- SEM. ANOVAs revealed that Perl did not vary over the course of the day in all organs analyzed, Per2 did only significantly change in the liver and Reverba did only significantly change in the adrenal in Syt $10^{\mathrm{Cre} / \mathrm{Cre}} \mathrm{Bmal}^{\mathrm{fl} /-}$ mice. Bmal1 and Dbp did still show significant changes over the course of the day in Syt $10^{\mathrm{Cre} / \mathrm{Cre}} \mathrm{Bmal1}^{\mathrm{fl} / \text { - }}$ mice. 
Rhythms in Per1 and Per2 mRNA as well as in Reverb $\alpha$ were no longer detectable in most organs, whereas Dbp and Bmal1 rhythms continued to oscillate, though in many cases with reduced amplitude. To conclude, in the absence of a functional SCN clock peripheral expression rhythms are principally sustained, but dampened for some genes and no longer detectable for others, suggesting that synchronized rhythmicity cannot be fully maintained in constant darkness without the SCN clock. 


\subsubsection{Discussion}

We have shown that the Syt $10^{\text {cre/Cre }}$ Bmal1 $1^{\mathrm{fl}-\text { - }}$ mouse model is a functional SCN clock knock-out resulting in a loss of clock-driven behavior as well as in a lack of detectable clock gene expression rhythms in the SCN in constant darkness. Despite this absence of the SCN clock, corticosterone released from the adrenal showed rhythmicity in LD. The amplitude of this corticosterone rhythm, however, was reduced compared to control animals and importantly, the rhythm dampened over time in DD, potentially being completely abolished after prolonged exposure to DD. In LD, synchronized clock gene rhythms in peripheral organs were sustained in the absence of a functional SCN clock. Upon release into DD, peripheral clock gene rhythms were disrupted. Our results suggest that in LD the SCN clock is dispensable for the synchronization of peripheral clocks, in DD, however, clock gene rhythms (gradually) desynchronize and thus peripheral tissues become arrhythmic on the organ level.

\section{The SCN clock is not necessary for masking of locomotor activity}

The clock genes Per1 and Dbp show no detectable expression rhythm in the SCN on the second day in DD. Given that Per1 is an input gene of the clock machinery, which reacts relatively fast on external stimuli and $D b p$ is a usually considered a clock output gene, we are quite confident that the SCN clock is markedly impaired in Syt $10^{\text {Cre/Cre }} B m a l 1^{f /-}$ mice in DD. It is likely that also in LD, clock gene rhythms will be abolished in the SCN. Given that there are reports on residual rhythmic clock gene or clock output gene expression in arrhythmic clock mutants in LD (Oster et al., 2003a; van der Veen et al., 2008), which likely reflect an acute effect of light (masking) on the SCN, confirmation of the lack of rhythmic clock gene expression in the SCN of Syt $10^{\mathrm{Cre} / \mathrm{Cre}} \mathrm{Bmal} / 1^{\mathrm{fl} /}$ - mice in LD will be necessary. Despite an arrhythmic SCN clock, locomotor behavior is rhythmic in LD conditions. We show that this behavioral synchronization to the light dark cycle is light-driven (masking) and not clock-driven. The fact that masking seems principally intact in Syt $10^{\text {cre/cre }}$ $B m a l 1^{f /-}$ mice suggests that the SCN clock is not necessary for behavioral masking effects. However, it has been proposed that the $\mathrm{SCN}$ as a structure is necessary for masking because a complete lack of locomotor activity rhythmicity in LD conditions is seen in SCN lesioned animals (Stephan and Zucker, 1972; Ibuka et al., 1977; Aguilar-Roblero et al., 1986; Lehman et al., 1987; Sujino et al., 2003). It cannot be ruled out, though, that this lack of behavioral rhythmicity in LD is due to the damage of optic nerves concomitant to SCN lesions. One study shows persistence of parts of the masking response after SCN lesions. However, the question whether the degree of masking by light correlates with the degree of optic chiasm damage has not been addressed so far (Redlin and Mrosovsky, 1999). It seems unlikely, that all SCN lesion studies are complicated by concomitant optic tract damage and therefore the only explanation for the difference between our genetic model and the SCN lesion model is that the clock machinery is not necessary for masking. However, it seems that light information to the brain area which regulates masking passes through the SCN. Thus, SCN lesions, which also destroy these neuronal pathways, disrupt the masking response, whereas our genetic model leaves it intact. 


\section{The SCN clock is dispensable for corticosterone rhythms in LD; in DD rhythms dampen}

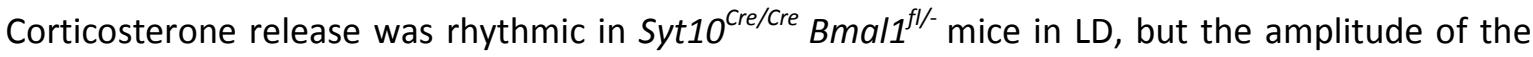
rhythm was reduced compared to controls. In contrast, corticosterone is arrhythmic in LD after SCN ablation (Moore and Eichler, 1972; Sage et al., 2001). This suggests that the SCN is necessary for rhythmic corticosterone release, whereas the SCN clock is dispensable. However, the fact that the rhythm did not reach the full amplitude but was markedly dampened suggests that the SCN clock is involved in regulating the amplitude of corticosterone rhythms. This is in line with studies showing that in LD conditions there is an interplay between the local clock of the adrenal and the central clock in the SCN in regulating corticosterone release rhythms (Oster et al., 2006b). If either the adrenal clock or all other clocks including the SCN clock are impaired, the corticosterone rhythm is dampened. The fact that corticosterone rhythms are completely lost after SCN lesion suggests that light information reaches the adrenal clock via the SCN. It has been shown that light regulates the activity of autonomic efferents to the periphery and also directly regulates clock gene expression and corticosterone release in the adrenal via the autonomic nervous system (ANS). After SCN lesion, light loses the ability to regulate the ANS (Niijima et al., 1992; Niijima et al., 1993) as well as the ability to induce clock genes in the adrenal (Ishida et al., 2005) and to regulate corticosterone release (Buijs et al., 1999). These studies suggest that there is no functional pathway that can circumvent that passing through the SCN, which is in line with early descriptions of retino-hypothalamic tract (RHT) projections (Moore and Lenn, 1972). More recent anterograde labeling of the RHT, however, has revealed projections from the retina to the retrochiasmatic area and lateral and anterior hypothalamus in rats (Johnson et al., 1988a) and to additional hypothalamic sites in primates (Abizaid et al., 2004). However, the question whether these extra-SCN projections play any functional role in entraining the adrenal and other peripheral clocks remains open. The light-pulse studies described above would strongly speak against this possibility. Upon release of the animals into constant darkness the corticosterone rhythms dampened and on the second day in DD the corticosterone rhythm was hardly detectable any more. This suggests that in DD a functional SCN clock is necessary to maintain rhythmic corticosterone release and that the adrenal cannot maintain the corticosterone rhythm, which is in line with previous reports (Oster et al., 2006b). So far we have examined rhythmicity for up to 2 days in DD. It will be necessary to extend this time axis for a few more days to ensure that the hormonal rhythm is completely abolished over time in DD.

We conclude that the SCN clock is dispensable for corticosterone rhythms in LD, but rhythmic SCN output is necessary for high-amplitude rhythms of corticosterone release. Rhythmic release of corticosterone in LD might be a direct masking effect of light on the adrenal, alternatively, the endogenous adrenal clock might drive rhythmic corticosterone release. Therefore our next step was to test, whether the adrenal clock is rhythmic in $5 y t 10^{\mathrm{Cre} / \mathrm{Cre}} \mathrm{Bmal1} \mathrm{fl/}^{\mathrm{f}}$ mice. 


\section{SCN clock is not necessary for rhythmic gene expression in LD}

To test, whether light can directly entrain the adrenal and other peripheral clocks in the absence of the SCN clock, we measured clock gene expression in peripheral organs in Syt10 $0^{\mathrm{Cre} / \mathrm{Cre}} \mathrm{Bmal} \mathrm{fl}^{\mathrm{fl}-}$ mice in LD. Surprisingly, all peripheral clocks and all clock genes we analyzed were perfectly rhythmic in Syt $10^{\text {Cre/Cre }}$ Bmal1 ${ }^{f /-}$ mice. This is in contrast to SCN lesion studies which showed nonrhythmic clock gene expression in peripheral organs in LD (Sakamoto et al., 1998; Hara et al., 2001; Terazono et al., 2003). We conclude that light information which passes through the SCN can entrain peripheral clocks in the absence of an SCN clock. It is likely that this information is transmitted via neuronal signals, because hormonal output from the SCN should be completely arrhythmic due to arrhythmic clock gene expression in the SCN (as noted above, however, the lack of clock gene rhythmicity in the SCN needs to be confirmed in LD). In line with this it has been shown at least for the liver, that denervation results in arrhythmic hepatic clock gene expression (Terazono et al., 2003).

The question whether peripheral clocks are directly light entrained by neuronal connections from the SCN or whether they are indirectly entrained via rhythmic signals such as rhythmic feeding remains open. Food can be an important synchronization signal for peripheral clocks and given that locomotor activity is rhythmic in Syt $10^{\text {cre/Cre }} \mathrm{Bmal}{ }^{\mathrm{fl}-\mathrm{-}}$ mice in LD feeding might be as well. Thus it will be interesting to measure the diurnal rhythm in food uptake in these mice. If these mice do indeed feed rhythmically, one could try to abolish this feeding rhythm by a constant feeding protocol to investigate whether rhythmic feeding is necessary for rhythmicity in peripheral clocks or not.

The fact that peripheral clocks are rhythmic in LD conditions in Syt10 ${ }^{\mathrm{Cr} / / \mathrm{Cre}} \mathrm{Bmal} 1^{\mathrm{fl} / \text { - }}$ mice does not necessarily mean that clocks are indeed entrained by the light dark cycle. An alternative explanation is that rhythmicity is merely masked by light. To differentiate between these two

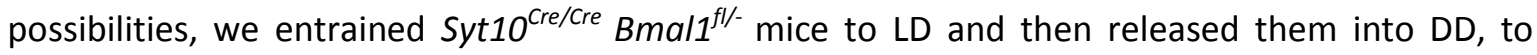
measure clock gene rhythmicity in constant conditions. If peripheral clocks were entrained, then they should still show rhythmicity in the first days in DD.

\section{Peripheral clocks dampen in DD}

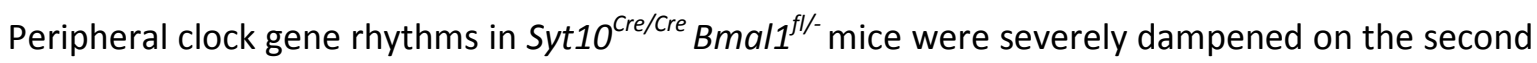
day in DD. This finding clearly ruled out masking of peripheral clocks in LD but speaks for an entrainment mechanism. Interestingly, some genes seem to dampen faster than others: rhythms in Per1 and Per2 as well as Reverba were severely dampened or even lost on the second day in $\mathrm{DD}$, whereas Bmal1 and Dbp rhythms appeared more stable. This suggests that different parts of the clockwork vary in their stability and sensitivity to perturbance. Interestingly those genes, which were more affected, have been shown to be externally controlled: in the SCN Period genes constitute the input to the molecular clock (Hirota and Fukada, 2004) and studies investigating the kinetics of re-entrainment of peripheral gene rhythms after a light-dark shift report that Period genes are among the fastest genes to shift, suggesting a role for Pers in the input of the 
clock mechanism also in peripheral clocks (Reddy et al., 2002; Kiessling et al., 2010). The kinetics of food entrainment show a similar picture with Period genes reacting much faster than the rest of the TTL (Asher et al., 2010). In addition, Per2 is systemically controlled and its expression rhythm can be uncoupled from the expression rhythm of the whole organ in a conditional liver clock knock-out (Kornmann et al., 2007). Thus maybe Per2, being systemically controlled, reacts directly on the loss of rhythmic signal after release in DD, whereas other genes take longer. Reverb $\alpha$ is a nuclear hormone receptor, which can act as a metabolic sensor (Raghuram et al., 2007) and resets relatively fast both during food entrainment (Asher et al., 2010) as well as during light entrainment (Kiessling et al., 2010), at least in some organs. Interestingly, although we find that different genes vary in their reaction to release into $D D$, different organs seem to react relatively similar, suggesting that the mechanism which synchronizes organs in LD is common to all organs.

In conclusion, we show that the SCN clock is dispensable for peripheral clock gene rhythms in LD, but upon release into DD, peripheral clocks dampen in the absence of a functional SCN clock in vivo. Thus peripheral clocks can be synchronized either directly by light or via the SCN and these pathways seem to some extend redundant. The question whether and under which conditions there is a gating of the light signal via the SCN clock remains open and could be addressed by analyzing these SCN clock-less mice under challenging conditions, e.g. a rapid shift of the light dark cycle. 


\subsection{Towards developing a Split-Cre system to target sub-regions of the SCN}

\subsubsection{Specific genetic manipulation of the SCN-core}

As described in the Introduction, the $\mathrm{SCN}$ is sub-divided into a core and a surrounding shell region with respect to cell morphology, neuropeptide and neurotransmitter content, afferent and efferent connections and the phasing of clock gene expression (Introduction Fig. 2). However, until today, the role of SCN subdivisions in regulating circadian output in vivo is not clear. We focused on the SCN core, as tracing studies as well as gene expression studies indicated that the SCN core might be specialized as input region of the SCN.

Given that the SCN is such a small nucleus $\left(\sim 0.04 \mathrm{~mm}^{3}\right)$, conventional lesion experiments are clearly not suitable to answer these questions. We therefore decided to genetically manipulate the SCN core by targeting the expression of a Diphtheria toxin (DT) receptor to this region (Buch et al., 2005). As mouse cells are endogenously not sensitive to DT, targeting the DT receptor (DTR) to specific regions enables to set very specific lesions upon injection of DT. In addition, we aimed at disrupting a conditional allele of the essential clock gene Bmal1 (Storch et al., 2007) in the SCN core.

Our hypothesis was, that the SCN core is important to regulate photic entrainment of the SCN. Given that the SCN core expresses the neuropeptide VIP, which is an important synchronization factor for SCN cells, a second hypothesis was that the SCN core might be necessary for synchronized output of the SCN. To test these hypotheses wheel running behavior of genetically SCN core lesioned and SCN core clock knock-out mice will be analyzed. We expect that mice with a specific lesion of the SCN core will be either impaired in photic entrainment (if the core is important for transmitting light information to the rest of the SCN) or they show impaired rhythmicity (if the core is necessary for maintaining synchrony within the SCN). By comparing core lesioned animals (via the use of the DTR system) and core Bmal1 knock-out animals the respective contribution of the core cells versus those of the core clock could be untangled.

\subsubsection{Genetic model and Split Cre principle}

The Cre/loxp system, which allows the expression transgenes or the disruption of endogenous genes in a spatially and temporally controlled manner has substantially improved our understanding of mammalian physiology (Nagy, 2000). The Cre/loxP system is a binary system consisting of a so-called floxed mouse line, in which a genomic region of interest is flanked by loxP sites and a Cre driver line, which expresses the Cre recombinase enzyme in a certain subset of cells. If Cre is active in a cell it induces recombination between loxP sites resulting in the deletion of the genomic region between them and therefore in gene disruption. Cre can also be temporally controlled by fusing it to a mutated version of the binding domain of the estrogen receptor (ERT2); ERT2 sequesters Cre in the cytoplasm, upon treatment with the estrogen analog tamoxifen, however, Cre is released and can enter the nucleus (Indra et al., 1999; Hayashi and McMahon, 2002). Today, numerous Cre as well as floxed mouse lines are available allowing the generation of various conditional knock-out mice. However, one of the major problems of the 
current Cre/loxP system is the lack of specificity of Cre lines. Especially in the brain, most promoters seem not to be active in only one specific nucleus. Therefore Cre lines specific for one brain nucleus or even specific for sub-regions of brain nuclei are very rare. We screened the Allen Brain Atlas for genes expressed specifically in the SCN core (Lein et al., 2007). However, no such gene was found. To overcome this problem, we developed a modified Cre/loxP system that should substantially improve specificity. The system is based on the complementation of two individually inactive fragments, which was originally developed for the ß-galactosidase enzyme and is now widely used in GFP or Luciferase systems to detect protein interaction or cellular coexpression (Ullmann et al., 1967; Zhang et al., 2004; Villalobos et al., 2007). The idea is to split the Cre recombinase enzyme into a $\mathrm{N}$-Cre and a C-Cre part, which individually are not active. If both parts are present in the same cell, however, functional full Cre is reconstituted (Fig. 11). By adding leucine zippers on the $\mathrm{N}$-Cre and the $\mathrm{C}$-Cre parts, reconstitution of Cre will be facilitated.

Full-Cre (active)

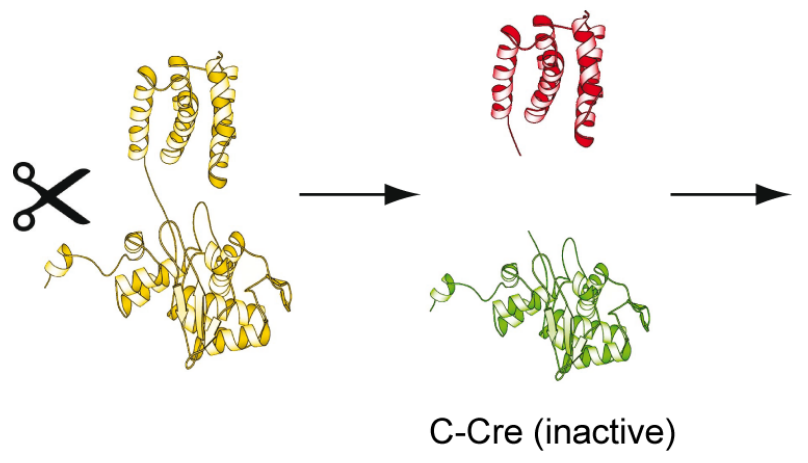

Reconstituted Cre (active)

Figure 11: Split Cre principle.

Cre recombinase is split into a N-terminal and a C-terminal part, which individually are not active. If they are expressed in the same cell, however, they can reconstitute functional Cre. By expressing $\mathrm{N}$-Cre and C-Cre under the control of two different promoters, functional Cre is restricted to those cells, in which both promoters are co-active and thus very specific Cre expression can be achieved.

Similar binary Cre systems have been developed in vitro and recently, Split Cre systems have also been used in vivo to activate fluorescent reporters (Casanova et al., 2003; Jullien et al., 2003; Jullien et al., 2007; Xu et al., 2007; Hirrlinger et al., 2009). In previous experiments in our lab different splitting sites of Cre based on predicted functional motifs and published Cre mutagenesis experiments were tested in a cell culture system: Different combinations of Cytomegalovirus (CMV) promoter driven $\mathrm{N}$-Cre and $\mathrm{C}$-Cre constructs were co-transfected together with a recombination reporter construct into Cos7 cells and the most effective combination was chosen for further experiments. If co-expressed, this combination of $\mathrm{N}$-Cre and $\mathrm{C}-\mathrm{Cre}$, which resulted in a 252 amino acid N-Cre part and a 98 amino acid C-Cre part, was as effective as native Cre in recombineering the reporter construct in vitro. The codon improved Cre sequence (iCre) was used to generate N-Cre and C-Cre constructs (Shimshek et al., 2002).

By expressing $\mathrm{N}$-Cre and $\mathrm{C}$-Cre under two different promoters with overlapping expression in the SCN core, we will generate a SCN core specific Cre driver mouse line (Split Cre line), which will 
allow us to specifically manipulate this brain region. First, we will specifically lesion SCN core cells using the DTR system. This will be achieved by crossing Split Cre mice to a floxed mouse line which was generated in our lab recently by Dr. Zhou - in which a floxed stop cassette prevents expression of the DTR CDNA, upon Cre mediated recombination, however, the stop cassette will be removed and the DTR cDNA will be expressed (Fig. 12). Injection of DT will then result in apoptosis of those cells that express the receptor by inhibition of the translation machinery. In addition the DTR construct contains a CD9 sequence which has been shown to enhance DTR sensitivity to DT (Brown et al., 1993; Cha et al., 2000). Secondly, we will generate a SCN core clock knock-out by crossing Split Cre mice to a mouse line expressing a conditional allele of the essential clock gene Bmal1, in which the basic helix loop helix domain is floxed (Storch et al., 2007) (Fig. 12). Cre recombination in SCN core cells will lead to Bmal1 knock-out and therefore to a breakdown of the molecular circadian clock in these cells.

\section{A Targeted expression of DTR}

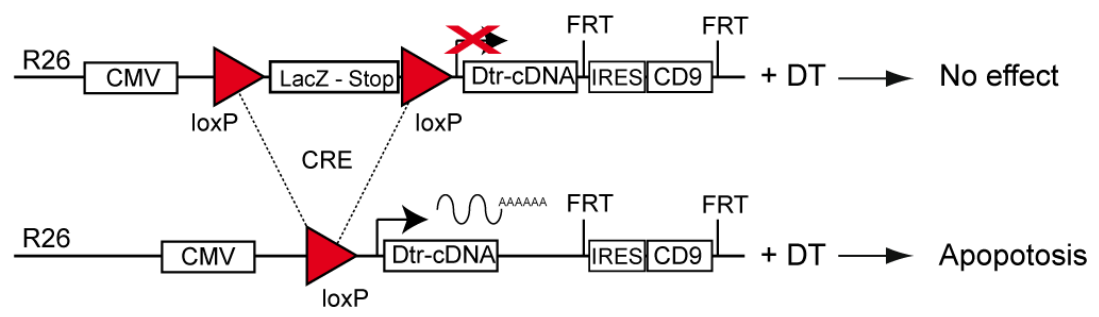

B Targeted disruption of Bmal1

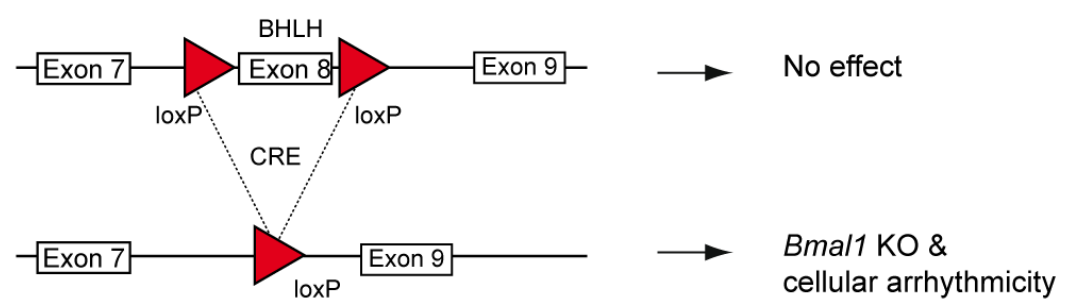

Figure 12: Genetic strategies to achieve cellular ablation and cellular clock knock-out.

A) Design of the floxed Diphtheria toxin receptor (DTR) mouse line. A DTR cassette driven by a CMV promoter was inserted into the Rosa26 locus by homologous recombination in ES cells. Cre mediated recombination will delete the floxed stop cassette and thereby enable expression of DTR. Upon injection of DT, cells expressing DTR will undergo apoptosis. As negative reporter LacZ was included to the floxed stop cassette. The DTR co-receptor CD9 was added to enhance DT sensitivity of DTR; the CD9 cassette was FRT flanked in order to enable Flippase mediated deletion of this part, if negative side-effects of CD9 expression would be detected. B) Design of the conditional Bmal1 mouse line, generated by Storch and colleagues (Storch et al., 2007). Cre mediated excision of floxed exon 8, which contains the essential basic helix loop helix domain, results in Bmal1 disruption and cellular arrhythmicity. 


\subsubsection{Screening for suitable promoter pairs}

In order to generate the respective $\mathrm{N}$-Cre and $\mathrm{C}$-Cre mice, which together would elicit specific recombination in the SCN core, we screened for suitable promoters driving $\mathrm{N}$-Cre and C-Cre expression using the Allen Brain Atlas database and high-throughput in situ hybridization (Lein et al., 2007). A suitable promoter pair should be co-expressed in the core of the SCN, but not coexpressed in other brain regions or other parts of the body. In addition, any co-expression during development would induce non-reversible recombination of the conditional allele in this cell and in all progenitor cells. After comparing the expression of interesting candidates in the SCN and in other brain areas, we chose the very promising gene pair Synaptotamgin10 (Syt10) and Vasoactive intestinal polypeptide (VIP). VIP is the main marker of the SCN core and strongly expressed therein. VIP expression is also prominent in scattered cells in the cortex, the inferior colliculus and scattered cells in the outer plexiform layer of the olfactory bulb. Syt10 is expressed throughout SCN and additionally in cortex layers 2,5 and 6 , in the dentate gyrus of the hippocampus and in the olfactory bulb to only mention some expression sites. A detailed description of Syt10 expression in the brain and in the periphery is found in section "'3.1 Publication: Synaptotagmin10-Cre, a driver to disrupt clock genes in the SCN". Importantly, the only co-expression sites of VIP and Syt10 seem to be in the core of the SCN. The fact that Syt10 is not expressed in peripheral organs with the exception of the testis (see section 3.1) ensures that Syt10 and VIP are not co-expressed in regions outside the CNS. According to the Genepaint database, which provides gene expression data in the mouse embryo on embryonic day 14 , Sy 10 and VIP seem also not co-expressed outside the SCN core during development (http://www.genepaint.org/). Comparing in situ hybridization data obtained on different brain sections, however, does not prove co-expression of two genes. We therefore performed double fluorescent in situ hybridization experiments using Syt10 and VIP probes on frozen brain sections and showed co-expression of Sy10 and VIP in the core cells of the SCN (Fig. 13). Thus we conclude, that Syt10 and VIP are suitable promoter pairs to achieve recombination focused on the SCN core.

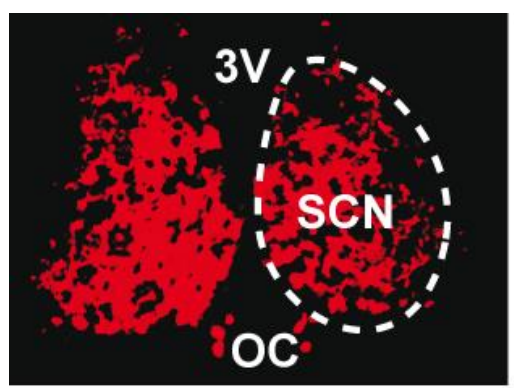

Syt10 - Cy5

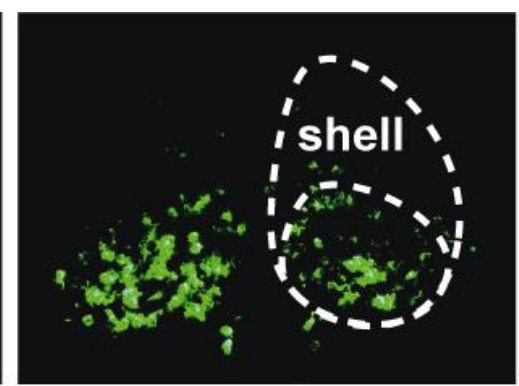

VIP - Alexa488

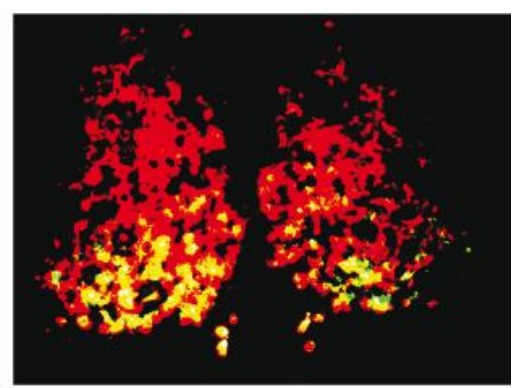

Overlay

Figure 13: Double fluorescent in situ hybridization confirms co-expression of VIP and Syt10 in the SCN core.

Syt10 was labeled with Cy5 in red, whereas VIP was labeled in green with Alexa488. The overlay shows coexpression in the SCN core. 


\subsubsection{Cloning of vectors}

Two mouse lines had to be generated: a Syt10 $0^{N-C r e}$ line and a VIP C-cre line. Inserting Cre into the endogenous locus should most reliably reflect endogenous expression patterns. However, inserting the Cre sequence into the ATG of a gene is expected to disrupt the endogenous gene. As most members of the huge family of Synaptotagmins are also expressed in the SCN (Syt1, 2, 4, 5, 9, 11, 13, 14 and 16; Allen Brain Atlas; (Lein et al., 2007)), we expected that inserting Cre into the Syt10 gene locus should not interfere with SCN function due to redundant expression of other Syts. Thus, we decided to generate a knock-in line for Syt $10^{N-c r e}$. For VIPC-Cre a knock-in strategy seemed not suitable, as VIP knock-out animals - even in the heterozygous state - show impaired photic entrainment of the circadian system (Colwell et al., 2003). A number of studies investigated the promoter elements of VIP, unfortunately, however, the element driving VIP expression in the SCN core was not identified so far (Tolentino et al., 1995; Tsuruda et al., 1996; Waschek et al., 1999). Thus a conventional transgenic strategy seemed not feasible, as we would have had to guess which parts of the promoter are necessary to target C-Cre expression to the SCN core. The use of BAC transgenics, however, overcomes this problem by inserting the entire genomic region of interest. In addition, a high throughput project had identified a VIP BAC clone that was used successfully to generate VIP GFP mice expressing GFP in the SCN (Gong et al., 2003). Thus we decided to take the same BAC clone for generating a VIP ${ }^{C-C r e} B A C$ transgenic line by pronuclear injection.

The generation of the Syt $10^{N-C r e}$ vector was facilitated by the fact that a Syt10 $0^{\text {cre }}$ knock-in mouse line had been generated in the lab previously (Syt10 ${ }^{\text {cre }}$, for details see section 3.1). This vector was modified such that the full Cre sequence was replaced by the $\mathrm{N}$-Cre sequence followed by IRES and Amcyan. The Syt10 $0^{N-C r e}$ vector map is found in Fig. 14. The vector was sequence verified and used for ES cell electroporation.

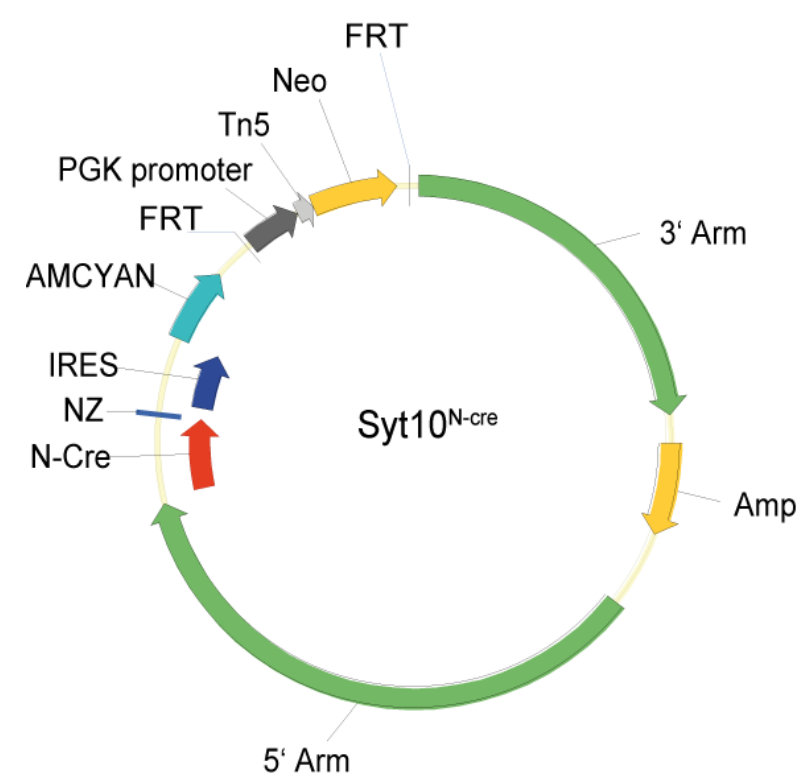

Figure 14: Syt10 ${ }^{N-C r e}$ targeting vector.

5' and 3' homology arms are taken from the Syt10 genomic region. The $\mathrm{N}$-Cre cassette is inserted into the Syt10 locus such that the endogenous ATG of Syt10 is replaced by the N-Cre cassette. NCre is followed by the N-terminal leucine zipper (NZ). The fluorescent marker Amcyan is added after IRES. The selection marker neomycin (Neo) is preceded by a prokaryotic $(\operatorname{Tn} 5)$ and an eukaryotic (PGK) promoter to drive Neo expression in bacteria as well as in ES cells. The Neo cassette is FRT flanked in order to delete this cassette by Flippase in vivo. The selection marker ampicillin (Amp) is used for bacterial screening. 
The VIP ${ }^{C-C r e}$ vector was generated by recombineering method: the C-Cre sequence followed by IRES and the EYFP cDNA was inserted into the ATG of the VIP gene in the BAC vector (RP23-25A8 from the C57BL/6J BAC library RPCl-23 (Osoegawa et al., 2000). In addition the FRT flanked selection marker neomycin was inserted in order to enable screening for positive clones. The neomycin cassette was deleted in the following step by electroporation and induction of a Flippase plasmid. The final construct was analyzed by restriction digest and the inserted Cre cassette was sequence verified (Fig. 15). In addition a VIP $P^{\text {-cre ind. }}$ vector was generated as described for the VIP $P^{c-C r e}$ vector but with the addition of an ERT2 sequence after the C-Cre CDNA to generate a VIPC-Cre ind. mouse line that would be inducible by tamoxifen treatment. An inducible Split Cre line will be important in case of unexpected co-expression of Syt10 and VIP during development. However, given that this modification adds another level of complexity and might not be necessary if the non- inducible Split Cre model is specific, we decided to keep this vector as a backup and only generate mice from this vector if necessary.
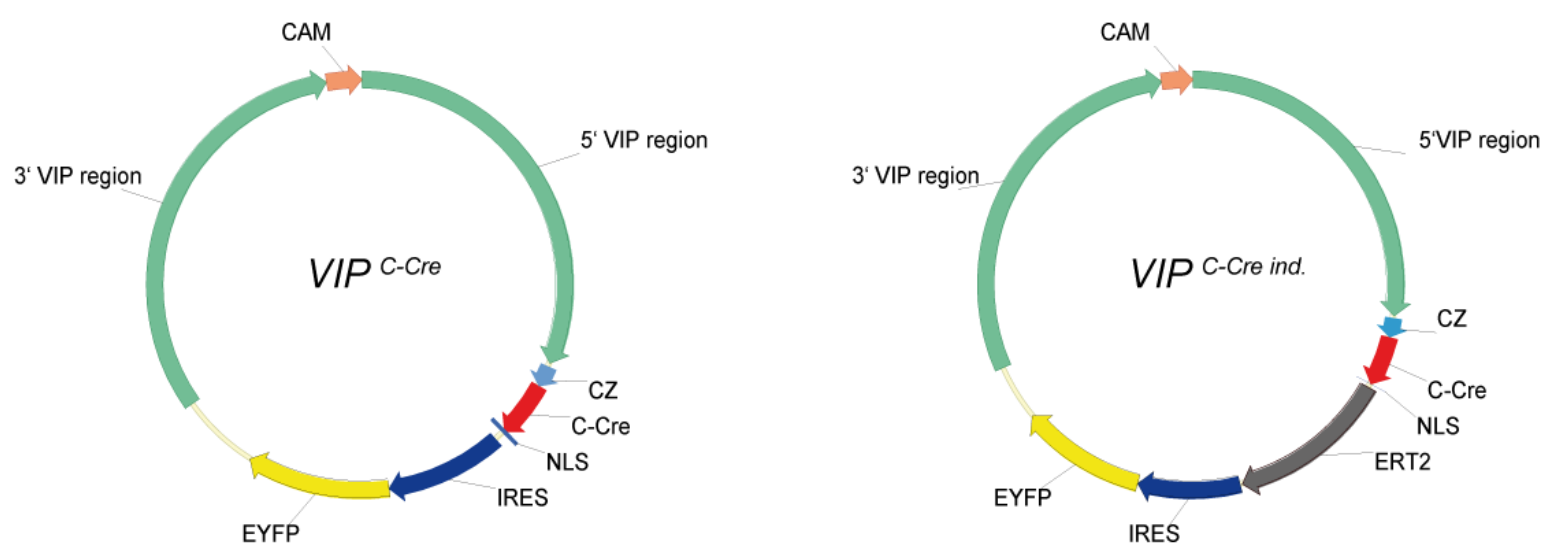

Figure 15: VIP ${ }^{c-C r e}$ and VIP ${ }^{c-C r e ~ i n d .}$ BAC vectors.

The C-Cre cassette consisting of the C-terminal leucine zipper (CZ), the C-Cre sequence followed by a nuclear localization signal (NLS) and an EYFP marker added after IRES was recombineered into the VIP BAC vector such that the endogenous VIP ATG as replaced with the cloning cassette. Chloramphenicol (CAM) was used as selection marker. For the generation of an inducible C-Cre an estrogen receptor sequence (ERT2) sequence was added after the C-Cre cDNA (right panel).

\subsubsection{Generating Syt10 ${ }^{N-C r e}$ knock-in mouse line}

The linearized Syt10 $0^{N-C r e}$ vector was electroporated into 129/SVPas embryonic stem (ES) cells by the MPI-BPC transgenic core facility. 122 neomycin resistant clones were analyzed by southern blotting using an internal and an external probe. The internal probe detected an $8.3 \mathrm{~kb}$ knock-in band, whereas the external probe detected a $8.9 \mathrm{~kb}$ knock-in band; in addition both probes detected a $14.7 \mathrm{~kb}$ wild-type band. ES cell clone number 17 showed the expected knock-in and wild-type bands (Fig. 16). This positive ES cell clone no 17 was used for ES cell aggregation performed by the MPI-BPC transgenic facility. ES cell aggregation resulted in 48 chimeric animals ranging from very low to $100 \%$ chimerism judged on the basis of fur color. Males showing $90 \%$ 
chimerism were backcrossed to $\mathrm{C} 57 \mathrm{BL} / 6 \mathrm{~N}$ females. Germ line transmission in the offspring was detected by genotyping PCR (not shown, genotyping was done as described for Syt10 ${ }^{\mathrm{Cre}}$ mice, see section 3.1) and southern blotting of tail DNA (Fig. 16).

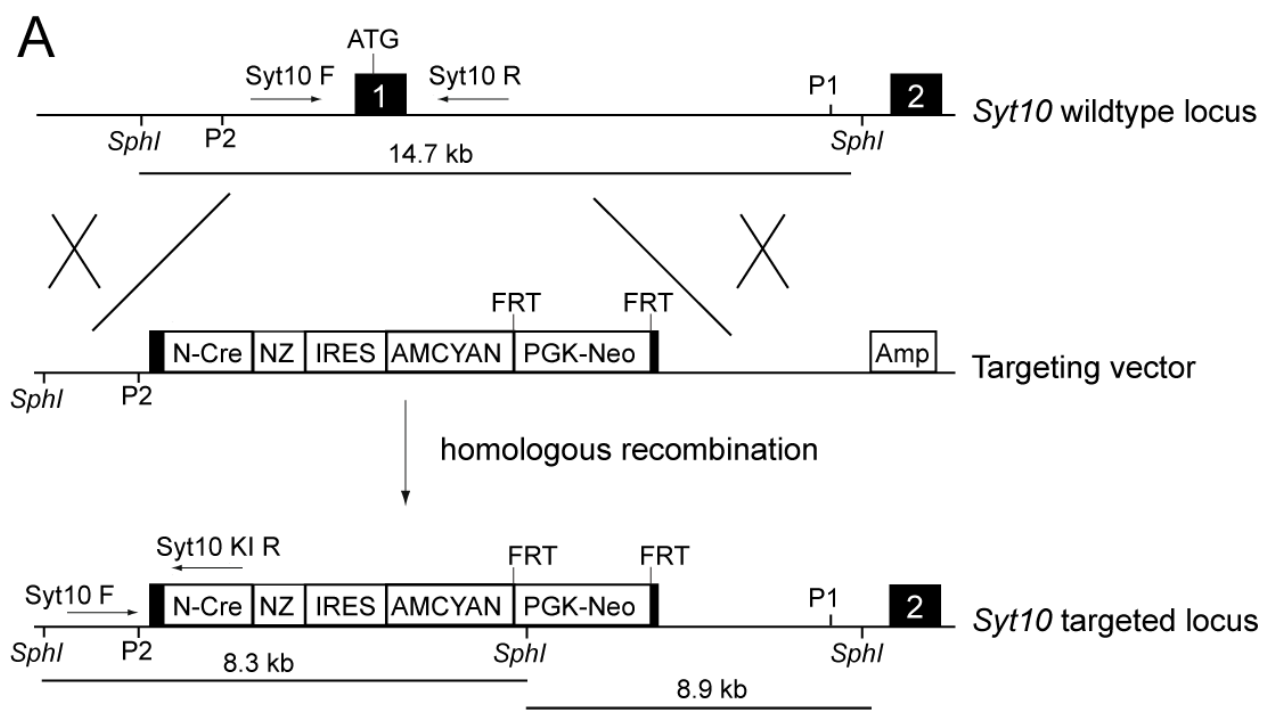

B

ES cells

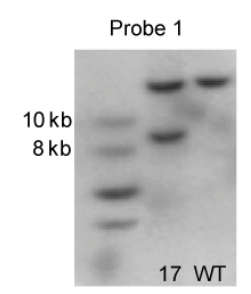

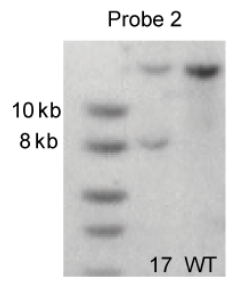

C

Tail DNA

Figure 16: Syt10 $0^{N-C r e}$ targeting strategy and southern verification.

A) Targeting strategy for generation of Syt10 $10^{N-C r e}$ mice. Black boxes mark exons. The endogenous Syt10 ATG located in exon 1 was replaced by the $\mathrm{N}$-Cre cassette (see Fig. 4 for abbreviations) via homologous recombination in ES cells. Correct integration was verified via southern blotting using an external probe (P1) and an internal probe (P2), which detect a $8.9 \mathrm{~kb}$ and a $8.3 \mathrm{~kb}$ knock-in band after restriction digest with Sphl enzyme, respectively. In addition, P1 and P2 detected a $14.7 \mathrm{~kb}$ wild-type band. Genotyping primers (Syt10 F, Syt10 R, Syt10 KI R) are depicted as arrows. B) Southern blotting of ES cell DNA from clone number 17 showed the correct bands using external and internal probes. 17: clone 17; WT: wild-type. C) Tail DNA from offspring of chimeric animals confirmed germ line transmission of the construct. 1,2,3: animal number 1-3; WT: wild-type tail DNA; ES: ES DNA from clone 17.

As the first ES cell screen only yielded one positive ES cell clone, a second round of ES cell electroporation was done. This second round resulted in four additional ES clones with correct integration site. One of these positive clones was used for ES cell aggregation and also resulted in germ line transmission. This $S y t 10^{N-C r e ~} 2$ line was always kept independently from Syt $10^{N-C r e}$. Given that neomycin can interfere with Cre expression, the FRT flanked neomycin cassette was deleted 
by crossing $S y t 10^{N-C r e}$ mice to a mouse line that ubiquitously expresses Flippase (Farley et al., 2000). Neomycin deletion in the offspring was confirmed by PCR. The Flippase allele was outcrossed in the next generation by back-crossing to $\mathrm{C} 57 \mathrm{BL} / 6 \mathrm{~N}$.

\subsubsection{Generating VIP ${ }^{c-C r e}$ BAC transgenic mouse lines}

The final VIP $P^{C-C r e}$ vector was purified and injected into the pronucleus of B6CBA oocytes (hybrid between $\mathrm{C} 57 \mathrm{BL} / 6 \mathrm{~J}$ and $\mathrm{CBA}$ ) by the MPI-BPC transgenic core facility. Resulting animals were genotyped by PCR detecting C-Cre (Fig. 17). 285 animals were screened and only one was positive for C-Cre, which gives a success rate of $0.3 \%$.

A

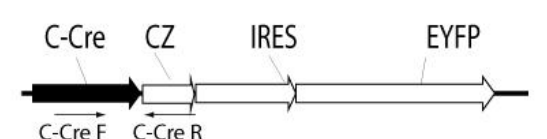

VIP Bac vector

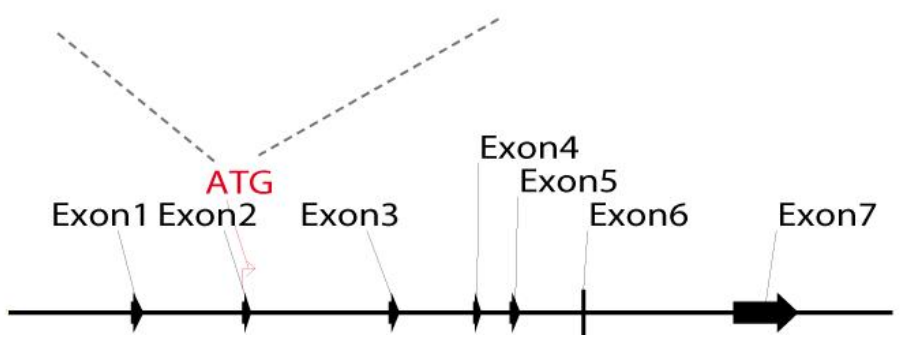

B Genotyping PCR

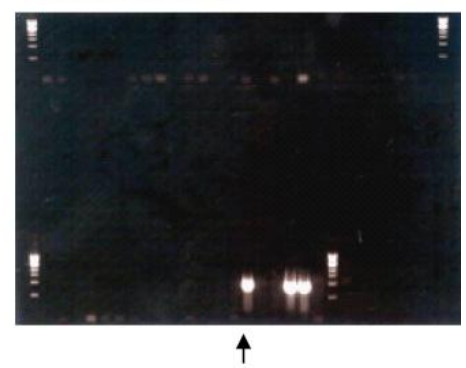

Figure 17: BAC transgenic strategy for generation of VIP ${ }^{c-C r e}$ mice.

A) The VIP Bac vector was modified by insertion of the C-Cre cassette into the ATG of VIP (for abbreviations see Fig. 5). Genotyping primers are depicted as arrows. B) Genotyping PCR on tail DNA using the primers CCre $\mathrm{F}$ and C-Cre R. The arrow indicates the first positive animal. The last three rows are two positive controls followed by the negative control.

Offspring of the positive VIP ${ }^{C-C r e}$ founder was also tested by southern blotting (data not shown). The very low success rate of $0.3 \%$ was probably due to technical difficulties in handling BAC DNA. As we needed at least three independent founder lines to make sure that one of them would show the expected C-Cre expression pattern, we decided to instruct a company (Polygene, Zürich), which is experienced in the generation of BAC transgenic mice, with generating additional founders (on $\mathrm{C} 57 \mathrm{BL} / 6 \mathrm{~J}$ background). Polygene delivered two additional independent founders after four months. As one of the delivered lines was unfortunately not C-Cre positive and must have been confounded before sending, Polygene started another round of injections and delivered three more independent founders after six additional months. Thus we had six independent $V I P^{C-C r e}$ founder lines, one from our facility $\left(V I P^{C-C r e}\right)$ and five from Polygene $\left(V I P^{C-C r e} P\right.$ ${ }^{5}$ ). To screen for the line that shows the best C-Cre expression pattern, we crossed all lines independently to the Syt10 ${ }^{N-C r e}$ line and to a LacZ reporter mouse line (Soriano, 1999). 


\subsubsection{LacZ reporter analysis}

An overview over the breeding strategy is depicted in Figure 18. First, Syt10 $10^{N-c r e}$ mice were bred with a reporter mouse strain which expresses LacZ after Cre mediated excision of a floxed stop codon $\left(\right.$ Rosa26 ${ }^{\text {Lacz }}$ ) (Soriano, 1999) and a double positive Syt10 ${ }^{N-C r e}$ Rosa26 $6^{\text {Lacz }}$ line was established. This line was then crossed independently to all 6 VIP ${ }^{C-C r e}$ BAC transgenic founder lines.

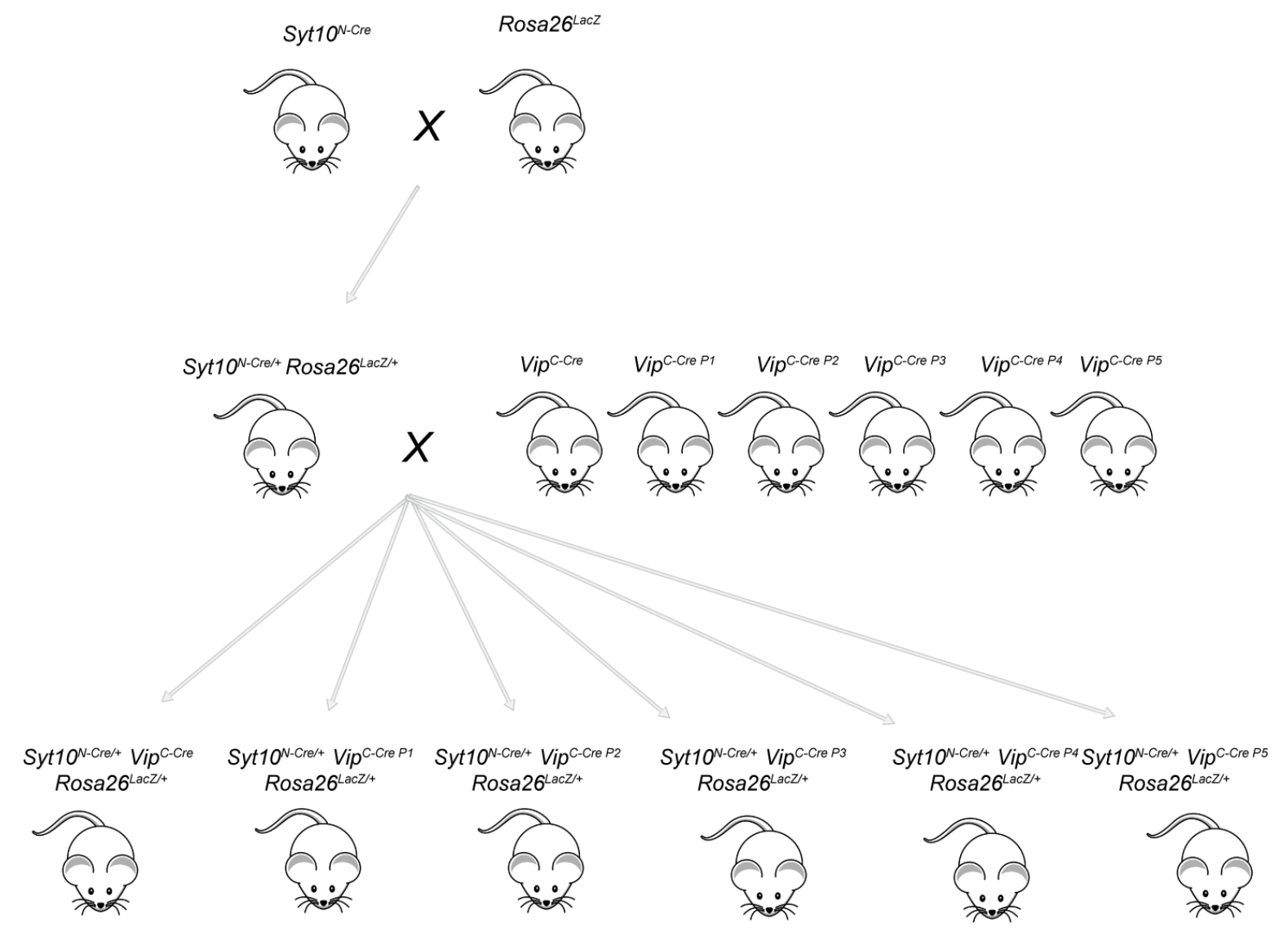

Figure 18: Breeding strategy for LacZ reporter analysis.

Syt $10^{N-C r e}$ mice were bred to a Rosa $26^{L a C Z}$ reporter strain. Double positive offspring was then independently crossed to the six VIP-Cre BAC transgenic founder lines. Triple positive offspring, containing N-Cre, C-Cre and the reporter allele were used for LacZ analysis.

Offspring, which was triple positive for the $\mathrm{N}-\mathrm{Cre}$, the C-Cre and the LacZ allele were used for LacZ reporter analysis of the SCN. $25 \mu \mathrm{m}$ brain sections containing the SCN were stained for LacZ and counter-stained with a nuclear stain (red). Unfortunately none of the 6 independent lines showed any LacZ staining in the SCN (nor in other brain regions on the same section) (Fig. 19). The experiments were repeated for 2-3 animals per genotype, but always gave negative results. Positive controls of the genotype Syt $10^{\text {Cre }}$ Rosa26 $6^{\text {LacZ }}$, however, showed the expected LacZ staining in the SCN. 


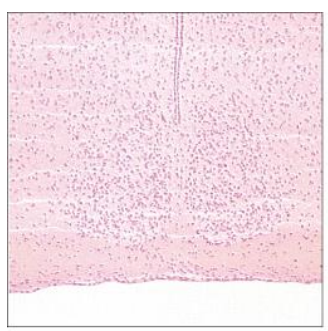

Syt10 N-Cre/N-Cre VIPC-Cre $R 26 R^{\text {LacZ }}$

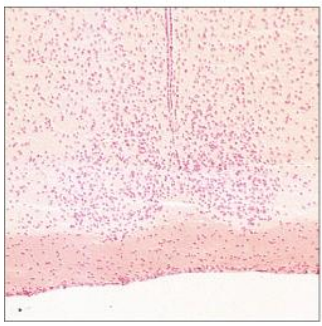

Syt10 $0^{\text {-Cre/N-Cre }}$ VIPC-Cre P3 $R 26 R^{\operatorname{LacZ}}$

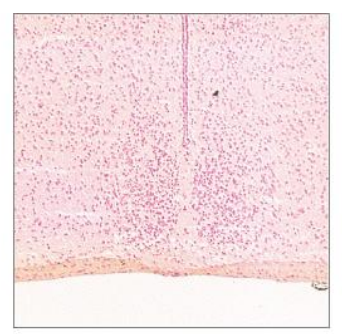

Syt10 $0^{N-C r e / N-C r e ~}$ VIPC-CreP1 $R 26 R^{\text {LacZ }}$

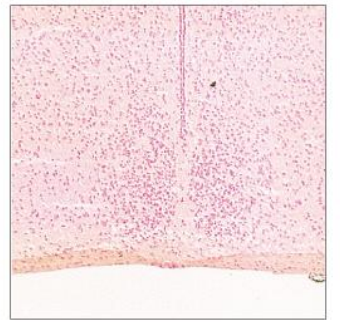

Syt10 $0^{\mathrm{N}-\mathrm{Cre} N \text {-Cre }}$ VIP C-Cre P4 $R 26 R^{\operatorname{LacZ}}$

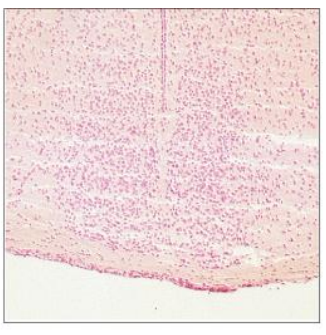

Syt10 ${ }^{\mathrm{N}-\mathrm{Cre} N \mathrm{~N}-\mathrm{Cre}}$ VIPC-Cre P2 $R 26 R^{\operatorname{LaCZ}}$

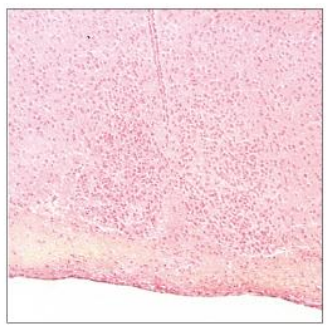

Syt10 ${ }^{\mathrm{N}-\mathrm{Cre} / \mathrm{N}-\mathrm{Cre}}$ VIPC-Cre P5 $R 26 R^{L a C Z}$

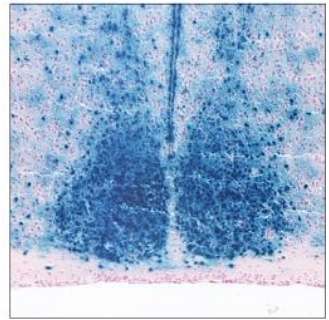

Syt10 Cre/t $R 26 R^{L a c Z}$

Figure 19: LacZ analysis of SCNs in six independent Split Cre LacZ lines.

$25 \mu \mathrm{m}$ SCN sections of mice positive for N-Cre, C-Cre and LacZ were analyzed using LacZ staining. Six independent lines (from independent $V I P^{C-C r e}$ founders) were analyzed. While the positive control $\left(S y t 10^{\text {Cre }}\right.$ Rosa26 ${ }^{\text {LacZ }}$ ) showed the expected LacZ positive staining in the SCN, all other lines were LacZ negative.

The same analysis was performed for Syt $10^{N-C r e ~} 2$ VIP ${ }^{C-C r e}$ Rosa26 $6^{\text {Lacz }}$ mice. Also these mice did not show any LacZ staining in the SCN, suggesting that the lack of recombination was not specific to the first Syt10 $0^{N-\text {-cre }}$ line (e.g. mutations specifically in this ES cell clone).

\subsubsection{Trouble shooting}

A number of reasons could explain the lack of recombination. Firstly, Syt10 driven N-Cre expression might be not strong enough. We have previously shown that the recombination efficiency of Syt $10^{\text {cre }}$ in the SCN is dependent on Cre copy number. Homozygous Syt $10^{\text {cre/cre }}$ is more efficient in recombineering a floxed Bmal1 allele than heterozygous Syt $10^{\mathrm{Cre} /+}$ (see section 3.1). We therefore argued that this might be similar for the Split Cre situation and established breedings in order to obtain mice homozygous for Syt $10^{N-C r e / N-C r e}$, positive for the VIPC-Cre transgene and positive for the LacZ allele. We performed LacZ reporter analysis in four of the six independent lines but unfortunately none showed LacZ activity in the SCN (Fig. 20). Thus the lack of recombined reporter allele cannot be rescued by two alleles of Syt $10^{N-C r e}$. As it has been shown that two reporter alleles can be more efficient than one reporter allele in reporting recombination events (Xu et al., 2007), we also analyzed mice, which were homozygous for Syt10 $10^{N-C r e / N-C r e}$ and

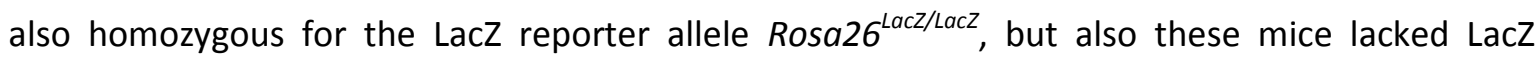
positive cells in the SCN. 


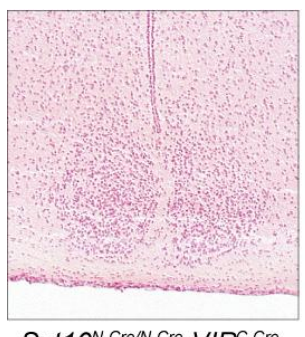

Syt10 N-Cre/N-Cre VIPC-Cre

$R 26 R^{L a C Z}$

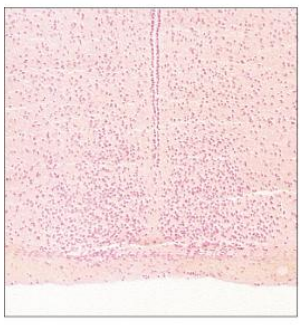

Syt10 $10^{\mathrm{N}-\mathrm{Cre} / \mathrm{N}-\mathrm{Cre}}$ VIPC-Cre P2 $R 26 R^{\operatorname{LaCZ}}$

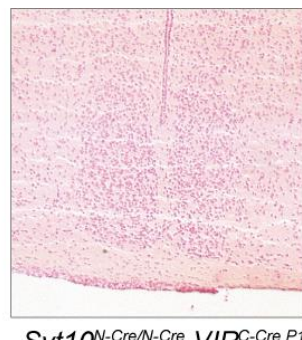

$R 26 R^{\operatorname{LacZ}}$

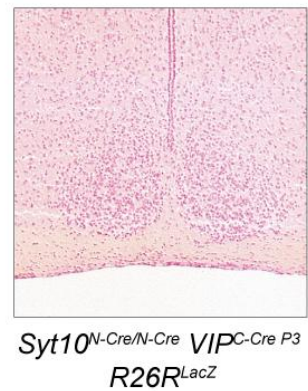

Figure 20: LacZ analysis of SCNs of 4 independent Split Cre LacZ lines with two $\mathrm{N}$-Cre alleles.

$25 \mu \mathrm{m} \mathrm{SCN}$ sections of mice homozygous for $\mathrm{N}$-Cre, positive for $\mathrm{C}$-Cre and positive for LacZ were analyzed using LacZ staining. 4 independent lines (from independent $V I P^{\text {C-cre }}$ founders) were analyzed. All lines lacked LacZ staining, although the positive control showed LacZ positive cells (not shown).

Secondly, the reporter might be inadequate to detect Cre mediated recombination, although this seems not very likely, given that this reporter is widely used to analyze Cre expression patterns and was also used successfully in our lab (see section "3.1 Publication: Synaptotagmin10-Cre, a driver to disrupt clock genes in the $\left.\mathrm{SCN}^{\prime \prime}\right)$. However, it has been shown before that Cre reporter lines can differ substantially in the resulting recombination efficiency (Jullien et al., 2007). To completely rule out the possibility that the lack of recombination was specific to the LacZ reporter line, two independent lines were crossed to a second reporter line in which Cre recombination mediates the expression of human alkaline phosphatase (AP) (Lobe et al., 1999). AP staining of sections did not result in any staining in the $\mathrm{SCN}$ of triple positive mice, although the positive control did show the expected staining (Fig. 21). Thus lack of reporter recombination is not unique for the LacZ reporter line.

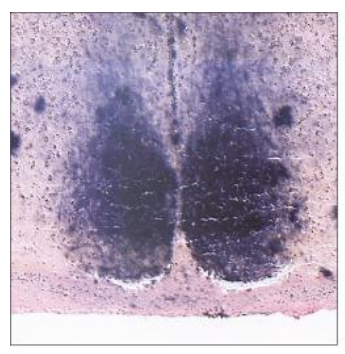

Syt10 ${ }^{\text {cre/t }} A P^{\text {pos }}$

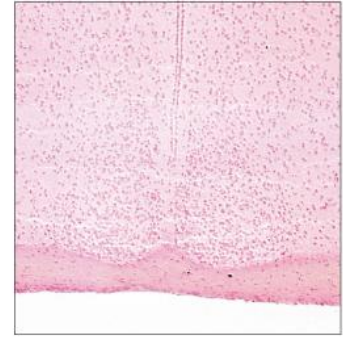

Syt10 $0^{N-C r e /+}$ VIPC-Cre $A P^{\text {pos }}$

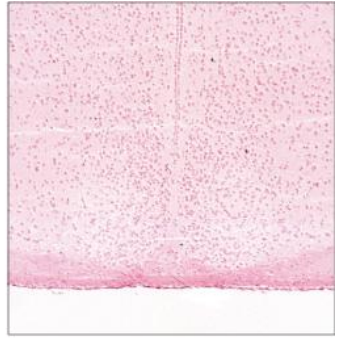

Syt10 $0^{N-C r e /+}$ VIPC-Cre P1 $A P^{\text {pos }}$

Figure 21: AP analysis of SCNs in 2 independent Split Cre LacZ AP lines.

$25 \mu \mathrm{m}$ SCN sections of mice positive for $\mathrm{N}$-Cre, positive for $\mathrm{C}$-Cre and positive for the AP transgene were analyzed using AP staining. 2 independent lines (from the independent VIP ${ }^{C-C r e} 1$ and 3 were analyzed. All lines lacked AP staining, although the positive control did show AP positive cells in the SCN. 
Lack of recombination could be also due to one of the lines not expressing the N-Cre or C-Cre transcripts or not expressing them at sufficient levels. To test this possibility we isolated RNA from SCN punches from different Split Cre lines (Syt10 $0^{N-C r e /+}$ VIP $\left.{ }^{C-C r e X}\right)$ and analyzed N-Cre and C-Cre levels by PCR. As a positive control RNA isolated from Syt10 ${ }^{\text {Cre }}$ SCNs was used. As shown in Figure $22 \mathrm{~A}$ and $22 \mathrm{~B}$ all lines containing Syt $10^{N-C r e}$ show the expected PCR product and most Split Cre lines also express the C-Cre transcript with the exception of Split P1. Quantitative real time PCR revealed that both Syt $10^{N-C r e}$ lines express the $\mathrm{N}$-Cre transcript in the $\mathrm{SCN}$ at levels that are comparable to those in the Syt10 cre line (Fig. 22C). C-Cre transcript levels in the SCN differed widely among different BAC transgenic lines, however with the exception of the VIPC-Cre ${ }^{P 1}$ line, all lines showed transcript levels that were at least as high as those in the Syt10 $0^{\text {cre }}$ line (Fig. 22D). The fact that some lines express C-Cre transcript levels that are much higher than Syt10 ${ }^{\text {Cre }}$ expression levels is expected as endogenous VIP expression is stronger than endogenous Syt10 expression in the SCN.

A
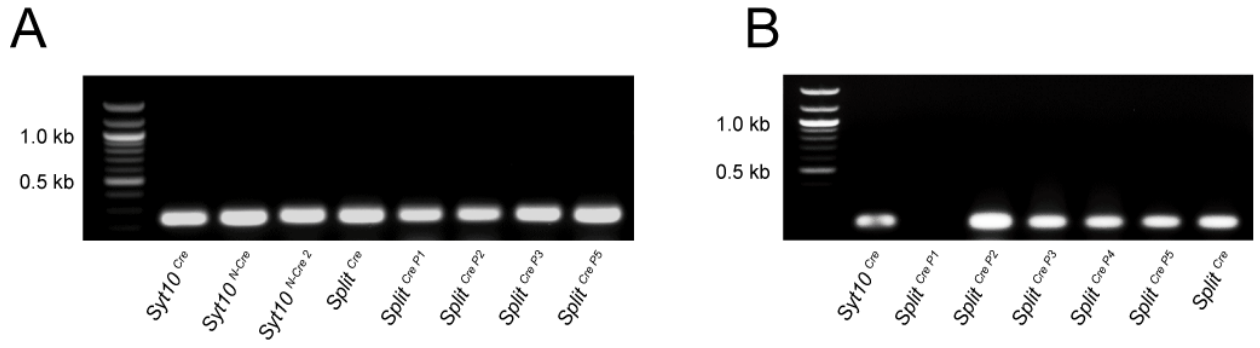

C

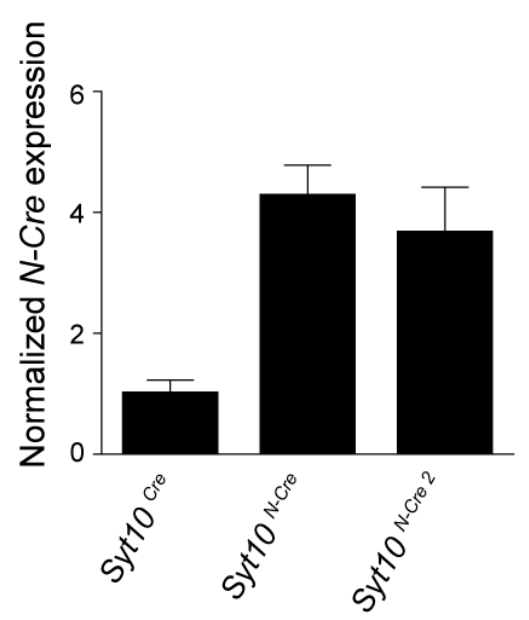

D

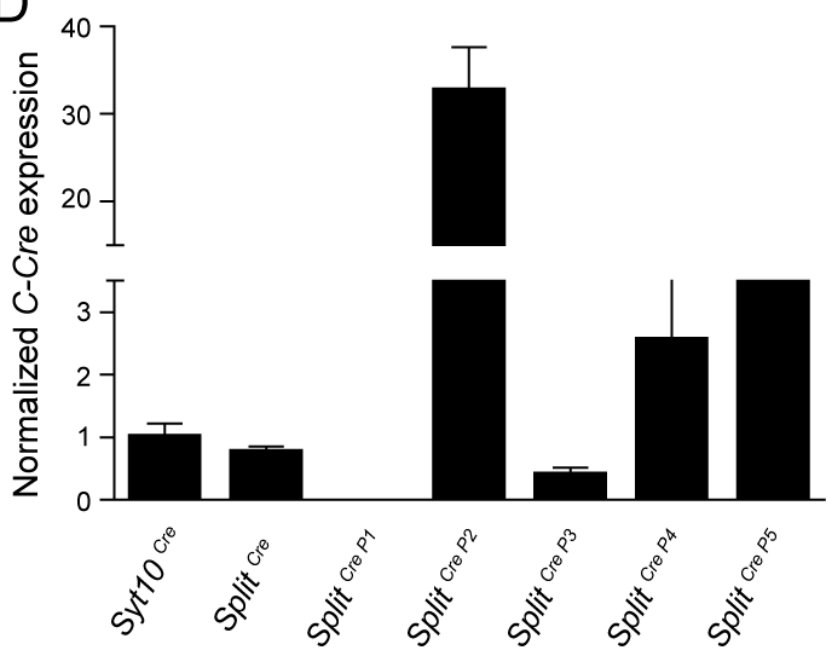

Figure 22: Expression analysis of $\mathrm{N}$-Cre and $\mathrm{C}$-Cre transcripts.

A) N-Cre PCR on SCN cDNA from different mouse lines. Expected PCR product size: 250 bp. B) C-Cre PCR on SCN CDNA from different mouse lines. Expected PCR product size: 197 bp. C) Quantitative real time PCR analysis of N-Cre transcript levels in the SCN of different mouse lines. For Syt10 ${ }^{N-C r e}$ all Split Cre line data and the $\operatorname{Syt} 10^{N-C r e}$ data were pooled (as they all contain $S y t 10^{N-C r e}$ ). D) Quantitative real time PCR analysis of CCre transcript levels in the SCN of different mouse lines. All expression data were normalized against the house-keeping gene Eefa1 and for each SCN Six6 expression was used as an SCN marker to confirm specificity of SCN punches. 
To ensure that the transcripts did not harbor a mutation that prevents Split-Cre from working, PCR products obtained from the qPCRs (containing parts of $\mathrm{N}$-Cre or C-Cre sequence) from all lines were sequence-verified. The complete $\mathrm{N}$-Cre and C-Cre cassettes including the NZ and the CZ were sequence verified in the Syt $10^{N-C r e}$ and the VIP ${ }^{C-C r e}$ line. Thus, mutations in the Cre sequence cannot be the reason for a lack of recombination.

\subsubsection{Discussion}

In summary, we generated two independent Syt10 ${ }^{N-c r e}$ knock-in lines as well as 6 independent VIP ${ }^{C-C r e} B A C$ transgenic lines. All lines with the exception of one VIP ${ }^{C-C r e} B A C$ transgenic line express the respective $\mathrm{N}$-or $\mathrm{C}$-Cre transcript in the $\mathrm{SCN}$ and no mutations were detected in the expressed transcripts.

The lack of recombination could be due to insufficient levels of transcripts. The fact that the C-Cre transcript is expressed at significantly higher levels than the $\mathrm{N}$-Cre transcript in at least some of the VIP ${ }^{c-c r e}$ lines, suggests that the $\mathrm{N}$-Cre transcript is rate-limiting. We have shown previously that the Syt $10^{\text {cre }}$ driver only efficiently disrupts a conditional allele of Bmal1 in the homozygous state, indicating that Syt10 driven Cre expression is not particularly strong. In the case of Split Cre one would predict that due to the probability of finding a C-Cre association partner in the cell more NCre is necessary for efficient recombination, thus, Syt10 driven N-Cre - even in the homozygous state - might be not sufficient for LacZ reporter recombination. In line with that, it has been shown previously, that driving Split Cre parts from the moderate R26R promoter and the strong CAG promoter results in relatively weak recombination efficiency in some tissues including the brain (Jullien et al., 2007) and those studies that showed efficient Split Cre induced recombination in vivo used strong promoters like pancreatic and duodenal homeobox 1 (Pdx1) to drive expression in the pancreas (Xu et al., 2007) and glial fibrillary acidic protein (GFAP) and proteolipid protein (myelin) 1 (Plp1) to drive expression in the brain (Hirrlinger et al., 2009). Thus maybe another, stronger promoter should be chosen for driving N-Cre expression. According to the Allen brain atlas, Delta-like 1 homolog (DIk1), for example, seems to be strongly expressed in the SCN. Alternatively, one could try to virally introduce a CMV driven $\mathrm{N}$-Cre construct by stereo-tactic injection into the SCN or the third ventricle.

The lack of recombination could also be caused by different cellular localization of the N- and CCre proteins. We only added a nuclear localization signal (NLS) to the C-Cre targeting vector, which might have targeted the $\mathrm{C}$-Cre protein to the nucleus, whereas the $\mathrm{N}$-Cre protein was localized to the cytoplasm and therefore no reconstitution was possible. However, most current Cre lines including the Syt10 ${ }^{\text {cre }}$ line described in section 3.1 are designed without NLS. It has been shown that native Cre is able to enter the nucleus and that adding a NLS does not enhance nuclear localization. Nuclear targeting determinants have been mapped to the first $123 \mathrm{~N}$ terminal amino acids of the Cre sequence (Le et al., 1999). In addition, an in vitro Split Cre study showed that $\mathrm{N}$ - and $\mathrm{C}$-Cre parts can efficiently recombine a reporter construct without addition of any NLS. The authors showed that native N-Cre (amino acids 1-194) translocates to the nucleus, whereas C-Cre does not. Thus according the literature, adding an NLS to the N-Cre part seemed not necessary. However, due to the fact that we added leucine zippers on both Cre parts, one 
could speculate that the $\mathrm{N}$-Cre protein is kept in the cytoplasm due to its leucine zippers. Of interest, a recently published report which used a Split Cre system to estimate co-expression of genes in vivo also used leucine zippers as interaction domain, but added NLSs at both the N-Cre and the C-Cre part (Hirrlinger et al., 2009). However, in their design, only the first 50 amino acids of Cre were used as N-Cre part and thus adding a NLS was necessary, given that the endogenous nuclear targeting determinant of Cre was probably impaired. Of interest, another study which also used leucine zippers as interaction domain and splitted Cre at similar sites than we did showed that in HK293 cells the efficiency of recombination dropped from $27 \%$ to $12 \%$ if only an $\mathrm{N}$ terminal NLS was present compared to NLSs at both Cre parts (Xu et al., 2007). Thus maybe adding a NLS to the N-Cre construct would increase recombination efficiency in our Split Cre in vivo model.

Of note, however, the exact same constructs did show very efficient recombination in the cell culture experiments, which were performed in our lab previously. Thus the differences we see in vivo might be due to neuron specific effects (as the in vitro experiments were performed in Cos7 cells, which are monkey kidney cells). Alternatively, they could depend on the expression level as discussed above, as in vitro the constructs were driven by the strong CMV promoter and this overexpression might have been sufficient to overcome these problems. Thus carful titrating the expression levels of both Cre parts in a cell culture experiment should help to estimate how the recombination efficiency depends on $\mathrm{C}-\mathrm{Cre}$ and $\mathrm{N}$-Cre expression levels. 


\subsection{Manuscript: The circadian clock genes Per1 and Per2 regulate the metabolic response to sleep restriction in mice}

Jana Husse ${ }^{* 1}$, Sophie Charlotte Hintze ${ }^{* 1,2}$, Gregor Eichele ${ }^{1}$, Hendrik Lehnert ${ }^{2}$, Henrik Oster ${ }^{1,3}$

${ }^{1}$ : Max Planck Institute for Biophysical Chemistry, Göttingen, Germany

${ }^{2}: 1^{\text {st }}$ Medical Clinic, University of Lübeck, Germany

*: these authors contributed equally to this work

This manuscript is being prepared for submission to PLOS ONE. 


\section{Abstract}

Human and animal studies show that sleep has a strong impact on the regulation of metabolism. Average daily sleep duration correlates negatively with body weight and short sleep promotes the development of unfavorable metabolic sequelae such as obesity and disturbances in glucose disposal. Both sleep and metabolism are under the control of endogenous circadian clocks that regulate the adaptation of physiology and behavior to the 24 hour day. This prompted us to analyze the impact of clock genes on the metabolic response to sleep restriction (SR). We compared metabolic effects of a five-day SR paradigm mimicking a human night shift schedule between wild-type mice and congenic Per1/2 double mutants that lack a functional circadian clock. We show that five days of SR lead to increased food intake and body weight, accompanied by elevated adipokine levels and altered hepatic expression profiles of metabolically relevant clock target genes in wild-type mice. By contrast, Per1/2 double mutant mice show attenuated metabolic responses to SR in most parameters tested, suggesting that the clock gene machinery has an important role in mediating the metabolic response to SR. Moreover, we show that SRinduced circadian and metabolic disruption persists for at least one week after treatment, indicating that short episodes of sleep disruption are sufficient to induce persistent physiological effects as seen in human shift workers. 


\section{Introduction}

The incidence of obesity and type 2 diabetes has dramatically increased in almost all countries of the world in the last decades. This development cannot be fully explained by changes in lifestyle such as the constant availability of high-caloric food and reduced physical activity [1]. Another factor that might be involved is sleep. Correlating with the rise of obesity average diurnal sleep times have dramatically decreased. Whereas the typical daily sleep duration was eight to nine hours in 1960, it had decreased to seven hours in 1995; today, almost a third of adults report sleeping less than six hours per night $[2,3,4]$. Night shift work, which is usually accompanied by decreased sleep duration and quality [5], is associated with a higher risk of developing obesity and metabolic syndrome $[6,7,8]$, thus raising the possibility that sleep curtailment might contribute to obesity directly [3]. A causal link between acute sleep loss and appetite regulation has been established in several laboratory studies. Sleep restricted subjects report higher appetite and hunger feelings [9] and - if allowed free access to food - also eat more [10]. In addition, blood levels of the appetite regulating hormones leptin and ghrelin are altered $[3,4]$ and pre-diabetic changes in glucose homeostasis are observed [3,9,11,12].

Animal studies support these findings. Restricting sleep over extended times in rodents leads to increased food intake accompanied by changes in leptin and ghrelin levels $[13,14,15,16]$. In addition hypothalamic expression of the anorexigenic hormonal precursor pro-opiomelanocortin (POMC) decreases while (orexigenic) neuropeptide Y (NPY) levels are induced [17]. Further, levels of proinflammatory cytokines released from adipose tissue are elevated which might indicate inflammation of adipose tissue [18]. Of note, many rodent sleep restriction (SR) paradigms result in increased corticosterone levels which might be a confounding factor in some of the reported effects $[19,20,21]$.

Several lines of evidence show that metabolism is regulated by the circadian clock. In mammals genetically encoded circadian timekeepers regulate $24 \mathrm{~h}$ rhythms of sleep-wake behavior as well as many physiological and metabolic functions in the body. Transcriptome studies in metabolically relevant peripheral tissues such as liver, adipocytes and pancreas show that many rate-limiting steps in different metabolic pathways are clock controlled $[22,23]$. The clock genes Period1 (Per1) and Period2 (Per2) are key elements of the circadian clock and play partially redundant roles in this clock mechanism. The genetic deletion of both genes in mice, however, leads to a complete disruption of the circadian clock [24]. Clock disruption promotes obesity, type 2 diabetes and the development of the metabolic syndrome $[25,26,27,28,29,30]$. Interestingly, SR can induce the expression of the clock genes Per1 and Per2 in various regions of the brain [31,32,33]. Collectively, these findings led us to postulate that the circadian clock machinery mediates the metabolic consequences of SR. Therefore, we compared metabolic changes in response to a five-day SR paradigm applied to wild-type and arrhythmic Per1/2 double mutant mice. We show that in wildtype mice SR alters food intake and body weight regulation accompanied by changes in adipokine levels and in the diurnal expression profile of metabolic genes in the liver. Most of these effects can be observed even one week after cessation of the SR treatment. Importantly, Per1/2 deficient mice show highly attenuated metabolic SR effects, indicating an involvement of the Per genes and the clock machinery in the mechanism by which sleep influences metabolism. 


\section{Material and Methods}

\section{Animals}

All animal experiments were carried out in compliance with the German Law on Animal Welfare and were approved by the Office for Consumer Protection and Food Safety of the State of Lower Saxony. Per1/2 double mutant mice were generated from Per1 (Per1 ${ }^{\text {Brd1 }}$ ) [24] and Per2 (Per2 ${ }^{\text {Brd1 }}$ ) [34] mutant mice (both backcrossed to C57BL/6 for at least 10 generations). Genotyping was performed as described [24,34]. 9-11 week old male C57BL/6 and congenic Per1/2 mice were used for all experiments. Body weight at the beginning of the experiment was not different between wild-type and Per1/2 mutant mice.

\section{Sleep restriction}

Sleep restriction (SR) was performed using the gentle handling protocol $[35,36]$ during the first six hours of the light phase (Zeitgeber time (ZT) 0-6) for five consecutive days. Mice were observed throughout the SR time and kept awake by introducing novel objects into the cage as soon as the animals adopted a sleeping posture (eyes closed, no movement). Mice were kept in grouped cages (3-5) in a $12 \mathrm{h:12} \mathrm{h}$ light-dark cycle (LD) at 50 lux light intensity with constant temperature $\left(20 \pm 0.5^{\circ} \mathrm{C}\right.$ ) and humidity (50-60 \%) and ad libitum access to standard chow food (Ssniff V1126, Soest, Germany) and water. Activity was measured using custom-made infrared sensors installed on the lid of each cage and analyzed using ClockLab Software (Actimetrics, Evanston, IL). Animals were assigned to either the control, the sleep restricted or the recovery group. Sleep restricted mice were sacrificed by cervical dislocation on the last (fifth) day of SR. Control animals were kept under the same conditions, but were allowed to sleep ad libitum. Mice from the recovery group were sleep restricted for five days, kept undisturbed for seven days afterwards and killed on the seventh day after the end of SR. Blood was collected into EDTA-coated capillary tubes (Microvette CB300 from Sarstedt, Nümbrecht, Deutschland) to obtain plasma after centrifugation.

\section{Immunoassays}

Corticosterone was measured from plasma samples using the ImmuChem Double Antibody ${ }^{125}$ IRadioimmunoassay Kit (MP Biomedicals, Solon, $\mathrm{OH}$ ); plasma leptin was measured using the Mouse Leptin ELISA Kit (Crystal Chem, Downers Grove, IL) according to the manufacturers' protocols.

\section{Quantitative real-time $P C R$ ( $q P C R$ )}

Total RNA was extracted from RNAlater (Ambion, Darmstadt, Germany) protected liver and epididymal adipose tissue samples using RNeasy Mini Kit and RNeasy Lipid Tissue Mini Kit (Qiagen, Hilden, Germany), respectively. On-column DNAse treatment was performed to avoid residual genomic DNA contamination. cDNA synthesis was performed using Superscript II reverse transcriptase (Invitrogen, Darmstadt, Germany) and Oligo-dT primers. qPCR was performed using iQ SYBR Green Supermix on an iCycler thermocycler (Bio-Rad, München, Germany) according to the manufacturer's protocol. Primer sequences are available on request. Eef1 $\alpha$ expression was 
used as housekeeping gene and relative quantification ( $\Delta \Delta-\mathrm{CT}$ method) was performed as described [37].

Data analysis

All data are shown as mean +/- SEM. Statistical comparisons were made using Graph Pad Prism software (GraphPad, La Jolla, CA); p-values below 0.05 were considered significant. Student's ttests were used for comparison of two groups and ANOVAs when more than two groups were compared. Where time and group interactions were compared two-way ANOVAs with Bonferroni post-tests were used. Where normality tests revealed deviations from a Gaussian distribution, non-parametric analyses were used (Mann-Whitney $U$ test or Kruskal-Wallis test with Dunn's Multiple Comparison post-test, respectively). To compare data to a hypothetical median Wilcoxon signed rank tests were applied. Unless stated otherwise statistical comparisons were always made between control and SR or control and recovery period in the same genotype. 


\section{Results}

\section{Sleep restriction disrupts diurnal activity rhythms in wild-type and Per1/2 mutant mice}

After five consecutive days of six hours of SR in the early light phase profound behavioral changes were observed. Diurnal infrared locomotor activity profiles showed that wild-type mice responded by reducing their activity in the second half of the dark period in an attempt to compensate for the sleep lost during the first half of the day (Fig. $1 \mathrm{~A} \& \mathrm{C}$ ), while total activity levels were unaltered (102 +/- $10.4 \%$ of control week activity). Quantification of the relative activity during light and dark periods showed that under SR mice were less active in the dark phase compared to controls (Fig. $1 \mathrm{E}$; Mann-Whitney-test; SR vs. control; $p=0.0079$ ) which resulted in equal activity in the light and dark phases (Wilcoxon signed rank test; tested against hypothetical median of 50\%). However, overall entrainment to the light-dark (LD) cycle was maintained with clear onsets of activity around "lights off" (ZT 12; Fig. 1 A \& C). 

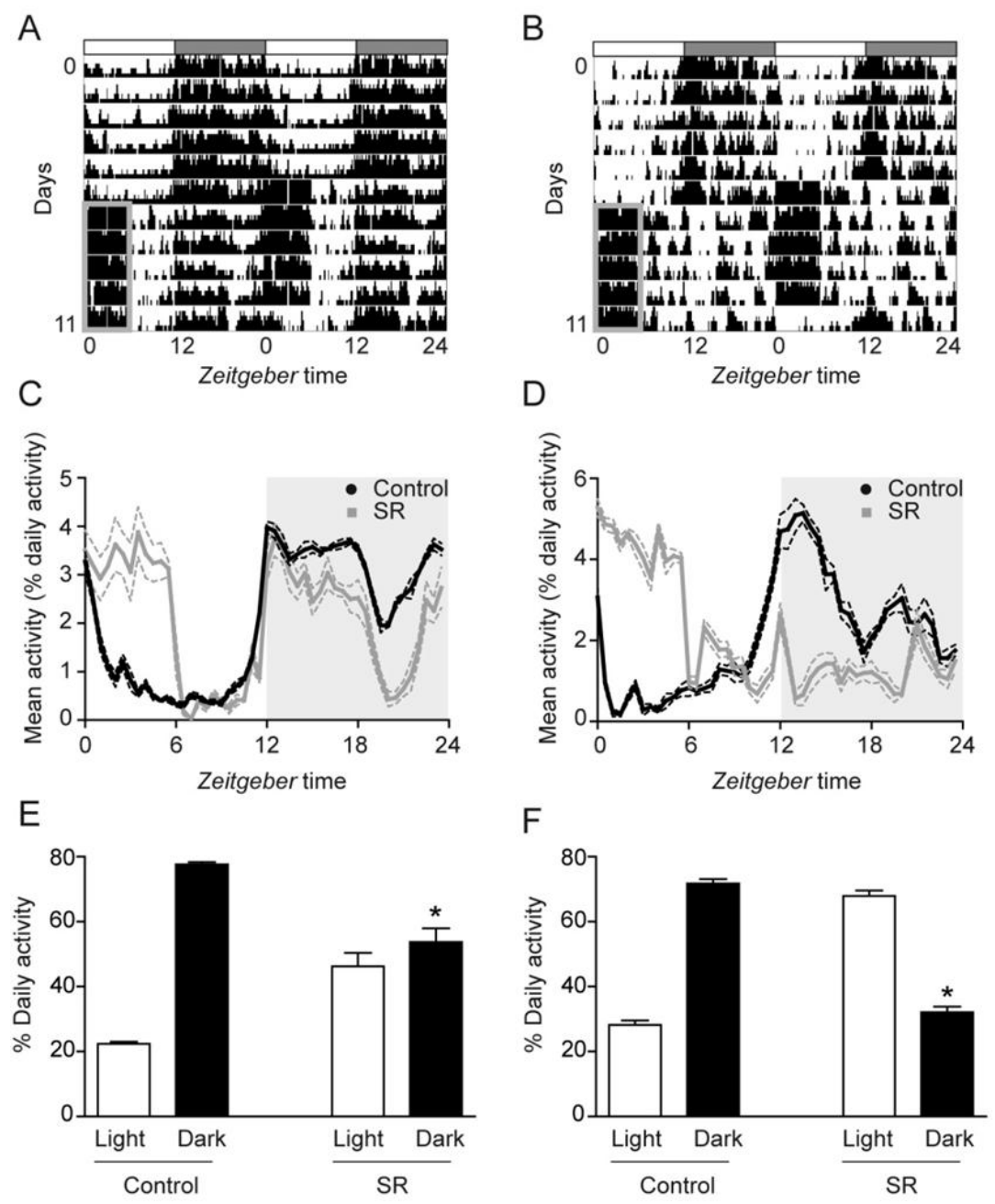

Fig 1: Sleep restriction (SR) disrupts diurnal activity rhythms in wild-type and Per1/2 mutant mice.

Representative double plotted activity recordings of wild-type $(A)$ and congenic Per1/2 double mutants (B) during five days of control and five days of SR. Time of SR (ZTO-6) is highlighted with a grey rectangle. Light and dark phases are indicated by white and grey boxes, respectively. Mean activity profiles of wild-type (C) and congenic Per1/2 double mutants (D) during five days of control and five days of SR. Light and dark phases are indicated in white and grey, respectively. Mean activity profiles were generated by plotting the relative locomotor activity for every $30 \mathrm{~min}$ bin as percentage of total daily activity. Data are plotted as mean and SEM (dotted lines). Quantification of relative activity during light (ZTO-12) and during dark phases (ZT12-24) of wild-types (E) and Per1/2 double mutants (F), Mann Whitney-test; Per1/2 dark activity control vs. Per $1 / 2$ dark activity SR; $p=0.0159$. All data are shown as mean $+/-$ SEM $(n=5-7) ; *: p<0.05$, tested against respective control group.

In Per1/2 mutants activity was synchronized to the LD cycle during the control week (Figs. 1 B \& D), but with advanced activity onsets, as has been reported previously [24,38]. In sharp contrast to wild-type mice, sleep-restricted Per1/2 mutants completely lost their normal LD activity pattern. During SR, their main activity period was shifted to the morning and, consequently, the distribution of activity between light and dark phases was reversed (Fig. 1 B, D, F). Assuming that reduced activity during the dark phase in part reflects sleep rebound in response to the sleep lost in the morning, this would indicate an elevated sleep rebound in the Per mutants. In line with this, 
we observed marked differences in the number of interventions that were necessary to keep the different genotypes awake during SR. On average wild-type mice needed 2.0 and 4.7 disturbances in the first and last hour of SR, respectively, while at the same time Per1/2 mutants required 4.9 and 15.0 disturbances to stay awake (Suppl. Fig. 1; Mann-Whitney test; wild-type vs. Per1/2 mutants; first and last hour of SR; $p<0.0001$ and $p=0.0003$, respectively).

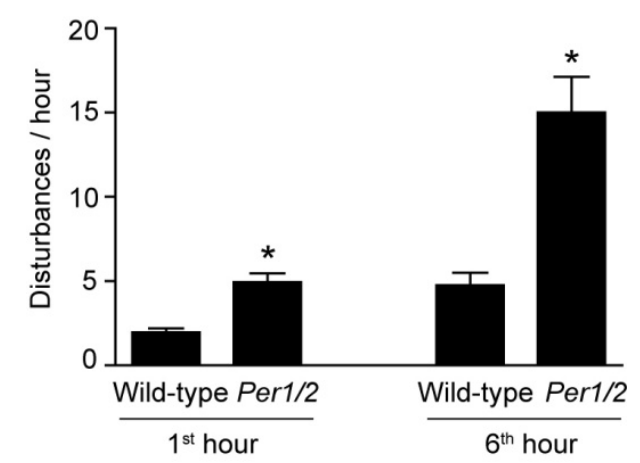

Suppl. Fig 1: Increased sleep drive in Per1/2 mutants.

Number of disturbances per hour necessary to keep mice awake in the first and last hour of SR.

$*: p<0.05$, tested against wild-type.

\section{SR leads to hyperphagia in wild-type mice; Per1/2 mutants show attenuated effects.}

Analogous to what had previously been reported for mice and humans $[10,13,16,39]$ a pronounced increase in food intake was observed in wild-type mice in response to SR. Food intake on the fifth day of SR was significantly increased compared to the control period (Fig. 2A; t-test; $p$ $=0.0002$ ). In contrast Per1/2 mutants did not change their food intake during SR (Fig. 2A). Both genotypes failed to gain weight during the SR period, whereas they gained roughly $1 \mathrm{~g}$ of body weight during the control period (Fig. 2B; Mann-Whitney tests; $p<0.0001$ for both genotypes SR compared to respective control period). The additional food intake in wild-type mice during $S R$ was due to increased feeding during the light phase (Fig. 2C; ANOVA and Bonferroni post-test; control light phase vs. SR light phase; $p<0.001$ ). In consequence, SR caused a dampening in LD feeding rhythms in wild-type mice (Fig. 2C). Per1/2 mutants did not show clear LD feeding rhythms in any condition, but consumed comparable amounts during the light and during the dark phase with no changes during SR (Fig. 2D; ANOVA; $p>0.05$ ). 
A

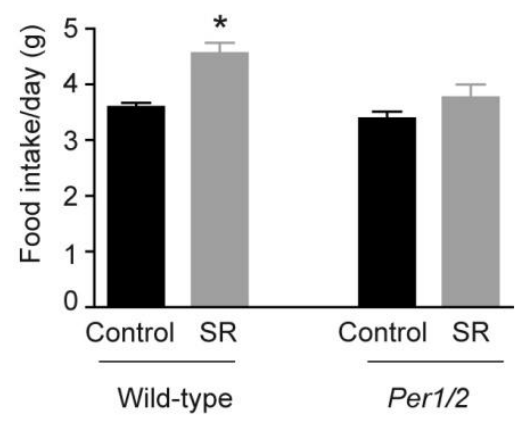

C

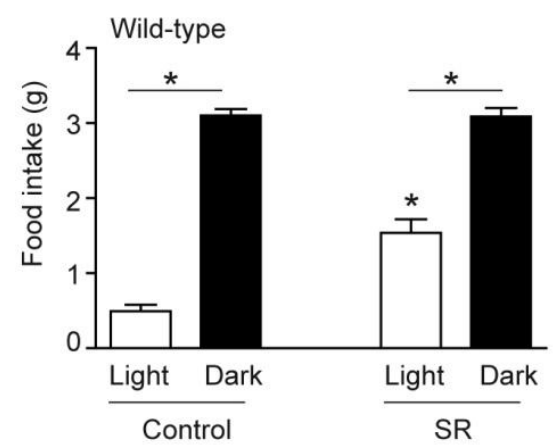

B

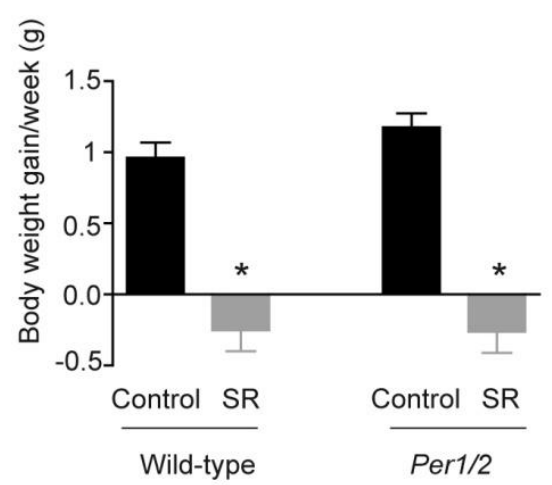

D

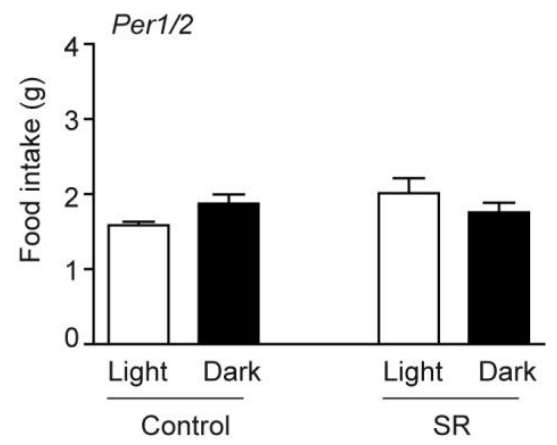

Fig 2: SR leads to metabolic changes in wild-type mice; Per1/2 mutants show attenuated effects.

Food intake per day (A) and body weight gain per week (B) during control and on the fifth day of SR for wildtype and Per1/2 double mutants. C) Food intake during the light phase (ZT0-12) and the dark phase (ZT1824) for wild-types and Per1/2 mutants during control and on the fifth day of SR (D); ANOVA and Bonferroni post-test; wild-type light vs. wild-type dark in control and SR conditions; $p<0.001$. All data are shown as mean +/- SEM; sample sizes are 5-8 for food intake and 35-45 for body weight data; *: p < 0.05, tested against (non SR) control conditions.

\section{Hormonal responses to $\mathrm{SR}$}

In order to test whether some of the observed changes would be attributable to stress effects elicited by our gentle handling SR protocol, we measured diurnal plasma corticosterone profiles during control and SR conditions. In wild-type mice corticosterone levels peaked at the beginning of the dark phase (ZT12) under both control and SR conditions. A two-way ANOVA detected significant effects of time but no differences between control and SR conditions in these animals (Fig. 3A; factor time; $p<0.0001$ ), indicating a robust diurnal variation of corticosterone levels that is not affected by SR. Importantly, no acute manipulation effects were detected at ZT6, at the end of the SR period. Thus, we conclude that our gentle handling protocol did not result in significant hypothalamic-pituitary-adrenal (HPA) axis activation in wild-type mice, unlike shown in other sleep restriction paradigms $[17,19,20,21,40]$. Similar to previous studies of mice with a genetically disrupted clock [37,41,42], Per1/2 deficient mice did not show any diurnal corticosterone rhythms under control conditions. However, SR induced plasma corticosterone levels at noon (ZT6), which 
represents the end of the SR period and therefore might reflect an acute effect of sleep loss or of the manipulation procedure (Fig.3B; two-way ANOVA, factor time $p=0.0002$; interaction $p=$ 0.0086 ; post-test $\mathrm{p}<0.01$ at ZT6).

As the anorexigenic adipokine leptin had previously been shown to be altered after SR in humans and rodents [3,13], we measured plasma leptin during control and SR conditions. To avoid acute effects of the SR manipulations we determined leptin levels at the opposite phase of the LD cycle in the middle of the night (ZT18). At this time plasma leptin was elevated more than 3-fold after SR in wild-type mice (Fig. 3C; t-test; control vs. SR; $p=0.0088$ ). Hyperleptinemia was observed in Per deficient mice already under control conditions, but no further changes were seen after SR (Fig. 3C). We also measured mRNA levels of a number of adipokines in epididymal fat tissue at ZT18. Interestingly, retinol-binding protein 4 (RBP4), an adipokine involved in insulin resistance [43], was up-regulated by SR in wild-type mice (Fig. 3D; Mann-Whitney test; control vs. SR; $p=$ 0.0159). Per1/2 mutants showed elevated RBP4 expression levels during control conditions already, and no changes during SR (Fig.3D). No significant effects of SR were observed on mRNA levels of TNF $\alpha$, Visfatin, Adipsin, PAl-1, Resistin and Adiponectin in wild-type mice (data not shown).

A

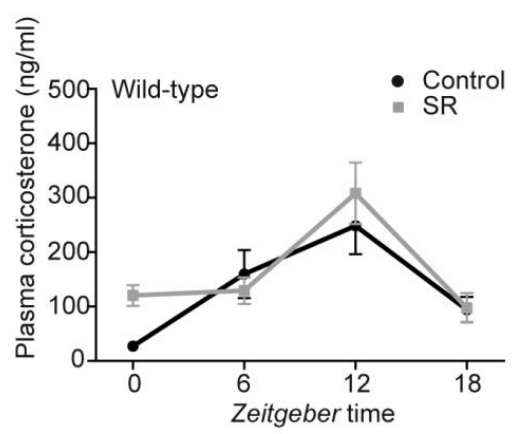

C

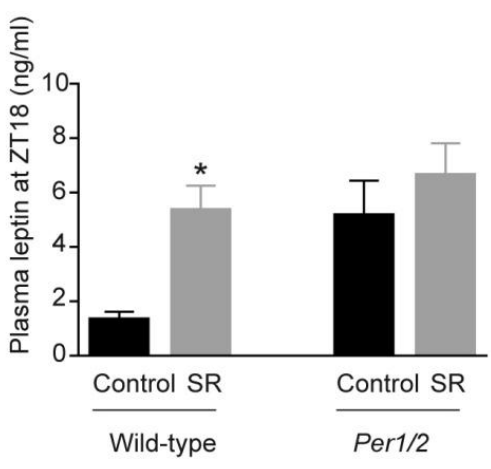

B

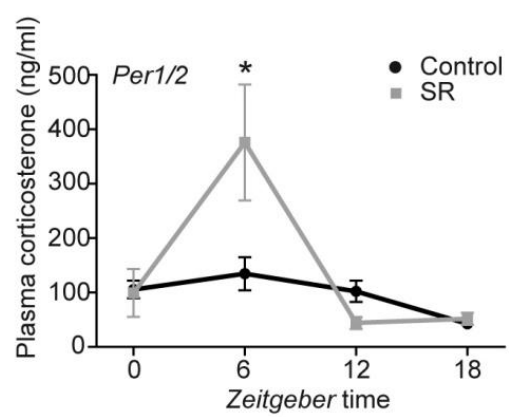

D

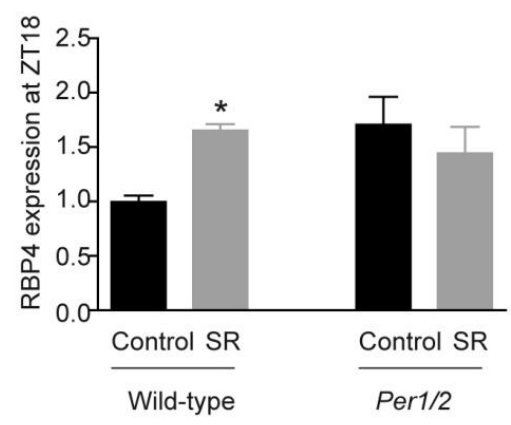

Fig 3: Hormonal changes during SR are less profound in Per1/2 mutants.

Diurnal plasma corticosterone profiles during control (black) and SR (grey) for wild-types (A) and Per1/2 mutants (B). *: $\mathrm{p}<0.05$ Bonferroni post-test test after two-way ANOVA. C) Plasma leptin concentration at ZT 18. D) RBP4 mRNA expression in adipose tissue at ZT18. All SR data were collected on the fifth day of SR. All data are shown as mean +/- SEM, sample sizes are 3-5 per time point; *: $p<0.05$, tested against respective control group. 


\section{SR alters clock controlled metabolic genes in the liver}

So far our data suggest that the circadian clock is likely to mediate metabolic consequences of sleep disruption. Therefore we investigated the expression of several metabolically relevant clock controlled genes in the liver. We found that under control conditions the glucose transporter Glut2 was rhythmically expressed in the liver of wild-type mice peaking at the light-dark transition (ZT 12), which under normal sleep conditions marks the end of the rest (fasting) period (Fig. 4A). SR caused a severe blunting of diurnal Glut2 expression rhythms in wild-type mice with Glut2 mRNA levels remaining constantly low over the course of the day (Fig. 4A). As expected Per1/2 deficient mice showed Glut2 mRNA levels that only marginally fluctuated over the course of the day while SR did not have much influence on overall Glut2 transcription (Fig. 4A). Several clock controlled nuclear hormone receptors have been suggested to link the clock to cellular metabolism [44]. We determined the hepatic expression profiles of two nuclear receptors involved in lipid metabolism, peroxisome proliferator-activated receptor $\alpha$ (PPAR $\alpha)$ and PPAR . Both transcripts showed diurnal expression rhythms under control conditions, and PPARY expression was clearly dampened after SR in wild-type animals (Fig. 4B, C). In Per1/2 deficient mice no significant diurnal rhythmicity was observed in either control or SR conditions (Fig. 4B, C). In summary, SR caused marked changes in the diurnal transcriptional regulation of metabolically relevant genes in wild-type livers. Although Per deficiency seems to potentiate the effects of SR on activity rhythms, only minor metabolic effects were observed as food intake, adipokine levels and hepatic gene transcription were not changed by SR.

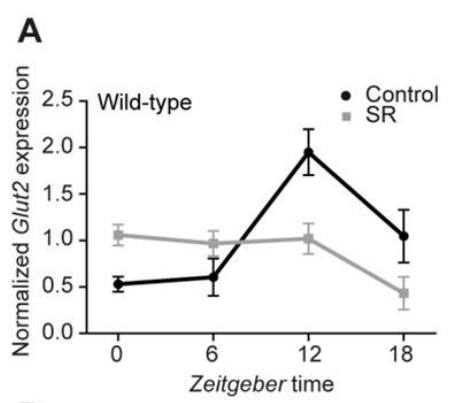

B
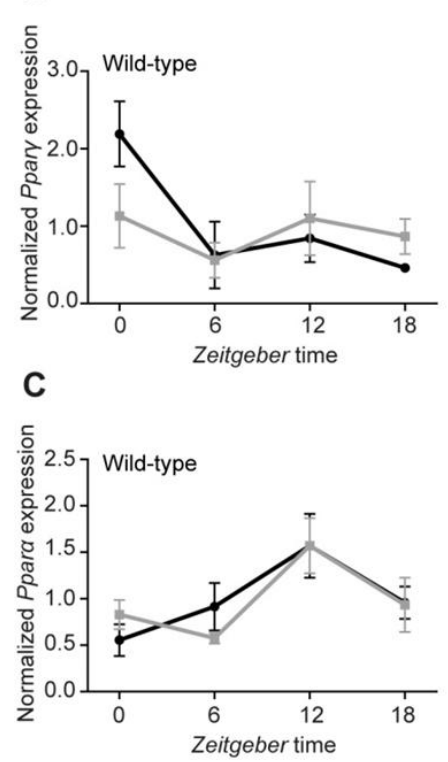

Fig 4: Molecular changes during SR parallel metabolic changes.

Hepatic Glut2 (A), PPARY (B) and PPARQ (C) mRNA expression profiles during control (black) and SR (grey) for wildtypes and Per1/2 mutants. All SR data were collected on the fifth day of SR. All data are shown as mean +/- SEM, sample sizes are 3-4 per time point.

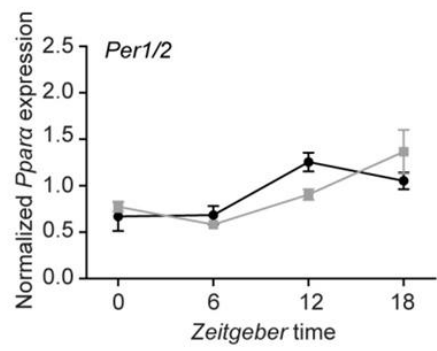




\section{Persistence of SR induced metabolic changes}

In humans night shift work is correlated with long-lasting detrimental effects on metabolism, promoting obesity and the development of the metabolic syndrome [5]. To test whether the metabolic effects we observed after five days of SR would also show persistence after the end of the manipulation, we retested a third cohort of animals seven days after the end of the SR period and compared them to the normal sleep group. Remarkably, we found a number of SR effects that persisted after one week of recovery. Mean locomotor activity profiles of the recovery week still showed decreased activity in the second half of the dark phase (Fig. 5A; two-way ANOVA; Bonferroni post-test; $p<0.01$ ). In contrast, Per deficient mice showed activity patterns that were undistinguishable from their activity during control conditions (Fig. 5B), suggesting that the change in diurnal activity distribution during SR was a rather acute masking effect of sleep loss or of the SR manipulation procedure in the mutants. We also analyzed the persistence of metabolic changes. Food intake during the recovery week remained slightly, but significantly increased in wild-types $(3.60+/-0.07 \mathrm{~g} /$ day during control period vs. $4.01+/-0.04 \mathrm{~g} /$ day on seventh day of recovery; t-test; $p=0.0098)$. Interestingly, wild-type mice also gained more body weight in the recovery period than during control conditions (Fig. 5C and 2B; Mann-Whitney test; $p=0.0452$ ). Again, this effect was not seen in Per deficient mice, which gained even less body weight during recovery than during control conditions (Fig. 5C and 2B; Mann-Whitney test; $p=0.0004$ ). Persistence of metabolic changes was also observed at the hormonal level as plasma leptin remained significantly increased after one week of recovery in wild-types (Fig. 5D and Fig. 3C; ttest; $p=0.0253$ ) whereas no difference was detected in Per1/2 mutants (Fig. 5D and Fig. $3 C$ ). Importantly, even some of the molecular changes described during SR were still present one week after the end of SR. Diurnal variation of hepatic Glut2 expression remained severely dampened and the control group peak at ZT12 was abolished (Fig. $5 \mathrm{E}$ and Fig. 4A), indicating that recovery from even short episodes of sleep disruption might take significantly longer than previously anticipated. 
A

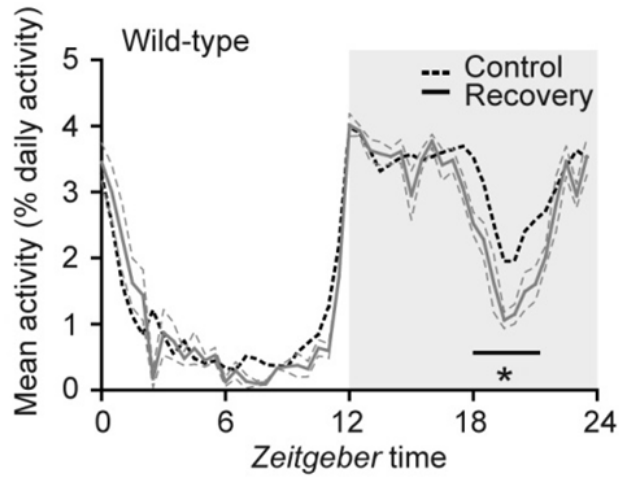

C

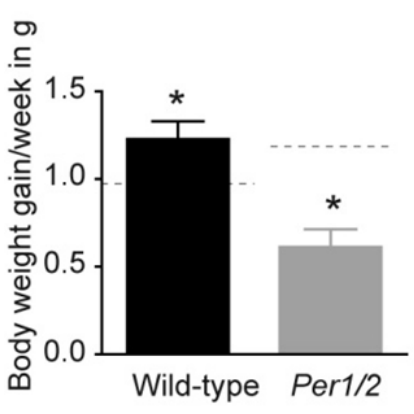

D

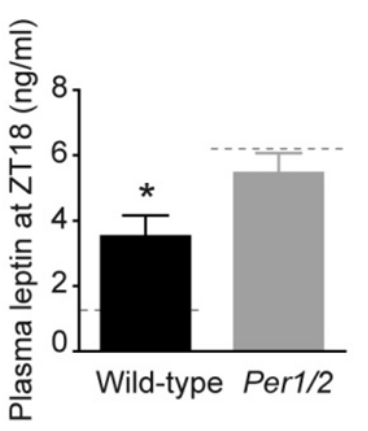

B

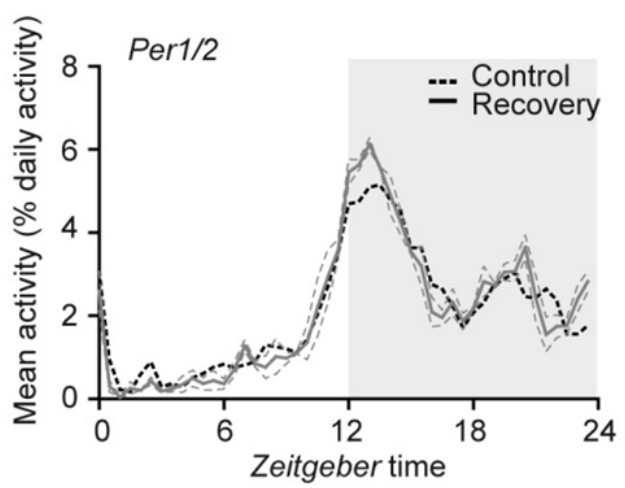

E

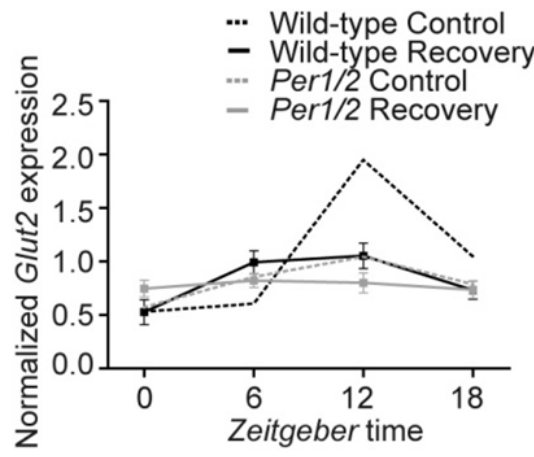

Fig 5: SR induced changes persist for at least one week.

A) Mean infrared activity profiles of wild-type mice in A) and Per1/2 mutants in B) during five days of control and five days of recovery. Data are plotted as relative activity for every $30 \mathrm{~min}$ bin as mean and SEM (dotted lines). Mean values for the control week are re-plotted in dotted lines from Fig. 1. C) Body weight gain per week. The dotted line indicates mean control week levels from Fig. 2 (0.96 g in wild-types and 1.18 $\mathrm{g}$ in Per1/2 mutants). D) Plasma leptin concentration at ZT 18. The dotted line indicates mean levels during control conditions, data are replotted from Fig. $3(1.29 \mathrm{ng} / \mathrm{ml}$ in wild-types and $6.22 \mathrm{ng} / \mathrm{ml}$ in Per1/2 mutants). E) Hepatic Glut2 expression profile during recovery for wild-types (black) and Per1/2 mutants (grey). Expression levels during control conditions are re-plotted from Fig. 4 in dotted lines. All data are shown as mean +/- SEM, sample sizes are 3-5 for activity, leptin and Glut2 data and 16-17 for body weight data; * $p<0.05$, tested against respective control group. 


\section{Discussion}

We show that five consecutive days of SR have persistent effects on wild-type mice at behavioral, physiological and molecular levels. Physiological and molecular SR effects are severely blunted in circadian clock deficient Per $1 / 2$ mutants suggesting that the circadian clock is involved in the regulation of the metabolic response to sleep disruption.

\section{Stress-free SR by gentle handling}

We used a gentle handling protocol to prevent mice from sleeping in the first six hours of the day during their normal rest phase. This protocol did not significantly affect overall activity levels, which would have confounded any metabolic effects of SR. Instead, we observed a diurnal redistribution of activity with a reduction during the second half of the night, likely representing sleep rebound to recover sleep lost during the SR period in the morning. In consequence, our SR protocol likely did not result in extended loss of sleep, but rather represents a change in sleep timing reminiscent of what is observed in human night shift workers [45]. Since in our study we only indirectly assessed sleep by measuring overall activity, it would be interesting to analyze the effects of the SR paradigm by electroencephalography to determine if the similarity between our animal model and the human shift work situation extends to other parameters such as sleep fragmentation and changes in sleep macro architecture $[45,46,47]$. Many SR protocols in rodents, in which animals are sleep restricted for example using a rotating wheel, induce a significant amount of stress measured as an activation of the HPA axis $[17,19,20,21,40]$. Our gentle handling protocol, however, did not result in significant increases in glucocorticoid levels in wild-type mice and, thus, can be considered a stress-free SR protocol for mice.

\section{SR induces metabolic changes in wild-types}

$S R$ induced changes at all levels of metabolic organization in wild-type mice. Sleep restricted animals became hyperphagic with an increase in food intake mainly during the day, their normal rest phase, as was reported before [48]. Despite this, mice did not gain body weight during SR, which has been proposed to result from an increased metabolic rate due to compensatory brown adipose tissue mediated thermogenesis $[13,14,15,39]$. In line with the hyperphagia during SR, after SR wild-type mice showed increased body weight gain, similar to human studies in which SR leads to increased appetite and food intake $[9,10]$ and, in the long run, correlates with increased weight gain [1].

SR was accompanied by increased levels of the anorexigenic adipokine leptin, as was previously reported $[40,49]$, without a decrease in food intake. This state of leptin resistance persisted for at least one week after the end of SR. Hyperleptinemia is a common symptom in obesity and an early marker for the metabolic syndrome $[50,51,52,53]$. The apparent discrepancy between our findings and two other rodent studies showing decreased leptin levels after sleep restriction might be explained by differences in the experimental paradigms (total sleep deprivation vs. SR) or by the different times of day at which leptin was measured $[15,21]$. The mRNA of another adipokine, RBP4, was also elevated in sleep-restricted wild-type mice. RBP4 is member of the 
lipocalin family, transporters of small hydrophobic molecules such as lipids or retinol in the blood. RBP4 is up-regulated in human obesity and metabolic syndrome [54,55] and, if over-expressed in mice, causes insulin resistance [43]. Thus the increase in RBP4 expression observed under SR conditions might contribute to the previously described SR-mediated effects on glucose homeostasis [2].

\section{Metabolic clock target genes are altered during SR}

During and after SR we also found marked changes in the expression profiles of metabolically relevant clock target genes in the wild-type liver. Under control conditions hepatic Glut2 mRNA was rhythmic with highest levels around the light-dark transition (ZT12) as reported before [25]. At this time, towards the end of the rest phase, GLUT2 facilitates the hepatic export of glucose derived from gluconeogenetic and glycogenolytic processes to maintain constant blood glucose levels [25]. SR led to a loss of this rhythm and an overall decrease of expression, reminiscent of what is seen after liver specific disruption of the circadian clock [25]. Reduced GLUT2 levels have been shown to lead to pronounced impairments in glucose homeostatic regulation in mice and humans $[25,56]$. The blunted diurnal Glut2 expression rhythms, together with increased RBP4, might form the molecular basis of the disturbed glucoregulatory response observed during SR $[3,9,11,12]$. Interestingly, the suppression of Glut2 expression persisted for at least one week after the end of SR, indicating a lasting impairment of glucose homeostatic regulation well beyond the actual SR episode. In addition, the expression of the nuclear hormone receptor PPARY was changed after SR. Nuclear receptors are sensors of dietary lipids, vitamins and lipophilic hormones and many are directly clock controlled [44]. PPARY was initially identified as a key regulator of adipogenesis, however more recently it has been shown to be a central regulator of glucose metabolism and energy homeostasis and thiazolidinediones which target PPARY are used to treat diabetes type 2 [57]. Thus, the dampened expression of PPARs that we observed during SR could be a molecular correlate of impaired hepatic energy metabolism.

\section{SR induced effects in Per1/2 mutants}

In Per1/2 mutants, SR caused a reversal of diurnal activity distribution. During SR Per1/2 mutants were predominantly active during the light phase and showed little activity during the whole dark period. This extended rest during the night suggests an increased homeostatic response to $S R$ which is supported by our observation that during SR Per1/2 animals needed more interventions than wild-type animals to be kept awake as has been described before for other clock mutants [58]. This increased sleep drive is in line with electroencephalographical data: although not commented on by the authors, the increase in delta power during slow-wave-sleep rebound after sleep deprivation is stronger in Per1/2 mutants indicative of a sleep homeostatic phenotype [38]. Importantly, these changes in behavioral locomotor activity were completely uncoupled from the metabolic effects, as SR induced metabolic changes were almost absent in Per1/2 mutants. Per1/2 mutants, like wild-types, failed to gain weight during SR. Increased food intake, however, was not seen in the mutants, as was the wild-type increase in body weight gain after the end of SR. Instead, Per1/2 mutants gained less body weight after SR compared to control conditions, in line 
with an absence of hyperphagia and constant leptin and RBP4 levels during and after SR. Of note, however, both leptin and RBP4 mRNA were already elevated in mutants relative to wild-types during control conditions. Increased leptin was shown before for Per1/2 mutants [59] and together with wild-type-like levels of food intake suggests an innate state of leptin resistance in these mice. Thus, Per1/2 mutants already show first signs of disturbed metabolic function under normal sleep conditions, which is in accord with a number of recent studies on metabolic impairments upon clock dysfunction (reviewed in [29]). One might argue that in the mutants such disturbed metabolic baseline state may prevent any further deterioration during SR. However, such a ceiling effect is not very likely, given that much higher plasma leptin levels have been shown in older mice or in mice on a high fat diet [60] and also a more than 3-fold induction of RBP4 expression was found in a conditional Glut4 knock-out mouse model [43]. Thus the adipokine levels of Per1/2 mutants in control conditions are clearly below the saturation point and could potentially increase more, e.g. after extended SR. In addition to the behavioral and endocrine data SR did not alter the expression of several of the metabolic clock controlled genes that were found to be changed in wild-type animals. Some of those, such as Glut2, were previously shown to be locally controlled by the hepatocyte clock machinery [25], indicating that the role of Per genes in metabolic SR responses is not restricted to systemic regulation but extends to local processes within target tissues.

Per gene expression has previously been discussed as a potential mediator of sleep loss responses in the cerebral cortex $[31,32,33]$; we here extend these findings to central appetite regulation and peripheral metabolic function. Our data indicate that sleep may enact regulatory functions on peripheral metabolism via the circadian clock, e.g. by changes in transcription of clock controlled genes $[25,26,30,61,62]$. Of course the question remains whether the absence of SR effects in Per1/2 mutants is the consequence of circadian clock deficiency or rather reflects a pleiotropic non-circadian function of Per genes in metabolic regulation. This question is very difficult to solve, given that all clock genes regulate each other via autoregulatory transcriptional feedback loops. Therefore, in other arrhythmic circadian clock mutants Per transcript levels would also be affected. In Bmal1 deficient mice, for example, Period genes are transcribed at extremely low levels over the course of the day [63]. One approach could be to overexpress Per genes. However, the level and timing of upregulation would have to be very carefully controlled as ectopic expression of Per1 under a constitutive promoter has been shown to impair behavioral rhythms in transgenic rats [64]. A more informative approach to the problem would be to test mice with a conditional disruption of clock or Per function in specific tissues to analyze metabolic SR effects at tissue levels.

In conclusion we show persisting metabolic changes after SR in wild-type mice, which are largely absent in arrhythmic Per1/2 mutants. These changes span all levels of organization, from feeding behavior to hepatic gene expression and are highly reminiscent of metabolic alterations observed in human shift workers. Together, our findings suggest that the circadian clock machinery is a key regulator in the long-term metabolic adjustment by SR and that circadian animal models may provide a means to identifying new mechanism-based therapies against the adverse effects of night shift work in humans. 


\section{Acknowledgments}

We thank Johanna Barclay and Jochen Fründ for helpful comments on the manuscript. HO is an Emmy Noether Fellow of the DFG. This work is supported by the German Research Foundation (DFG; SFB 654) to HO \& HL. JH is supported by the Max Planck Society.

\section{References}

1. Van Cauter E, Knutson KL (2008) Sleep and the epidemic of obesity in children and adults. Eur J Endocrinol 159 Suppl 1: S59-66.

2. Knutson KL (2007) Impact of sleep and sleep loss on glucose homeostasis and appetite regulation. Sleep Med Clin 2: 187-197.

3. Knutson KL, Spiegel K, Penev P, Van Cauter E (2007) The metabolic consequences of sleep deprivation. Sleep Med Rev 11: 163-178.

4. Knutson KL, Van Cauter E (2008) Associations between sleep loss and increased risk of obesity and diabetes. Ann N Y Acad Sci 1129: 287-304.

5. Boivin DB, Tremblay GM, James FO (2007) Working on atypical schedules. Sleep Med 8: 578589.

6. Karlsson B, Knutsson A, Lindahl B (2001) Is there an association between shift work and having a metabolic syndrome? Results from a population based study of 27,485 people. Occup Environ Med 58: 747-752.

7. Antunes LC, Levandovski R, Dantas G, Caumo W, Hidalgo MP (2010) Obesity and shift work: chronobiological aspects. Nutr Res Rev 23: 155-168.

8. Szosland D (2010) Shift work and metabolic syndrome, diabetes mellitus and ischaemic heart disease. Int J Occup Med Environ Health 23: 287-291.

9. Spiegel K, Tasali E, Penev P, Cauter EV (2004) Brief Communication: Sleep Curtailment in Healthy Young Men Is Associated with Decreased Leptin Levels, Elevated Ghrelin Levels, and Increased Hunger and Appetite. Ann Intern Med 141: 846-850.

10. Brondel L, Romer MA, Nougues PM, Touyarou P, Davenne D (2010) Acute partial sleep deprivation increases food intake in healthy men. Am J Clin Nutr 91: 1550-1559.

11. Schmid SM, Hallschmid M, Jauch-Chara K, Wilms B, Lehnert H, et al. (2011) Disturbed glucoregulatory response to food intake after moderate sleep restriction. Sleep 34: 371377.

12. Spiegel K, Leproult R, Van Cauter E (1999) Impact of sleep debt on metabolic and endocrine function. Lancet 354: 1435-1439.

13. Everson CA, Crowley WR (2004) Reductions in circulating anabolic hormones induced by sustained sleep deprivation in rats. Am J Physiol Endocrinol Metab 286: E1060-1070.

14. Koban M, Sita LV, Le WW, Hoffman GE (2008) Sleep deprivation of rats: the hyperphagic response is real. Sleep 31: 927-933. 
15. Koban M, Swinson KL (2005) Chronic REM-sleep deprivation of rats elevates metabolic rate and increases UCP1 gene expression in brown adipose tissue. Am J Physiol Endocrinol Metab 289: E68-74.

16. Rechtschaffen A, Bergmann BM (1995) Sleep deprivation in the rat by the disk-over-water method. Behav Brain Res 69: 55-63.

17. Koban M, Le WW, Hoffman GE (2006) Changes in hypothalamic corticotropin-releasing hormone, neuropeptide $\mathrm{Y}$, and proopiomelanocortin gene expression during chronic rapid eye movement sleep deprivation of rats. Endocrinology 147: 421-431.

18. Yehuda S, Sredni B, Carasso RL, Kenigsbuch-Sredni D (2009) REM sleep deprivation in rats results in inflammation and interleukin-17 elevation. J Interferon Cytokine Res 29: 393398.

19. Mongrain V, Hernandez SA, Pradervand S, Dorsaz S, Curie T, et al. (2010) Separating the contribution of glucocorticoids and wakefulness to the molecular and electrophysiological correlates of sleep homeostasis. Sleep 33: 1147-1157.

20. Meerlo P, Koehl M, van der Borght K, Turek FW (2002) Sleep restriction alters the hypothalamic-pituitary-adrenal response to stress. J Neuroendocrinol 14: 397-402.

21. Bodosi B, Gardi J, Hajdu I, Szentirmai E, Obal F, Jr., et al. (2004) Rhythms of ghrelin, leptin, and sleep in rats: effects of the normal diurnal cycle, restricted feeding, and sleep deprivation. Am J Physiol Regul Integr Comp Physiol 287: R1071-1079.

22. Laposky AD, Bass J, Kohsaka A, Turek FW (2008) Sleep and circadian rhythms: key components in the regulation of energy metabolism. FEBS Lett 582: 142-151.

23. Bray MS, Young ME (2009) The role of cell-specific circadian clocks in metabolism and disease. Obes Rev 10 Suppl 2: 6-13.

24. Zheng B, Albrecht U, Kaasik K, Sage M, Lu W, et al. (2001) Nonredundant roles of the mPer1 and mPer2 genes in the mammalian circadian clock. Cell 105: 683-694.

25. Lamia KA, Storch KF, Weitz CJ (2008) Physiological significance of a peripheral tissue circadian clock. Proc Natl Acad Sci U S A 105: 15172-15177.

26. Marcheva B, Ramsey KM, Buhr ED, Kobayashi Y, Su H, et al. (2010) Disruption of the clock components CLOCK and BMAL1 leads to hypoinsulinaemia and diabetes. Nature 466: 627631.

27. Yang S, Liu A, Weidenhammer A, Cooksey RC, McClain D, et al. (2009) The Role of mPer2 Clock Gene in Glucocorticoid and Feeding Rhythms. Endocrinology 150: 2153-2160.

28. Dallmann R, Weaver DR (2010) Altered body mass regulation in male mPeriod mutant mice on high-fat diet. Chronobiol Int 27: 1317-1328.

29. Kovac J, Husse J, Oster H (2009) A time to fast, a time to feast: the crosstalk between metabolism and the circadian clock. Mol Cells 28: 75-80.

30. Turek FW, Joshu C, Kohsaka A, Lin E, Ivanova G, et al. (2005) Obesity and metabolic syndrome in circadian Clock mutant mice. Science 308: 1043-1045.

31. Franken P, Thomason R, Heller HC, O'Hara BF (2007) A non-circadian role for clock-genes in sleep homeostasis: a strain comparison. BMC Neurosci 8: 87. 
32. Wisor JP, O'Hara BF, Terao A, Selby CP, Kilduff TS, et al. (2002) A role for cryptochromes in sleep regulation. BMC Neurosci 3: 20.

33. Wisor JP, Pasumarthi RK, Gerashchenko D, Thompson CL, Pathak S, et al. (2008) Sleep deprivation effects on circadian clock gene expression in the cerebral cortex parallel electroencephalographic differences among mouse strains. J Neurosci 28: 7193-7201.

34. Zheng B, Larkin DW, Albrecht U, Sun ZS, Sage M, et al. (1999) The mPer2 gene encodes a functional component of the mammalian circadian clock. Nature 400: 169-173.

35. Tobler I, Jaggi K (1987) Sleep and EEG spectra in the Syrian hamster (Mesocricetus auratus) under baseline conditions and following sleep deprivation. J Comp Physiol [A] 161: 449459.

36. Franken P, Tobler I, Borbely AA (1993) Effects of 12-h sleep deprivation and of 12 -h cold exposure on sleep regulation and cortical temperature in the rat. Physiol Behav 54: 885894.

37. Oster H, Damerow S, Kiessling S, Jakubcakova V, Abraham D, et al. (2006) The circadian rhythm of glucocorticoids is regulated by a gating mechanism residing in the adrenal cortical clock. Cell Metab 4: 163-173.

38. Shiromani PJ, Xu M, Winston EM, Shiromani SN, Gerashchenko D, et al. (2004) Sleep rhythmicity and homeostasis in mice with targeted disruption of mPeriod genes. Am J Physiol Regul Integr Comp Physiol 287: R47-57.

39. Rechtschaffen A, Gilliland MA, Bergmann BM, Winter JB (1983) Physiological correlates of prolonged sleep deprivation in rats. Science 221: 182-184.

40. Mullington JM, Haack M, Toth M, Serrador JM, Meier-Ewert HK (2009) Cardiovascular, inflammatory, and metabolic consequences of sleep deprivation. Prog Cardiovasc Dis 51: 294-302.

41. Yang S, Liu A, Weidenhammer A, Cooksey RC, McClain D, et al. (2009) The role of mPer2 clock gene in glucocorticoid and feeding rhythms. Endocrinology 150: 2153-2160.

42. Kennaway DJ, Owens JA, Voultsios A, Varcoe TJ (2006) Functional central rhythmicity and light entrainment, but not liver and muscle rhythmicity, are Clock independent. Am J Physiol Regul Integr Comp Physiol 291: R1172-1180.

43. Yang Q, Graham TE, Mody N, Preitner F, Peroni OD, et al. (2005) Serum retinol binding protein 4 contributes to insulin resistance in obesity and type 2 diabetes. Nature 436: 356-362.

44. Yang X, Downes M, Yu RT, Bookout AL, He W, et al. (2006) Nuclear receptor expression links the circadian clock to metabolism. Cell 126: 801-810.

45. Akerstedt T (2003) Shift work and disturbed sleep/wakefulness. Occup Med (Lond) 53: 89-94.

46. Drake CL, Roehrs T, Richardson G, Walsh JK, Roth T (2004) Shift work sleep disorder: prevalence and consequences beyond that of symptomatic day workers. Sleep 27: 14531462.

47. Akerstedt T (1998) Shift work and disturbed sleep/wakefulness. Sleep Med Rev 2: 117-128.

48. Salgado-Delgado R, Angeles-Castellanos M, Buijs MR, Escobar C (2008) Internal desynchronization in a model of night-work by forced activity in rats. Neuroscience 154 : 922-931. 
49. Vgontzas AN, Zoumakis E, Bixler EO, Lin HM, Follett H, et al. (2004) Adverse effects of modest sleep restriction on sleepiness, performance, and inflammatory cytokines. J Clin Endocrinol Metab 89: 2119-2126.

50. Yildiz BO, Suchard MA, Wong ML, McCann SM, Licinio J (2004) Alterations in the dynamics of circulating ghrelin, adiponectin, and leptin in human obesity. Proc Natl Acad Sci U S A 101: 10434-10439.

51. Deng Y, Scherer PE (2010) Adipokines as novel biomarkers and regulators of the metabolic syndrome. Ann N Y Acad Sci 1212: E1-E19.

52. Licinio J, Mantzoros C, Negrao AB, Cizza G, Wong ML, et al. (1997) Human leptin levels are pulsatile and inversely related to pituitary-adrenal function. Nat Med 3: 575-579.

53. Kotani K, Sakane N (2011) Leptin:adiponectin ratio and metabolic syndrome in the general Japanese population. Korean J Lab Med 31: 162-166.

54. Mostafaie N, Sebesta C, Zehetmayer S, Jungwirth S, Huber KR, et al. (2011) Circulating retinolbinding protein 4 and metabolic syndrome in the elderly. Wien Med Wochenschr.

55. Graham TE, Yang Q, Bluher M, Hammarstedt A, Ciaraldi TP, et al. (2006) Retinol-binding protein 4 and insulin resistance in lean, obese, and diabetic subjects. N Engl J Med 354: 2552-2563.

56. Santer R, Steinmann B, Schaub J (2002) Fanconi-Bickel syndrome--a congenital defect of facilitative glucose transport. Curr Mol Med 2: 213-227.

57. Kawai M, Rosen CJ (2010) PPARgamma: a circadian transcription factor in adipogenesis and osteogenesis. Nat Rev Endocrinol 6: 629-636.

58. Laposky A, Easton A, Dugovic C, Walisser J, Bradfield C, et al. (2005) Deletion of the mammalian circadian clock gene BMAL1/Mop3 alters baseline sleep architecture and the response to sleep deprivation. Sleep 28: 395-409.

59. Fu L, Patel MS, Bradley A, Wagner EF, Karsenty G (2005) The molecular clock mediates leptinregulated bone formation. Cell 122: 803-815.

60. Ahren B, Mansson S, Gingerich RL, Havel PJ (1997) Regulation of plasma leptin in mice: influence of age, high-fat diet, and fasting. Am J Physiol 273: R113-120.

61. Sadacca LA, Lamia KA, Delemos AS, Blum B, Weitz CJ (2010) An intrinsic circadian clock of the pancreas is required for normal insulin release and glucose homeostasis in mice. Diabetologia.

62. Doi R, Oishi K, Ishida N (2010) CLOCK regulates circadian rhythms of hepatic glycogen synthesis through transcriptional activation of Glycogen synthase 2. Journal of Biological Chemistry: -

63. Bunger MK, Wilsbacher LD, Moran SM, Clendenin C, Radcliffe LA, et al. (2000) Mop3 is an essential component of the master circadian pacemaker in mammals. Cell 103: 10091017.

64. Numano R, Yamazaki S, Umeda N, Samura T, Sujino M, et al. (2006) Constitutive expression of the Period1 gene impairs behavioral and molecular circadian rhythms. Proc Natl Acad Sci U S A 103: 3716-3721. 


\section{Chapter 4: Conclusion and Perspectives}

Since each Results Section of this thesis is concluded with a separate Discussion, this part will provide a more comprehensive conclusion linking the different parts of this thesis and giving some perspectives on future research.

\section{A role for the clock as integrator between different physiological functions}

As described in the Introduction a central unsolved question is what adaptive significance clocks have. It seems likely that the circadian clock provides a fitness advantage, since clocks are universal to nearly all organisms and have evolved in all domains of life, probably by a convergent mechanism (Pittendrigh, 1993). In this context, the finding that all mouse clock mutants that have been discovered so far are viable and most of them seem not to have obvious impairments was very surprising. Within the last years, however, reports on various phenotypes of such clock-less mutants accumulated, suggesting a role of the circadian clock in processes such as cell-cycle regulation (Matsuo et al., 2003) and DNA damage repair (Oklejewicz et al., 2008), cancer development (Fu et al., 2002), aging (Kondratov et al., 2006), psychiatric diseases (Mukherjee et al.; Roybal et al., 2007; Hampp et al., 2008), memory formation (Garcia et al., 2000; Van der Zee et al., 2008), the reward system (Abarca et al., 2002; McClung et al., 2005; Spanagel et al., 2005) and the regulation of sleep (reviewed in (Landgraf et al., 2011). However, the interpretation of the role of the circadian clock in these processes is complicated by the fact that most of the described phenotypes are restricted to a specific clock gene and are often not found in other clock mutants, raising the question of pleiotropic effects of different clock components. A phenotype which seems more consistent across different clock mutant mice is altered metabolic homeostasis (Rudic et al., 2004; Turek et al., 2005; Yang et al., 2009; Dallmann and Weaver, 2010; Marcheva et al., 2010). I contributed to a published review on the interaction of clocks and metabolism (Kovac et al., 2009). This publication is included in the Introduction of this thesis. Furthermore, desynchrony within the circadian system, which is observed during jet lag and shift work, is associated with metabolic impairments (Karlsson et al., 2001; Scheer et al., 2009; Antunes et al., 2010; Szosland, 2010). Thus it appears that one major function of the circadian system is to keep internal synchrony of physiological functions. If such synchrony is lost, metabolic impairments arise. Sleep curtailment, which is very common in our industrialized society, has also been correlated to negative metabolic consequences such obesity (Knutson et al., 2007; Knutson and Van Cauter, 2008). Thus both, sleep and clock disruption seem to result in metabolic impairment.

At this point one part of this thesis ties in and addresses the potential role of the circadian clock as a mediator between sleep and metabolism. We asked whether the loss of a functional circadian clock in Per $1 / 2$ mutants changes the response of the metabolic system to sleep disturbance. We demonstrated that Per1/2 mutants indeed show less metabolic alterations after sleep disturbance, indicating that the circadian clock is involved in regulating this response. This study raises the possibility that the circadian clock is an important integrator between two 
different physiologically relevant systems, namely sleep and metabolic regulation. Thus our work provides evidence for a more complex role of the circadian system than just synchronizing physiology to external time. Our work is potentially of clinical relevance since sleep curtailment as well as obesity are major problems of industrialized societies and deepening the understanding of the underlying mechanisms might contribute to the development of new pharmaceutical approaches.

\section{Redundant pathways within the circadian timing system}

Within the last decade it became increasingly clear that the mammalian circadian timing system is not as centralized as commonly believed with a pacemaker restricted to the SCN but that many highly autonomous clocks tick in all different tissues of the body (Tosini and Menaker, 1996; Balsalobre et al., 1998; Yamazaki et al., 2000; Yoo et al., 2004). Therefore, currently, one of the most important open questions in the circadian field is how this network of different clocks is organized and what adaptive significance such a multi-clock system provides. Why is it better to have local clocks in all organs which need be synchronized to each other as well as to external time, than having a system which centrally controls all physiological rhythms? At a first glance it might appear that such a multi-clock system is prone to internal desynchrony which, as described above, can have adverse consequences. However, a multi-clock system would have the advantage that redundancy will protect the system against perturbation and thus stabilize it. At the same time such a complex system might be more plastic and fine-tunable and therefore better suited to adapt to a complex environment. 

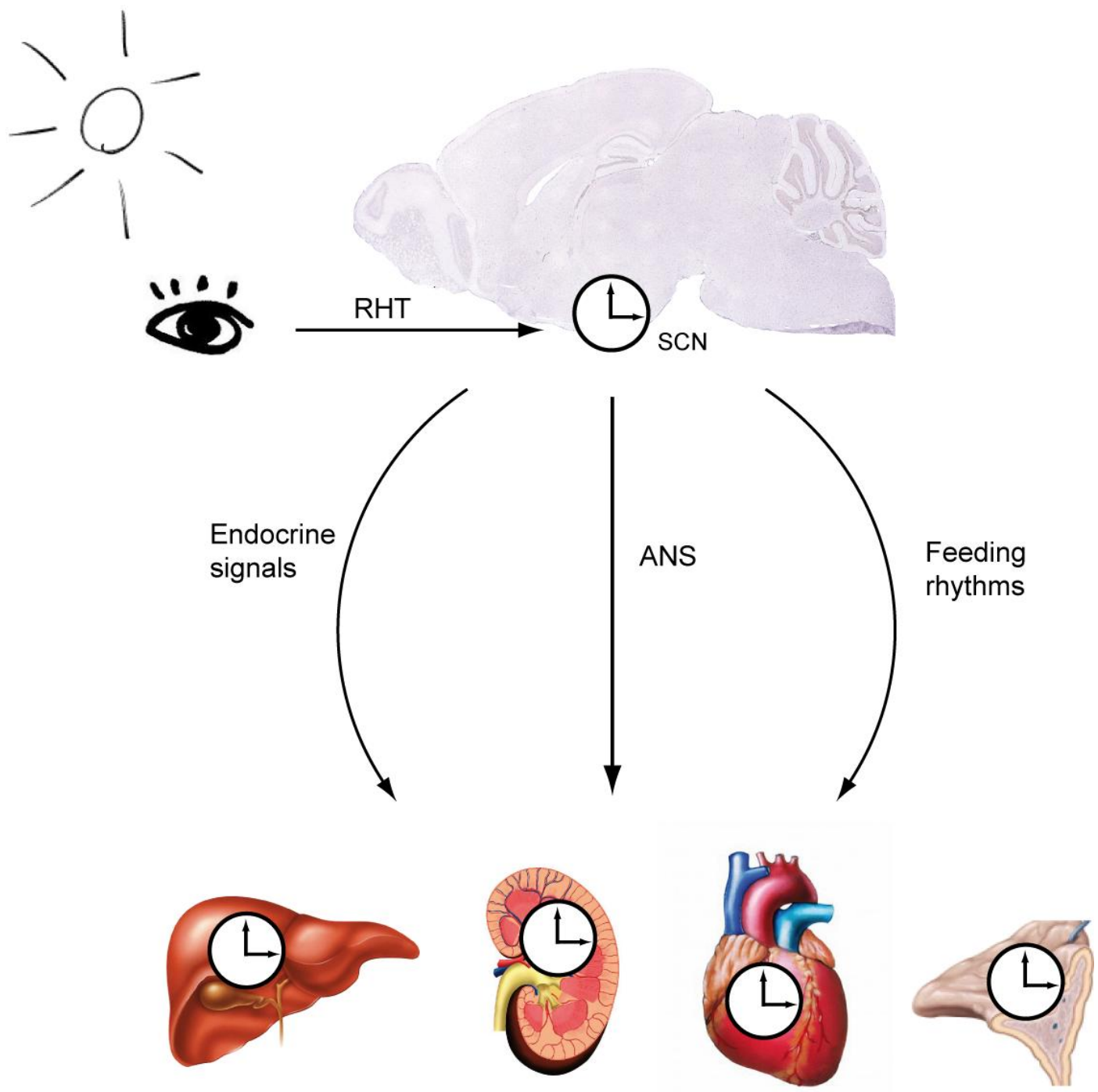

Fig.22: A hierarchical network of clocks.

The SCN synchronizes the periphery via the autonomic nervous system (ANS), via endocrine signals (e.g. corticosterone) and indirectly via feeding rhythms. Light reaches the SCN via the retino-hypothalamic tract (RHT). The widely held view is that the SCN is necessary for entrainment of the periphery to light-dark cycles. We show, in contrast, that the SCN clock is dispensable for light entrainment of the periphery. In conditions devoid of time information, however, the SCN clock is necessary to sustain rhythms in peripheral organs.

The second part of this thesis investigated the question how centralized the mammalian circadian system is. According to the current view the SCN synchronizes peripheral clocks neuronally via the autonomic nervous system (ANS) as well as hormonally (e.g. via corticosterone and melatonin) (Fig.22) (Dibner et al., 2010). In addition, the SCN might indirectly synchronize the periphery by regulating feeding rhythms, as food has been shown to be a potent Zeitgeber for peripheral clocks (Damiola et al., 2000). The widely held view of a hierarchical system with a master pacemaker in the SCN which is necessary to synchronize the periphery in vivo mainly came from SCN lesion studies. However, this very invasive approach is complicated by the inevitable destruction of 
neuronal pathways which transmit light information from the eye to the periphery. We used a non-invasive genetic approach to disrupt the clock in the SCN and analyzed peripheral clocks in this model.

To our surprise peripheral clocks sustained rhythmicity in light-dark conditions in the absence of a functional SCN clock, suggesting that the SCN clock is dispensable for synchronization of peripheral clocks to the light dark cycle. Although the SCN is necessary for light entrainment of peripheral clocks, a rhythmic SCN is not. However, upon release into constant darkness, peripheral clock rhythms were markedly dampened and we expect that these clocks will become completely arrhythmic with persistent exposure to DD. Thus, it seems that there are two partially redundant mechanisms by which peripheral clocks can be entrained: either by the endogenous SCN clock (which is the only possibility in DD) or by light. This adds another example for redundancy to the circadian system which might stabilize and fine tune the system. This redundancy is reminiscent of other aspects of the circadian system: in mammals, all clock genes have paralogs with partially redundant function with the exception of Bmal1 (but see (Shi et al., 2010)). Principally circadian rhythmicity can be maintained in the absence of one of the paralogs (e.g. in Per1 or Per2 mutants); this rhythmicity, however, is usually less stable as seen for example in the increase in cycle to cycle onset variation (Spoelstra et al., 2004; Pendergast and Yamazaki, 2011). Also at the level of input to the circadian system there is substantial redundancy and, both, rod and cone photoreceptors as well as the novel photoreceptor melanopsin contribute to the photic entrainment of the circadian clock (Hattar et al., 2003).

But, what is the role of the SCN clock if it is principally dispensable in LD? Our work also gives first clues: although we see rhythmic corticosterone release in LD, this rhythm is markedly dampened in SCN clock-deficient mice, suggesting that the interplay between the central and local peripheral clocks is necessary to amplify the signal and yield maximal amplitude rhythmicity. Thus an additional advantage of a multi-level circadian gating would be that signals can be amplified. As mentioned above, it is likely that the advantage of a multi-clock system would become more apparent under challenging conditions. One such potential perturbation would be an experimental jet lag paradigm. It would be interesting to analyze the role of the SCN clock during re-entrainment of the multi-clock system after a shift in the light dark cycle by following the kinetics of re-entrainment of different peripheral clocks as it has been previously described in wild-types (Kiessling et al., 2010).

\section{Conditional clock mutants}

After having described the existence endogenous clocks in different tissues of the body, one focus of the circadian field is now on investigating the functional role of individual peripheral clocks in vivo. A role for the adrenal clock has been demonstrated in gating the adrenal's sensitivity to ACTH and thereby regulating the circadian rhythm of corticosterone release (Oster et al., 2006b). More recently it was shown, that a conditional disruption of the liver clock results in impaired glucose homeostasis (Lamia et al., 2008), whereas conditionally deleting the pancreatic $\beta$-cell 
clocks leads to a diabetic phenotype in mice (Marcheva et al., 2010; Sadacca et al., 2010). This is in line with the finding that within each organ 5-10\% of the transcriptome is clock controlled, however, the overlap of such rhythmic genes between different tissues is relatively small, indicating local clocks regulate those genes which are essential for the physiologic function of this respective organ (Akhtar et al., 2002; Panda et al., 2002b; Oster et al., 2006a; Storch et al., 2007). If this control is impaired, as is the case in tissue clock knock-outs, then this organ's function is markedly impaired resulting in the described physiological alterations. Most studies make use of the Cre/loxp system to achieve spatially controlled genetic disruption. Alternatively the tetracycline transactivator (tTA) system may be used (Hong et al., 2007). While it appears that the Cre system is suitable to specifically target peripheral clocks, for the brain, this seems more complicated because genes with expression patterns that are restricted to a specific brain nucleus are rare. However, the generation of Cre driver lines for specific brain regions is clearly necessary, because particularly the function of brain clocks remains unsolved.

A third part of this thesis describes the generation and characterization of a Synaptotagmin 10 (Syt10) Cre driver mouse line, which was designed to specifically target the SCN. A high throughput screen, which aimed at finding genes specifically expressed in the SCN, revealed that there is no gene with expression restricted to the SCN. We therefore chose Syt10 which was the best candidate concerning the ratio of strong, ubiquitous expression in the SCN and few additional expression sites. We provide a detailed characterization of the expression sites of the Syt10Cre driver which is strongly expressed in the majority of SCN cells and also in additional brain areas. We deleted the essential clock gene Bmal1 using the Syt $10^{\text {Cre }}$ driver and showed that this results in behavioral arrhythmicity as expected from an efficient SCN knock-out. We further used these arrhythmic Syt $10^{\mathrm{Cr} / \mathrm{Cre}} \mathrm{Bmal1}{ }^{\mathrm{fl}-}$ - mice to analyze the role of the SCN clock in light entrainment of the periphery as discussed above. The Syt $10^{\text {Cre }}$ line, however, though probably the best SCN Cre driver currently available, is clearly not completely $\mathrm{SCN}$ specific, and in the future a more specific tool for manipulating the $\mathrm{SCN}$ in vivo will be necessary.

The fourth part of this thesis aimed at developing a system which will enable more specific targeting of the Cre recombinase. We developed a binary Cre system, termed split Cre system, which is based on the complementation of two Cre parts (N-Cre and C-Cre) which individually are not active, but will reconstitute functional Cre when co-expressed under the control of different but overlapping promoters. The efficiency of the system had been confirmed in cell culture experiments in our lab previously. The aim was to generate a Cre driver mouse for the core subregion of the $\mathrm{SCN}$, which is thought to be its photic input region. We aimed at using this SCN core specific Cre driver to set very localized genetic lesions and to analyze its effects on circadian output. We chose the Syt10 promoter to drive N-Cre and the VIP promoter to drive C-Cre. Unfortunately, due to technical difficulties, which are elaborated in the Discussion of this respective section of this thesis, we are not yet at a stage where we can use the split Cre mice to ablate SCN core cells. It seems that the efficiency of our system is too low, potentially due to insufficient expression of one of the Cre parts. Future research should aim at optimizing this combinatorial system in order to achieve very specific and at the same time efficient 
recombination in the SCN core. It appears that specificity and efficiency are two prerequisites for successful Cre mediated conditional gene disruption, which can be difficult to meet at the same time. However, in order to achieve SCN specific or SCN sub-region specific recombination, a combinatorial system is clearly necessary due to the lack of specific promoters. A slightly modified approach to solve this problem would be to express one Cre part using a transgenic mouse model (e.g. VIP ${ }^{\text {C-cre }}$ ), but delivering the second Cre part virally by injection into the third ventricle. In that case the second Cre part could even be driven by a relatively strong and ubiquitous promoter to enhance efficiency, because the VIP driven C-Cre expression in combination with the diffusion radius of the virus should provide sufficient specificity. Alternatively, the combined use of Cre and Flippase recombinase systems could prove successful to achieve very specific recombination (Luo et al., 2008). In summary, combinatorial Cre systems provide promising means to achieve very specific genetic manipulation in mice. 


\section{References}

Abarca C, Albrecht U, Spanagel R (2002) Cocaine sensitization and reward are under the influence of circadian genes and rhythm. Proc Natl Acad Sci U S A 99:9026-9030.

Abe M, Herzog ED, Yamazaki S, Straume M, Tei H, Sakaki Y, Menaker M, Block GD (2002) Circadian rhythms in isolated brain regions. J Neurosci 22:350-356.

Abizaid A, Horvath B, Keefe DL, Leranth C, Horvath TL (2004) Direct visual and circadian pathways target neuroendocrine cells in primates. Eur J Neurosci 20:2767-2776.

Abraham D, Dallmann R, Steinlechner S, Albrecht U, Eichele G, Oster H (2006) Restoration of circadian rhythmicity in circadian clock-deficient mice in constant light. J Biol Rhythms 21:169-176.

Abrahamson EE, Moore RY (2001) Suprachiasmatic nucleus in the mouse: retinal innervation, intrinsic organization and efferent projections. Brain Res 916:172-191.

Aguilar-Roblero R, Garcia-Hernandez F, Aguilar R, Arankowsky-Sandoval G, Drucker-Colin R (1986) Suprachiasmatic nucleus transplants function as an endogenous oscillator only in constant darkness. Neurosci Lett 69:47-52.

Ahren B, Mansson S, Gingerich RL, Havel PJ (1997) Regulation of plasma leptin in mice: influence of age, high-fat diet, and fasting. Am J Physiol 273:R113-120.

Akhtar RA, Reddy AB, Maywood ES, Clayton JD, King VM, Smith AG, Gant TW, Hastings MH, Kyriacou CP (2002) Circadian cycling of the mouse liver transcriptome, as revealed by cDNA microarray, is driven by the suprachiasmatic nucleus. Curr Biol 12:540-550.

Albrecht U, Sun ZS, Eichele G, Lee CC (1997) A differential response of two putative mammalian circadian regulators, mper1 and mper2, to light. Cell 91:1055-1064.

Allen G, Rappe J, Earnest DJ, Cassone VM (2001) Oscillating on borrowed time: diffusible signals from immortalized suprachiasmatic nucleus cells regulate circadian rhythmicity in cultured fibroblasts. J Neurosci 21:7937-7943.

Antle MC, Mistlberger RE (2000) Circadian clock resetting by sleep deprivation without exercise in the Syrian hamster. J Neurosci 20:9326-9332.

Antunes LC, Levandovski R, Dantas G, Caumo W, Hidalgo MP (2010) Obesity and shift work: chronobiological aspects. Nutr Res Rev 23:155-168.

Aschoff J (1965) Circadian Rhythms in Man. Science 148:1427-1432.

Asher G, Reinke H, Altmeyer M, Gutierrez-Arcelus M, Hottiger MO, Schibler U (2010) Poly(ADPRibose) Polymerase 1 Participates in the Phase Entrainment of Circadian Clocks to Feeding. Cell 142:943-953.

Aton SJ, Colwell CS, Harmar AJ, Waschek J, Herzog ED (2005) Vasoactive intestinal polypeptide mediates circadian rhythmicity and synchrony in mammalian clock neurons. Nat Neurosci 8:476-483.

Avivi A, Oster H, Joel A, Beiles A, Albrecht U, Nevo E (2002) Circadian genes in a blind subterranean mammal II: conservation and uniqueness of the three Period homologs in 
the blind subterranean mole rat, Spalax ehrenbergi superspecies. Proc Natl Acad Sci U S A 99:11718-11723.

Balsalobre A, Damiola F, Schibler U (1998) A serum shock induces circadian gene expression in mammalian tissue culture cells. Cell 93:929-937.

Bando H, Nishio T, van der Horst GT, Masubuchi S, Hisa Y, Okamura H (2007) Vagal regulation of respiratory clocks in mice. J Neurosci 27:4359-4365.

Beaver LM, Gvakharia BO, Vollintine TS, Hege DM, Stanewsky R, Giebultowicz JM (2002) Loss of circadian clock function decreases reproductive fitness in males of Drosophila melanogaster. Proc Natl Acad Sci U S A 99:2134-2139.

Bell-Pedersen D, Cassone VM, Earnest DJ, Golden SS, Hardin PE, Thomas TL, Zoran MJ (2005) Circadian rhythms from multiple oscillators: lessons from diverse organisms. Nat Rev Genet 6:544-556.

Benedict C, Hallschmid M, Lassen A, Mahnke C, Schultes B, Birgir Schioth H, Born J, Lange T (2011) Acute sleep deprivation reduces energy expenditure in healthy men. Am J Clin Nutr.

Bergmann BM, Everson CA, Kushida CA, Fang VS, Leitch CA, Schoeller DA, Refetoff S, Rechtschaffen A (1989) Sleep deprivation in the rat: V. Energy use and mediation. Sleep 12:31-41.

Berson DM, Dunn FA, Takao M (2002) Phototransduction by retinal ganglion cells that set the circadian clock. Science 295:1070-1073.

Bobrzynska KJ, Mrosovsky N (1998) Phase shifting by novelty-induced running: activity doseresponse curves at different circadian times. J Comp Physiol [A] 182:251-258.

Bodosi B, Gardi J, Hajdu I, Szentirmai E, Obal F, Jr., Krueger JM (2004) Rhythms of ghrelin, leptin, and sleep in rats: effects of the normal diurnal cycle, restricted feeding, and sleep deprivation. Am J Physiol Regul Integr Comp Physiol 287:R1071-1079.

Boivin DB, Tremblay GM, James FO (2007) Working on atypical schedules. Sleep Med 8:578-589.

Borbely AA (1982) A two process model of sleep regulation. Hum Neurobiol 1:195-204.

Bray MS, Shaw CA, Moore MWS, Garcia RAP, Zanquetta MM, Durgan DJ, Jeong WJ, Tsai J-Y, Bugger $\mathrm{H}$, Zhang D, Rohrwasser A, Rennison JH, Dyck JRB, Litwin SE, Hardin PE, Chow C-W, Chandler MP, Abel ED, Young ME (2008) Disruption of the circadian clock within the cardiomyocyte influences myocardial contractile function, metabolism, and gene expression. Am J Physiol Heart Circ Physiol 294:H1036-1047.

Brondel L, Romer MA, Nougues PM, Touyarou P, Davenne D (2010) Acute partial sleep deprivation increases food intake in healthy men. Am J Clin Nutr 91:1550-1559.

Brown JG, Almond BD, Naglich JG, Eidels L (1993) Hypersensitivity to diphtheria toxin by mouse cells expressing both diphtheria toxin receptor and CD9 antigen. Proc Natl Acad Sci U S A 90:8184-8188.

Brown TM, Colwell CS, Waschek JA, Piggins HD (2007) Disrupted neuronal activity rhythms in the suprachiasmatic nuclei of vasoactive intestinal polypeptide-deficient mice. J Neurophysiol 97:2553-2558. 
Buch T, Heppner FL, Tertilt C, Heinen TJ, Kremer M, Wunderlich FT, Jung S, Waisman A (2005) A Cre-inducible diphtheria toxin receptor mediates cell lineage ablation after toxin administration. Nat Methods 2:419-426.

Buhr ED, Yoo SH, Takahashi JS (2010) Temperature as a universal resetting cue for mammalian circadian oscillators. Science 330:379-385.

Buijs RM, Kalsbeek A (2001) Hypothalamic integration of central and peripheral clocks. Nat Rev Neurosci 2:521-526.

Buijs RM, Wortel J, Van Heerikhuize JJ, Feenstra MGP, Ter Horst GJ, Romijn HJ, Kalsbeek A (1999) Anatomical and functional demonstration of a multisynaptic suprachiasmatic nucleus adrenal (cortex) pathway. European Journal of Neuroscience 11:1535-1544.

Buijs RM, la Fleur SE, Wortel J, Van Heyningen C, Zuiddam L, Mettenleiter TC, Kalsbeek A, Nagai K, Niijima A (2003) The suprachiasmatic nucleus balances sympathetic and parasympathetic output to peripheral organs through separate preautonomic neurons. J Comp Neurol 464:36-48.

Busino L, Bassermann F, Maiolica A, Lee C, Nolan PM, Godinho SI, Draetta GF, Pagano M (2007) SCFFbxl3 controls the oscillation of the circadian clock by directing the degradation of cryptochrome proteins. Science 316:900-904.

Cailotto C, Lei J, van der Vliet J, van Heijningen C, van Eden CG, Kalsbeek A, Pevet P, Buijs RM (2009) Effects of nocturnal light on (clock) gene expression in peripheral organs: a role for the autonomic innervation of the liver. PLoS One 4:e5650.

Cambras T, Lopez L, Arias JL, Diez-Noguera A (2005) Quantitative changes in neuronal and glial cells in the suprachiasmatic nucleus as a function of the lighting conditions during weaning. Brain Res Dev Brain Res 157:27-33.

Casanova E, Lemberger T, Fehsenfeld S, Mantamadiotis T, Schutz G (2003) Alpha complementation in the Cre recombinase enzyme. Genesis 37:25-29.

Cha JH, Brooke JS, Ivey KN, Eidels L (2000) Cell surface monkey CD9 antigen is a coreceptor that increases diphtheria toxin sensitivity and diphtheria toxin receptor affinity. J Biol Chem 275:6901-6907.

Chaput JP, Despres JP, Bouchard C, Tremblay A (2007) Short sleep duration is associated with reduced leptin levels and increased adiposity: Results from the Quebec family study. Obesity (Silver Spring) 15:253-261.

Colwell CS (2000) Rhythmic coupling among cells in the suprachiasmatic nucleus. J Neurobiol 43:379-388.

Colwell CS, Michel S, Itri J, Rodriguez W, Tam J, Lelievre V, Hu Z, Liu X, Waschek JA (2003) Disrupted circadian rhythms in VIP- and PHI-deficient mice. Am J Physiol Regul Integr Comp Physiol 285:R939-949.

Daan S, Beersma DG, Borbely AA (1984) Timing of human sleep: recovery process gated by a circadian pacemaker. Am J Physiol 246:R161-183.

Dallmann R, Weaver DR (2010) Altered body mass regulation in male mPeriod mutant mice on high-fat diet. Chronobiol Int 27:1317-1328. 
Damiola F, Le Minh N, Preitner N, Kornmann B, Fleury-Olela F, Schibler U (2000) Restricted feeding uncouples circadian oscillators in peripheral tissues from the central pacemaker in the suprachiasmatic nucleus. Genes Dev 14:2950-2961.

Davidson AJ, Castanon-Cervantes O, Leise TL, Molyneux PC, Harrington ME (2009) Visualizing jet lag in the mouse suprachiasmatic nucleus and peripheral circadian timing system. Eur J Neurosci 29:171-180.

de la Iglesia HO, Meyer J, Carpino A, Jr., Schwartz WJ (2000) Antiphase oscillation of the left and right suprachiasmatic nuclei. Science 290:799-801.

de Vries MJ, Treep JA, de Pauw ES, Meijer JH (1994) The effects of electrical stimulation of the optic nerves and anterior optic chiasm on the circadian activity rhythm of the Syrian hamster: involvement of excitatory amino acids. Brain Res 642:206-212.

Deboer T, Detari L, Meijer JH (2007) Long term effects of sleep deprivation on the mammalian circadian pacemaker. Sleep 30:257-262.

Deboer T, Vansteensel MJ, Detari L, Meijer JH (2003) Sleep states alter activity of suprachiasmatic nucleus neurons. Nat Neurosci 6:1086-1090.

DeBruyne JP, Weaver DR, Reppert SM (2007) CLOCK and NPAS2 have overlapping roles in the suprachiasmatic circadian clock. Nat Neurosci 10:543-545.

DeCoursey PJ, Walker JK, Smith SA (2000) A circadian pacemaker in free-living chipmunks: essential for survival? J Comp Physiol A 186:169-180.

Dibner C, Schibler U, Albrecht U (2010) The mammalian circadian timing system: organization and coordination of central and peripheral clocks. Annu Rev Physiol 72:517-549.

Dodd AN, Salathia N, Hall A, Kevei E, Toth R, Nagy F, Hibberd JM, Millar AJ, Webb AA (2005) Plant circadian clocks increase photosynthesis, growth, survival, and competitive advantage. Science 309:630-633.

Ebisawa T et al. (2001) Association of structural polymorphisms in the human period3 gene with delayed sleep phase syndrome. EMBO Rep 2:342-346.

Edgar DM, Dement WC (1991) Regularly scheduled voluntary exercise synchronizes the mouse circadian clock. Am J Physiol 261:R928-933.

Engeland WC, Arnhold MM (2005) Neural circuitry in the regulation of adrenal corticosterone rhythmicity. Endocrine 28:325-332.

Everson CA, Crowley WR (2004) Reductions in circulating anabolic hormones induced by sustained sleep deprivation in rats. Am J Physiol Endocrinol Metab 286:E1060-1070.

Farley FW, Soriano P, Steffen LS, Dymecki SM (2000) Widespread recombinase expression using FLPeR (flipper) mice. Genesis 28:106-110.

Francis AJ, Coleman GJ (1997) Phase response curves to ambient temperature pulses in rats. Physiol Behav 62:1211-1217.

Franken P, Tobler I, Borbely AA (1993) Effects of 12-h sleep deprivation and of 12-h cold exposure on sleep regulation and cortical temperature in the rat. Physiol Behav 54:885-894.

Franken P, Thomason R, Heller HC, O'Hara BF (2007) A non-circadian role for clock-genes in sleep homeostasis: a strain comparison. BMC Neurosci 8:87. 
Franken P, Lopez-Molina L, Marcacci L, Schibler U, Tafti M (2000) The transcription factor DBP affects circadian sleep consolidation and rhythmic EEG activity. J Neurosci 20:617-625.

Franken P, Dudley CA, Estill SJ, Barakat M, Thomason R, O'Hara BF, McKnight SL (2006) NPAS2 as a transcriptional regulator of non-rapid eye movement sleep: genotype and sex interactions. Proc Natl Acad Sci U S A 103:7118-7123.

Freedman MS, Lucas RJ, Soni B, von Schantz M, Munoz M, David-Gray Z, Foster R (1999) Regulation of mammalian circadian behavior by non-rod, non-cone, ocular photoreceptors. Science 284:502-504.

Fu L, Pelicano H, Liu J, Huang P, Lee C (2002) The circadian gene Period2 plays an important role in tumor suppression and DNA damage response in vivo. Cell 111:41-50.

Gangwisch JE, Malaspina D, Boden-Albala B, Heymsfield SB (2005) Inadequate sleep as a risk factor for obesity: analyses of the NHANES I. Sleep 28:1289-1296.

Garcia JA, Zhang D, Estill SJ, Michnoff C, Rutter J, Reick M, Scott K, Diaz-Arrastia R, McKnight SL (2000) Impaired cued and contextual memory in NPAS2-deficient mice. Science 288:22262230.

Gehring W, Rosbash M (2003) The coevolution of blue-light photoreception and circadian rhythms. J Mol Evol 57 Suppl 1:S286-289.

Gerendai I, Halasz B (2000) Central nervous system structures connected with the endocrine glands. findings obtained with the viral transneuronal tracing technique. Exp Clin Endocrinol Diabetes 108:389-395.

Glaser FT, Stanewsky R (2005) Temperature synchronization of the Drosophila circadian clock. Curr Biol 15:1352-1363.

Godinho SI, Maywood ES, Shaw L, Tucci V, Barnard AR, Busino L, Pagano M, Kendall R, Quwailid MM, Romero MR, O'Neill J, Chesham JE, Brooker D, Lalanne Z, Hastings MH, Nolan PM (2007) The after-hours mutant reveals a role for Fbxl3 in determining mammalian circadian period. Science 316:897-900.

Gong S, Zheng C, Doughty ML, Losos K, Didkovsky N, Schambra UB, Nowak NJ, Joyner A, Leblanc G, Hatten ME, Heintz N (2003) A gene expression atlas of the central nervous system based on bacterial artificial chromosomes. Nature 425:917-925.

Gottlieb DJ, Punjabi NM, Newman AB, Resnick HE, Redline S, Baldwin CM, Nieto FJ (2005) Association of sleep time with diabetes mellitus and impaired glucose tolerance. Arch Intern Med 165:863-867.

Green RM, Tingay S, Wang ZY, Tobin EM (2002) Circadian rhythms confer a higher level of fitness to Arabidopsis plants. Plant Physiol 129:576-584.

Guldner FH (1983) Numbers of neurons and astroglial cells in the suprachiasmatic nucleus of male and female rats. Exp Brain Res 50:373-376.

Guler AD, Ecker JL, Lall GS, Haq S, Altimus CM, Liao HW, Barnard AR, Cahill H, Badea TC, Zhao H, Hankins MW, Berson DM, Lucas RJ, Yau KW, Hattar S (2008) Melanopsin cells are the principal conduits for rod-cone input to non-image-forming vision. Nature 453:102-105. 
Guo H, Brewer JM, Lehman MN, Bittman EL (2006) Suprachiasmatic regulation of circadian rhythms of gene expression in hamster peripheral organs: effects of transplanting the pacemaker. J Neurosci 26:6406-6412.

Guo H, Brewer JM, Champhekar A, Harris RB, Bittman EL (2005) Differential control of peripheral circadian rhythms by suprachiasmatic-dependent neural signals. Proc Natl Acad Sci U S A 102:3111-3116.

Haack M, Sanchez E, Mullington JM (2007) Elevated inflammatory markers in response to prolonged sleep restriction are associated with increased pain experience in healthy volunteers. Sleep 30:1145-1152.

Hamada T, Antle MC, Silver R (2004) Temporal and spatial expression patterns of canonical clock genes and clock-controlled genes in the suprachiasmatic nucleus. Eur J Neurosci 19:17411748.

Hampp G, Ripperger JA, Houben T, Schmutz I, Blex C, Perreau-Lenz S, Brunk I, Spanagel R, AhnertHilger G, Meijer JH, Albrecht U (2008) Regulation of monoamine oxidase A by circadianclock components implies clock influence on mood. Curr Biol 18:678-683.

Hara R, Wan K, Wakamatsu H, Aida R, Moriya T, Akiyama M, Shibata S (2001) Restricted feeding entrains liver clock without participation of the suprachiasmatic nucleus. Genes Cells 6:269-278.

Hasler G, Buysse DJ, Klaghofer R, Gamma A, Ajdacic V, Eich D, Rossler W, Angst J (2004) The association between short sleep duration and obesity in young adults: a 13-year prospective study. Sleep 27:661-666.

Hattar S, Lucas RJ, Mrosovsky N, Thompson S, Douglas RH, Hankins MW, Lem J, Biel M, Hofmann F, Foster RG, Yau KW (2003) Melanopsin and rod-cone photoreceptive systems account for all major accessory visual functions in mice. Nature 424:76-81.

Hayashi S, McMahon AP (2002) Efficient recombination in diverse tissues by a tamoxifen-inducible form of Cre: a tool for temporally regulated gene activation/inactivation in the mouse. Dev Biol 244:305-318.

Hendricks JC (2003) Invited review: Sleeping flies don't lie: the use of Drosophila melanogaster to study sleep and circadian rhythms. J Appl Physiol 94:1660-1672; discussion 1673.

Hendricks JC, Finn SM, Panckeri KA, Chavkin J, Williams JA, Sehgal A, Pack Al (2000) Rest in Drosophila is a sleep-like state. Neuron 25:129-138.

Herzog ED, Aton SJ, Numano R, Sakaki Y, Tei H (2004) Temporal precision in the mammalian circadian system: a reliable clock from less reliable neurons. J Biol Rhythms 19:35-46.

Hirota T, Fukada $Y$ (2004) Resetting mechanism of central and peripheral circadian clocks in mammals. Zoolog Sci 21:359-368.

Hirrlinger J, Scheller A, Hirrlinger PG, Kellert B, Tang W, Wehr MC, Goebbels S, Reichenbach A, Sprengel R, Rossner MJ, Kirchhoff $F$ (2009) Split-cre complementation indicates coincident activity of different genes in vivo. PLoS ONE 4:e4286.

Hitze B, Bosy-Westphal A, Bielfeldt F, Settler U, Plachta-Danielzik S, Pfeuffer M, Schrezenmeir J, Monig H, Muller MJ (2009) Determinants and impact of sleep duration in children and adolescents: data of the Kiel Obesity Prevention Study. Eur J Clin Nutr 63:739-746. 
Hong HK, Chong JL, Song W, Song EJ, Jyawook AA, Schook AC, Ko CH, Takahashi JS (2007) Inducible and reversible Clock gene expression in brain using the tTA system for the study of circadian behavior. PLoS Genet 3:e33.

Husse J, Zhou X, Shostak A, Oster H, Eichele G (2011) Synaptotagmin10-Cre, a Driver to Disrupt Clock Genes in the SCN. J Biol Rhythms 26:379-389.

Ibuka N, Inouye SI, Kawamura H (1977) Analysis of sleep-wakefulness rhythms in male rats after suprachiasmatic nucleus lesions and ocular enucleation. Brain Res 122:33-47.

Indra AK, Warot X, Brocard J, Bornert JM, Xiao JH, Chambon P, Metzger D (1999) Temporallycontrolled site-specific mutagenesis in the basal layer of the epidermis: comparison of the recombinase activity of the tamoxifen-inducible Cre-ER(T) and Cre-ER(T2) recombinases. Nucleic Acids Res 27:4324-4327.

Ishida A, Mutoh T, Ueyama T, Bando H, Masubuchi S, Nakahara D, Tsujimoto G, Okamura H (2005) Light activates the adrenal gland: timing of gene expression and glucocorticoid release. Cell Metab 2:297-307.

Jacob N, Vuillez P, Lakdhar-Ghazal N, Pevet P (1999) Does the intergeniculate leaflet play a role in the integration of the photoperiod by the suprachiasmatic nucleus? Brain Res 828:83-90.

Jakubcakova V, Oster H, Tamanini F, Cadenas C, Leitges M, van der Horst GT, Eichele G (2007) Light entrainment of the mammalian circadian clock by a PRKCA-dependent posttranslational mechanism. Neuron 54:831-843.

Jasper MS, Engeland WC (1994) Splanchnic neural activity modulates ultradian and circadian rhythms in adrenocortical secretion in awake rats. Neuroendocrinology 59:97-109.

Johnson CH, Golden SS, Ishiura M, Kondo T (1996) Circadian clocks in prokaryotes. Mol Microbiol 21:5-11.

Johnson RF, Morin LP, Moore RY (1988a) Retinohypothalamic projections in the hamster and rat demonstrated using cholera toxin. Brain Res 462:301-312.

Johnson RF, Moore RY, Morin LP (1988b) Loss of entrainment and anatomical plasticity after lesions of the hamster retinohypothalamic tract. Brain Res 460:297-313.

Jud C, Schmutz I, Hampp G, Oster H, Albrecht U (2005) A guideline for analyzing circadian wheelrunning behavior in rodents under different lighting conditions. Biol Proced Online 7:101116.

Jullien N, Sampieri F, Enjalbert A, Herman JP (2003) Regulation of Cre recombinase by ligandinduced complementation of inactive fragments. Nucleic Acids Res 31:e131.

Jullien N, Goddard I, Selmi-Ruby S, Fina JL, Cremer H, Herman JP (2007) Conditional transgenesis using Dimerizable Cre (DiCre). PLoS One 2:e1355.

Kalsbeek A, Buijs RM (2002) Output pathways of the mammalian suprachiasmatic nucleus: coding circadian time by transmitter selection and specific targeting. Cell Tissue Res 309:109-118.

Kalsbeek A, Scheer FA, Perreau-Lenz S, La Fleur SE, Yi CX, Fliers E, Buijs RM (2011) Circadian disruption and SCN control of energy metabolism. FEBS Lett 585:1412-1426.

Karlsson B, Knutsson A, Lindahl B (2001) Is there an association between shift work and having a metabolic syndrome? Results from a population based study of 27,485 people. Occup Environ Med 58:747-752. 
Kiessling S, Eichele G, Oster H (2010) Adrenal glucocorticoids have a key role in circadian resynchronization in a mouse model of jet lag. J Clin Invest 120:2600-2609.

Knutson KL (2007) Impact of sleep and sleep loss on glucose homeostasis and appetite regulation. Sleep Med Clin 2:187-197.

Knutson KL, Van Cauter E (2008) Associations between sleep loss and increased risk of obesity and diabetes. Ann N Y Acad Sci 1129:287-304.

Knutson KL, Spiegel K, Penev P, Van Cauter E (2007) The metabolic consequences of sleep deprivation. Sleep Med Rev 11:163-178.

$\mathrm{Ko} \mathrm{CH}$, Takahashi JS (2006) Molecular components of the mammalian circadian clock. Hum Mol Genet 15 Suppl 2:R271-277.

Koban M, Swinson KL (2005) Chronic REM-sleep deprivation of rats elevates metabolic rate and increases UCP1 gene expression in brown adipose tissue. Am J Physiol Endocrinol Metab 289:E68-74.

Koban M, Le WW, Hoffman GE (2006) Changes in hypothalamic corticotropin-releasing hormone, neuropeptide $Y$, and proopiomelanocortin gene expression during chronic rapid eye movement sleep deprivation of rats. Endocrinology 147:421-431.

Koban M, Sita LV, Le WW, Hoffman GE (2008) Sleep deprivation of rats: the hyperphagic response is real. Sleep 31:927-933.

Kondratov RV, Kondratova AA, Gorbacheva VY, Vykhovanets OV, Antoch MP (2006) Early aging and age-related pathologies in mice deficient in BMAL1, the core componentof the circadian clock. Genes Dev 20:1868-1873.

Konopka RJ, Benzer S (1971) Clock mutants of Drosophila melanogaster. Proc Natl Acad Sci U S A 68:2112-2116.

Kopp C, Albrecht U, Zheng B, Tobler I (2002) Homeostatic sleep regulation is preserved in mPer1 and mPer2 mutant mice. Eur J Neurosci 16:1099-1106.

Kornmann B, Schaad O, Bujard H, Takahashi JS, Schibler U (2007) System-driven and oscillatordependent circadian transcription in mice with a conditionally active liver clock. PLoS Biol 5:e34.

Kramer A, Yang FC, Snodgrass P, Li X, Scammell TE, Davis FC, Weitz CJ (2001) Regulation of daily locomotor activity and sleep by hypothalamic EGF receptor signaling. Science 294:25112515.

Kriegsfeld L, LeSauter J, Silver R (2004) Targeted microlesions reveal novel organization of the hamster suprachiasmatic nucleus. J Neurosci 24:2449-2457.

Kuhlman SJ, Silver R, Le Sauter J, Bult-Ito A, McMahon DG (2003) Phase resetting light pulses induce Per1 and persistent spike activity in a subpopulation of biological clock neurons. J Neurosci 23:1441-1450.

la Fleur SE, Kalsbeek A, Wortel J, Buijs RM (2000) Polysynaptic neural pathways between the hypothalamus, including the suprachiasmatic nucleus, and the liver. Brain Res 871:50-56.

Lamia KA, Storch KF, Weitz CJ (2008) Physiological significance of a peripheral tissue circadian clock. Proc Natl Acad Sci U S A 105:15172-15177.

Landgraf D, Shostak A, Oster H (2011) Clock genes and sleep. Pflugers Arch. 
Landis CA, Bergmann BM, Ismail MM, Rechtschaffen A (1992) Sleep deprivation in the rat: XV. Ambient temperature choice in paradoxical sleep-deprived rats. Sleep 15:13-20.

Laposky A, Easton A, Dugovic C, Walisser J, Bradfield C, Turek F (2005) Deletion of the mammalian circadian clock gene BMAL1/Mop3 alters baseline sleep architecture and the response to sleep deprivation. Sleep 28:395-409.

Larsen PJ, Enquist LW, Card JP (1998) Characterization of the multisynaptic neuronal control of the rat pineal gland using viral transneuronal tracing. Eur J Neurosci 10:128-145.

Le Y, Gagneten S, Tombaccini D, Bethke B, Sauer B (1999) Nuclear targeting determinants of the phage P1 cre DNA recombinase. Nucleic Acids Res 27:4703-4709.

Leak RK, Moore RY (2001) Topographic organization of suprachiasmatic nucleus projection neurons. J Comp Neurol 433:312-334.

Leak RK, Card JP, Moore RY (1999) Suprachiasmatic pacemaker organization analyzed by viral transynaptic transport. Brain Res 819:23-32.

Lehman MN, Silver R, Gladstone WR, Kahn RM, Gibson M, Bittman EL (1987) Circadian rhythmicity restored by neural transplant. Immunocytochemical characterization of the graft and its integration with the host brain. J Neurosci 7:1626-1638.

Lein ES et al. (2007) Genome-wide atlas of gene expression in the adult mouse brain. Nature 445:168-176.

LeSauter J, Silver R (1999) Localization of a suprachiasmatic nucleus subregion regulating locomotor rhythmicity. J Neurosci 19:5574-5585.

Levine JD, Weiss ML, Rosenwasser AM, Miselis RR (1991) Retinohypothalamic tract in the female albino rat: a study using horseradish peroxidase conjugated to cholera toxin. J Comp Neurol 306:344-360.

Li JD, Burton KJ, Zhang C, Hu SB, Zhou QY (2009) Vasopressin receptor V1a regulates circadian rhythms of locomotor activity and expression of clock-controlled genes in the suprachiasmatic nuclei. Am J Physiol Regul Integr Comp Physiol 296:R824-830.

Lin C, Todo T (2005) The cryptochromes. Genome Biol 6:220.

Liu AC, Welsh DK, Ko CH, Tran HG, Zhang EE, Priest AA, Buhr ED, Singer O, Meeker K, Verma IM, Doyle FJ, 3rd, Takahashi JS, Kay SA (2007) Intercellular coupling confers robustness against mutations in the SCN circadian clock network. Cell 129:605-616.

Lobe CG, Koop KE, Kreppner W, Lomeli H, Gertsenstein M, Nagy A (1999) Z/AP, a double reporter for cre-mediated recombination. Dev Biol 208:281-292.

Loh DH, Dragich JM, Kudo T, Schroeder AM, Nakamura TJ, Waschek JA, Block GD, Colwell CS (2011) Effects of vasoactive intestinal Peptide genotype on circadian gene expression in the suprachiasmatic nucleus and peripheral organs. J Biol Rhythms 26:200-209.

Looby P, Loudon AS (2005) Gene duplication and complex circadian clocks in mammals. Trends Genet 21:46-53.

Lowrey PL, Shimomura K, Antoch MP, Yamazaki S, Zemenides PD, Ralph MR, Menaker M, Takahashi JS (2000) Positional syntenic cloning and functional characterization of the mammalian circadian mutation tau. Science 288:483-492.

Luo L, Callaway EM, Svoboda K (2008) Genetic dissection of neural circuits. Neuron 57:634-660. 
Mairan D (1729) Observation botanique. Histoire de l'Académie royale des sciences.

Marcheva B, Ramsey KM, Buhr ED, Kobayashi Y, Su H, Ko CH, Ivanova G, Omura C, Mo S, Vitaterna MH, Lopez JP, Philipson LH, Bradfield CA, Crosby SD, JeBailey L, Wang X, Takahashi JS, Bass $J$ (2010) Disruption of the clock components CLOCK and BMAL1 leads to hypoinsulinaemia and diabetes. Nature 466:627-631.

Maret S, Dorsaz S, Gurcel L, Pradervand S, Petit B, Pfister C, Hagenbuchle O, O'Hara BF, Franken P, Tafti M (2007) Homer1a is a core brain molecular correlate of sleep loss. Proc Natl Acad Sci U S A 104:20090-20095.

Matsuo T, Yamaguchi S, Mitsui S, Emi A, Shimoda F, Okamura H (2003) Control mechanism of the circadian clock for timing of cell division in vivo. Science 302:255-259.

Maywood ES, Chesham JE, O'Brien JA, Hastings MH (2011a) A diversity of paracrine signals sustains molecular circadian cycling in suprachiasmatic nucleus circuits. Proc Natl Acad Sci USA.

Maywood ES, Chesham JE, Meng QJ, Nolan PM, Loudon AS, Hastings MH (2011b) Tuning the period of the mammalian circadian clock: additive and independent effects of CK1epsilonTau and FbxI3Afh mutations on mouse circadian behavior and molecular pacemaking. J Neurosci 31:1539-1544.

McClung CA, Sidiropoulou K, Vitaterna M, Takahashi JS, White FJ, Cooper DC, Nestler EJ (2005) Regulation of dopaminergic transmission and cocaine reward by the Clock gene. Proc Natl Acad Sci U S A 102:9377-9381.

McDearmon EL, Patel KN, Ko CH, Walisser JA, Schook AC, Chong JL, Wilsbacher LD, Song EJ, Hong HK, Bradfield CA, Takahashi JS (2006) Dissecting the functions of the mammalian clock protein BMAL1 by tissue-specific rescue in mice. Science 314:1304-1308.

Meerlo P, Koehl M, van der Borght K, Turek FW (2002) Sleep restriction alters the hypothalamicpituitary-adrenal response to stress. J Neuroendocrinol 14:397-402.

Meng QJ, Logunova L, Maywood ES, Gallego M, Lebiecki J, Brown TM, Sladek M, Semikhodskii AS, Glossop NR, Piggins HD, Chesham JE, Bechtold DA, Yoo SH, Takahashi JS, Virshup DM, Boot-Handford RP, Hastings MH, Loudon AS (2008) Setting clock speed in mammals: the CK1 epsilon tau mutation in mice accelerates circadian pacemakers by selectively destabilizing PERIOD proteins. Neuron 58:78-88.

Meyer-Bernstein EL, Jetton AE, Matsumoto SI, Markuns JF, Lehman MN, Bittman EL (1999) Effects of suprachiasmatic transplants on circadian rhythms of neuroendocrine function in golden hamsters. Endocrinology 140:207-218.

Mistlberger RE (2005) Circadian regulation of sleep in mammals: Role of the suprachiasmatic nucleus. Brain Research Reviews 49:429-454.

Mistlberger RE, Skene DJ (2004) Social influences on mammalian circadian rhythms: animal and human studies. Biol Rev Camb Philos Soc 79:533-556.

Mistlberger RE, Belcourt J, Antle MC (2002) Circadian clock resetting by sleep deprivation without exercise in Syrian hamsters: dark pulses revisited. J Biol Rhythms 17:227-237.

Moga MM, Moore RY (1997) Organization of neural inputs to the suprachiasmatic nucleus in the rat. J Comp Neurol 389:508-534. 
Mongrain V, Hernandez SA, Pradervand S, Dorsaz S, Curie T, Hagiwara G, Gip P, Heller HC, Franken $P$ (2010) Separating the contribution of glucocorticoids and wakefulness to the molecular and electrophysiological correlates of sleep homeostasis. Sleep 33:1147-1157.

Moore RY, Eichler VB (1972) Loss of a circadian adrenal corticosterone rhythm following suprachiasmatic lesions in the rat. Brain Res 42:201-206.

Moore RY, Lenn NJ (1972) A retinohypothalamic projection in the rat. J Comp Neurol 146:1-14.

Morin LP, Johnson RF, Moore RY (1989) Two brain nuclei controlling circadian rhythms are identified by GFAP immunoreactivity in hamsters and rats. Neurosci Lett 99:55-60.

Morin LP, Shivers KY, Blanchard JH, Muscat L (2006) Complex organization of mouse and rat suprachiasmatic nucleus. Neuroscience 137:1285-1297.

Moriya T, Yoshinobu Y, Kouzu Y, Katoh A, Gomi H, Ikeda M, Yoshioka T, Itohara S, Shibata S (2000) Involvement of glial fibrillary acidic protein (GFAP) expressed in astroglial cells in circadian rhythm under constant lighting conditions in mice. J Neurosci Res 60:212-218.

Mukherjee S, Coque L, Cao IL, Kumar J, Chakravarty S, Asaithamby A, Graham A, Gordon E, Enwright JF, 3rd, Dileone RJ, Birnbaum SG, Cooper DC, McClung CA Knockdown of Clock in the Ventral Tegmental Area Through RNA Interference Results in a Mixed State of Mania and Depression-Like Behavior. Biol Psychiatry.

Mullington JM, Haack M, Toth M, Serrador JM, Meier-Ewert HK (2009) Cardiovascular, inflammatory, and metabolic consequences of sleep deprivation. Prog Cardiovasc Dis 51:294-302.

Muscat L, Tischler RC, Morin LP (2005) Functional analysis of the role of the median raphe as a regulator of hamster circadian system sensitivity to light. Brain Res 1044:59-66.

Muyrers JP, Zhang Y, Stewart AF (2001) Techniques: Recombinogenic engineering--new options for cloning and manipulating DNA. Trends Biochem Sci 26:325-331.

Nagano M, Adachi A, Nakahama K, Nakamura T, Tamada M, Meyer-Bernstein E, Sehgal A, Shigeyoshi $Y$ (2003) An abrupt shift in the day/night cycle causes desynchrony in the mammalian circadian center. J Neurosci 23:6141-6151.

Nagy A (2000) Cre recombinase: the universal reagent for genome tailoring. Genesis 26:99-109.

Nakajima M, Imai K, Ito H, Nishiwaki T, Murayama Y, Iwasaki H, Oyama T, Kondo T (2005) Reconstitution of circadian oscillation of cyanobacterial KaiC phosphorylation in vitro. Science 308:414-415.

Nakamura W, Yamazaki S, Takasu NN, Mishima K, Block GD (2005) Differential response of Period 1 expression within the suprachiasmatic nucleus. J Neurosci 25:5481-5487.

Naylor E, Bergmann BM, Krauski K, Zee PC, Takahashi JS, Vitaterna MH, Turek FW (2000) The circadian clock mutation alters sleep homeostasis in the mouse. J Neurosci 20:8138-8143.

Niijima A, Nagai K, Nagai N, Nakagawa H (1992) Light enhances sympathetic and suppresses vagal outflows and lesions including the suprachiasmatic nucleus eliminate these changes in rats. J Auton Nerv Syst 40:155-160.

Niijima A, Nagai K, Nagai N, Akagawa H (1993) Effects of light stimulation on the activity of the autonomic nerves in anesthetized rats. Physiol Behav 54:555-561. 
Nishino H, Kiyomi K, Brooks CM (1976) The role of suprachiasmatic nuclei of the hypothalamus in the production of circadian rhythm. Brain Res 112:45-59.

Noguchi T, Watanabe K, Ogura A, Yamaoka S (2004) The clock in the dorsal suprachiasmatic nucleus runs faster than that in the ventral. Eur J Neurosci 20:3199-3202.

O'Neill JS, Reddy AB (2011) Circadian clocks in human red blood cells. Nature 469:498-503.

O'Neill JS, van Ooijen G, Dixon LE, Troein C, Corellou F, Bouget FY, Reddy AB, Millar AJ (2011) Circadian rhythms persist without transcription in a eukaryote. Nature 469:554-558.

Oklejewicz M, Destici E, Tamanini F, Hut RA, Janssens R, van der Horst GT (2008) Phase resetting of the mammalian circadian clock by DNA damage. Curr Biol 18:286-291.

Osoegawa K, Tateno M, Woon PY, Frengen E, Mammoser AG, Catanese JJ, Hayashizaki Y, de Jong PJ (2000) Bacterial artificial chromosome libraries for mouse sequencing and functional analysis. Genome Res 10:116-128.

Oster H (2006) The genetic basis of circadian behavior. Genes Brain Behav 5 Suppl 2:73-79.

Oster H, van der Horst GT, Albrecht U (2003a) Daily variation of clock output gene activation in behaviorally arrhythmic mPer/mCry triple mutant mice. Chronobiol Int 20:683-695.

Oster H, Damerow S, Hut RA, Eichele G (2006a) Transcriptional profiling in the adrenal gland reveals circadian regulation of hormone biosynthesis genes and nucleosome assembly genes. J Biol Rhythms 21:350-361.

Oster H, Avivi A, Joel A, Albrecht U, Nevo E (2002) A switch from diurnal to nocturnal activity in S. ehrenbergi is accompanied by an uncoupling of light input and the circadian clock. Curr Biol 12:1919-1922.

Oster H, Werner C, Magnone MC, Mayser H, Feil R, Seeliger MW, Hofmann F, Albrecht U (2003b) cGMP-dependent protein kinase II modulates mPer1 and mPer2 gene induction and influences phase shifts of the circadian clock. Curr Biol 13:725-733.

Oster H, Damerow S, Kiessling S, Jakubcakova V, Abraham D, Tian J, Hoffmann MW, Eichele G (2006b) The circadian rhythm of glucocorticoids is regulated by a gating mechanism residing in the adrenal cortical clock. Cell Metab 4:163-173.

Ottenweller JE, Meier AH (1982) Adrenal innervation may be an extrapituitary mechanism able to regulate adrenocortical rhythmicity in rats. Endocrinology 111:1334-1338.

Ottenweller JE, Meier AH, Ferrell BR, Horseman ND, Proctor A (1978) Extrapituitary regulation of the circadian rhythm of plasma corticosteroid concentration in rats. Endocrinology 103:1875-1879.

Ouyang Y, Andersson CR, Kondo T, Golden SS, Johnson CH (1998) Resonating circadian clocks enhance fitness in cyanobacteria. Proc Natl Acad Sci U S A 95:8660-8664.

Panda S, Sato TK, Castrucci AM, Rollag MD, DeGrip WJ, Hogenesch JB, Provencio I, Kay SA (2002a) Melanopsin (Opn4) requirement for normal light-induced circadian phase shifting. Science 298:2213-2216.

Panda S, Antoch MP, Miller BH, Su AI, Schook AB, Straume M, Schultz PG, Kay SA, Takahashi JS, Hogenesch JB (2002b) Coordinated transcription of key pathways in the mouse by the circadian clock. Cell 109:307-320. 
Pando MP, Morse D, Cermakian N, Sassone-Corsi P (2002) Phenotypic rescue of a peripheral clock genetic defect via SCN hierarchical dominance. Cell 110:107-117.

Pendergast JS, Yamazaki S (2011) Masking Responses to Light in Period Mutant Mice. Chronobiol Int 28:657-663.

Pennartz CM, Hamstra R, Geurtsen AM (2001) Enhanced NMDA receptor activity in retinal inputs to the rat suprachiasmatic nucleus during the subjective night. J Physiol 532:181-194.

PerkinElmerCetus (1989) Amplifications: 2:1-3.

Pfaffl MW (2001) A new mathematical model for relative quantification in real-time RT-PCR. Nucleic Acids Res 29:e45.

Pittendrigh CS (1954) On Temperature Independence in the Clock System Controlling Emergence Time in Drosophila. Proc Natl Acad Sci U S A 40:1018-1029.

Pittendrigh CS (1993) Temporal organization: reflections of a Darwinian clock-watcher. Annu Rev Physiol 55:16-54.

Pittendrigh CS, Minis DH (1972) Circadian systems: longevity as a function of circadian resonance in Drosophila melanogaster. Proc Natl Acad Sci U S A 69:1537-1539.

Preitner N, Damiola F, Lopez-Molina L, Zakany J, Duboule D, Albrecht U, Schibler U (2002) The orphan nuclear receptor REV-ERBalpha controls circadian transcription within the positive limb of the mammalian circadian oscillator. Cell 110:251-260.

Prolo LM, Takahashi JS, Herzog ED (2005) Circadian rhythm generation and entrainment in astrocytes. J Neurosci 25:404-408.

Prosser RA, Edgar DM, Heller HC, Miller JD (1994) A possible glial role in the mammalian circadian clock. Brain Res 643:296-301.

Provencio I, Rollag MD, Castrucci AM (2002) Photoreceptive net in the mammalian retina. This mesh of cells may explain how some blind mice can still tell day from night. Nature 415:493.

Raghuram S, Stayrook KR, Huang P, Rogers PM, Nosie AK, McClure DB, Burris LL, Khorasanizadeh S, Burris TP, Rastinejad F (2007) Identification of heme as the ligand for the orphan nuclear receptors REV-ERBalpha and REV-ERBbeta. Nat Struct Mol Biol 14:1207-1213.

Rajaratnam SM, Redman JR (1999) Social contact synchronizes free-running activity rhythms of diurnal palm squirrels. Physiol Behav 66:21-26.

Ralph MR, Menaker M (1988) A mutation of the circadian system in golden hamsters. Science 241:1225-1227.

Ralph MR, Foster RG, Davis FC, Menaker M (1990) Transplanted suprachiasmatic nucleus determines circadian period. Science 247:975-978.

Rash JE, Olson CO, Pouliot WA, Davidson KG, Yasumura T, Furman CS, Royer S, Kamasawa N, Nagy JI, Dudek FE (2007) Connexin36 vs. connexin32, "miniature" neuronal gap junctions, and limited electrotonic coupling in rodent suprachiasmatic nucleus. Neuroscience 149:350371.

Rasouli N, Kern PA (2008) Adipocytokines and the metabolic complications of obesity. J Clin Endocrinol Metab 93:S64-73. 
Rechtschaffen A, Bergmann BM (1995) Sleep deprivation in the rat by the disk-over-water method. Behav Brain Res 69:55-63.

Rechtschaffen A, Gilliland MA, Bergmann BM, Winter JB (1983) Physiological correlates of prolonged sleep deprivation in rats. Science 221:182-184.

Reddy AB, Field MD, Maywood ES, Hastings MH (2002) Differential Resynchronisation of Circadian Clock Gene Expression within the Suprachiasmatic Nuclei of Mice Subjected to Experimental Jet Lag. The Journal of Neuroscience 22:7326-7330.

Redlin U, Mrosovsky N (1999) Masking by light in hamsters with SCN lesions. J Comp Physiol A 184:439-448.

Refinetti R, Nelson DE, Menaker M (1992) Social stimuli fail to act as entraining agents of circadian rhythms in the golden hamster. J Comp Physiol [A] 170:181-187.

Refinetti R, Kaufman CM, Menaker M (1994) Complete suprachiasmatic lesions eliminate circadian rhythmicity of body temperature and locomotor activity in golden hamsters. J Comp Physiol A 175:223-232.

Reick M, Garcia JA, Dudley C, McKnight SL (2001) NPAS2: an analog of clock operative in the mammalian forebrain. Science 293:506-509.

Roenneberg T, Merrow M (2002) Life before the clock: modeling circadian evolution. J Biol Rhythms 17:495-505.

Rosa Neto JC, Lira FS, Venancio DP, Cunha CA, Oyama LM, Pimentel GD, Tufik S, Oller do Nascimento CM, Santos RV, de Mello MT (2010) Sleep deprivation affects inflammatory marker expression in adipose tissue. Lipids Health Dis 9:125.

Rosbash M (2009) The implications of multiple circadian clock origins. PLoS Biol 7:e62.

Roybal K, Theobold D, Graham A, DiNieri JA, Russo SJ, Krishnan V, Chakravarty S, Peevey J, Oehrlein N, Birnbaum S, Vitaterna MH, Orsulak P, Takahashi JS, Nestler EJ, Carlezon WA, Jr., McClung CA (2007) Mania-like behavior induced by disruption of CLOCK. Proc Natl Acad Sci U S A 104:6406-6411.

Ruby NF, Burns DE, Heller HC (1999) Circadian rhythms in the suprachiasmatic nucleus are temperature-compensated and phase-shifted by heat pulses in vitro. J Neurosci 19:86308636.

Rudic RD, McNamara P, Curtis AM, Boston RC, Panda S, Hogenesch JB, Fitzgerald GA (2004) BMAL1 and CLOCK, two essential components of the circadian clock, are involved in glucose homeostasis. PLoS Biol 2:e377.

Sadacca LA, Lamia KA, Delemos AS, Blum B, Weitz CJ (2010) An intrinsic circadian clock of the pancreas is required for normal insulin release and glucose homeostasis in mice. Diabetologia.

Sage D, Maurel D, Bosler O (2001) Involvement of the suprachiasmatic nucleus in diurnal ACTH and corticosterone responsiveness to stress. Am J Physiol Endocrinol Metab 280:E260269.

Sakamoto K, Nagase T, Fukui H, Horikawa K, Okada T, Tanaka H, Sato K, Miyake Y, Ohara O, Kako $\mathrm{K}$, Ishida N (1998) Multitissue circadian expression of rat period homolog (rPer2) mRNA is 
governed by the mammalian circadian clock, the suprachiasmatic nucleus in the brain. J Biol Chem 273:27039-27042.

Saper CB, Fuller PM, Pedersen NP, Lu J, Scammell TE (2010) Sleep state switching. Neuron 68:1023-1042.

Sato TK, Panda S, Miraglia L, Reyes TM, Rudic RD, McNamara P, Naik KA, FitzGerald GA, Kay SA, Hogenesch JB (2004) A functional genomics strategy reveals Rora as a component of the mammalian circadian clock. Neuron 43:527-537.

Scheer FA, Pirovano C, Van Someren EJ, Buijs RM (2005) Environmental light and suprachiasmatic nucleus interact in the regulation of body temperature. Neuroscience 132:465-477.

Scheer FA, Hilton MF, Mantzoros CS, Shea SA (2009) Adverse metabolic and cardiovascular consequences of circadian misalignment. Proc Natl Acad Sci U S A 106:4453-4458.

Schmid SM, Hallschmid M, Jauch-Chara K, Wilms B, Lehnert H, Born J, Schultes B (2011) Disturbed glucoregulatory response to food intake after moderate sleep restriction. Sleep 34:371377.

Schmutz I, Wendt S, Schnell A, Kramer A, Mansuy IM, Albrecht U (2011) Protein Phosphatase 1 (PP1) Is a Post-Translational Regulator of the Mammalian Circadian Clock. PLoS One 6:e21325.

Shaw PJ, Tononi G, Greenspan RJ, Robinson DF (2002) Stress response genes protect against lethal effects of sleep deprivation in Drosophila. Nature 417:287-291.

Shea SA, Hilton MF, Orlova C, Ayers RT, Mantzoros CS (2005) Independent circadian and sleep/wake regulation of adipokines and glucose in humans. J Clin Endocrinol Metab 90:2537-2544.

Sheeba V, Sharma VK, Chandrashekaran MK, Joshi A (1999) Persistence of eclosion rhythm in Drosophila melanogaster after 600 generations in an aperiodic environment. Naturwissenschaften 86:448-449.

Shi S, Hida A, McGuinness OP, Wasserman DH, Yamazaki S, Johnson CH (2010) Circadian Clock Gene Bmal1 Is Not Essential; Functional Replacement with its Paralog, Bmal2. Current Biology 20:316-321.

Shimshek DR, Kim J, Hubner MR, Spergel DJ, Buchholz F, Casanova E, Stewart AF, Seeburg PH, Sprengel R (2002) Codon-improved Cre recombinase (iCre) expression in the mouse. Genesis 32:19-26.

Shiromani PJ, Xu M, Winston EM, Shiromani SN, Gerashchenko D, Weaver DR (2004) Sleep rhythmicity and homeostasis in mice with targeted disruption of mPeriod genes. Am J Physiol Regul Integr Comp Physiol 287:R47-57.

Siepka SM, Yoo SH, Park J, Song W, Kumar V, Hu Y, Lee C, Takahashi JS (2007) Circadian mutant Overtime reveals F-box protein FBXL3 regulation of cryptochrome and period gene expression. Cell 129:1011-1023.

Silver R, LeSauter J, Tresco PA, Lehman MN (1996) A diffusible coupling signal from the transplanted suprachiasmatic nucleus controlling circadian locomotor rhythms. Nature 382:810-813. 
Simon C, Gronfier C, Schlienger JL, Brandenberger G (1998) Circadian and ultradian variations of leptin in normal man under continuous enteral nutrition: relationship to sleep and body temperature. J Clin Endocrinol Metab 83:1893-1899.

Soriano P (1999) Generalized lacZ expression with the ROSA26 Cre reporter strain. Nat Genet 21:70-71.

Spanagel R, Pendyala G, Abarca C, Zghoul T, Sanchis-Segura C, Magnone MC, Lascorz J, Depner M, Holzberg D, Soyka M, Schreiber S, Matsuda F, Lathrop M, Schumann G, Albrecht U (2005) The clock gene Per2 influences the glutamatergic system and modulates alcohol consumption. Nat Med 11:35-42.

Spiegel K, Leproult R, Van Cauter E (1999) Impact of sleep debt on metabolic and endocrine function. Lancet 354:1435-1439.

Spiegel K, Tasali E, Penev P, Cauter EV (2004a) Brief Communication: Sleep Curtailment in Healthy Young Men Is Associated with Decreased Leptin Levels, Elevated Ghrelin Levels, and Increased Hunger and Appetite. Ann Intern Med 141:846-850.

Spiegel K, Leproult R, L'Hermite-Baleriaux M, Copinschi G, Penev PD, Van Cauter E (2004b) Leptin levels are dependent on sleep duration: relationships with sympathovagal balance, carbohydrate regulation, cortisol, and thyrotropin. J Clin Endocrinol Metab 89:5762-5771.

Spoelstra K, Albrecht U, van der Horst GT, Brauer V, Daan S (2004) Phase responses to light pulses in mice lacking functional per or cry genes. J Biol Rhythms 19:518-529.

Steinlechner S, Jacobmeier B, Scherbarth F, Dernbach H, Kruse F, Albrecht U (2002) Robust circadian rhythmicity of Per1 and Per2 mutant mice in constant light, and dynamics of Per1 and Per2 gene expression under long and short photoperiods. J Biol Rhythms 17:202209.

Stephan FK, Zucker I (1972) Circadian rhythms in drinking behavior and locomotor activity of rats are eliminated by hypothalamic lesions. Proc Natl Acad Sci U S A 69:1583-1586.

Stephan FK, Nunez AA (1977) Elimination of circadian rhythms in drinking, activity, sleep, and temperature by isolation of the suprachiasmatic nuclei. Behav Biol 20:1-61.

Stopa EG, King JC, Lydic R, Schoene WC (1984) Human brain contains vasopressin and vasoactive intestinal polypeptide neuronal subpopulations in the suprachiasmatic region. Brain Res 297:159-163.

Storch KF, Paz C, Signorovitch J, Raviola E, Pawlyk B, Li T, Weitz CJ (2007) Intrinsic circadian clock of the mammalian retina: importance for retinal processing of visual information. Cell 130:730-741.

Sujino M, Masumoto KH, Yamaguchi S, van der Horst GT, Okamura H, Inouye ST (2003) Suprachiasmatic nucleus grafts restore circadian behavioral rhythms of genetically arrhythmic mice. Curr Biol 13:664-668.

Szosland D (2010) Shift work and metabolic syndrome, diabetes mellitus and ischaemic heart disease. Int J Occup Med Environ Health 23:287-291.

Taheri S, Lin L, Austin D, Young T, Mignot E (2004) Short sleep duration is associated with reduced leptin, elevated ghrelin, and increased body mass index. PLoS Med 1:e62. 
Takahashi JS, DeCoursey PJ, Bauman L, Menaker M (1984) Spectral sensitivity of a novel photoreceptive system mediating entrainment of mammalian circadian rhythms. Nature 308:186-188.

Terazono H, Mutoh T, Yamaguchi S, Kobayashi M, Akiyama M, Udo R, Ohdo S, Okamura H, Shibata $S$ (2003) Adrenergic regulation of clock gene expression in mouse liver. Proc Natl Acad Sci U S A 100:6795-6800.

Thompson CL, Wisor JP, Lee CK, Pathak SD, Gerashchenko D, Smith KA, Fischer SR, Kuan CL, Sunkin SM, Ng LL, Lau C, Hawrylycz M, Jones AR, Kilduff TS, Lein ES (2010) Molecular and anatomical signatures of sleep deprivation in the mouse brain. Front Neurosci 4:165.

Tobler I, Jaggi K (1987) Sleep and EEG spectra in the Syrian hamster (Mesocricetus auratus) under baseline conditions and following sleep deprivation. J Comp Physiol [A] 161:449-459.

Toh KL, Jones CR, He Y, Eide EJ, Hinz WA, Virshup DM, Ptacek LJ, Fu YH (2001) An hPer2 phosphorylation site mutation in familial advanced sleep phase syndrome. Science 291:1040-1043.

Tolentino PJ, Dikkes P, Tsuruda L, Ebert K, Fink JS, Villa-Komaroff L, Lamperti ED (1995) Quantitative analysis of the expression of a VIP transgene. Brain Res Mol Brain Res 33:4760.

Tosini G, Menaker M (1996) Circadian rhythms in cultured mammalian retina. Science 272:419421.

Tsuruda LM, Lamperti ED, Lewis SE, Tolentino PJ, Dikkes P, Villa-Komaroff L, Ebert KM, Fink JS (1996) Region-specific central nervous system expression and axotomy-induced regulation in sympathetic neurons of a VIP-beta-galactosidase fusion gene in transgenic mice. Brain Res Mol Brain Res 42:181-192.

Turek FW, Joshu C, Kohsaka A, Lin E, Ivanova G, McDearmon E, Laposky A, Losee-Olson S, Easton A, Jensen DR, Eckel RH, Takahashi JS, Bass J (2005) Obesity and metabolic syndrome in circadian Clock mutant mice. Science 308:1043-1045.

Ukai H, Ueda HR (2010) Systems biology of mammalian circadian clocks. Annu Rev Physiol 72:579603.

Ullmann A, Jacob F, Monod J (1967) Characterization by in vitro complementation of a peptide corresponding to an operator-proximal segment of the beta-galactosidase structural gene of Escherichia coli. J Mol Biol 24:339-343.

Ulrich-Lai YM, Arnhold MM, Engeland WC (2006) Adrenal splanchnic innervation contributes to the diurnal rhythm of plasma corticosterone in rats by modulating adrenal sensitivity to ACTH. Am J Physiol Regul Integr Comp Physiol 290:R1128-1135.

Van Cauter E, Knutson KL (2008) Sleep and the epidemic of obesity in children and adults. Eur J Endocrinol 159 Suppl 1:S59-66.

van der Veen DR, Mulder EG, Oster H, Gerkema MP, Hut RA (2008) SCN-AVP release of mPer1/mPer2 double-mutant mice in vitro. J Circadian Rhythms 6:5.

Van der Zee EA, Havekes R, Barf RP, Hut RA, Nijholt IM, Jacobs EH, Gerkema MP (2008) Circadian time-place learning in mice depends on cry genes. Curr Biol 18:844-848. 
Vgontzas AN, Zoumakis E, Bixler EO, Lin HM, Follett H, Kales A, Chrousos GP (2004) Adverse effects of modest sleep restriction on sleepiness, performance, and inflammatory cytokines. J Clin Endocrinol Metab 89:2119-2126.

Vgontzas AN, Papanicolaou DA, Bixler EO, Lotsikas A, Zachman K, Kales A, Prolo P, Wong ML, Licinio J, Gold PW, Hermida RC, Mastorakos G, Chrousos GP (1999) Circadian interleukin-6 secretion and quantity and depth of sleep. J Clin Endocrinol Metab 84:2603-2607.

Villalobos V, Naik S, Piwnica-Worms D (2007) Current state of imaging protein-protein interactions in vivo with genetically encoded reporters. Annu Rev Biomed Eng 9:321-349.

Viola AU, Archer SN, James LM, Groeger JA, Lo JC, Skene DJ, von Schantz M, Dijk DJ (2007) PER3 polymorphism predicts sleep structure and waking performance. Curr Biol 17:613-618.

Vitaterna MH, King DP, Chang AM, Kornhauser JM, Lowrey PL, McDonald JD, Dove WF, Pinto LH, Turek FW, Takahashi JS (1994) Mutagenesis and mapping of a mouse gene, Clock, essential for circadian behavior. Science 264:719-725.

Vujovic N, Davidson AJ, Menaker M (2008) Sympathetic input modulates, but does not determine, phase of peripheral circadian oscillators. Am J Physiol Regul Integr Comp Physiol 295:R355-360.

Waschek JA, Bravo DT, Sena M, Casillas R, Rodriguez W, Nguyen T, Colburn S (1999) Targeting of embryonic and postnatal autonomic and enteric neurons with a vasoactive intestinal peptide transgene. J Neurochem 73:1739-1748.

Welsh DK, Takahashi JS, Kay SA (2010) Suprachiasmatic nucleus: cell autonomy and network properties. Annu Rev Physiol 72:551-577.

Welsh DK, Logothetis DE, Meister M, Reppert SM (1995) Individual neurons dissociated from rat suprachiasmatic nucleus express independently phased circadian firing rhythms. Neuron 14:697-706.

Wisor JP, O'Hara BF, Terao A, Selby CP, Kilduff TS, Sancar A, Edgar DM, Franken P (2002) A role for cryptochromes in sleep regulation. BMC Neurosci 3:20.

Wisor JP, Pasumarthi RK, Gerashchenko D, Thompson CL, Pathak S, Sancar A, Franken P, Lein ES, Kilduff TS (2008) Sleep deprivation effects on circadian clock gene expression in the cerebral cortex parallel electroencephalographic differences among mouse strains. J Neurosci 28:7193-7201.

Woelfle MA, Ouyang Y, Phanvijhitsiri K, Johnson CH (2004) The adaptive value of circadian clocks: an experimental assessment in cyanobacteria. Curr Biol 14:1481-1486.

Xu Y, Xu G, Liu B, Gu G (2007) Cre reconstitution allows for DNA recombination selectively in dualmarker-expressing cells in transgenic mice. Nucleic Acids Res 35:e126.

Xu Y, Padiath QS, Shapiro RE, Jones CR, Wu SC, Saigoh N, Saigoh K, Ptacek L, Fu YH (2005) Functional consequences of a CKIdelta mutation causing familial advanced sleep phase syndrome. Nature 434:640-644.

Yamaguchi S, Isejima H, Matsuo T, Okura R, Yagita K, Kobayashi M, Okamura H (2003) Synchronization of cellular clocks in the suprachiasmatic nucleus. Science 302:1408-1412. 
Yamazaki S, Numano R, Abe M, Hida A, Takahashi R, Ueda M, Block GD, Sakaki Y, Menaker M, Tei $H(2000)$ Resetting central and peripheral circadian oscillators in transgenic rats. Science 288:682-685.

Yan J, Wang H, Liu Y, Shao C (2008) Analysis of gene regulatory networks in the mammalian circadian rhythm. PLoS Comput Biol 4:e1000193.

Yan L, Silver R (2002) Differential induction and localization of mPer1 and mPer2 during advancing and delaying phase shifts. Eur J Neurosci 16:1531-1540.

Yan L, Karatsoreos I, Lesauter J, Welsh DK, Kay S, Foley D, Silver R (2007) Exploring spatiotemporal organization of SCN circuits. Cold Spring Harb Symp Quant Biol 72:527-541.

Yang S, Liu A, Weidenhammer A, Cooksey RC, McClain D, Kim MK, Aguilera G, Abel ED, Chung JH (2009) The Role of mPer2 Clock Gene in Glucocorticoid and Feeding Rhythms. Endocrinology 150:2153-2160.

Yerushalmi S, Green RM (2009) Evidence for the adaptive significance of circadian rhythms. Ecol Lett 12:970-981.

Yoo SH, Yamazaki S, Lowrey PL, Shimomura K, Ko CH, Buhr ED, Siepka SM, Hong HK, Oh WJ, Yoo OJ, Menaker M, Takahashi JS (2004) PERIOD2::LUCIFERASE real-time reporting of circadian dynamics reveals persistent circadian oscillations in mouse peripheral tissues. Proc Natl Acad Sci U S A 101:5339-5346.

Zee PC, Goldstein CA (2010) Treatment of shift work disorder and jet lag. Curr Treat Options Neurol 12:396-411.

Zhang EE, Liu AC, Hirota T, Miraglia L, Welch G, Pongsawakul PY, Liu X, Atwood A, Huss JW, 3rd, Janes J, Su Al, Hogenesch JB, Kay SA (2009) A genome-wide RNAi screen for modifiers of the circadian clock in human cells. Cell 139:199-210.

Zhang S, Ma C, Chalfie M (2004) Combinatorial marking of cells and organelles with reconstituted fluorescent proteins. Cell 119:137-144.

Zheng B, Larkin DW, Albrecht U, Sun ZS, Sage M, Eichele G, Lee CC, Bradley A (1999) The mPer2 gene encodes a functional component of the mammalian circadian clock. Nature 400:169173.

Zheng B, Albrecht U, Kaasik K, Sage M, Lu W, Vaishnav S, Li Q, Sun ZS, Eichele G, Bradley A, Lee CC (2001) Nonredundant roles of the mPer1 and mPer2 genes in the mammalian circadian clock. Cell 105:683-694. 


\section{Acknowledgements}

First, I would like thank my supervisor, Gregor Eichele, for his continuous support and advise in the last four years. I appreciate the liberty with which I was allowed to work in his group and also his numerous ideas, suggestions and constructive criticisms.

I am particularly grateful to Henrik Oster, who adopted me in his growing circadian "family". Thanks for always helping me with my questions and concerns, for many valuable suggestions and a lot of support and encouragement in the last years. I really appreciate all the time and efforts you invested in me and my research.

I want to thank the members of my thesis committee, Nils Brose and Erik Maronde for their suggestions. Special thanks to Erik Maronde for encouragement and helpful suggestions and for never missing a committee meeting despite considerable travel distance.

Thanks to all members of the Department Genes and Behavior for the nice and fruitful working atmosphere. Special thanks to Lars Geffers, Nadia Sanchez and to Ana Martinez Hernandez (... and I believe in shooting stars). I thank Xunlei Zhou for experimental advise during cloning. Thanks to Helena Miletic and Christine van den Bogaart for considerable organizational support.

Thanks to all current and former members of the circadian rhythms group for the collaborative and amicable working environment. I profited enormously from endless discussions and experimental advice and help from all of you! Special thanks to Johanna Barclay for revising parts of this thesis and for many valuable thoughts, to Judit Meyer-Kovac for her friendship and support especially in challenging times, to Silke Kiessling, Dominic Landgraf and Alexei Leliavski for inspiring discussions and to Nadine Naujokat for her amicable support. Thanks to Anton Shostak for his contribution to the behavioral phenotpying of the Syt10 Bmal1 mice.

Thanks to Charlotte Hintze, a very motivated MD student, for her help and collaboration in the sleep restriction project.

Thanks to Maren Brockmeyer for help with brain sectioning and to Frauke Grabbe and Cornelia Sieverding for help with in situ hybridization. Thanks to Barbara Fischer for help with genotyping.

I owe thanks to my animal care takers, Ute Kunze, Alexandra Driehorst, Simone Brauer and Sascha Krause for looking after my mice and Stefanie Thiel for expert genotyping assistance. Thanks to Ulli Franke for pronucleus injections, Sharif Mahsur for ES cell electroporation and Kirsten Kiel for ES cell aggregation.

Last but not least thanks to my family and friends for all their support within the last years. Thanks, Jochen, for sharing enthusiasm for science and life with me! Your loving support in the last years helped me enormously to finish this work.

Jana. 


\section{Curriculum Vitae}

\section{Personal data}

Name: $\quad$ Jana Lioba Husse

Date of birth: $\quad 07.10 .1981$

Place of birth: Schweinfurt, Germany

\section{Education}

2007-2011: PhD student in the group of Prof Gregor Eichele at the Department of Genes and Behavior, Max-Planck-Institute for Biophysical Chemistry, Göttingen, Germany; project: "Genetic disruption of the master pacemaker in the suprachiasmatic nucleus sheds light on the hierarchical organization of the mammalian circadian timing system"

2006-2007: Diploma thesis in the group of Dr Bertram Gerber at the Department of Genetics and Neurobiology, University of Würzburg, Germany; project: "Does editing of the synapsin mRNA play a role for associative learning?"

2001-2007: Student of Biology (Diplom) at the University of Würzburg, Germany, major in neurobiology, minors in genetics and biopsychology

2005: Project work in the group of Prof Martin Giurfa at the Research Center on Animal Cognition, Toulouse, France; project: "Reinforcer-devaluation in honeybee olfactory conditioning"

2001-2003: Research assistant with Dr Bertram Gerber, University of Würzburg, Germany, project : "Appetitive olfactory learning in Drosophila larvae"

2001: $\quad$ Abitur, Celtis Gymnasium, Schweinfurt, Germany 


\section{Publications}

Journal articles:

Pre-PhD:

Husse J*, Saumweber T*, Gerber B (2011) Innate Attractiveness and Associative Learnability of Odors Can Be Dissociated in Larval Drosophila. Chem Senses 36: 223-235.

* these authors contributed equally

Gerber B, Neuser K, Husse J, Stock P (2005) Appetitive olfactory learning in Drosophila larvae: effects of repetition, reward strength, age, gender, assay type and memory span. Animal Behaviour 69: 891-898.

PhD:

Barclay J, Husse J, Oster H (2011) Adrenal glucocorticoids as a target for jet lag therapies. Expert Review of Endocrinology and Metabolism 6: 673-679.

Husse J, Zhou X, Shostak A, Oster H, Eichele G (2011) Synaptotagmin10-Cre, a Driver to Disrupt Clock Genes in the SCN. J Biol Rhythms 26: 379-389.

Husse J*, Kovac J*, Oster H (2009) A time to fast, a time to feast: the crosstalk between metabolism and the circadian clock. Mol Cells 28: 75-80.

* these authors contributed equally

\section{Articles under review:}

Barclay J, Husse J, Bode B, Naujokat N, Meyer-Kovac J, Schmid S, Lehnert H, Oster H: Peripheral circadian desynchrony promotes metabolic disruption in a mouse model of shiftwork. Under review by The Journal of Clinical Investigation. 


\section{Conference contributions:}

Jana Husse, Xunlei Zhou, Anton Shostak, Henrik Oster and Gregor Eichele, Synaptotagmin10-Cre, a driver to disrupt clock genes in the SCN, Poster presentation at the XII Congress of the European Biological Rhythms Society, August 20-26, 2011, Oxford, England: Abstract Book page 127.

Johanna Lee Barclay, Jana Husse, Brid Bode, Judit Kovac, Hendrik Lehnert and Henrik Oster, Circadian behavioral, metabolic, and transcriptional disruption in a mouse model of shift work, XII Congress of the European Biological Rhythms Society, August 20-26, 2011, Oxford, England: Abstract Book page 125.

Jana Husse, Charlotte Hintze, Gregor Eichele, Hendrik Lehnert and Henrik Oster, Period genes regulate the metabolic response to sleep loss, ENDO, June 4-7, Boston, Massachusetts: Endocr Rev, Vol. 32, P1-367.

Johanna Lee Barclay, Jana Husse, Brid Bode, Judit Kovac, Hendrik Lehnert and Henrik Oster, Sleep, the Circadian Clock, and Metabolism, ENDO, June 4-7, Boston, Massachusetts: Endocr Rev, Vol. 32, P1-368

Jana Husse, Charlotte Hintze, Gregor Eichele, Hendrik Lehnert and Henrik Oster, Per genes regulate the metabolic response to sleep loss, Poster presentation at the Winterschool Plasticity Across Systems, December 1-3, 2010, Lübeck, Germany.

Jana Husse, Charlotte Hintze, Gregor Eichele, Hendrik Lehnert and Henrik Oster, Per genes regulate the metabolic response to sleep loss, Poster presentation at the 12th biennial meeting of the society for research on biological rhythms, May 22-26, 2010, Destin, Florida, Abstract Book page 141-142.

Jana Husse, Xunlei Zhou and Gregor Eichele, Regionalization of the murine suprachiasmatic nucleus, Poster presentation at Göttingen Graduate School for Neurosciences and Molecular Biosciences (GGNB) science day, 23 November 2009.

Jana Husse, Xunlei Zhou and Gregor Eichele, Using a binary CRE system to study the functional anatomy of the murine SCN, Poster presentation at Göttingen Graduate School for Neurosciences and Molecular Biosciences (GGNB) opening, 21 November 2008.

Jana Husse, Xunlei Zhou and Gregor Eichele, Using a Split-CRE System to study the functional anatomy of the mouse SCN, Talk and poster presentation at EU-clock summer school chronobiology 2008, Laulasmaa, Estonia, June 7-14. 